Prepared in cooperation with Louisiana Coastal Areas Science and Technology Program and in collaboration with Louisiana State University, the Louisiana Governor's Office of Coastal Protection and Restoration, and the University of Louisiana at Lafayette

\title{
Geomorphic and Ecological Effects of Hurricanes Katrina and Rita on Coastal Louisiana Marsh Communities
}

Open-File Report 2011-1094 



\section{Geomorphic and Ecological Effects of Hurricanes Katrina and Rita on Coastal Louisiana Marsh Communities}

By Sarai C. Piazza, Gregory D. Steyer, Kari F. Cretini, Charles E. Sasser, Jenneke M. Visser, Guerry 0. Holm, Jr., Leigh Anne Sharp, D. Elaine Evers, and John R. Meriwether

Prepared in cooperation with Louisiana Coastal Areas Science and Technology Program and in collaboration with Louisiana State University, the Louisiana Governor's Office of Coastal Protection and Restoration, and the University of Louisiana at Lafayette

Open-File Report 2011-1094 


\section{U.S. Department of the Interior \\ KEN SALAZAR, Secretary \\ U.S. Geological Survey \\ Marcia K. McNutt, Director}

U.S. Geological Survey, Reston, Virginia: 2011

This and other USGS information products are available at http://store.usgs.gov/

U.S. Geological Survey

Box 25286, Denver Federal Center

Denver, C0 80225

To learn about the USGS and its information products visit http://www.usgs.gov/ 1-888-ASK-USGS

Any use of trade, product, or firm names is for descriptive purposes only and does not imply endorsement by the U.S. Government.

Although this report is in the public domain, permission must be secured from the individual copyright owners to reproduce any copyrighted materials contained within this report.

Suggested citation:

Piazza, S.C., Steyer, G.D., Cretini, K.F., Sasser, C.E., Visser, J.M., Holm, G.O., Jr., Sharp, L.A., Evers, D.E., and Meriwether, J.R., 2011, Geomorphic and ecological effects of Hurricanes Katrina and Rita on coastal Louisiana marsh communities: U. S. Geological Survey Open-File Report 2011-1094, 126 p. 


\section{Acknowledgments}

We wish to recognize the financial support of the Louisiana Coastal Area Science \& Technology Program in accomplishing this research.

We would like to thank all of the landowners who provided permission to access their properties to conduct this assessment, especially the Louisiana Department of Wildlife and Fisheries, Apache Corporation, Delacroix Corporation, Jeanerette Lumber, Louisiana Land and Exploration Company, and Miami Corporation. A tremendous amount of field, laboratory, and analytical assistance was provided by personnel from many agencies and affiliations. Five Rivers Services, LLC, staff includes Jason Byrd and Brad Griffin, and U.S. Army Engineer Research and Development Center staff includes Glen Suir. Louisiana State University personnel includes Azure Bevington, Thomas Blanchard, Dan Bond, Edward Castaneda-Moya, Jay Gore, Manoch Kongchum, Brian Milan, Alaina Owens, Eric Peterson, and Daniel Sasser. Louisiana Governor's Office of Coastal Protection and Restoration (OCPR) personnel includes Brady Carter, Mike Miller, Tommy McGinnis, Mark Mouledous, John Troutman, and Dona Weifenbach. University of Louisiana at Lafayette personnel includes Katherine Zaunbrecher and Matt Williams. We would also like to thank Brian Perez of CH2M Hill.

Evamaria Koch (University of Maryland Center for Marine Science) and Michael Beck (OCPR) reviewed the document and provided useful comments.

This project could not have been completed without the field efforts, sample processing, data entry, and input of U.S. Geological Survey personnel including Gregg Snedden, Jeff Broussard, Brady Couvillion, Ada Diz, Jessica Goodwin, Arianne Logwood, Alison Martin, and Elin Sandy. 


\section{Contents}

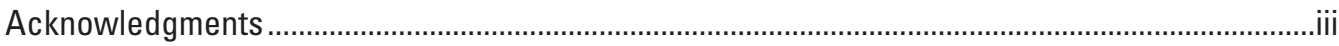

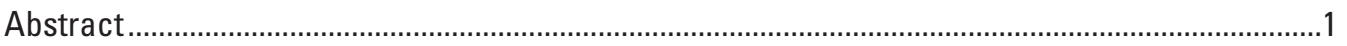

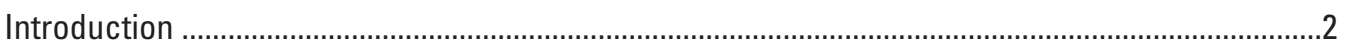

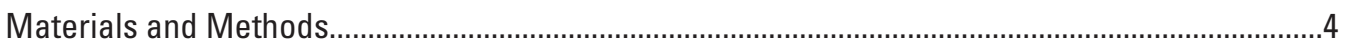

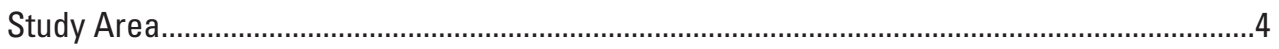

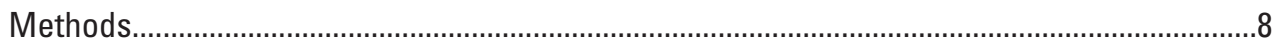

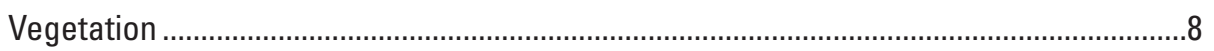

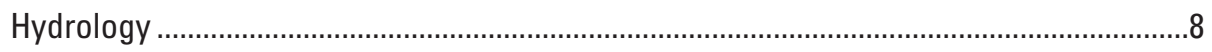

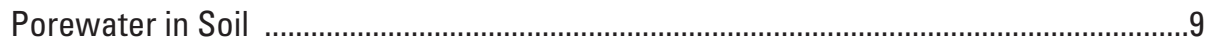

Sediment Deposition and Condition ..............................................................................

Bulk Density and Organic Matter....................................................................................

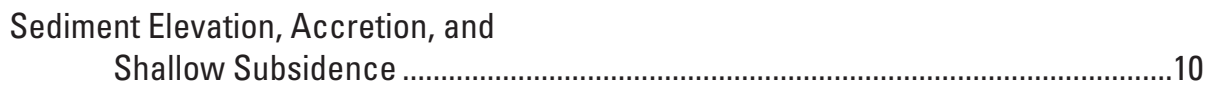

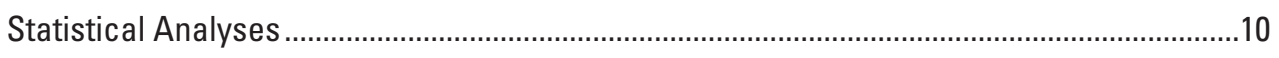

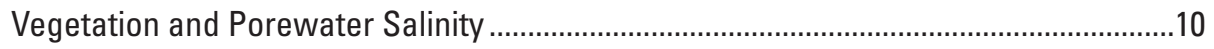

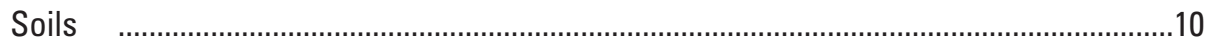

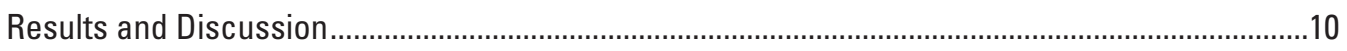

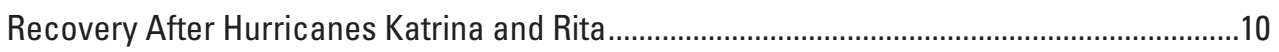

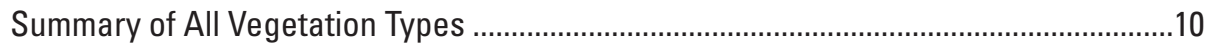

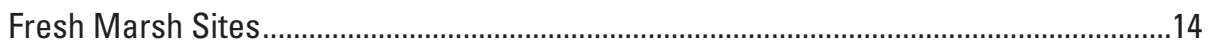

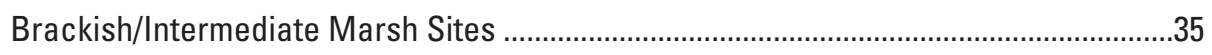

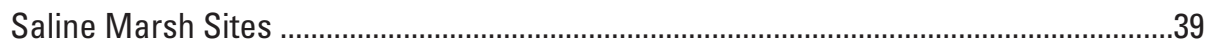

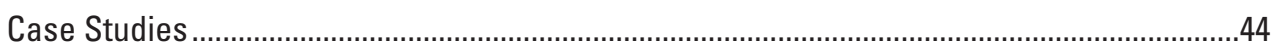

Case Study 1: CRMS0605-H and CRMS1277-H .............................................................

Overall Site Description .................................................................................... 44

Salinity Before and After the Storms...................................................................4

Plant Biomass Before and After the Storms ........................................................4

Plant Community Change After the Storms .........................................................49

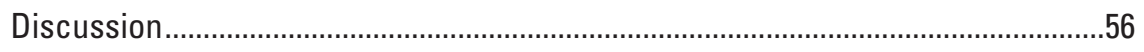

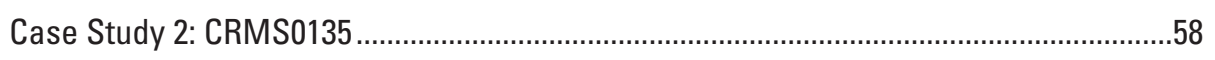

Overall Site Description ........................................................................................58

Surface-Water and Porewater Salinities ................................................................61

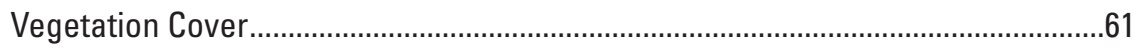

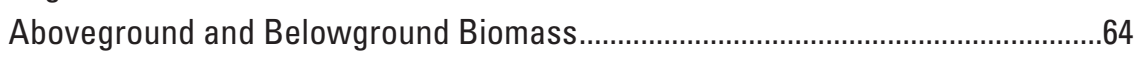

Sediment Characterization, Accretion, and Elevation...............................................67

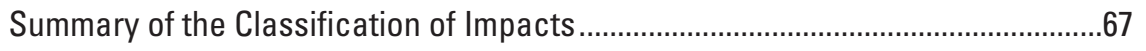

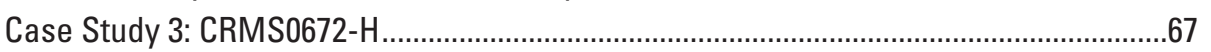

Overall Site Description...................................................................................67

Surface-Water and Porewater Salinity...............................................................72

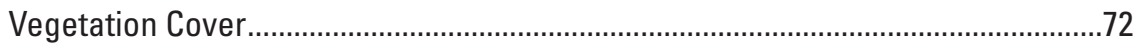

Aboveground and Belowground Biomass..........................................................

Sediment Characterization, Accretion, and Elevation..............................................77

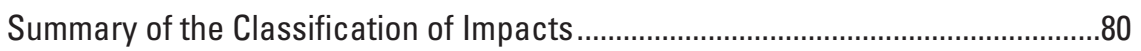




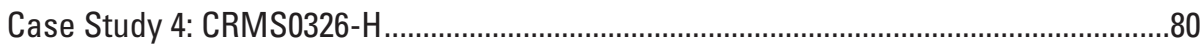

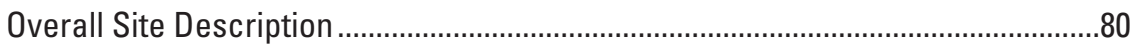

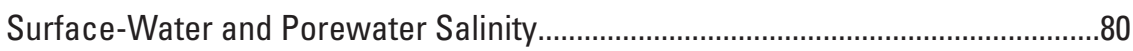

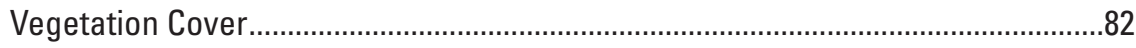

Aboveground and Belowground Biomass..............................................................82

Sediment Characterization, Accretion, and Elevation..............................................85

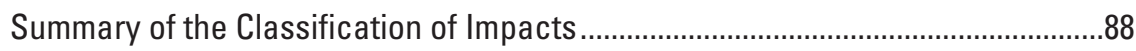

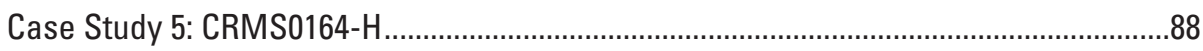

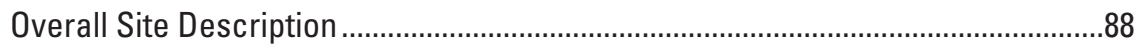

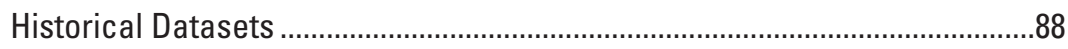

Monitoring Program for the Louisiana Offshore Oil Port ................................91

Marsh Stability ...........................................................................................

Surface-Water and Porewater Salinity...............................................................91

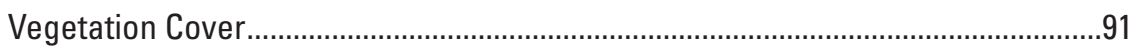

Aboveground and Belowground Biomass...........................................................91

Sediment Characterization, Accretion, and Elevation............................................95

Summary of the Classification of Impacts .............................................................95

Soil Process Rates of Wetlands in the Chenier and Deltaic Plains of Louisiana............98

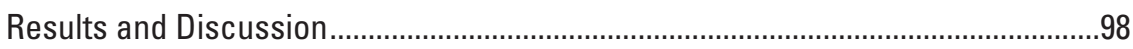

Accretion Rates Between the Chenier and Deltaic Plains .............................98

Contribution of Organic and Mineral Fractions to Soil Accretion ...................99

Organic, Mineral, and Nutrient Content in Relation to

Accumulation Rates.............................................................................100

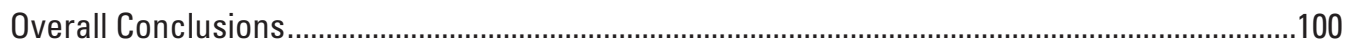

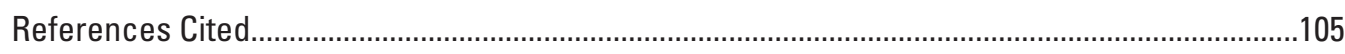

Appendix 1. Hydrographs for study sites within the Coastwide Reference Monitoring

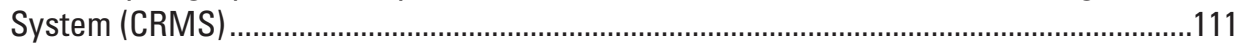

Appendix 2. Site elevation and accretion at study sites within the Coastwide

Reference Monitoring System (CRMS) ........................................................................118

\section{Figures}

1. The interconnected influences of hurricane storm surge on marsh dynamics..................

2. Thirty intensive site locations within coastal Louisiana ...................................................

3. Coastal Louisiana divided into nine hydrologic basins ...................................................

4. Mean values of porewater salinity for fresh, brackish/intermediate, and saline marsh types by season ....................................................................................12

5. Total live vegetation cover for fresh, brackish/intermediate, and saline

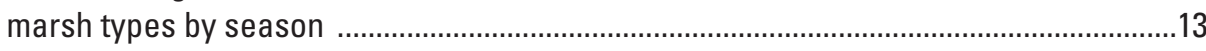

6. Percentages of disturbance and nondisturbance taxa present in live vegetation cover of fresh, brackish/intermediate, and saline vegetation types by season ............................................................................................................... 14

7. Live aboveground biomass in fresh, brackish/intermediate, and saline marsh types by season

8. Total belowground biomass in fresh, brackish/intermediate, and saline marsh types by season 
9. Mean values of porewater salinity for fresh, brackish/intermediate, and saline marshes by type of hurricane influence and year.

10. Porewater salinity at the end of the growing season in $\mathbf{2 0 0 6}$ and in 2007 at study sites within fresh, brackish/intermediate, and saline marshes

11. Total live cover of emergent vegetation at fresh, brackish/intermediate, and saline marsh sites at the end of the growing season in 2006 and in 2007

12. Cover by disturbance taxa (black bars) relative to nondisturbance taxa in emergent vegetation at fresh marsh sites at the end of the growing season in 2006 and in 2007

13. Percentages of biomass composed of disturbance versus nondisturbance species at fresh marsh sites in 2006 and 2007

14. Species composition of biomass harvested at sites CRMS0128 and CRMS0128-H by season.

15. Species composition of biomass harvested at sites CRMS0605 and CRMS0605-H by season...

16. Live aboveground biomass is displayed for each habitat type by level of hurricane influence and year

17. Total and live aboveground biomass at fresh marsh sites where historical data were available

18. Peak aboveground biomass at the end of growing seasons in 2006 and 2007 for each habitat type by hurricane influence and year

19. Total aboveground biomass at the end of growing seasons in 2006 and 2007 at fresh, brackish/intermediate, and saline marsh sites.

20. Total belowground biomass at the end of growing seasons in 2006 and 2007 at fresh, brackish/intermediate, and saline marsh sites

21. Mean values of belowground biomass for each marsh type by hurricane influence and year.

22. Total and live belowground biomass at fresh marsh sites at the end of growing seasons.

23. Cover of disturbance taxa relative to nondisturbance taxa in emergent vegetation at brackish/intermediate marsh sites at the end of growing season in 2006 and 2007

24. Percentages of biomass in disturbance versus non-disturbance species at brackish/intermediate marsh sites for 2006 and 2007

25. Species composition of biomass harvested at sites CRMS0135 and CRMS0135- $\mathrm{H}$ by season

26. Percentages of biomass from disturbance and nondisturbance species in 2006 and 2007 for each marsh type by hurricane influence

27. Locations of Coastwide Reference Monitoring System (CRMS) sites 0605-H, 0605, 1277-H, and 1277 sites within the Lake Misere and Mermentau River watershed

28. Continuous and discrete samples of porewater salinity taken from $30 \mathrm{~cm}$ deep at Coastwide Reference Monitoring System (CRMS) site 0605-H from 2005 to 2007

29. The plant community at Coastwide Reference Monitoring System (CRMS) site $0605-\mathrm{H}$ before and after Hurricane Rita.

30. Aboveground live, dead, and total biomass at the end of growing seasons at Coastwide Reference Monitoring System (CRMS) site 0605-H before Hurricanes

Katrina and Rita and two years thereafter....

31. Live belowground biomass for Coastwide Reference Monitoring System (CRMS) site $0605-\mathrm{H}$ at the end of growing seasons before Hurricane Rita and two years thereafter. 
32. Live aboveground biomass at Coastwide Reference Monitoring System

(CRMS) sites $1277-\mathrm{H}$ and $0605-\mathrm{H}$

33. Live aboveground biomass at Coastwide Reference Monitoring System

(CRMS) sites 0605- $\mathrm{H}$ and 0268- $\mathrm{H}$...

34. Live belowground biomass at Coastwide Reference Monitoring System

(CRMS) sites $0605-\mathrm{H}$ and $1277-\mathrm{H}$

35. Live belowground biomass at Coastwide Reference Monitoring System

(CRMS) sites $0605-\mathrm{H}$ and $0268-\mathrm{H}$

36. Live aboveground biomass and species composition by season two years after Hurricane Rita.

37. Characteristics of initial plant recolonization by clonal, patch-forming species prior to the seedbank release of annual species at Coastwide Reference Monitoring System (CRMS) site 0605-H

38. A description of plant community change at Coastwide Reference Monitoring System (CRMS) site 0605-H following Hurricane Rita.

39. Vegetation in marshes north of Lake Misere, near Coastwide

Reference Monitoring System (CRMS) site 0605- $\mathrm{H}$

40. Timeline of vegetation community changes and relative plant biomass before and after Hurricane Rita

41. Location of Coastwide Reference Monitoring System (CRMS) sites 0135-H and 0135 within middle Breton Sound basin ..

42. Coastwide Reference Monitoring System (CRMS) site 0135 on May 4, 2006, after Hurricanes Katrina and Rita

43. Mean values of daily surface-water salinity and discrete porewater salinity at $30 \mathrm{~cm}$ deep from April 2006 to November 2007 at site Coastwide Reference Monitoring System (CRMS) site 0135

44. Seasonal species composition of total live vegetation cover at Coastwide Reference Monitoring System (CRMS) site 0135

45. Coastwide Reference Monitoring System (CRMS) site 0135 after Hurricanes Katrina and Rita

46. Seasonal coverage of disturbance taxa relative to nondisturbance taxa at Coastwide Reference Monitoring System (CRMS) site 0135

47. Total and live aboveground biomass at a historically sampled site near Lake Cuatro Caballo and at Coastwide Reference Monitoring System (CRMS) site.

48. Live and dead aboveground biomass by season at Coastwide Reference Monitoring System (CRMS) site 0135

49. Species composition of live aboveground biomass by season at Coastwide Reference Monitoring System (CRMS) site 0135

50. Seasonal aboveground biomass of disturbance and nondisturbance taxa at Coastwide Reference Monitoring System (CRMS) site 0135

51. Seasonal above and belowground biomass at Coastwide Reference Monitoring System (CRMS) site 0135

52. Seasonal belowground biomass of dead and live components at Coastwide Reference Monitoring System (CRMS) site 0135

53. Bulk density and caesium-137 profiles at Coastwide Reference Monitoring System (CRMS) site 0135

54. Depth profiles of bulk density, nitrogen, and carbon at Coastwide Reference Monitoring System (CRMS) site 0135

55. Location of Coastwide Reference Monitoring System (CRMS) sites 0672-H and 0672 within lower Calcasieu/Sabine basin

56. Seasonal discrete porewater salinity at Coastwide Reference Monitoring System (CRMS) site $0672-\mathrm{H}$ 
57. Average daily surface-water salinity from a sampling station within the CS20 project of the Coastal Wetlands Planning, Protection and Restoration Act (CWPPRA) from January 2005 to July 2007

58. Seasonal species composition of total live vegetation cover at Coastwide Reference Monitoring System (CRMS) site 0672-H.

59. Live vegetation cover of disturbance taxa relative to nondisturbance taxa by season at Coastwide Reference Monitoring System (CRMS) site 0672-H.

60. Live and dead aboveground biomass by season at Coastwide Reference Monitoring System (CRMS) site 0672-H

61. Species composition of live aboveground biomass by season at Coastwide Reference Monitoring System (CRMS) site 0672-H

62. Total aboveground and belowground biomass by season at Coastwide Reference Monitoring System (CRMS) site 0672-H.

63. Live and dead components of total belowground biomass by season at Coastwide Reference Monitoring System (CRMS) site 0672-H

64. Depth profiles of bulk density, nitrogen, and carbon at Coastwide Reference Monitoring System (CRMS) site 0672-H

65. Short term accretion rates at Coastwide Reference Monitoring System (CRMS) site 0672-H and elevation and accretion change at CRMS0672

66. Location of Coastwide Reference Monitoring System (CRMS) sites 0326-H and 0326 within lower Terrebonne basin. .81

67. Discrete porewater salinity measured by season at $30 \mathrm{~cm}$ deep at Coastwide Reference Monitoring System (CRMS) site 0326-H

68. Mean values of daily surface-water salinity and discrete porewater salinity measured at $30 \mathrm{~cm}$ deep from April 2006 to November 2007 at Coastwide Reference Monitoring System (CRMS) site 0326 .

69. Species composition (all Spartina alterniflora) of total live vegetation cover by season at Coastwide Reference Monitoring System (CRMS) site 0326-H

70. Seasonal cover of nondisturbance taxa at Coastwide Reference Monitoring System (CRMS) site 0326-H.

71. Live and dead aboveground biomass by season at Coastwide Reference Monitoring System (CRMS) site 0326- $\mathrm{H}$

72. Total and live aboveground biomass measured at the end of growing seasons at Coastwide Reference Monitoring System (CRMS) site 0326- $\mathrm{H}$ .85

73. Total aboveground and belowground biomass by season at Coastwide Reference Monitoring System (CRMS) site 0326- $\mathrm{H}$

74. Live and dead components of total belowground biomass by season at Coastwide Reference Monitoring System (CRMS) site 0326-H

75. Depth profiles of bulk density, nitrogen, and carbon at Coastwide Reference Monitoring System (CRMS) site 0326- $\mathrm{H}$

76. Bulk density and caesium-137 profiles at Coastwide Reference Monitoring System (CRMS) site 0326-H.

77. Rate of elevation change at Coastwide Reference Monitoring System (CRMS) site $0362-\mathrm{H}$.

78. Location of Coastwide Reference Monitoring System (CRMS) sites 0164-H and 0164 within lower Barataria basin

79. Discrete porewater salinity measured at $30 \mathrm{~cm}$ deep by season at Coastwide Reference Monitoring System (CRMS) site 0164-H

80. Species composition (all Spartina alterniflora) of total live vegetation cover by season at Coastwide Reference Monitoring System (CRMS) site 0164-H . 
81. Species composition (all Spartina alterniflora) of seasonal live aboveground biomass at site Coastwide Reference Monitoring System (CRMS) site 0164- $\mathrm{H}$

82. Total and live aboveground biomass at the end of growing seasons at saline marsh sites with availability of historical data acquired before Hurricanes Katrina and Rita

83. Aboveground biomass at the end of growing seasons as measured during various studies conducted in the vicinity of Coastwide Reference Monitoring System (CRMS) site 0164-H.

84. Live and dead belowground biomass by season at Coastwide Reference Monitoring System (CRMS) site 0164- $\mathrm{H}$.

85. Depth profiles of bulk density, nitrogen, and carbon at Coastwide Reference Monitoring System (CRMS) site 0164- $\mathrm{H}$.

86. Mean values of bulk density by various depth intervals at Coastwide Reference Monitoring System (CRMS) site 0164-H

87. Feldspar marker horizon and short-term accretion on July 10,2008 , at Coastwide Reference Monitoring System (CRMS) site 0164-H

88. Carbon and nitrogen content in sediment and their ratios from the upper $20 \mathrm{~cm}$ of soil across different marsh types, with combined values from the Louisiana chenier and deltaic plains

89. The distribution of carbon and nitrogen accumulation in sediment across different marsh types, with combined values from the Louisiana chenier and deltaic plains

\section{Tables}

1. Intensive study site locations, associated marsh types, hurricane influence area, region, and sampling event details

2. Porewater salinity by marsh type. Minimum, mean, and maximum values by season and for the entire study period are presented

3. Observed taxa characterized as disturbance because of their typical presence in marshes that have been recently disturbed by physical or biological forces.

4. Results of analysis of variance testing for porewater salinity at the end of growing seasons in fresh, brackish/intermediate, and saline marsh types

5. Site-specific summaries of soils, porewater salinity, and vegetation data

6. Results of analysis of variance testing for aboveground biomass from nondisturbance species in fresh and brackish/intermediate marsh types

7. Results of analysis of variance testing for live aboveground biomass at the end of growing seasons in fresh, brackish/intermediate, and saline marsh types

8. Comparisons of aboveground and belowground biomass among different marsh types before and after Hurricanes Katrina and Rita.

9. Results of analysis of variance testing for peak aboveground biomass in fresh, brackish/intermediate, and saline marsh types

10. Results of analysis of variance testing for total belowground biomass at the end of growing seasons in fresh, brackish/intermediate, and saline marsh types

11. Changes in clonal expansion of ten monospecific patches of three species observed at CRMSO605-H on February 28 and May 9, 2007 
12. Summary of mean values for long-term (since 1963) rates of soil accretion and organic/mineral accumulation in herbaceous marshes of the chenier and deltaic plains of Louisiana.

13. Mean values for long-term rates of soil accretion in three marsh types in the deltaic and chenier plains of Louisiana

14. Regression relationships between long-term rates of vertical accretion and accumulation of organic and mineral matter for three marsh types across Louisiana at research sites from the Coastwide Reference Monitoring System paired with sites that were historically sampled by Holm, 2006

15. Mean values of organic, mineral, nitrogen, and carbon density in the upper $20 \mathrm{~cm}$ of soil in three marsh types.

16. Mean values of accumulation rates of organic, mineral, nitrogen, and carbon fractions in soil from three marsh types in the deltaic and chenier plains of Louisiana.

17. Comparison of study parameters for fresh, brackish/intermediate, and saline marsh types and sample year

\section{Conversion Factors}

SI to Inch/Pound

\begin{tabular}{lcl}
\hline Multiply & By & \multicolumn{1}{c}{ To obtain } \\
\hline centimeter $(\mathrm{cm})$ & Length & inch (in.) \\
millimeter $(\mathrm{mm})$ & 0.3937 & inch (in.) \\
\hline square meter $\left(\mathrm{m}^{2}\right)$ & 0.03937 & square foot $\left(\mathrm{ft}^{2}\right)$ \\
\hline cubic centimeter $\left(\mathrm{cm}^{3}\right)$ & Area & cubic inch $\left(\mathrm{in}^{3}\right)$ \\
cubic meter $\left(\mathrm{m}^{3}\right)$ & 10.76 & cubic foot $\left(\mathrm{ft}^{3}\right)$ \\
\hline & Volume & \\
\hline gram $(\mathrm{g})$ & 0.06102 & ounce, avoirdupois $(\mathrm{oz})$ \\
\hline becquerel per liter $(\mathrm{Bq} / \mathrm{L})$ & 35.31 & \\
\hline
\end{tabular}

Temperature in degrees Celsius $\left({ }^{\circ} \mathrm{C}\right)$ may be converted to degrees Fahrenheit $\left({ }^{\circ} \mathrm{F}\right)$ as follows:

${ }^{\circ} \mathrm{F}=\left(1.8 x^{\circ} \mathrm{C}\right)+32$

Vertical coordinate information is referenced to the insert datum name (and abbreviation) here, for instance, "North American Vertical Datum of 1988 (NAVD 88)"

Horizontal coordinate information is referenced to the insert datum name (and abbreviation) here, for instance, "North American Datum of 1983 (NAD 83)" 


\title{
Geomorphic and Ecological Effects of Hurricanes Katrina and Rita on Coastal Louisiana Marsh Communities
}

\author{
By Sarai C. Piazza', Gregory D. Steyer', Kari F. Cretini', Charles E. Sasser ${ }^{2}$, Jenneke M. Visser ${ }^{3}$, \\ Guerry 0. Holm, Jr. ${ }^{2}$, Leigh Anne Sharp ${ }^{4}$, Elaine Evers' ${ }^{2}$, and John R. Meriwether ${ }^{5}$
}

\section{Abstract}

Hurricanes Katrina and Rita made landfall in 2005, subjecting the coastal marsh communities of Louisiana to various degrees of exposure. We collected data after the storms at 30 sites within fresh (12), brackish/intermediate (12), and saline (6) marshes to document the effects of saltwater storm surge and sedimentation on marsh community dynamics. The 30 sites were comprised of 15 pairs. Most pairs contained one site where data collection occurred historically (that is, prestorms) and one Coastwide Reference Monitoring System site. Data were collected from spring 2006 to fall 2007 on vegetative species composition, percentage of vegetation cover, aboveground and belowground biomass, and canopy reflectance, along with discrete porewater salinity, hourly surface-water salinity, and water level. Where available, historical data acquired before Hurricanes Katrina and Rita were used to compare conditions and changes in ecological trajectories before and after the hurricanes. Sites experiencing direct and indirect hurricane influences (referred to in this report as levels of influence) were also identified, and the effects of hurricane influence were tested on vegetation and porewater data. Within fresh marshes, porewater salinity was greater in directly impacted areas, and this heightened salinity was reflected in decreased aboveground and belowground biomass and increased cover of disturbance species in the directly impacted sites. At the brackish/intermediate marsh sites, vegetation variables and porewater salinity were similar in directly and indirectly impacted areas, but porewater salinity was higher than expected throughout the study. Interestingly, directly impacted saline marsh sites had lower porewater salinity than indirectly impacted sites, but aboveground biomass was greater at the directly impacted sites.

Because of the variable and site-specific nature of hurricane influences, we present case studies to help define postdisturbance baseline conditions in fresh, brackish/ intermediate, and saline marshes. In fresh marshes, the mechanism of hurricane influence varied across the landscape. In the western region, saltwater storm surge inundated freshwater marshes and remained for weeks, effectively causing damage that reset the vegetation community. This is in contrast to the direct physical disturbance of the storm surge in the eastern region, which flipped and relocated marsh mats, thereby stressing the vegetation communities and providing an opportunity for disturbance species to colonize. In the brackish/intermediate marsh, disturbance species took advantage of the opportunity provided by shifting species composition caused by physical and saltwater-induced perturbations, although this shift is likely to be short lived. Saline marsh sites were not negatively impacted to a severe degree by the hurricanes. Species composition of vegetation in saline marshes was not affected, and sediment deposition appeared to increase vegetative productivity.

The coastal landscape of Louisiana is experiencing high rates of land loss resulting from natural and anthropogenic causes and is experiencing subsidence rates greater than 10.0 millimeters per year $\left(\mathrm{mm} \mathrm{yr}^{-1}\right)$; therefore, it is important to understand how hurricanes influence sedimentation and soil properties. We document long-term vertical accretion rates and accumulation rates of organic matter, bulk density, carbon and nitrogen. Analyses using caesium-137 to calculate long-term vertical accretion rates suggest that accretion under impounded conditions is less than in nonimpounded conditions in the brackish marsh of the chenier plain. Our data also support

\footnotetext{
${ }^{1}$ U.S. Geological Survey, National Wetlands Research Center, Lafayette, Louisiana

2 Louisiana State University, Department of Oceanography and Coastal Sciences

${ }^{3}$ University of Louisiana at Lafayette, Department of Renewable Resources

${ }^{4}$ Louisiana Governor's Office of Coastal Protection and Restoration

${ }^{5}$ University of Louisiana at Lafayette, Department of Physics
} 
previous studies indicating that accumulation rates of organic matter explain much of the variability associated with vertical accretion in brackish/intermediate and saline marshes. In fresh marshes, more of the variability associated with vertical accretion was explained by mineral accumulation than in the other marsh types. The marsh types in this study span a wide distribution of nutrient accumulation rates but exhibit similar upper limits of carbon (200 grams per square meter per year [ $\left.\mathrm{g} \mathrm{m}^{-2} \mathrm{yr}^{-1}\right]$ ) and nitrogen (10-14 $\left.\mathrm{g} \mathrm{m}^{-2} \mathrm{yr}^{-1}\right)$ accumulation. Information regarding site-specific soil properties is provided through soil profiles, and short-term elevation change and accretion are also reported for sites where historical data collection occurred.

This study provides new ecological baseline conditions following Hurricanes Katrina and Rita and an assessment of site-specific hurricane impacts, recovery, and potential changes in ecological trajectories. Paired with the ongoing data collection through the Coastwide Reference Monitoring System program, this study should provide useful information for resource managers and modelers that can be used for comparisons of conditions occurring after future landscapescale disturbances.

\section{Introduction}

The coastal wetlands of Louisiana have sustained the highest rate of wetland loss in the United States, with approximately $2,976 \mathrm{~km}^{2}$ of wetlands converting to open water from 1956 to 2004 (Barras, 2006). Many factors, both natural and human-induced, have been linked to land loss, including altered hydrology, saltwater intrusion, wave erosion, and high relative sea level rise (RSLR) (Boesch and others, 1994). Stone and others (1997) identified hurricanes as a primary force controlling the transgressive evolution of the barrier islands of Louisiana. Recent evidence also suggests the importance of hurricanes in altering coastal wetland landscapes (Guntenspergen and others, 1995; Barras, 2006, 2007; Steyer, 2008). Since Hurricane Andrew in 1992, there have been two major ( ${ }^{3}$ category 3$)$ storms, Hurricanes Katrina and Rita, to strike Louisiana and significantly influence barrier islands and interior coastal wetlands. Four additional hurricanes (< category 3), Georges (1998), Lili (2002), Gustav (2008), and Ike (2008), made landfall in Louisiana or near the Louisiana border with Texas or Mississippi, subjecting coastal marshes to storm surge and hurricane-force winds. The net wetland loss associated with Hurricanes Katrina and Rita (2005) alone was estimated at $562 \mathrm{~km}^{2}$ (Barras, 2006). Based on a 105-year dataset, Louisiana has hurricane return periods of 7 years in the eastern coastal zone, 10 years in central, and 15 years in western (Keim and others, 2007). Since 1995, an increase in storm intensity and frequency has been observed for the north-central Gulf of Mexico coast (Keim and others, 2007), including Louisiana.
Increased storm intensity and frequency could produce more major hurricanes, such as Hurricanes Katrina and Rita, which have the potential to dramatically influence Louisiana's coastal wetlands. Hurricane Katrina made landfall in eastern coastal Louisiana near Empire on August 29, 2005. Approximately one month later, Hurricane Rita struck western Louisiana near Johnsons Bayou on September 24, 2005. Assuming a constant annual loss rate $(\sim 62$ square kilometers per year $\left.\left[\mathrm{km}^{2} \mathrm{yr}^{-1}\right]\right)$ from 1956 to 2004, Hurricanes Katrina and Rita produced 9 year's worth of wetland loss in one month. Storm surge depths were greatest in eastern Louisiana marshes from Hurricane Katrina ( $>4.5 \mathrm{~m}$ ), while Hurricane Rita produced storm surge depths greater than $3 \mathrm{~m}$ in western Louisiana marshes. Both hurricanes produced winds greater than 161 kilometers per hour $\left(\mathrm{km} \mathrm{hr}^{-1}\right)$ in the vicinities where they made landfall, and tropical storm-force winds influenced the entire coastal landscape of Louisiana.

Hurricanes and related storm surges cause a wide range of impacts to coastal wetland systems (fig. 1). While severe habitat damage and mortality of vegetation caused by high winds and storm surge are not uncommon (Doyle and others, 1995; Guntenspergen and others, 1995; Cahoon, 2003; Barras, 2006; Barras, 2007), hurricanes produce beneficial subsidies of sediments to coastal wetlands, which affect their long-term sustainability (Cahoon and others, 1995; Nyman and others, 1995; Cahoon, 2003). Hurricanes and tropical storms can transport sediments from the inner shelf into coastal bays and marsh ecosystems within the northern Gulf of Mexico (Nyman and others, 1995; Perez and others, 2000; Walker and Hammack, 2000; Goni and others, 2006; Turner and others, 2006). Hurricanes often produce spatially complex patterns of wetland damage and benefits that vary with landscape attributes (geology, shoreline orientation, and management) and unique storm characteristics (intensity, duration, and path).

Storm-related damage to coastal wetlands is generally biological (for example, salt or inundation stress to vegetation) or physical (for example, organic mat upheaval or mineral erosion) in nature. Salinity and flooding pulses to coastal marsh ecosystems can result in significant alteration of vegetation communities (Chabreck and Palmisano, 1973; Meeder, 1987; Doyle and others, 1995; Steyer and others, 2007). Because plant associations are well established along estuarine salinity gradients (Odum and Hoover, 1988; Latham and others, 1994; Mitsch and Gosselink, 2000), episodic events that disrupt these gradients can cause plant death, decrease plant production, lead to changes in species distributions, and promote invasions of nonnative or opportunistic plant species (Ewel, 1986). Disturbances that alter salinity regimes provide opportunities for scientists to directly evaluate vegetation salt tolerance and indirectly evaluate competitive ability of marsh vegetation, two factors that have been suggested to be inversely related (Barbour, 1978; LaPeyre and others, 2001; Crain and others, 2004).

In addition to episodic disturbances, sea level rise has the potential to influence vegetation communities. Louisiana 


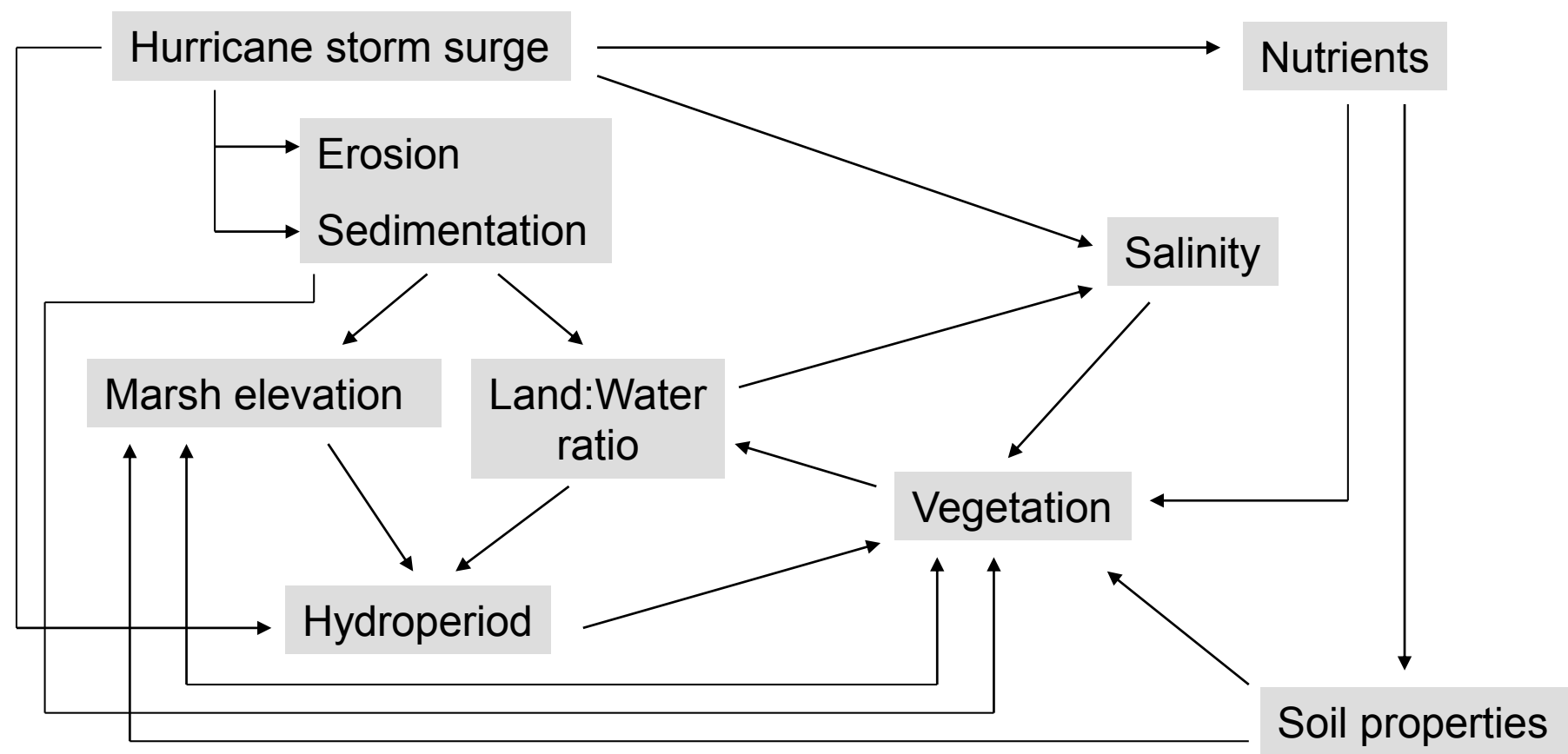

Figure 1. The interconnected influences of hurricane storm surge on marsh dynamics.

coastal marshes are particularly susceptible to sea level rise because of their naturally minimal slope and high subsidence rates. Global sea level rise is estimated to be between 1.0 and $2.4 \mathrm{~mm} \mathrm{yr}^{-1}$ (Douglas and Peltier, 2002). As global sea level increases, greater areas of the Louisiana coastal zone will be inundated with saline waters, potentially exposing vegetation that is not adapted to saline conditions. This issue is compounded by subsidence rates greater than $10 \mathrm{~mm} \mathrm{yr}^{-1}$ in some areas of the Louisiana coastal zone. Relative sea level rise accounts for global sea level rise and local subsidence thus it can be much greater than rates of global sea level rise. For Grand Isle, La., estimates of RSLR are approximately $9.85 \mathrm{~mm} \mathrm{yr}^{-1}$. With RSLR estimates of nearly $1 \mathrm{~cm}$ per year, coastal wetland communities of Louisiana will experience not only increased inundation and saltwater intrusion but will be more vulnerable to storm surges and erosion from future hurricanes.

Direct, physical damage from a hurricane usually takes the form of upheaval and redistribution of organic surface layers or extensive lateral compression of the marsh surface (that is, accordion-like folding and stacking of the marsh mat) (Guntenspergen and others, 1995). These organic surface layers can be up to $1.0 \mathrm{~m}$ thick (Evers and others, 2007), and their removal often results in landscape conversion of marsh to open water. Given the high rates of geological subsidence and sea level rise that Louisiana wetlands experience, the rate of landscape recovery from open water to marsh is slow and uncertain. The slow and uncertain pace of recovery is due to the slow and uncertain process by which coastal wetlands maintain an equilibrium elevation with sea level for their long-term stability. This equilibrium elevation is maintained through interactions among tidal flooding, sediment deposition, and plant production that compensate for the combined effects of local subsidence and eustatic sea level rise (Morris and others, 2002). In marsh areas that are sediment poor, are undergoing high subsidence, or have low productivity, an accretion and elevation deficit can exist that over time may result in a conversion to open water (DeLaune and others, 1983; Baumann and others, 1984; Nyman and others, 1993; Cahoon, 2003).

High-energy events such as hurricanes provide a significant pulse of mineral sediments that can contribute to elevation gain and help offset RSLR (Rejmanek and others, 1988; Day and others, 1995; Reed, 2002; Turner and others, 2006). Storm surges can account for extensive transport of sediments from the coastal inner shelf and bays to interior wetlands (Cahoon and others, 1995; Turner and others, 2006). This subsidy of sediments can increase wetland elevation and enhance plant nutrition. Mineral sedimentation plays an important role in marsh accretion by supplying nutrients that can promote plant production (Broome and others, 1975; DeLaune and others, 1981; Bricker-Urso and others, 1989; Nyman and others, 1990; DeLaune and others, 1992; Nyman and others, 1993). Given the volumetric characteristics 
of organic matter, its accumulation from aboveground and belowground production contributes more significantly to long-term vertical accretion of soil than to mineral fractions (McCaffrey and Thomson, 1980; Hatton and others, 1983; Nyman and others, 1993; Turner and others, 2001; Turner and others, 2004); however, both are critical in sediment-poor environments (Steyer, 2008).

Hurricanes can simultaneously influence both surface and subsurface soil processes, creating unpredictable changes to soil elevation when focusing on sediment deposition and erosion only (Cahoon, 2006). Aboveground and belowground production can also be impacted by hurricanes through flooding and the introduction of saltwater. When marshes experience storm-related plant mortality, organic matter decomposition can negatively influence marsh elevation. These impacts could offset potential benefits accrued through mineral introduction. The influence of subsurface processes on soil elevation (for example, sediment compaction, soil shrinkage, poststorm peat decomposition, soil swelling) can be a major difference between high frequency, low magnitude events and low frequency, high magnitude events (Cahoon, 2006).

Disturbance magnitude and characteristics of the impacted ecosystem determine the time required for ecosystem structure or function to return to predisturbance form or rate (DeAngelis, 1980). Vogt and others (1997) suggest that an ecosystem is resilient if its recovery periods are shorter than the recurrence interval of disturbance events. Very few studies of hurricane impacts have tracked development and recovery of vegetation communities beyond one growing season after the disturbance, limiting opportunities for the evaluation of ecosystem resiliency.

With respect to plant communities, a general gradient of decreasing subsidy from mineral sediment and increasing salt stress associated with storm surge is typically observed with increasing distance inland. Saline marshes experience damage from physical erosion, but because of their proximity to the coastline, they receive sediments from the inner continental shelf that move inshore with tropical disturbances. Saline marsh vegetation is better adapted than fresh marsh vegetation to the high salinity waters associated with hurricanes and the physical energy associated with storm surge. Fresh marshes experience more biological damage than saline marshes because they are highly organic environments where salinity impairs plant health and, in turn, alters the balance of organic matter that helps sustain elevation.

Previous research on hurricane impacts in coastal Louisiana has focused on physical disturbance of the marsh substrate (Morgan and others, 1958; Chamberlain, 1959; Guntenspergen and others, 1995; Barras, 2006; Barras, 2007) and sediment distribution (Baumann and others, 1984; Rejmanek and others, 1988; Cahoon and others, 1995; Nyman and others, 1995; Cahoon, 2003; Turner and others, 2006).

Fewer studies have investigated the effects of salinity intrusion and flooding on coastal marsh vegetation (Ensminger and Nichols, 1957; Chabreck and Palmisano, 1973; Meeder, 1987;
Jackson and others, 1995). Many of the prior investigations reported general observations, and other studies focused on small geographic areas or specific vegetation species of interest. There are relatively few studies (Cahoon and others, 1995; Guntenspergen and others, 1995; Jackson and others, 1995) that assess both physical and biological effects of hurricanes across broad geographic regions and vegetation communities.

Hurricane-induced saltwater intrusion and flooding provide an ideal opportunity to assess how wetland plant communities and species respond to a variety of stressors and subsidies following severe disturbance. Because the entire coast of Louisiana was influenced by Hurricanes Katrina and Rita, a coastwide assessment of impacts and recovery within fresh, brackish/intermediate, and saline marshes was designed by using field-based and remotely sensed data. Our objective was to document the effect of saltwater storm surge and sedimentation from Hurricanes Katrina and Rita on marsh community dynamics in coastal Louisiana. Specifically, we document new ecological baseline conditions following the two major hurricanes and assess site-specific hurricane impacts, recovery, and potential changes in ecological trajectories. Documenting new baseline conditions is important because catastrophic storms such as Katrina and Rita create a range of effects, from marginal impacts to a total resetting of the system, such that one static baseline condition may not equally apply to all community types.

\section{Materials and Methods}

\section{Study Area}

Thirty sites located within fresh (12), brackish/ intermediate (12), and saline (6) marsh communities across coastal Louisiana were selected for this study (fig. 2, table 1) on the influences of Hurricanes Katrina and Rita on coastal marshes. The sites provide detailed data on soils, vegetation, and porewater within different marsh communities. Site locations generally fall along north-south gradients within eastern, central, and western regions of the coast, which has been categorized into nine hydrologic basins by the Louisiana Coastal Wetlands Planning, Protection and Restoration Act Program (n.d.; fig. 3).

The parameters for determining whether a site or region was directly or indirectly influenced by the 2005 hurricanes were consistent with Steyer and others (2010). Direct influence was determined by evaluating areas exposed to at least two of the three following factors: hurricane force winds, storm surge greater than $2 \mathrm{~m}$ (Ebersole and others, 2007; McGee and others, 2007), and physical disturbance. Indirectly influenced areas experienced flooding from 0.0 to $1.2 \mathrm{~m}$ and tropical storm-force winds (Doyle and others, 2007). The eastern region includes an area directly influenced 


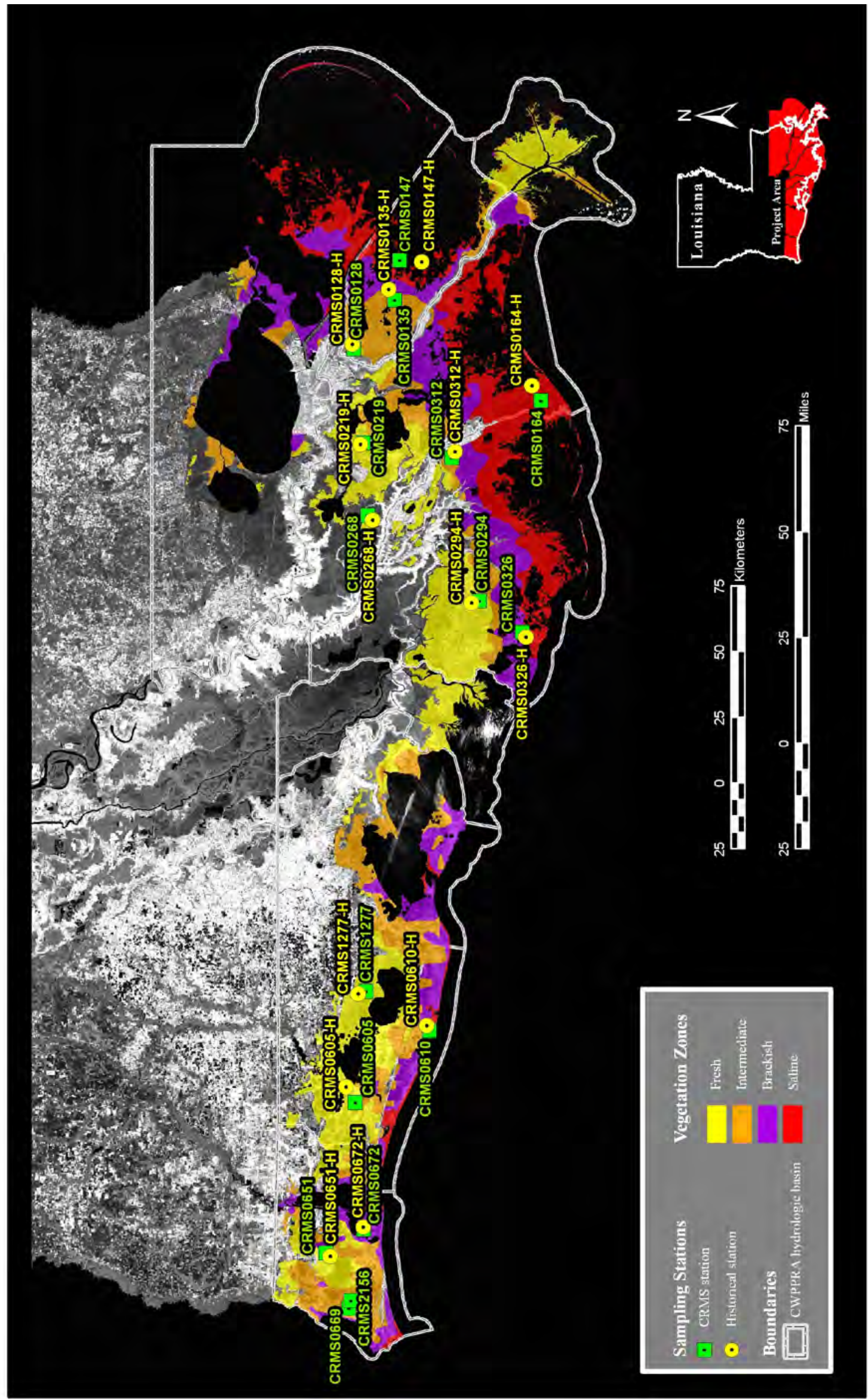

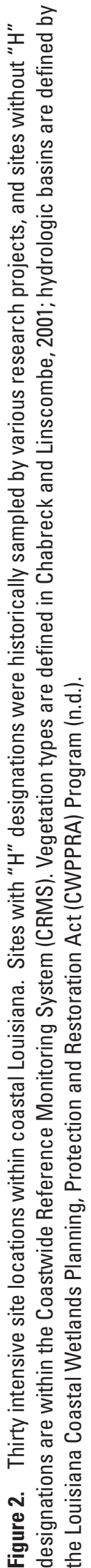


Table 1. Intensive study site locations, associated marsh types, hurricane influence area, region, and sampling event details.

[ ID, identification; UTM, Universal Transverse Mercator; CRMS, Coastwide Reference Monitoring System; H, historically sampled sites]

\begin{tabular}{|c|c|c|c|c|c|c|}
\hline Site ID & Marsh type & $\begin{array}{c}2005 \\
\text { hurricane influ- } \\
\text { ence }\end{array}$ & Region & UTM Y & UTM X & $\begin{array}{l}\text { Missed sam- } \\
\text { pling event }\end{array}$ \\
\hline CRMS0128 & Fresh & Direct & Eastern & 3304046.44 & 794926.32 & Summer 2007 \\
\hline CRMS0128-H & Fresh & Direct & Eastern & 3304476.93 & 796648.25 & Summer 2006 \\
\hline CRMS0135 & Brackish/Intermediate & Direct & Eastern & 3288445.77 & 813508.42 & None \\
\hline CRMS0135-H & Brackish/Intermediate & Direct & Eastern & 3290676.79 & 817515.16 & None \\
\hline CRMS0147 & Saline & Direct & Eastern & 3286564.23 & 828709.78 & None \\
\hline CRMS0147-H & Saline & Direct & Eastern & 3278155.79 & 828063.93 & None \\
\hline CRMS0164 & Saline & Indirect & Central & 3232787.60 & 775200.39 & None \\
\hline CRMS0164-H & Saline & Indirect & Central & 3236233.93 & 780828.40 & None \\
\hline CRMS0219 & Fresh & Indirect & Central & 3300396.61 & 759143.07 & None \\
\hline CRMS0219-H & Fresh & Indirect & Central & 3301502.44 & 758598.21 & None \\
\hline CRMS0268 & Fresh & Indirect & Central & 3298721.54 & 731669.82 & None \\
\hline CRMS0268-H & Fresh & Indirect & Central & 3296809.99 & 729760.19 & None \\
\hline CRMS0294 & Fresh & Indirect & Central & 3256189.48 & 698975.97 & None \\
\hline CRMS0294-H & Fresh & Indirect & Central & 3259134.40 & 698168.19 & None \\
\hline CRMS0312 & Brackish/Intermediate & Indirect & Central & 3266791.38 & 753464.56 & Spring 2006 \\
\hline CRMS0312-H & Brackish/Intermediate & Indirect & Central & 3265434.05 & 755785.15 & Spring 2006 \\
\hline CRMS0326 & Saline & Indirect & Central & 3239849.80 & 687109.59 & None \\
\hline CRMS0326-H & Saline & Indirect & Central & 3238431.55 & 685120.68 & None \\
\hline CRMS0605 & Fresh & Direct & Western & 3303357.00 & 508034.00 & None \\
\hline CRMS0605-H & Fresh & Direct & Western & 3306980.33 & 514030.15 & None \\
\hline CRMS0610 & Brackish/Intermediate & Direct & Western & 3275262.00 & 535288.00 & None \\
\hline CRMS0610-H & Brackish/Intermediate & Direct & Western & 3276220.94 & 537281.07 & None \\
\hline CRMS0651 & Brackish/Intermediate & Direct & Western & 3314723.06 & 450738.12 & None \\
\hline CRMS0651-H & Brackish/Intermediate & Direct & Western & 3312912.00 & 449408.00 & None \\
\hline CRMS0669 & Brackish/Intermediate & Direct & Western & 3305990.69 & 429573.82 & None \\
\hline CRMS0672 & Brackish/Intermediate & Direct & Western & 3300211.00 & 459731.00 & None \\
\hline CRMS0672-H & Brackish/Intermediate & Direct & Western & 3300398.00 & 460480.00 & None \\
\hline CRMS1277 & Fresh & Direct & Western & 3299450.66 & 550313.63 & None \\
\hline CRMS1277-H & Fresh & Direct & Western & 3302219.98 & 549282.01 & None \\
\hline CRMS2156 & Brackish/Intermediate & Direct & Western & 3305166.74 & 432586.58 & None \\
\hline
\end{tabular}

by Hurricane Katrina. Study sites located in this area of direct influence are within the Breton Sound hydrologic basin. The western region includes the area directly influenced by Hurricane Rita (Mermentau and Calcasieu/Sabine basins), and the central region, less influenced, was indirectly exposed to hurricane conditions.

Among the 30 study sites, pairs of sites were established along the north-south gradients (that is, 30 sites total comprised of 15 pairs). A typical pair consisted of one historical research or monitoring site and one site included in the Coastwide Reference Monitoring System (CRMS) (Steyer and others, 2003). Historical sites were sampled before Hurricanes Katrina and Rita as part of various research projects, and we used data from historical samplings of those sites to evaluate posthurricane effects and changes in ecological trajectories. In this study, we tried to build upon the historical research by sampling the same variables at or nearby the original sampling sites. The historical sites (containing an "-H" in the site name) were paired with CRMS sites to assess long-term recovery because CRMS monitoring 


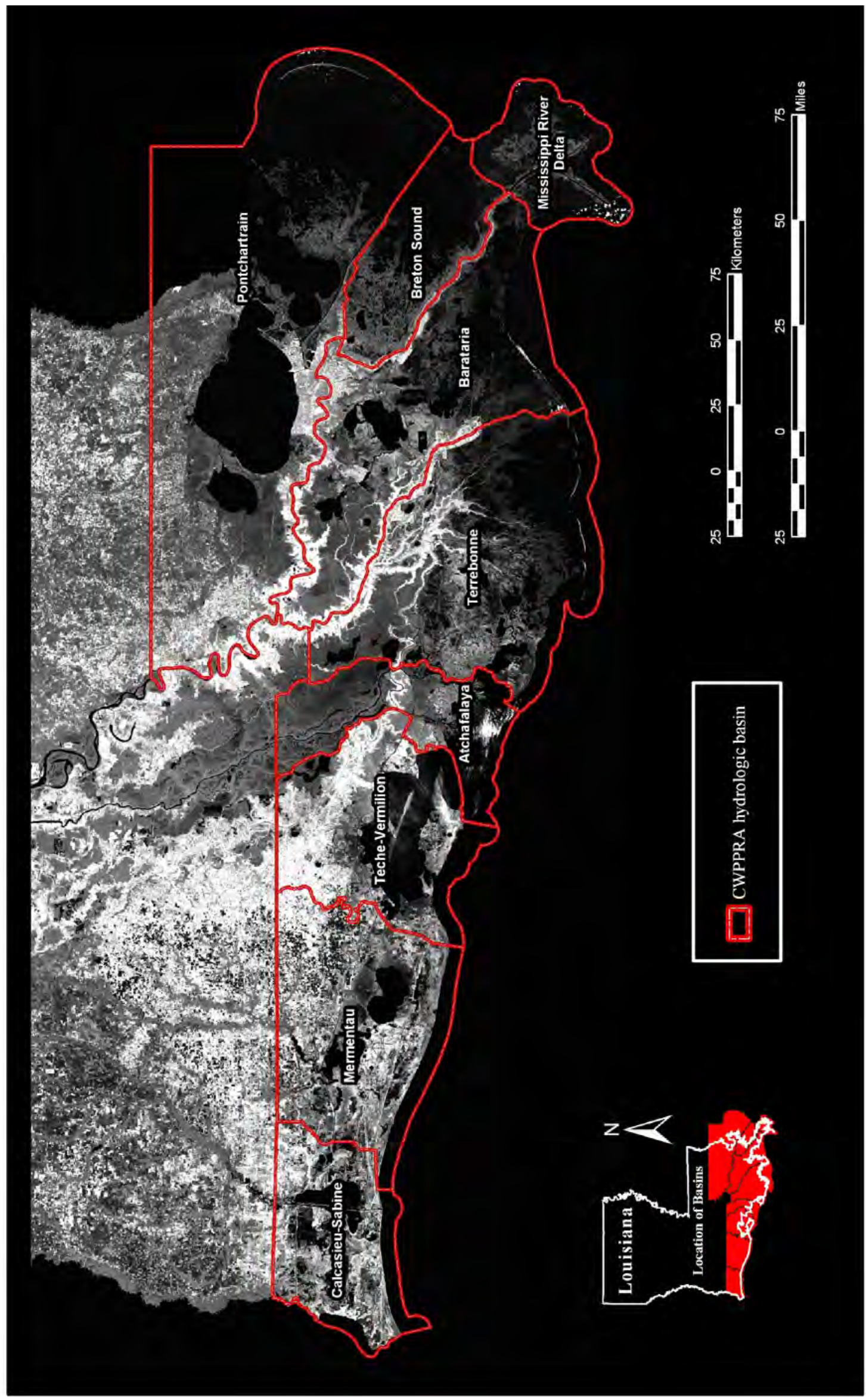


stations have a 20 -year funded life, and sampling at these locations will continue beyond the scope of our study.

Classifications of marsh vegetation were determined for the sites according to the Chabreck and Linscombe 2001 aerial survey. Fresh marsh sites were typically dominated by Panicum hemitomon (maidencane) and/or Sagittaria lancifolia (bulltongue). Although brackish and intermediate habitat types are distinct classes in the classification system of Chabreck and Linscombe (2001), we combined these sites into a brackish/intermediate vegetation type. This decision was based on the presence of Spartina patens (marshhay cordgrass) as a dominant species at the majority of brackish and intermediate sites within this study. Saline marsh sites were dominated by Spartina alterniflora (smooth cordgrass).

\section{Methods}

Data from seven sampling periods are included in this report. Sampling occurred quarterly from spring 2006 to fall 2007 (that is, spring [Apr. and May] 2006 and 2007; summer [July and Aug.] 2006 and 2007; fall [Sept. and Oct.] 2006 and 2007; winter [Jan. and Feb.] 2007). Occasionally throughout the study period, some sites could not be sampled because of access issues (for example, low water or conflicts with hunting seasons) or logistical problems (table 1).

\section{Vegetation}

Percentage of vegetation cover, species composition, and height of the dominant plants within a 2- by 2-m $\left(4-\mathrm{m}^{2}\right)$ plot were determined by using a modified Braun-Blanquet method described in Steyer and others (1995). This method only counts emergent vegetation that is rooted in the plot; therefore, floating aquatic vegetation is not reflected in percentage of cover values. Percentage of cover values can be greater than 100 percent because of multiple layers/canopies of vegetation within one plot.

Aboveground plant biomass was sampled by harvesting plant material from replicate $0.25-\mathrm{m}^{2}$ quadrats in three randomly selected locations within each study site. All standing live and dead stems were clipped within $1 \mathrm{~cm}$ of the sediment surface. Clipped stems and litter were placed in bags and returned to the laboratory. The plant material was not washed but was separated into live and dead components according to the presence (live) or absence (dead) of green pigment on the stems. Live material was separated by species, and stems were counted to determine stem density $\left(\right.$ stems $\mathrm{m}^{-2}$ ). All sorted material was oven dried at $65^{\circ} \mathrm{C}$ to a constant weight and weighed to the nearest $0.5 \mathrm{~g}$.

Following removal of aboveground material from each of the three clip plots, belowground biomass was sampled via 10-cm (4-inch) diameter cores made of aluminum or polyvinyl chloride (PVC). The cores were taken to a maximum depth of $40 \mathrm{~cm}$ or the entire mat thickness if the mat was less than
$40 \mathrm{~cm}$. Cores were sliced in the field or transported to the laboratory intact, divided into 8 -cm sections, and washed in 2.0-mm mesh sieves stacked within $0.5-\mathrm{mm}$ mesh sieves to remove soil particles and prevent loss of fine root material. Live roots and rhizomes were separated from the remaining matrix of dead roots and other organic material. Dead roots and rhizomes were separated into coarse and fine components. All belowground material (that is, live, dead coarse, and dead fine) was dried at $65^{\circ} \mathrm{C}$ to a constant weight and weighed to the nearest $0.5 \mathrm{~g}$.

Remotely sensed data of canopy reflectance were used to investigate the normalized difference vegetation index (NDVI) to detect live, green plant canopies in marsh communities. Steyer (2008) includes a complete explanation and methods for using NDVI to evaluate anomalies, as well as significant and persistent damage to Louisiana coastal marsh communities following Hurricanes Katrina and Rita. In brief, MODerate Resolution Imaging Spectroradiometer (commonly referred to as MODIS) imagery was collected monthly from February 2000 to March 2005. For each month, NDVI values were averaged to generate baseline NDVI values. These monthly baseline conditions were compared to composites for the end of the growing season immediately after Hurricanes Katrina and Rita and one growing season thereafter (fall 2005 and fall 2006) in order to evaluate index values occurring after the hurricanes. Scores that departed from average NDVI values were calculated for September and October 2005 and 2006 for individual pixels where study sites were located. In this study, departure from average scores ranged from -1.14 to 0.25 . Sites experiencing departure from average scores on the low end of the range (-1.14) experienced significant loss of vegetation (and likely conversion to open water), while sites with departures from average closer to 0.25 showed a higher density of vigorous vegetation beyond the baseline average. Sites with no variation between the monthly baseline average and the sampling date would receive a departure from average score of zero. Although the NDVI can be used to estimate aboveground biomass and productivity, we measured aboveground biomass directly for this study and used NDVI as a secondary tool to evaluate marsh condition and recovery after Hurricanes Katrina and Rita. The NDVI can be a useful tool to evaluate vegetative vigor but does not give any indication of species composition or vegetative community change.

\section{Hydrology}

Water level and salinity were measured hourly by using an YSI model 6920 multiparameter continuous hydrologic recorder or equivalent instrument at CRMS stations. Continuous hydrologic recorders were only established at one of the paired sites because of the proximity and hydrologic similarity of the sites to each other. The basic recorder measured water level through a pressure transducer by using a cable that was vented to the atmosphere. The recorders 
were surveyed to the North American Vertical Datum of 1988 (NAVD 88), and water levels to datum were used to calculate depth, duration, and frequency of marsh inundation. The instrument specifications and procedures for field deployment, servicing, data processing, and quality assurance are described in Steyer and others (1995). See appendix 1 for hydrographs of water level (ft, NAVD 88) and salinity at selected CRMS study sites with available data from April 1, 2006, to November 1, 2007.

\section{Porewater in Soil}

Samples of porewater were collected from soil at $30-\mathrm{cm}$ depth with a sipper probe to aid in extracting interstitial water (McKee and others, 1988). Porewater salinity was measured in the field with a portable, hand-held instrument (YSI 63). Procedures for fieldwork and quality assessment and control are described in Folse and West (2005).

\section{Sediment Deposition and Condition}

Sedimentation was determined from the distribution of caesium (caesium-137, 30-yr half life) in the sediment profile (DeLaune and others, 1978). Two cores were obtained at each station by twisting a $10-\mathrm{cm}$-diameter, thin-walled aluminum or $\mathrm{PVC}$ cylinder to a maximum depth of $50 \mathrm{~cm}$. Core collection for analyzing caesium-137 occurred during sampling period of fall 2006 (Sept. and Oct.) at all sites. Compaction was minimized by using large, thin-walled cores. The cores were sectioned in the field into $2-\mathrm{cm}$ increments, following procedures outlined in Folse and West (2005). In the laboratory, the specific activity of caesium-137 in each section was determined by using gamma ray spectroscopy with high-purity germanium detectors. The 662-kiloelectronvolt $(\mathrm{keV})$ gamma emission from caesium-137 was measured for a minimum of 11 hours. The gamma spectrometers were calibrated for energy and efficiency by using a referencemixed gamma ray source traceable to the National Institute of Standards and Technology. The specific activity (A) was calculated by using the following equation:

$$
A=\frac{C}{E B m t},
$$

where

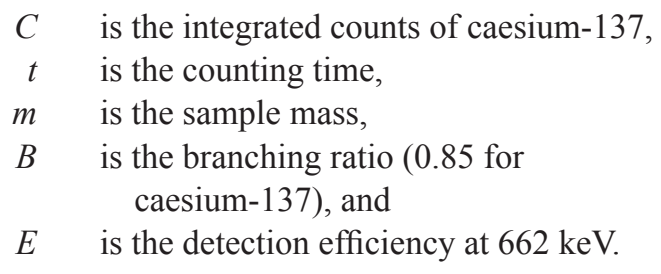

The depth profile of caesium-137 was determined by plotting the specific activity for each section. The centroid of a peak was determined by calculating a weighted average of the three points that define the peak. The depth of the peak was calculated by using the following equation:

$$
d=\frac{\sum_{i=1}^{3} y_{i} A_{i}}{\sum_{i=1}^{3} A_{i}}
$$

where

$$
\begin{array}{ll}
d & \text { is the depth of the peak } \\
y & \text { is the depth of the section, and } \\
A & \text { is specific caesium-137 activity. }
\end{array}
$$

Long-term accretion rates (centimeters per year $\left[\mathrm{cm} \mathrm{yr}^{-1}\right]$ ) were calculated by dividing the depth of the caesium-137 peak by the number of years since 1963. In 1963, caesium-137 was deposited from atmospheric fallout providing a marker horizon in sediment cores that can be reliably identified. This analysis and interpretation resulted in 49 datable cores from a total of 60 cores taken. Of the 30 total sites, 20 had two datable cores, 9 had one datable core, and only 1 did not have a datable core. After gamma counting, the samples were transferred to the Wetland Biogeochemistry Institute, Analytical Services Lab at Louisiana State University (Baton Rouge, La.) for carbon and nitrogen analyses.

A mean accretion rate was calculated for each site when two datable cores were available ( $\mathrm{n}=20$ sites); otherwise, only one estimate of accretion was available for the remaining sites $(n=9)$. We calculated the mean $(n=2)$ content of carbon, nitrogen, and mineral and organic matter (see below) for each depth interval $(2 \mathrm{~cm})$; these means were used to calculate accumulation. The sum of the bulk soil and nutrient constituents above the level of the 1963 layer was then divided by the appropriate age factor (difference in years, date of collection minus 1963) to estimate a yearly rate of accumulation.

\section{Bulk Density and Organic Matter}

Bulk density and percentage of organic matter were determined from the same cores $(n=60)$ used for caesium-137 analysis. Core sections were dried at $60{ }^{\circ} \mathrm{C}$ and ground through a $2-\mathrm{mm}$ mesh sieve. The material remaining on the sieve (mostly plant material) was then ground through a Wiley mill with $0.6 \mathrm{~mm}$ mesh. Bulk density (grams per cubic centimeter $\left[\mathrm{g} \mathrm{cm}^{-3}\right]$ ) was determined by dividing the dry weight of the core section by the section volume. Organic matter content was determined by using the loss-on-ignition method (Dean, 1974). A subsample of $1 \mathrm{~g}$ was removed from each section for combustion at $550^{\circ} \mathrm{C}$ for 2 hours. 


\section{Sediment Elevation, Accretion, and Shallow Subsidence}

Rod-surface elevation tables (RSET) were deployed at each CRMS station (16 total) and one historically sampled station (CRMS0326-H) to estimate elevation changes in marsh surface. The RSET is a removable instrument that was placed on permanently installed benchmarks driven into the substrate to refusal (10-18 $\mathrm{m}$ depth). The RSET was placed in the exact same location at each recording interval and measured changes in the distance between the marsh sediment surface and the instrument itself. Measurements were taken three times (that is, spring 2007, winter 2008, and fall 2008) following the procedures described in Cahoon and others $(2002 \mathrm{a}, \mathrm{b})$. The sediment elevation and accretion data collected in winter and fall 2008 are included in this report but this is the only data type for which 2008 data are reported. Sediment elevation and accretion must be sampled over longer periods of time (that is, usually a 6-month minimum interval between readings), so data collection occurred over a longer timescale for these data types than the vegetation, water, and soil parameters.

Three artificial marker horizons were established at each CRMS station and at a subset of historically sampled stations by using a feldspar marker technique (Knaus and Cahoon, 1990). A 1-cm layer of white feldspar clay was placed on the marsh surface in three $0.25-\mathrm{m}^{2}$ plots during either the spring 2006 or summer 2006 sampling period. Frozen marsh cores were extracted from each feldspar plot at the time of RSET readings, and the depth of sediment deposited over the marker horizon was measured to the nearest millimeter to determine the accretion rate.

By using the above two techniques in combination, estimates of shallow subsidence were calculated by subtracting measurements of elevation change from measurements of accretion (Cahoon and others, 1995). Two gages were used to provide estimates of RSLR in coastal Louisiana. The Grand Isle, La., gage (National Oceanic and Atmospheric Administration 8761724) was used for all sites in the eastern and central study areas, and the Sabine Pass, Tex., gage (National Oceanic and Atmospheric Administration 8770570) was used for the western region. Site elevation change $\left(\mathrm{cm} \mathrm{yr}^{-1}\right.$ ) was then compared to the projected RSLR estimates for each site for which we had sufficient data.

\section{Statistical Analyses}

All statistical analyses were performed by using SAS software (SAS Institute, Inc., 1989), and an alpha of 0.05 was used to indicate significance. Data were tested for normality by examining model residuals and homogeneity of variance to satisfy the assumptions of the statistical analyses performed. Subsequent $[\log 10(\mathrm{x}+1)]$ transformation was performed on porewater salinity data to improve normality.

\section{Vegetation and Porewater Salinity}

Site-specific comparisons of total and live aboveground biomass before and after Hurricanes Katrina and Rita were performed with analysis of variance (ANOVA). Pearson correlation was used to evaluate the potential relationships between total cover of live vegetation; live aboveground biomass; and porewater salinity among all vegetation types. Porewater salinity data acquired after the hurricanes were tested with ANOVA for site-specific, seasonal variation.

Aboveground and belowground biomass, porewater salinity, and total cover of live vegetation were analyzed with ANOVA to test for differences among vegetation type, season, and vegetation type-by-season interactions. In addition, the influence of hurricanes (that is, direct or indirect), year, and the interaction of hurricane influence by year was investigated for porewater salinity and belowground biomass at the end of growing seasons by using ANOVA.

Aboveground biomass data were subsetted into biomass and peak biomass at the end of growing seasons and were analyzed with ANOVA to test for differences among the level of hurricane influence, year, and the interaction of these two factors. To estimate values of biomass at the end of growing seasons, the biomass data were subsetted to include only those data that were harvested during the fall (Sept. and Oct.) of 2006 and 2007. Peak biomass was determined by the highest average biomass harvested at each site during each year. The highest biomass generally occurred either in summer or fall harvests. Percentages of aboveground biomass that were contributed by disturbance and nondisturbance species were also determined and averaged for each of three seasons (spring, summer, and fall).

\section{Soils}

Data on bulk density from two sites that were historically sampled were analyzed with t-tests to evaluate differences in values from before and after Hurricanes Katrina and Rita. Simple linear regression was used to examine relationships between long-term rates of vertical accretion and accumulation of organic and mineral matter within vegetation types.

\section{Results and Discussion}

\section{Recovery After Hurricanes Katrina and Rita}

\section{Summary of All Vegetation Types}

Within all vegetation types, porewater salinities were typically greatest in the spring and summer of 2006 and generally decreased throughout the study (table 2). In a 
Table 2. Porewater salinity by marsh type. Minimum, mean (with standard errors), and maximum values by season and for the entire study period are presented.

\begin{tabular}{|c|c|c|c|c|}
\hline Mash type & Season & Minimum & Mean (SE) & Maximum \\
\hline \multirow[t]{8}{*}{ Fresh } & Spring 2006 & 0.2 & $2.9(0.6)$ & 10.2 \\
\hline & Summer 2006 & 0.3 & $3.3(0.6)$ & 10.8 \\
\hline & Fall 2006 & 0.2 & $2.7(0.6)$ & 10.1 \\
\hline & Winter 2007 & 0.1 & $2.0(0.4)$ & 8.5 \\
\hline & Spring 2007 & 0.0 & $2.3(0.5)$ & 11.7 \\
\hline & Summer 2007 & 0.1 & $1.5(0.4)$ & 9.5 \\
\hline & Fall 2007 & 0.0 & $1.2(0.4)$ & 8.8 \\
\hline & Study & 0.0 & $2.2(0.2)$ & 11.7 \\
\hline \multirow[t]{8}{*}{ Brackish/Intermediate } & Spring 2006 & 6.4 & $11.3(0.6)$ & 19.0 \\
\hline & Summer 2006 & 4.5 & $11.1(0.7)$ & 18.6 \\
\hline & Fall 2006 & 4.4 & $12.2(1.0)$ & 23.7 \\
\hline & Winter 2007 & 4.9 & $11.4(0.8)$ & 21.3 \\
\hline & Spring 2007 & 1.4 & $10.0(0.9)$ & 19.2 \\
\hline & Summer 2007 & 1.8 & $7.9(0.7)$ & 15.9 \\
\hline & Fall 2007 & 0.1 & $9.5(1.1)$ & 20.7 \\
\hline & Study & 0.1 & $10.4(0.3)$ & 23.7 \\
\hline \multirow[t]{8}{*}{ Saline } & Spring 2006 & 12.4 & $21.3(1.7)$ & 30.7 \\
\hline & Summer 2006 & 16.9 & $22.5(1.3)$ & 29.6 \\
\hline & Fall 2006 & 12.4 & $21.3(1.7)$ & 30.7 \\
\hline & Winter 2007 & 13.2 & $18.0(0.7)$ & 22.4 \\
\hline & Spring 2007 & 5.4 & $16.9(1.3)$ & 22.7 \\
\hline & Summer 2007 & 9.7 & $17.6(1.1)$ & 25.4 \\
\hline & Fall 2007 & 0.0 & $15.8(2.0)$ & 26.4 \\
\hline & Study & 0.0 & $18.6(0.5)$ & 30.7 \\
\hline
\end{tabular}

characterization of the Louisiana coastal marshes from August 1968, Chabreck (1972) reported mean porewater salinity of $1.5( \pm 1.2)$ in fresh marshes, $5.7( \pm 3.2)$ in brackish/ intermediate marshes, and $15.9( \pm 3.1)$ in saline. In this study, seasonal porewater salinities were greater than those documented by Chabreck, averaging $2.2( \pm 0.2)$ in fresh, $10.4( \pm 0.3)$ in brackish/intermediate, and $18.6( \pm 0.5)$ in saline marshes. The only exception was fresh marsh in fall 2007 , when mean porewater salinity was $1.2( \pm 0.4)$. Porewater salinity differed significantly by vegetation type $(\mathrm{p}<0.0001)$ (fig. 4), with greatest salinity in saline marsh, followed by brackish/intermediate, and fresh marshes.

Salinity plays a major role in the regulation of plantcommunity dynamics because individual plant species have different tolerances and adaptations to deal with the osmotic and toxic effects of salt (Mitsch and Gosselink, 2000). Salinity tolerances of plant species determine vegetation zones in coastal wetlands (Gosselink, 1984), and changes in salinity affect community composition and species survival. Shifts in salinity cause the expansion of some plant species and the retreat of others, thus leading to shifts in community types along a salinity gradient. For example, increases in salinity above 2.0 can cause fresh marshes to shift to intermediate, and decreases in salinity below 2.0 can cause intermediate marshes to shift to fresh (Visser and others, 2003). Salinity levels above the optimal range of an individual species can lead to decreases in function (that is, productivity and reproduction) or death of that species.

Hurricanes Katrina and Rita inundated all marsh types with high-salinity storm surge. In western Louisiana, the marsh remained flooded with saline water for several weeks, exposing fresh and brackish/intermediate vegetation to conditions near or above their salinity thresholds. In addition to the site-specific surface-water salinities reported in appendix 1, we measured seasonal porewater salinity at each station. Porewater salinity is often higher than the 


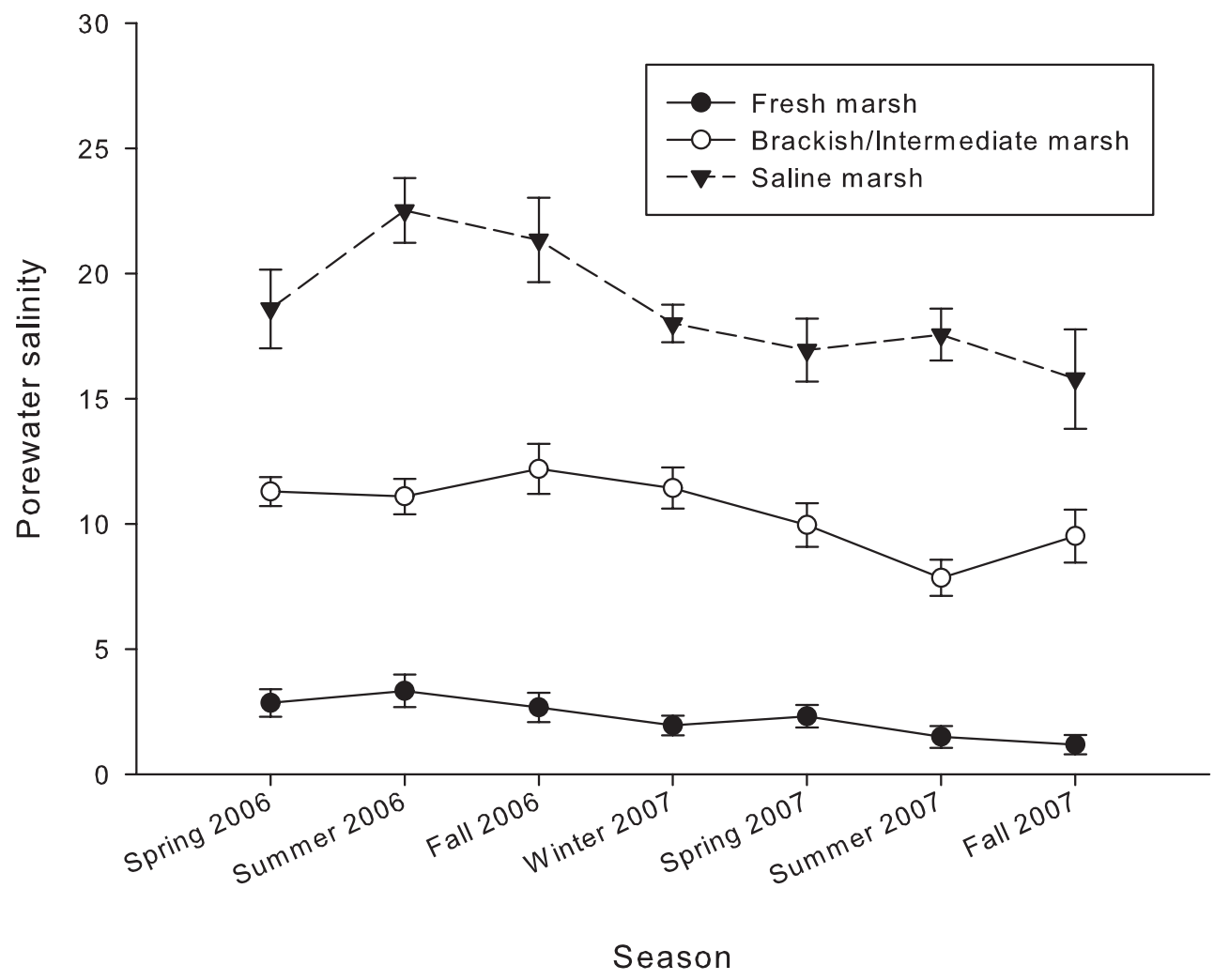

Figure 4. Mean values (see standard error bars) of porewater salinity for fresh, brackish/intermediate, and saline marsh types by season.

surface-water salinity at a site (Penfound and Hathaway, 1938; Hackney and Cruz, 1978; Alexander and Dunton, 2002) and, thus, is a better indicator of the root-zone environment than is surface-water salinity. If precipitation or other sources of freshwater are available after storm-surge inundation, porewater salinity tends to decline as it diffuses into the overlying surface water; however, if a freshwater source is not available, porewater salinity tends to increase from evapotranspiration. Alexander and Dunton (2002) showed that porewater and tidal-creek salinities in an estuarine marsh decreased as cumulative precipitation increased but that freshwater inflow from a river was more effective at flushing salt from soils than precipitation events alone. Timing of precipitation events also affects site salinity. For example, in the same estuarine marsh studied by Alexander and Dunton (2002), Dunton and others (2001) saw significant decreases in surface-water salinity and subsequent shifts in community composition in the summer of the second year of the study, which were attributed to large (that is, double the 50 -yr average) amounts of precipitation that fell early in the growing season of the second year. The timing of the large precipitation event led to the decrease in salinity because total rainfall in the first year of the study was similar to year two, but year one lacked the abundant rainfall early in the growing season that occurred in year two, thus leading to higher salinity in year one compared to year two. From fall 2005 (when Hurricanes Katrina and Rita made landfall) to July 2006, the coastal zone of Louisiana received less rainfall than the 30-yr mean (1971-2000, National Climatic Data Center) for this region, indicating that porewater salinities likely remained high because of the lack of available precipitation for flushing.

For this study, we examined fresh marshes dominated by Panicum hemitomon, brackish/intermediate marshes dominated by Spartina patens, and saline marshes dominated by Spartina alterniflora. Surface-water salinity tolerances for these species are available from field and greenhouse studies. Hester and others (2001) reported that a salinity of 4.0 significantly depressed both plant photosynthetic response and biomass in P. hemitomon. Prolonged exposure to even relatively low salinity levels was detrimental to this species. The hydrographs in appendix 1 show that surfacewater salinity at fresh marsh sites was generally 1.0 or less during the majority of the study; however, seasonal porewater salinities from 1.2 to 3.3 were observed, with seasonal maximum porewater salinities greater than 8.0 (table 2), thereby exposing $P$. hemitomon to salinities outside the ideal range.

Spartina patens has a greater tolerance for salinity than $P$. hemitomon. In a greenhouse study, La Peyre and others (2001) found that growth did not decrease with increasing salinity treatments from 0.0 to 8.0. Ewing and others (1995) 
found that live aboveground biomass of $S$. patens was greater in salinity treatments of 0.0 and 7.0 than in treatments of 14.0, 21.0, and 28.0. In a field experiment, Chabreck and Palmisano (1973) reported that a salt pulse up to 6.7 had no effect on $S$. patens total cover. In all seasons throughout our study, mean porewater salinity in brackish/intermediate marshes was close to or greater than 8.0, though maximum values in each season exceeded 15.0, which is at the high end of the range for brackish/intermediate marshes (table 2).

In saline marshes, mean porewater salinity was greater than 15.8 in all seasons, with all values well within the tolerance range of $S$. alterniflora, the dominant species within these marshes. The storm surge did not increase surface or porewater salinities beyond the ideal range for saline marshes.

Total cover of live vegetation showed seasonal trends among all vegetation types, with lowest mean values for cover occurring in winter 2007 or in the first sampling after the hurricanes (fig. 5). In the first growing season after the hurricanes, saline marsh sites exhibited the greatest live cover followed by fresh and brackish/intermediate sites. Throughout the second growing season after the hurricanes, live cover was greater at brackish/intermediate marsh sites than at fresh marsh sites, a reverse from 2006. When averaged throughout the study period, live cover in saline marsh sites was $80.4( \pm 2.8)$ percent; in brackish/intermediate marsh sites, it was $66.9( \pm 3.1)$ percent; and in fresh marsh sites, it was
$60.0( \pm 4.1)$ percent. Analysis of variance indicated that mean values of live total cover differed significantly according to the interaction of vegetation type and season $(p=0.0075)$.

Disturbance vegetation species occurred in fresh and brackish/intermediate marsh sites during all seasons, but no disturbance taxa were observed in saline marsh (fig. 6). Disturbance taxa are those that are found in marshes that have been recently disturbed by physical (for example, wind shear stress) or biological (for example, heavy grazing) forces. Taxa were assigned to the disturbance group based on the extensive experience of Drs. Sasser and Visser with disturbed and undisturbed marshes in coastal Louisiana (table 3). In 2006, cover of disturbance taxa relative to nondisturbance taxa was greater in brackish/intermediate marsh than in fresh marsh; however, disturbance taxa at brackish/intermediate sites decreased in the 2007 growing season (fig. 6). The opposite trend occurred in fresh marsh, with greater relative cover of disturbance species occurring in 2007 versus 2006. In both vegetation types, relative cover of disturbance taxa did not exceed 30 percent in either of the growing seasons after Hurricanes Katrina and Rita. The persistence of disturbance species in fresh and brackish/intermediate marshes two full growing seasons after the hurricanes is consistent with patterns observed by Guntenspergen and others (1995) after Hurricane Andrew.

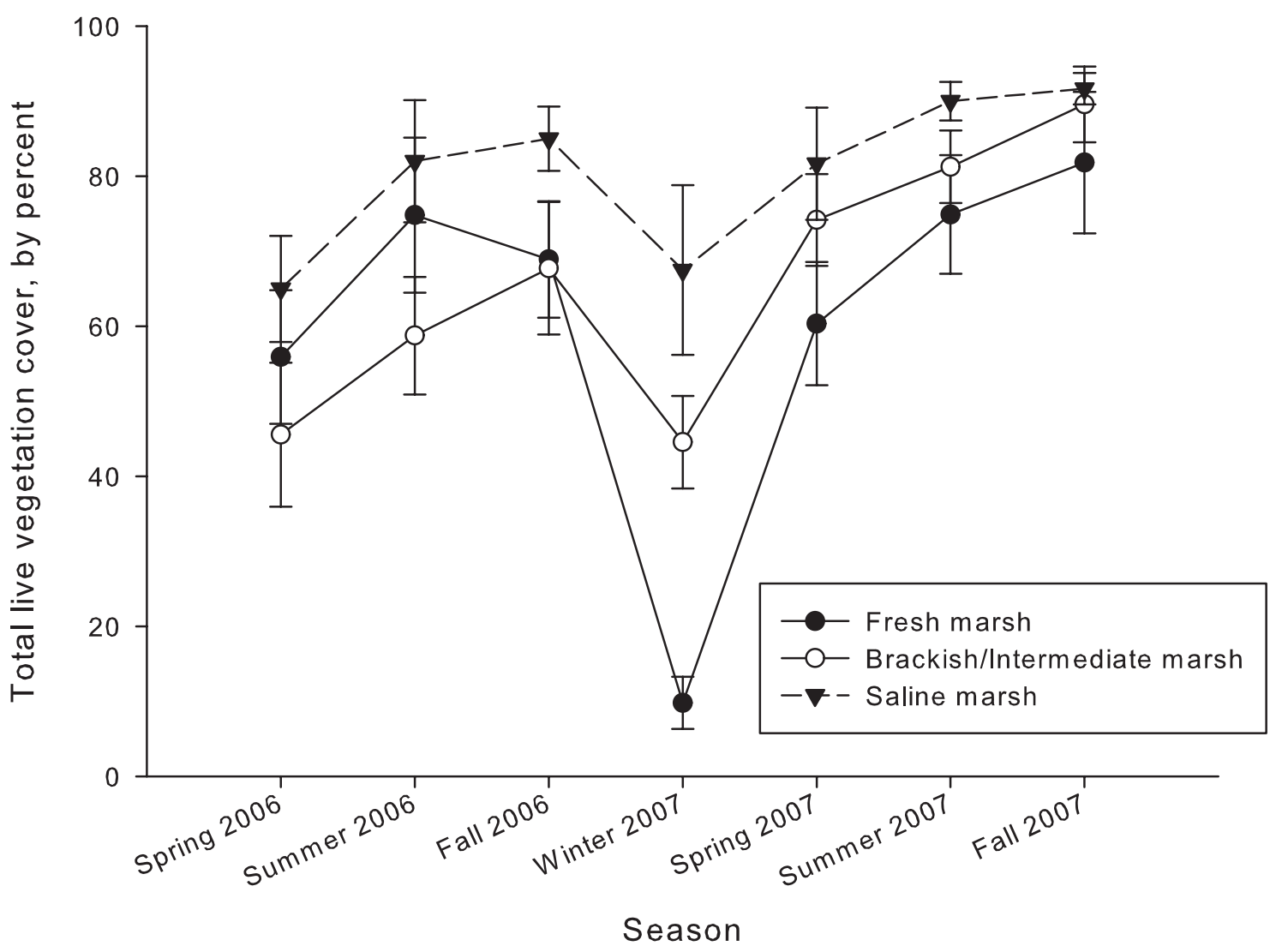

Figure 5. Total live vegetation cover (see standard error bars) for fresh, brackish/intermediate, and saline marsh types by season. 

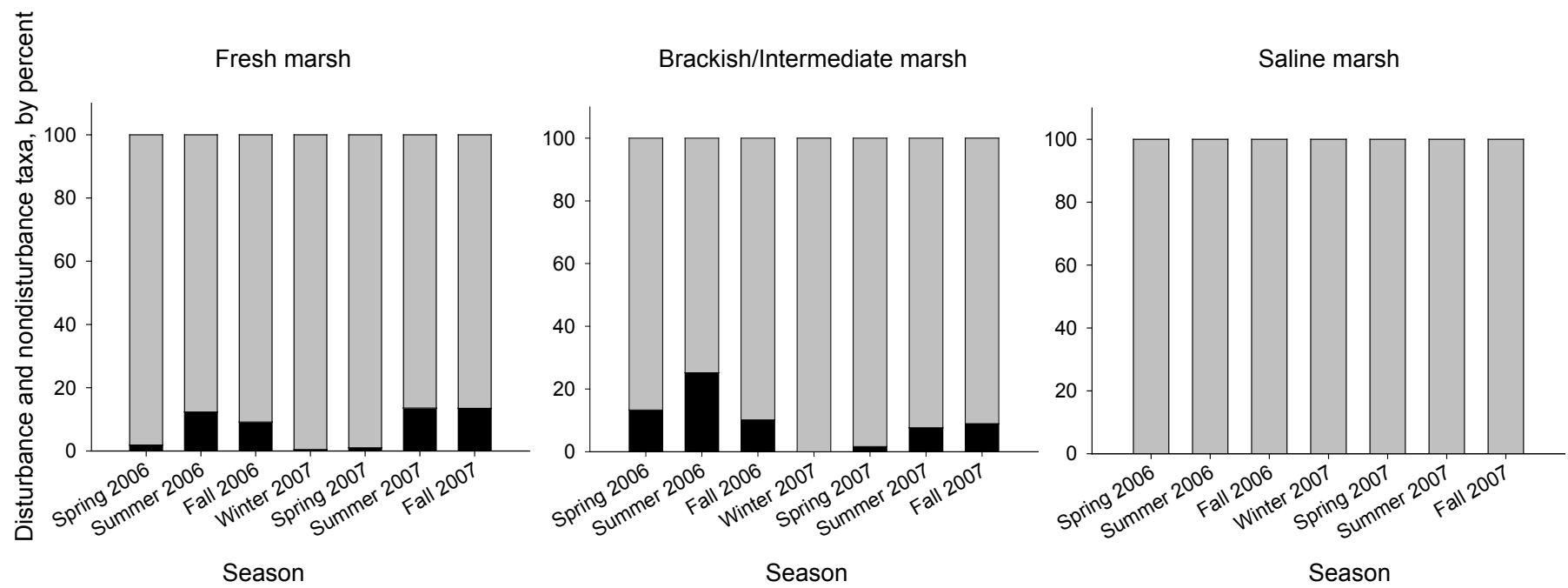

Figure 6. Percentages of disturbance (black bars) and nondisturbance (gray bars) taxa present in live vegetation cover of fresh, brackish/intermediate, and saline vegetation types by season.

During the first growing season after Hurricanes Katrina and Rita, live aboveground biomass was greatest at saline marsh sites, followed by brackish/intermediate and fresh marsh sites (fig. 7); however, in the second growing season after the hurricanes, brackish/intermediate marsh sites produced greater live aboveground biomass than saline sites, followed by fresh sites. This is different from what was observed in the data on live vegetation cover, according to which saline marsh sites produced the most live vegetation cover in the second growing season after the hurricanes, followed by fresh and brackish/intermediate marsh sites. The difference between the trends observed in live vegetation cover and live aboveground biomass emphasize the importance of looking at both variables together and may be explained by the fact that aboveground biomass is a parameter that is more sensitive to species composition and stem density than are estimates of vegetation cover. Typical of seasonal trends, live aboveground biomass was generally lowest in the winter and greatest in the summer or at the end of the growing season (fall). The greatest change in live aboveground biomass was observed in brackish/intermediate sites, with totals ranging from $108.0( \pm 222.6)$ grams of dry weight per square meter ( $\mathrm{g}$ dry weight $\mathrm{m}^{-2}$ ) in spring 2006 to $1,321.1$ $( \pm 740.9) \mathrm{g}$ dry weight $\mathrm{m}^{-2}$ in fall 2007. Analysis of variance indicated that the mean value of live aboveground biomass differed significantly among the interactions of vegetation type and season $(\mathrm{p}=0.0133)$.

When all vegetation types were combined, Pearson correlation showed a significant positive relationship between total cover of live vegetation and live aboveground biomass $(\mathrm{r}=0.56, \mathrm{p}<0.0001)$. Generally, as live vegetation cover increased, live aboveground biomass increased. This was not surprising because both variables are measures of live vegetation; however, these variables did not show the same trends when the data were separated by vegetation type. Total cover of live vegetation was negatively correlated with porewater salinity within brackish/intermediate marsh sites $(r=-0.4492, p<0.0001)$ and fresh marsh sites $(r=-0.32197$, $\mathrm{p}=0.003$ ) but was not significantly correlated at saline marsh sites. This correlation supports our general understanding of salinity tolerances specific to marsh types, with fresh and brackish/intermediate marshes being less tolerant of increases in salinity than saline marshes (for example, McKee and Mendelssohn, 1989; Howard and Mendelssohn, 1999; Spalding and Hester, 2007).

Total belowground biomass showed seasonal trends, with greatest values in winter 2007 within all vegetation types (fig. 8). Saline habitats produced greater belowground biomass than brackish/intermediate and fresh habitats throughout the entire study period. Belowground biomass differed significantly among vegetation types $(p<0.0001)$ and seasons $(p=0.0009)$ but not by the interaction of vegetation and season $(p=0.5830)$. Belowground biomass was significantly greater in winter 2007 than in all other seasons except spring 2006. The general seasonal patterns of belowground biomass were the inverse of patterns observed in live aboveground biomass.

\section{Fresh Marsh Sites}

Porewater salinity ranged from 0.0 to 11.7 at fresh marsh study sites. The overall study mean for fresh marsh sites was $2.2( \pm 0.2)$, which is greater than the $1.46( \pm 1.20)$ reported by Chabreck (1972) (table 2). The mean value for porewater salinity at the end of the growing season was significantly greater in $2006(2.6 \pm 0.5)$ than in 2007 $(1.1 \pm 0.3)$ (fig. 9). Sites within the directly influenced hurricane area also experienced significantly greater porewater 
Table 3. Observed taxa characterized as disturbance because of their typical presence in marshes that have been recently disturbed by physical or biological forces.

Disturbance taxa

Aeschynomene indica

Alternanthera philoxeroides

Amaranthus australis

Andropogon spp.

Centella erecta

Cirsium horridulum

Cyperus erythrorhizos

Cyperus spp.

Cyperus odoratus

Echinochloa spp.

Echinochloa crus-galli

Echinochloa walteri

Eupatorium capillifolium

\begin{tabular}{l}
\hline \multicolumn{1}{c}{ Disturbance taxa-Continued } \\
\hline Leptochloa fusca ssp. fascicularis \\
Mikania scandens \\
Panicum dichotomiflorum \\
Pluchea camphorata \\
Pluchea odorata \\
Ranunculus spp. \\
Rorippa palustris ssp. fernaldiana \\
Salix nigra \\
Sesbania drummondii \\
Sesbania herbacea \\
Sesbania spp. \\
Symphyotrichum spp. \\
Symphyotrichum subulatum \\
Symphyotrichum tenuifolium \\
Vigna luteola
\end{tabular}

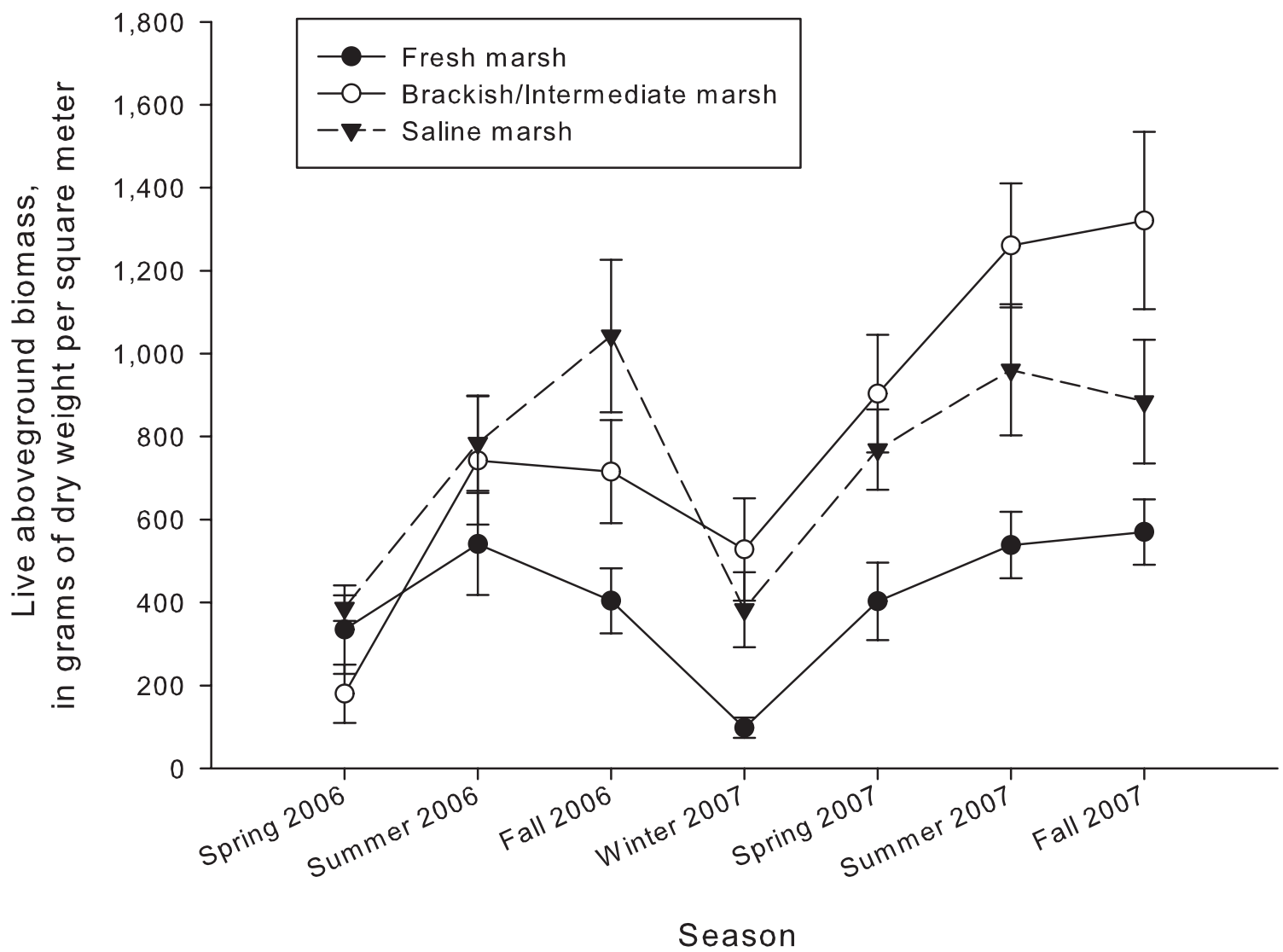

Figure 7. Live aboveground biomass (see standard error bars) in fresh, brackish/intermediate, and saline marsh types by season. 


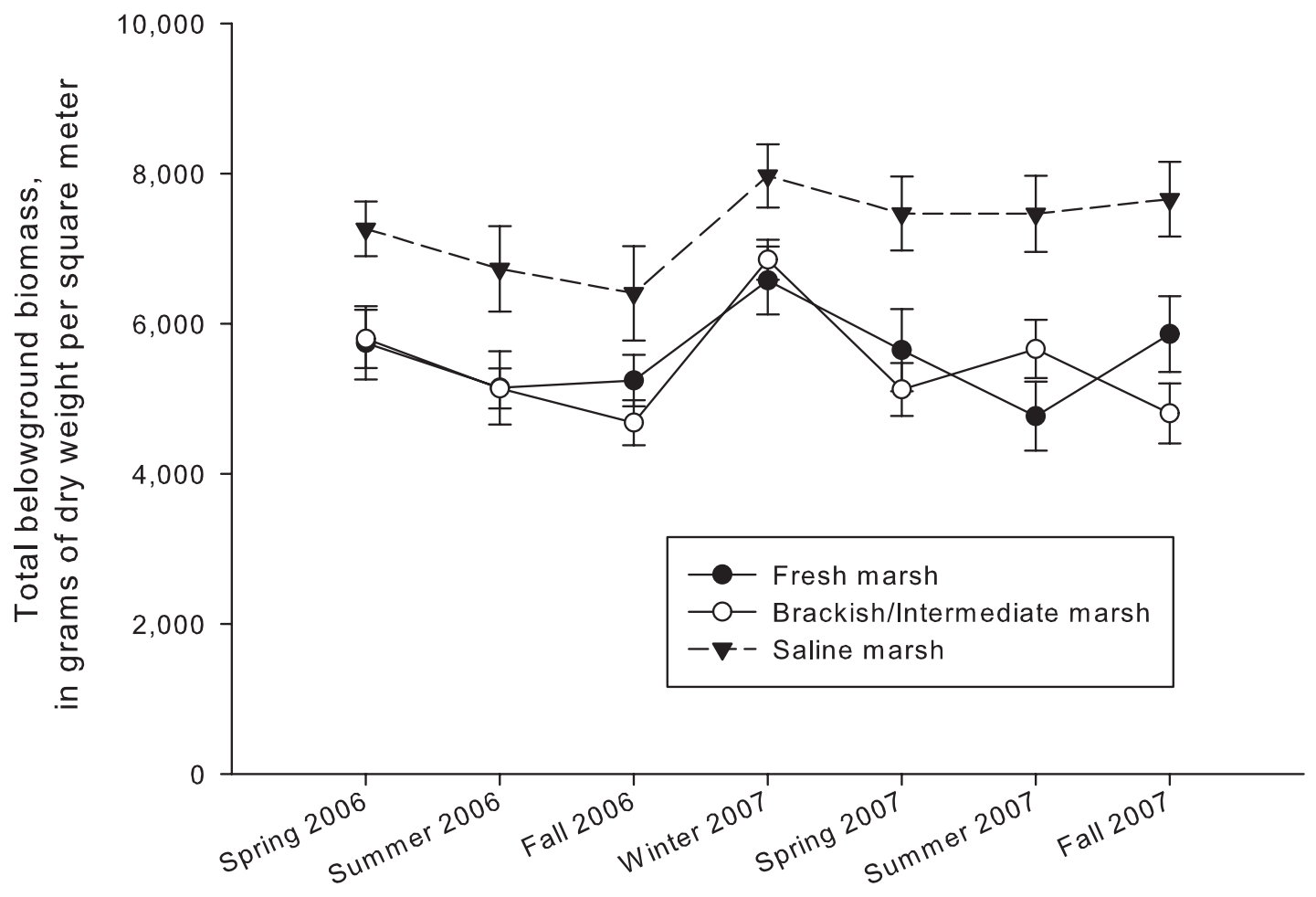

Figure 8. Total belowground biomass (see standard error bars) in fresh, brackish/ intermediate, and saline marsh types by season.

\section{Season}

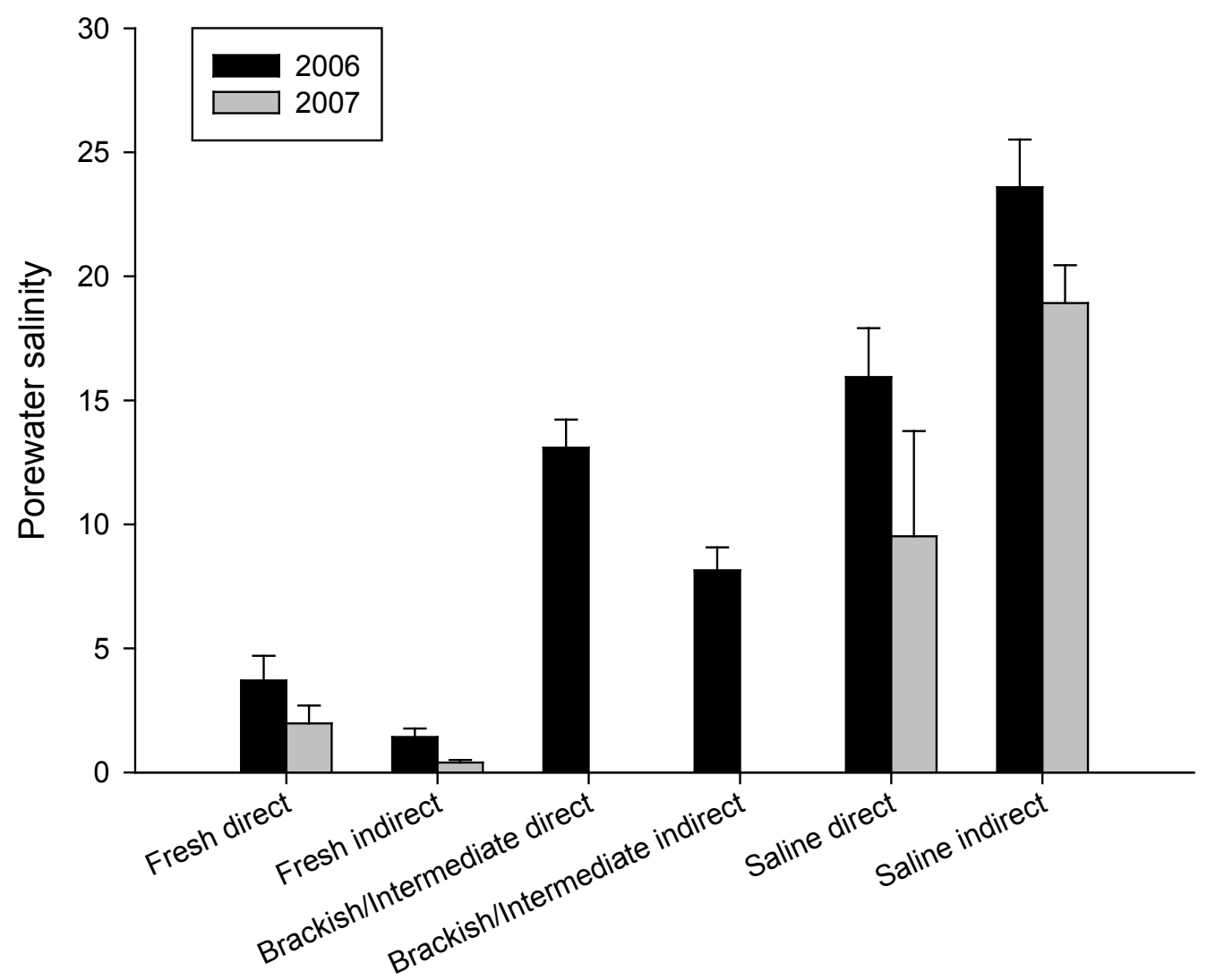

Figure 9. Mean values of porewater salinity (see standard error bars) for fresh, brackish/ intermediate, and saline marshes by type of hurricane influence (direct or indirect) and year. 
salinity $(2.8 \pm 0.6)$ as compared to the indirectly influenced area $(0.8 \pm 0.1)$, but the interaction of year and hurricane influence was not statistically significant (table 4). Of all the fresh marsh sites, porewater salinity at the end of growing seasons was greatest at CRMS0605 and CRMS0605-H in fall 2006 (fig. 10). Salinity at these sites was approximately 9 in 2006, abnormally high for fresh marshes (Chabreck, 1972). Porewater salinity remained high (8.5) at CRMS0605 through the end of the growing season in 2007 but decreased at CRMS0605-H. At the remainder of the fresh marsh sites, porewater salinity was typical of fresh marshes in both years except at CRMS0294 in fall 2006 (3.7); however, salinity dropped at this site to 0.3 by fall 2007 (table 5).

Across all fresh marsh sites, live vegetation cover at the end of growing seasons averaged $68.9( \pm 7.7)$ percent in 2006 and increased to $81.8( \pm 9.4)$ percent in 2007. The live cover at the end of the growing season in 2006 was similar to measurements of fresh marsh cover acquired before the storms in 2003 and 2004 under the CWPPRA monitoring program (http://www.lacoast.gov). There were no statistical differences in total live cover at the end of growing seasons between years, across levels of hurricane influence, or among interactions of years and hurricane influence $(p>0.05)$. Live cover at most sites increased or remained equal between fall 2006 and fall 2007 except at CRMS1277, CRMS1277-H, CRMS0219-H, and CRMS0128-H, where live cover decreased in the second growing season (fig. 11). Of the sites with less cover in fall 2007, the only site where cover decreased substantially was CRMS0128-H, where live cover decreased by 40 percent between fall 2006 and fall 2007, largely because of an increase in floating aquatics in the plot. Floating aquatics are not counted as live cover because

Table 4. Results of analysis of variance testing for porewater salinity at the end of growing seasons in fresh, brackish/ intermediate, and saline marsh types.

[Hurricane influence is defined as direct or indirect. P-values less than 0.05 indicate significant differences. $\mathrm{n}$, number; $\mathrm{p}, \mathrm{p}$-value]

\begin{tabular}{clc}
\hline \multicolumn{1}{c}{ Marsh type } & \multicolumn{1}{c}{ Factor } & p \\
\hline Fresh marsh (n=69) & Hurricane influence & 0.0088 \\
& Year & 0.0082 \\
& Hurricane influence by year & 0.7590 \\
& & \\
Brackish/Intermediate & Hurricane influence & 0.0996 \\
marsh (n=69) & Year & \\
& Hurricane influence by year & 0.09977 \\
& & \\
Saline marsh (n=35) & Hurricane influence & 0.0013 \\
& Year & 0.0062 \\
& Hurricane influence by year & 0.0438 \\
\hline
\end{tabular}
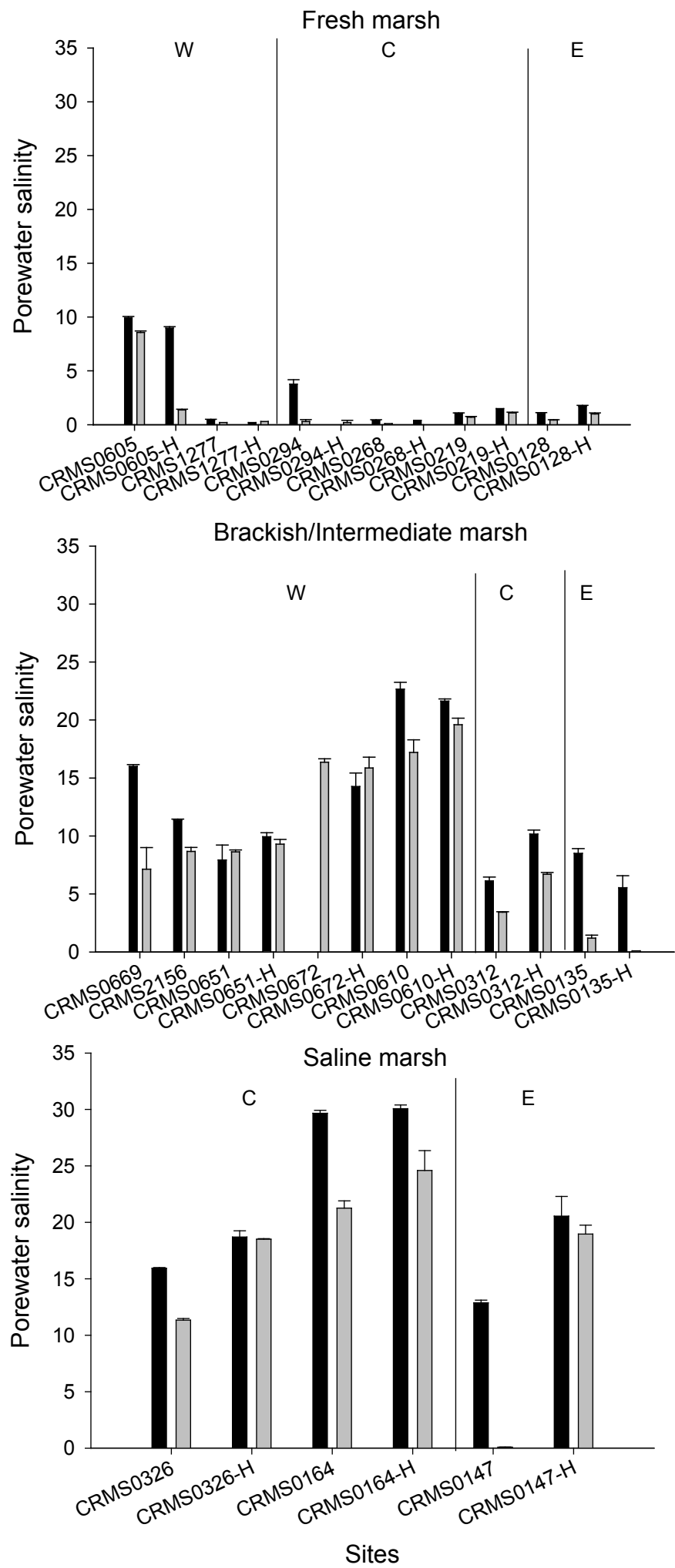

Figure 10. Porewater salinity at the end of the growing season in 2006 (black bars) and in 2007 (gray bars) at study sites within fresh, brackish/intermediate, and saline marshes. Sites with "H" designations were historically sampled by various research projects, and sites without " $\mathrm{H}$ " designations are within the Coastwide Reference Monitoring System (CRMS). Western (W), central $(C)$, and eastern $(E)$ regions of Louisiana are represented. 
Table 5. Site-specific summaries of soils, porewater salinity, and vegetation cover data.

[Disturbance taxa indicated in bold text. Underlined porewater values are $>1$ standard deviation, and bold porewater values are $>2$ standard deviations from the specific mean values delineated for marsh types by Chabreck, 1972 (fresh $=1.4 \pm 1.2$, brackish/intermediate $=5.7 \pm 3.15$, saline $=15.8 \pm 3.11$ ). Indirect hurricane influence defined by $<2 \mathrm{~m}$ of storm surge at sites not located in Calcasieu/Sabine, Mermentau, or Breton Sound hydrologic basins. ID, identification; FEMA, Federal Emergency Management Agency; m, meter; GOM, Gulf of Mexico; km, kilometer; cm, centimeter; g cm ${ }^{-3}$, grams per cubic centimeter;

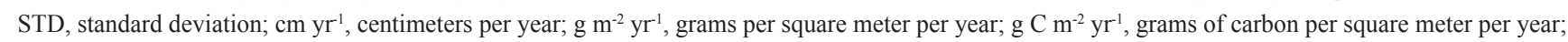
min, minimum; max, maximum; g dry weight $\mathrm{m}^{-2}$, grams of dry weight per square meter; *, estimates from one core only; NA, not applicable]

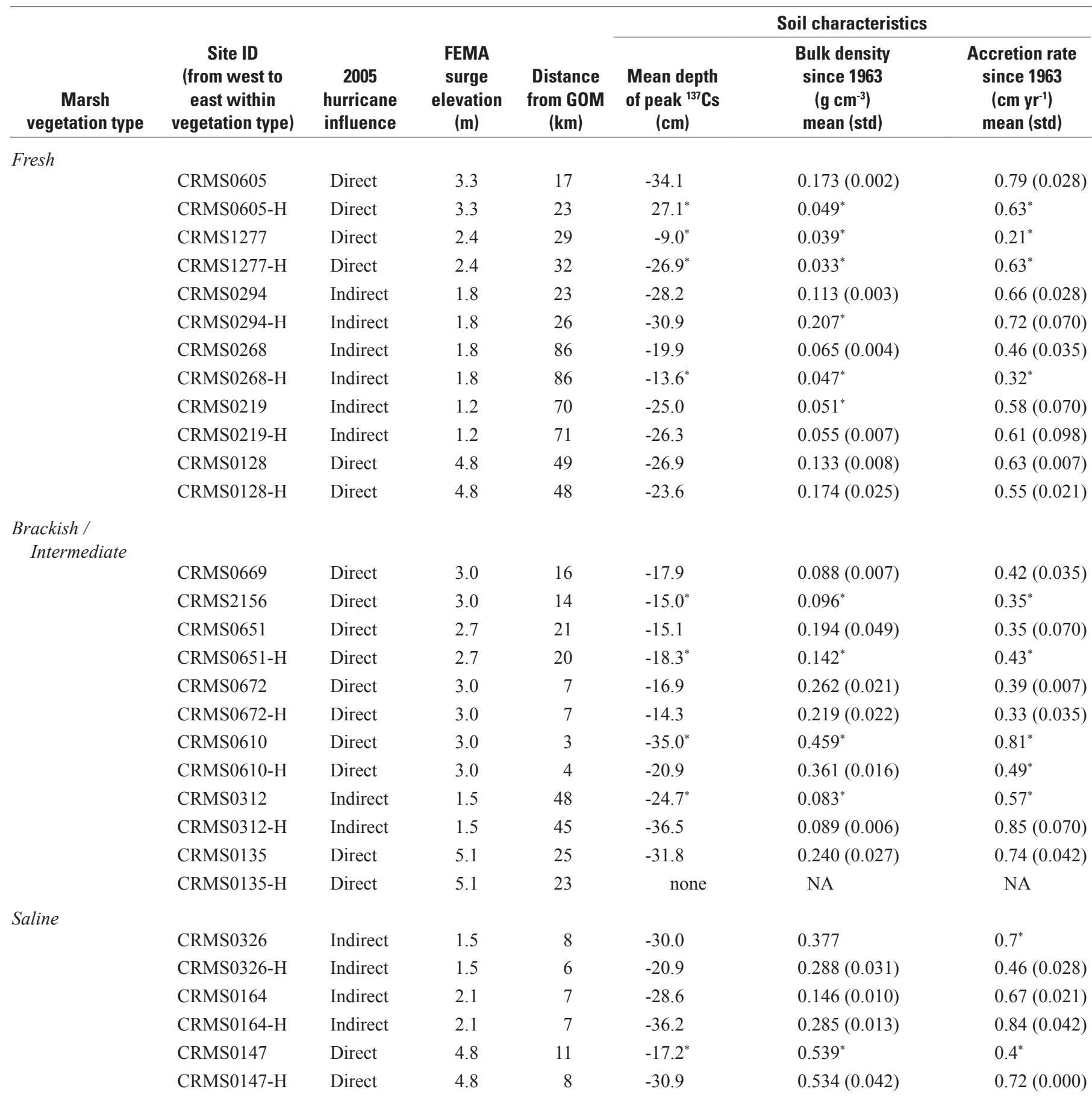


Porewater salinity

\begin{tabular}{|c|c|c|c|c|c|c|c|c|}
\hline $\begin{array}{l}\text { Carbon } \\
\left(\mathrm{g} \mathrm{m}^{-2} \mathrm{yr}^{-1}\right)\end{array}$ & $\begin{array}{l}\text { Nitrogen } \\
\left(\mathrm{g} \mathrm{m}^{-2} \mathrm{yr}^{-1}\right)\end{array}$ & $\begin{array}{l}\text { Mineral } \\
\text { accumulation } \\
\left(\mathrm{g} \mathrm{m}^{-2} \mathrm{yr}^{-1}\right)\end{array}$ & $\begin{array}{c}\text { Organic } \\
\text { accumulation } \\
\left(\mathrm{g} \mathrm{C} \mathrm{m}^{-2} \mathrm{yr}^{-1}\right)\end{array}$ & $\begin{array}{l}\text { End-of-season } \\
2006 \text { mean } \\
\text { (std) }\end{array}$ & $\begin{array}{l}\text { End-of-season } \\
2007 \text { mean } \\
\text { (std) }\end{array}$ & $\begin{array}{c}\text { Overall } \\
\text { study mean } \\
\text { (std) }\end{array}$ & $\begin{array}{c}\text { Overall } \\
\text { study min }\end{array}$ & $\begin{array}{c}\text { Overall } \\
\text { study max }\end{array}$ \\
\hline 207 (13.3) & $17.4(2.7)$ & $890(112)$ & $515(37)$ & $9.9(0.2)$ & $8.5(0.3)$ & $9.1(1.2)$ & 7.6 & 11.7 \\
\hline $113(18.0)$ & $5.2(1.1)$ & $110(27)$ & $242(40)$ & $8.9(0.3)$ & $1.3(0.1)$ & $5.6(3.4)$ & 1.3 & 9.2 \\
\hline $35(7.3)$ & $2.2(0.4)$ & $10(3)$ & $69(13)$ & $0.4(0.2)$ & $0.2(0.0)$ & $0.3(0.2)$ & 0.2 & 1.1 \\
\hline $81(11.0)$ & $4.7(1.0)$ & $42(8)$ & $160(25)$ & $0.2(0.0)$ & $0.3(0.0)$ & $0.2(0.0)$ & 0.2 & 0.3 \\
\hline 177 & 11.1 & $365(35)$ & 405 (28) & $\underline{3.7(0.7)}$ & $0.3(0.3)$ & $\underline{3.4(2.0)}$ & 0 & 6.4 \\
\hline $182(25.4)$ & $11.9(1.1)$ & 929 (148) & $457(50)$ & NA & $0.2(0.3)$ & $2.8(2.3)$ & 0 & 6.7 \\
\hline 125 (15.7) & $7.6(0.8)$ & $62(10)$ & 260 (29) & $0.4(0.1)$ & $0.1(0.0)$ & $0.2(0.2)$ & 0 & 0.5 \\
\hline $72(5.9)$ & $4.7(0.9)$ & $31(3)$ & 149 (18) & $0.4(0.0)$ & $0.0(0.0)$ & $0.2(0.2)$ & 0 & 0.6 \\
\hline $132(12.4)$ & $7.0(1.2)$ & $33(6)$ & $263(41)$ & $1.0(0.1)$ & $0.7(0.1)$ & $0.8(0.4)$ & 0.5 & 2.4 \\
\hline $144(25.1)$ & $9.0(1.3)$ & $53(16)$ & $302(48)$ & $1.5(0.0)$ & $1.1(0.1)$ & $1.2(0.2)$ & 0.9 & 1.9 \\
\hline $206(16.2)$ & $13.1(1.5)$ & 401 (97) & 473 (19) & $1.0(0.2)$ & $0.4(0.1)$ & $1.0(0.5)$ & 0.4 & 2.2 \\
\hline 144 (13.8) & $8.5(1.1)$ & 674 (93) & 339 (26) & $1.7(0.2)$ & $1.0(0.2)$ & $1.5(0.4)$ & 0.9 & 2.5 \\
\hline $102(7.9)$ & $5.7(0.6)$ & $142(12)$ & $251(15)$ & $16.0(0.3)$ & $7.1(3.2)$ & $11.9(4.6)$ & 3.4 & 16.3 \\
\hline $102(5.7)$ & $5.8(0.4)$ & 185 (69) & $253(20)$ & $11.3(0.2)$ & $8.6(0.6)$ & $9.7(1.7)$ & 5.8 & 11.7 \\
\hline 119 (18.1) & $7.7(1.4)$ & $482(94)$ & $272(36)$ & $7.9(2.2)$ & $8.6(0.3)$ & $\underline{8.9(1.6)}$ & 6.3 & 11.1 \\
\hline $132(12.5)$ & $8.8(0.9)$ & $452(72)$ & 307 (31) & $\underline{9.9(0.6)}$ & $\underline{9.3(0.7)}$ & $\underline{9.8(1.3)}$ & 7.5 & 11.5 \\
\hline $107(9.8)$ & $6.8(0.7)$ & 819 (214) & $283(20)$ & NA & $16.3(0.5)$ & $13.4(2.7)$ & 8.6 & 16.9 \\
\hline $80(5.3)$ & $4.2(0.5)$ & $527(94)$ & 241 (17) & $14.2(2.0)$ & $15.8(1.6)$ & $13.9(2.3)$ & 8.9 & 18.6 \\
\hline $120(20.4)$ & $10.2(1.1)$ & $3,199(307)$ & $472(33)$ & $22.6(1.0)$ & $17.2(1.9)$ & $15.9(3.6)$ & 9.2 & 23.7 \\
\hline $106(10.4)$ & $7.3(0.7)$ & 1,496 (135) & $354(21)$ & $21.6(0.3)$ & $19.6(1.0)$ & $17.8(4.2)$ & 7.5 & 21.3 \\
\hline 202 & 13.9 & $77(16)$ & $425(64)$ & $6.1(0.6)$ & $3.4(0.1)$ & $4.7(1.2)$ & 3.3 & 6.6 \\
\hline $204(20.0)$ & $14.0(1.4)$ & $313(78)$ & $483(45)$ & $\underline{10.1(0.6)}$ & $6.7(0.3)$ & $7.9(1.6)$ & 6 & 11.5 \\
\hline 127 (23.9) & $9.1(4.5)$ & $1,392(514)$ & $434(51)$ & $8.5(0.7)$ & $1.2(0.4)$ & $5.2(2.8)$ & 0.9 & 9.1 \\
\hline . & . & . & . & $5.5(1.8)$ & $0.1(0.0)$ & $3.6(2.7)$ & 0.1 & 7.6 \\
\hline $183(35.0)$ & $9.6(2.0)$ & $2,059(681)$ & $420(41)$ & $15.9(0.1)$ & $11.3(0.3)$ & $14.0(2.3)$ & 11.1 & 18.6 \\
\hline 154 (20.7) & $7.1(0.8)$ & $1,052(110)$ & 354 (11) & $\underline{18.7(1.0)}$ & $18.5(0.1)$ & $18.3(1.1)$ & 15.9 & 19.7 \\
\hline $132(12.4)$ & $9.6(0.9)$ & $598(90)$ & $390(29)$ & $29.6(0.5)$ & $\underline{21.2(1.1)}$ & $24.0(3.7)$ & 19.5 & 30.1 \\
\hline $203(34.8)$ & $11.9(1.5)$ & 1,911 (154) & $540(41)$ & $30.0(0.6)$ & $24.6(3.0)$ & $25.4(3.8)$ & 19 & 30.7 \\
\hline 104 (32.5) & $5.9(1.9)$ & $1,439(520)$ & 275 (22) & $12.8(0.4)$ & $0.0(0.1)$ & $9.8(4.9)$ & 0 & 14.6 \\
\hline $122(13.3)$ & $8.7(0.7)$ & $3,471(283)$ & $509(31)$ & $20.5(2.5)$ & $18.9(1.4)$ & $18.4(2.3)$ & 13.5 & 22.3 \\
\hline
\end{tabular}


Table 5. Site-specific summaries of soils, porewater salinity, and vegetation cover data.

[Disturbance taxa indicated in bold text. Underlined porewater values are $>1$ standard deviation, and bold porewater values are $>2$ standard deviations from the specific mean values delineated for marsh types by Chabreck, 1972 (fresh $=1.4 \pm 1.2$, brackish/intermediate $=5.7 \pm 3.15$, saline $=15.8 \pm 3.11)$. Indirect hurricane influence defined by $<2 \mathrm{~m}$ of storm surge at sites not located in Calcasieu/Sabine, Mermentau, or Breton Sound hydrologic basins. ID, identification; FEMA, Federal Emergency Management Agency; m, meter; GOM, Gulf of Mexico; km, kilometer; cm, centimeter; g cm³ ${ }^{-3}$ grams per cubic centimeter;

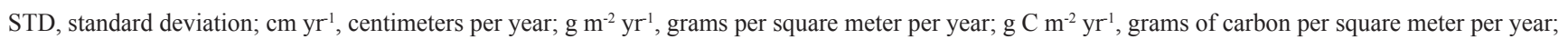
min, minimum; max, maximum; g dry weight $\mathrm{m}^{-2}$, grams of dry weight per square meter; *, estimates from one core only; NA, not applicable] —Continued

Vegetation data

Total live cover $(\%)$

\begin{tabular}{|c|c|c|c|c|c|}
\hline Marsh vegetation type & $\begin{array}{c}\text { Site ID } \\
\text { (from west } \\
\text { to east within } \\
\text { vegetation type) }\end{array}$ & $\begin{array}{c}2005 \\
\text { hurricane } \\
\text { influence }^{1} \\
\end{array}$ & End-of-season 2006 & $\begin{array}{c}\text { Dominant species } \\
\text { end-of-season } \\
2006 \text { ( } \% \text { cover) }\end{array}$ & End-of-se \\
\hline \multicolumn{6}{|l|}{ Fresh } \\
\hline & CRMS0605 & Direct & 55 & Echinochloa spp. (20) & 75 \\
\hline & CRMS0605-H & Direct & 8 & Spartina patens (8) & 80 \\
\hline & CRMS1277 & Direct & 75 & Panicum hemitomon (70) & 60 \\
\hline & CRMS1277-H & Direct & 95 & Panicum hemitomon (95) & 90 \\
\hline & CRMS0294 & Indirect & 75 & Eleocharis spp. (55) & 125 \\
\hline & CRMS0294-H & Indirect & 90 & Typha sp. (35) & 95 \\
\hline & CRMS0268 & Indirect & 100 & Panicum hemitomon (70) & 100 \\
\hline & CRMS0268-H & Indirect & 90 & Panicum hemitomon (70) & $\mathrm{n} /$ \\
\hline & CRMS0219 & Indirect & 60 & Leersia oryzoides (35) & 75 \\
\hline & CRMS0219-H & Indirect & 80 & Panicum hemitomon (45) & 70 \\
\hline & CRMS0128 & Direct & 70 & Ludwigia spp. (65) & 120 \\
\hline & CRMS0128-H & Direct & 50 & Polygonum spp. (25) & 10 \\
\hline \multicolumn{6}{|l|}{ Brackish / Intermediate } \\
\hline & CRMS0669 & Direct & 20 & Spartina patens (15) & 75 \\
\hline & CRMS2156 & Direct & 60 & $\begin{array}{l}\text { Spartina patens \& } \\
\text { Iva frutescens }(35)\end{array}$ & 90 \\
\hline & CRMS0651 & Direct & 80 & Spartina patens (50) & 95 \\
\hline & CRMS0651-H & Direct & 50 & Spartina patens (25) & 60 \\
\hline & CRMS0672 & Direct & 40 & Distichlis spicata (20) & 75 \\
\hline & CRMS0672-H & Direct & 20 & Paspalum vaginatum (15) & 105 \\
\hline & CRMS0610 & Direct & 85 & Distichlis spicata (50) & 65 \\
\hline & CRMS0610-H & Direct & 70 & Spartina patens (65) & 95 \\
\hline & CRMS0312 & Indirect & 60 & Spartina patens (60) & 100 \\
\hline & CRMS0312-H & Indirect & 100 & Spartina patens (95) & 95 \\
\hline & CRMS0135 & Direct & 100 & Echinochloa spp. (25) & 120 \\
\hline & CRMS0135-H & Direct & 100 & Spartina patens $(80)$ & 100 \\
\hline
\end{tabular}


Total aboveground biomass ( $g$ dry weight $\mathrm{m}^{-2}$ )
Total belowground biomass (g dry weight $\mathrm{m}^{-2}$ )

\begin{tabular}{|c|c|c|c|c|c|c|c|}
\hline $\begin{array}{c}\text { Dominant } \\
\text { species } \\
\text { end-of-season } \\
2007 \text { ( } \% \text { cover) }\end{array}$ & $\begin{array}{l}\text { Overall } \\
\text { study mean } \\
\text { (std) }\end{array}$ & $\begin{array}{l}\text { Overall study } \\
\text { min }\end{array}$ & $\begin{array}{l}\text { Overall study } \\
\max \end{array}$ & $\begin{array}{c}\text { End-of-season } \\
2006 \text { mean } \\
\text { (std) }\end{array}$ & $\begin{array}{l}\text { End-of-season } \\
2007 \text { mean } \\
\text { (std) }\end{array}$ & $\begin{array}{c}\text { End-of-season } \\
2006 \text { mean } \\
\text { (std) }\end{array}$ & $\begin{array}{c}\text { End-of-season } \\
2007 \text { mean } \\
\text { (std) }\end{array}$ \\
\hline Pluchea camphorata (25) & $48.3(31.4)$ & 0 & 77 & $248(160)$ & $959(234)$ & $3,494(695)$ & $4,114(852)$ \\
\hline Spartina patens $(40)$ & $35.8(40.4)$ & 1 & 80 & $102(24)$ & $707(606)$ & $3,800(373)$ & $5,209(1,141)$ \\
\hline Panicum hemitomon (50) & $58.4(24.9)$ & 4 & 75 & $698(214)$ & $643(206)$ & $4,261(807)$ & $5218(315)$ \\
\hline Panicum hemitomon (85) & $66.8(36.1)$ & 5 & 95 & $879(59)$ & $1,079(300)$ & $5,549(711)$ & $5,144(590)$ \\
\hline Typha sp. (80) & $72.1(28.2)$ & 35 & 125 & $543(207)$ & $853(437)$ & $4,862(1,331)$ & $6,860(1,392)$ \\
\hline Typha sp. (60) & $78.5(27.0)$ & 25 & 100 & $597(163)$ & $1,010(366)$ & $5,965(4,412)$ & $7,746(1,544)$ \\
\hline Panicum hemitomon (95) & $80.0(37.5)$ & 5 & 120 & $1,822(746)$ & $1,998(440)$ & $5,589(2,336)$ & $8,405(2,364)$ \\
\hline $\mathrm{n} / \mathrm{a}$ & $80.5(36.6)$ & 8 & 110 & $1,102(155)$ & $920(103)$ & $5,699(1,536)$ & $9,080(1,266)$ \\
\hline $\begin{array}{l}\text { Leersia oryzoides \& } \\
\quad \text { Panicum } \\
\quad \text { hemitomon }(30)\end{array}$ & $58.5(24.4)$ & 5 & 75 & $812(250)$ & $930(225)$ & $4,138(1,500)$ & $4,744(655)$ \\
\hline Panicum hemitomon (45) & $77.5(5.2)$ & 5 & 85 & $1,052(323)$ & $1,010(241)$ & $7,657(3,244)$ & $5,483(78)$ \\
\hline Polygonum spp. (35) & $61.0(47.4)$ & 3 & 120 & $761(660)$ & $628(176)$ & $5,682(1,171)$ & $4,719(1,069)$ \\
\hline $\begin{array}{l}\text { Alternanthera } \\
\quad \text { philoxeroides (10) }\end{array}$ & $27.1(30.9)$ & 3 & 80 & $1,009(446)$ & $430(267)$ & $6,212(1,352)$ & $3,619(443)$ \\
\hline Spartina patens $(45)$ & $41.4(25.9)$ & 10 & 75 & 218 (199) & $870(608)$ & $6,281(1,063)$ & $4,607(763)$ \\
\hline Spartina patens $(60)$ & $72.1(11.1)$ & 65 & 90 & $1,369(77)$ & $2,934(2,122)$ & $5,796(896)$ & $5,459(1,837)$ \\
\hline Spartina patens $(90)$ & $79.5(14.0)$ & 55 & 95 & $\begin{array}{c}2,568.00 \\
(1,258.70)\end{array}$ & $3,182(1,056)$ & $4,856(1,305)$ & $6,131(3,985)$ \\
\hline Spartina patens (35) & $69.2(17.6)$ & 50 & 95 & $1,903(411)$ & $2214(574)$ & $4,425(1,310)$ & $4,049(1,259)$ \\
\hline Distichlis spicata (50) & $49.2(23.3)$ & 10 & 75 & $1,980(122)$ & $1,347(332)$ & $4,148(232)$ & $5,248(572)$ \\
\hline $\begin{array}{l}\text { Distichlis spicata \& } \\
\quad \text { Paspalum } \\
\quad \text { vaginatum (45) }\end{array}$ & $36.7(38.2)$ & 5 & 105 & $2,295(1,280)$ & $2,317(463)$ & $4,434(1,291)$ & $3,336(1,212)$ \\
\hline Spartina patens $(50)$ & $62.1(18.4)$ & 30 & 80 & $1,255(365)$ & $2,216(494)$ & $3,535(616)$ & $4,229(525)$ \\
\hline Spartina patens (95) & $66(25.3)$ & 25 & 95 & $931(436)$ & $3,931(1,318)$ & $3,209(592)$ & $4,273(1,360)$ \\
\hline Spartina patens (85) & $63.3(27.5)$ & 25 & 100 & $1,642(1,331)$ & $865(202)$ & $4,857(428)$ & $2,220(1,007)$ \\
\hline Spartina patens $(70)$ & $80.8(19.3)$ & 45 & 100 & $2,572(306)$ & $1,649(959)$ & $5,280(1,772)$ & $4,383(1,248)$ \\
\hline $\begin{array}{l}\text { Spartina patens \& } \\
\quad \text { Vigna luteola }(35)\end{array}$ & $85(36.6)$ & 20 & 120 & $930(198)$ & $1,046(359)$ & NA & $6,938(459)$ \\
\hline Spartina patens $(80)$ & $91.4(14.9)$ & 60 & 100 & $3,173(641)$ & $2,331(1,166)$ & NA & $6,774(1,653)$ \\
\hline
\end{tabular}




\section{Geomorphic and Ecological Effects of Hurricanes Katrina and Rita on Coastal Louisiana Marsh Communities}

Table 5. Site-specific summaries of soils, porewater salinity, and vegetation cover data.

[Disturbance taxa indicated in bold text. Underlined porewater values are $>1$ standard deviation, and bold porewater values are $>2$ standard deviations from the specific mean values delineated for marsh types by Chabreck, 1972 (fresh $=1.4 \pm 1.2$, brackish/intermediate $=5.7 \pm 3.15$, saline $=15.8 \pm 3.11$ ). Indirect hurricane influence defined by $<2 \mathrm{~m}$ of storm surge at sites not located in Calcasieu/Sabine, Mermentau, or Breton Sound hydrologic basins. ID, identification; FEMA, Federal Emergency Management Agency; m, meter; GOM, Gulf of Mexico; km, kilometer; cm, centimeter; $\mathrm{g} \mathrm{cm}^{-3}$, grams per cubic centimeter; $\mathrm{STD}$, standard deviation; $\mathrm{cm} \mathrm{yr}^{-1}$, centimeters per year; $\mathrm{g} \mathrm{m}^{-2} \mathrm{yr}^{-1}$, grams per square meter per year; $\mathrm{g} \mathrm{C}^{-2} \mathrm{yr}^{-1}$, grams of carbon per square meter per year; min, minimum; max, maximum; g dry weight $\mathrm{m}^{-2}$, grams of dry weight per square meter; *, estimates from one core only; NA, not applicable]—Continued

Vegetation data-Continued

Total live cover (\%)

\begin{tabular}{|c|c|c|c|c|c|}
\hline Marsh vegetation type & $\begin{array}{c}\text { Site ID } \\
\text { (from west to } \\
\text { east within } \\
\text { vegetation type) }\end{array}$ & $\begin{array}{l}2005 \\
\begin{array}{l}\text { hurricane influ- } \\
\text { ence }^{1}\end{array}\end{array}$ & End-of-season 2006 & $\begin{array}{c}\text { Dominant species } \\
\text { end-of-season } \\
2006 \text { (\% cover) }\end{array}$ & End-of-season 2007 \\
\hline \multicolumn{6}{|l|}{ Saline } \\
\hline & CRMS0326 & Indirect & 65 & Spartina patens (35) & 85 \\
\hline & CRMS0326-H & Indirect & 85 & Spartina alterniflora (85) & 85 \\
\hline & CRMS0164 & Indirect & 95 & Spartina alterniflora $(80)$ & 95 \\
\hline & CRMS0164-H & Indirect & 90 & Spartina alterniflora $(90)$ & 95 \\
\hline & CRMS0147 & Direct & 85 & Spartina alterniflora (85) & 95 \\
\hline & CRMS0147-H & Direct & 90 & Spartina alterniflora (90) & 85 \\
\hline
\end{tabular}


Total live cover (\%)

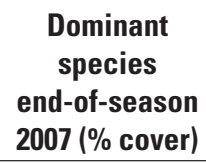

Schoenoplectus americanus (80)

Spartina alterniflora (85)

Spartina alterniflora (95)

Spartina alterniflora (90)

Spartina alterniflora (95)

Spartina alterniflora (95) Overall (std)
Total aboveground biomass (g dry weight $\mathrm{m}^{-2}$ )

End-of-season End-of-season End-of-season End-of-season study mean Overall study Overall study min $62.8(27.5) \quad 20$

$76.4(13.7) \quad 50$

$87.8(12.1) \quad 65$

$86.4(6.9) \quad 75$

$90.7(10.1) \quad 70$

$80(19.1) \quad 50$
max 2006 mean

(std)

95

85

100

95

100

95
Total belowground biomass (g dry weight $\mathrm{m}^{-2}$ )

\begin{tabular}{llll}
\multicolumn{1}{c}{$(\mathbf{s t d})$} & \multicolumn{1}{c}{ (std) } & \multicolumn{1}{c}{$($ (std) } & \multicolumn{1}{c}{ (std) } \\
& & & \\
& & & \\
$1,051(187)$ & $1,045(56)$ & $6,204(667)$ & $7,986(783)$ \\
& & & \\
$957(377)$ & $607(82)$ & $8,002(1,122)$ & $6,077(1,142)$ \\
$2,889(1,096)$ & $2,140(597)$ & $4,550(442)$ & $7,230(1,412)$ \\
$1,870(274)$ & $1,638(721)$ & $5,685(976)$ & $7,489(250)$ \\
$1,492(362)$ & $1,706(313)$ & NA & $7,391(2,032)$ \\
$1,970(64)$ & $1,620(464)$ & $7,580(1,560)$ & $9,778(354)$
\end{tabular}



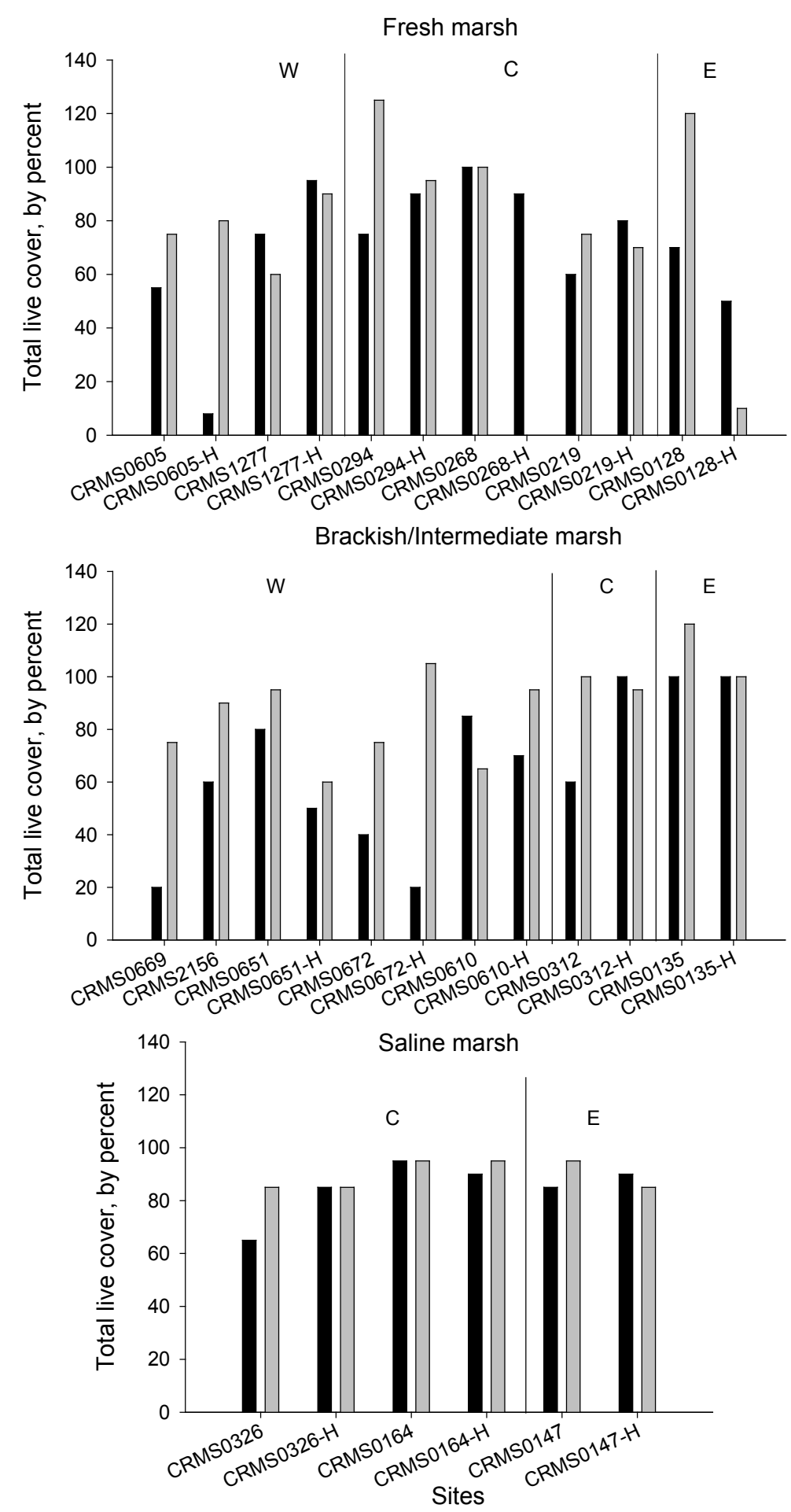

Figure 11. Total live cover of emergent vegetation at fresh, brackish/intermediate, and saline marsh sites at the end of the growing season in 2006 (black bars) and in 2007 (gray bars). Sites with " $\mathrm{H}$ " designations were historically sampled by various research projects, and sites without " $H$ " designations are within the Coastwide Reference Monitoring System (CRMS). Western (W), central (C), and eastern (E) regions of Louisiana are represented. they are not rooted, emergent vegetation within the permanent vegetation plot. The CRMS0605-H site showed the greatest change in cover between the end of the growing seasons of 2006 and 2007, with cover increasing by 72 percent. In fall 2006, CRMS0605-H was largely nonvegetated, and porewater salinity was approximately 8.5 , while in fall 2007 live cover was estimated at 80 percent, with porewater salinity at 1.4 (see case study 1 for further discussion).

We conducted comparisons of data from seven fresh marsh sites (CRMS0128, CRMS0128-H, CRMS0219-H, CRMS0294, CRMS0294-H, CRMS0605, and CRMS0605-H) where historical data acquired before Hurricanes Katrina and Rita were available. We found that the dominant vegetation species at fresh marsh sites differed among sites. Before the hurricanes, most fresh marsh sites were dominated by $P$. hemitomon, S. lancifolia, or occasionally, S. patens. At the end of the growing season in 2006, one site (CRMS0605) was dominated by multiple disturbance species, Echinochloa spp., while the other sites were dominated by species typical of fresh marshes (table 5). In the second growing season after the storms, dominant species differed from conditions documented before the storms at 33 percent of sites. When a difference occurred between dominant species before and after the hurricanes, the change was not always towards a disturbance species, as was observed at CRMS0605 and CRMS0128-H. Dominance at CRMS0219-H shifted from S. lancifolia before Hurricanes Katrina and Rita to P. hemitomon after the storms. At CRMS0605-H, dominance changed from $P$. hemitomon before the storms to $S$. patens after the storms (see case study 1 for additional information). At some sites (CRMS0294, CRMS0294-H, and CRMS0128), the differences between the end of the growing seasons of 2006 and 2007 were simply changes from one fresh marsh species to another (table 5). There was no consistent change in dominant species across fresh marsh sites (for example, change to intermediate or disturbance species), suggesting the importance of site-specific conditions. Temporary, site-specific changes caused by the degree of storm sediment deposition, salt exposure, erosion, and wrack deposition were characterized by Guntenspergen and others (1995) after Hurricane Andrew. They found that landscape structure before Hurricane Andrew and the path of the storm created a heterogeneous pattern of disturbance with various recovery rates.

Observations of live vegetation cover were grouped into percentages of relative cover among disturbance versus nondisturbance taxa. At the 
end of the growing season in 2006, disturbance taxa composed approximately 20 percent of the total cover at CRMS0128 and CRMS0128-H and greater than 65 percent at CRMS0605 (fig. 12). All three of these sites were within areas directly influenced by Hurricanes Rita (western region) and Katrina (eastern region) and experienced physical disturbance to the landscape because of hurricaneinduced marsh scouring, shearing, and eroding (Barras, 2006).

Other sites in the zone of direct influence did not show large percentages of disturbance taxa in fall 2006 (CRMS0605-H, CRMS1277, and CRMS1277-H), thereby illustrating the patchy nature of hurricane-related physical disturbance (Guntenspergen and others, 1995). The total cover of disturbance species increased in some sites in fall 2007 (fig. 12). Similar to 2006, there was substantial coverage by disturbance taxa at CRMS0605, CRMS0128, and CRMS0128-H in fall 2007, comprising greater than 40 percent of the total cover at these sites. The percentage of disturbance species also increased at CRMS0605-H, CRMS1277, and CRMS0294 in fall 2007. At CRMS0605-H, the increase in disturbance taxa from 2006 to 2007 coincided with an increase in total cover from 8 to 80 percent.

The contribution of disturbance species to aboveground biomass was significantly greater in the sites directly impacted by Hurricanes Katrina and Rita, but this contribution did not differ significantly by year or among interactions of the variables levels of hurricane influence and year (table 6). As reflected in the vegetation cover values, the percentage of biomass composed of disturbance species was greater in the second year after the hurricanes than in the first year (fig. 13). This increase indicates that some of the biomass recovery in the second year was caused by a greater amount of biomass from disturbance species. The largest percentage of disturbance species in fresh marsh sites occurred at CRMS0128 and CRMS0128-H in upper Breton Sound, an area that was impacted by some of the highest storm surge (4.8 m, Federal Emergency Management Agency [FEMA], 2006) in the path of Hurricane Katrina. Species that typically dominate coastal fresh marshes of Louisiana, such as P. hemitomon, S. lancifolia, or Zizaniopsis miliacea (giant cutgrass), were not present at either of these sites (Visser and others, 1998). The CRMS0128-H site was dominated by $S$. patens in the spring of 2006 , and this species remained an important component of the biomass into 2007 (fig. 14). CRMS0128 was dominated by Ludwigia leptocarpa (anglestem primrose-willow) and Vigna luteola (hairypod

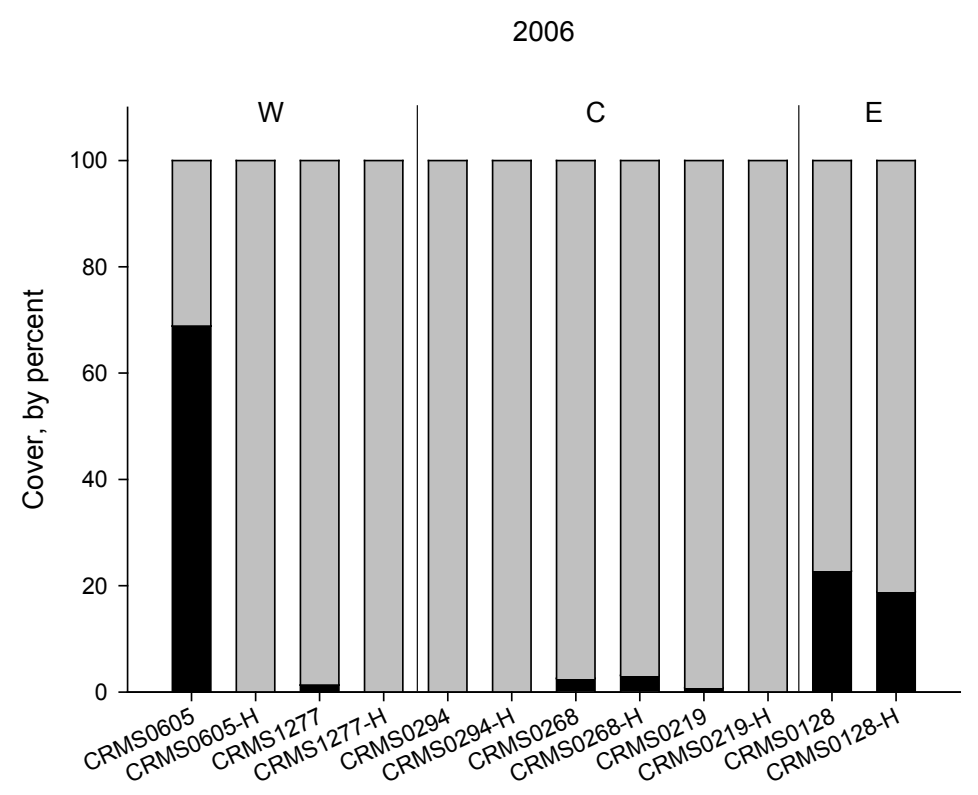

2007

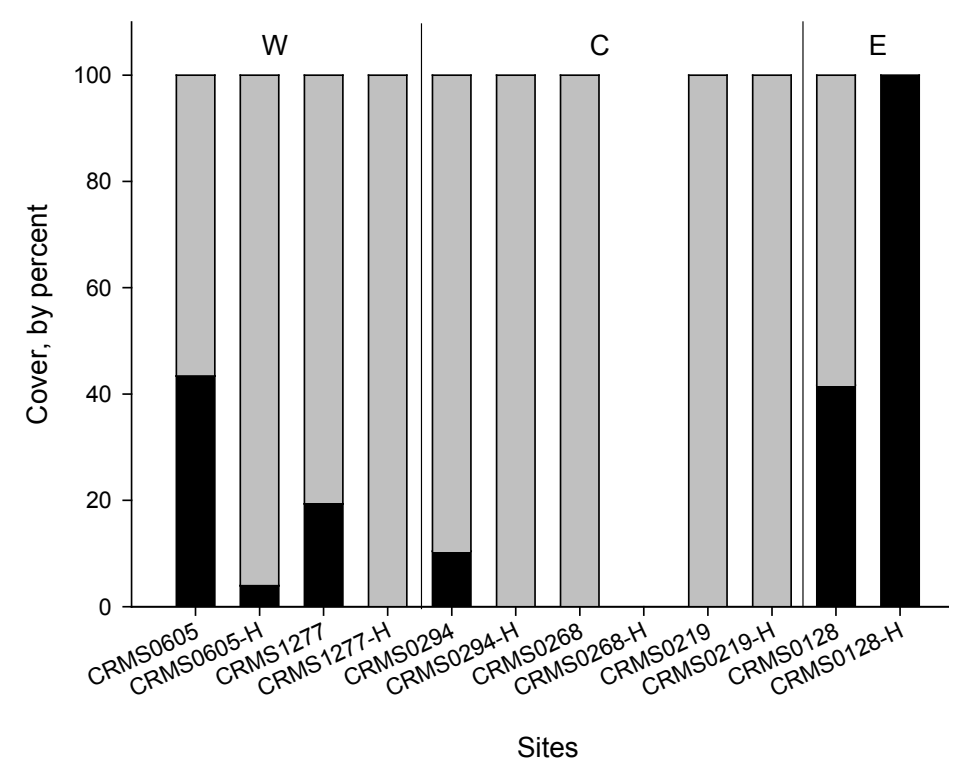

Figure 12. Cover by disturbance taxa (black bars) relative to nondisturbance taxa (gray bars) in emergent vegetation at fresh marsh sites at the end of the growing season in 2006 and in 2007. Sites with " $\mathrm{H}$ " designations were historically sampled by various research projects, and sites without " $\mathrm{H}$ " designations are within the Coastwide Reference Monitoring System (CRMS). Western (W), central (C), and eastern (E) regions of Louisiana are represented. 
Table 6. Results of analysis of variance testing for aboveground biomass from nondisturbance species in fresh and brackish/ intermediate marsh types.

[Hurricane influence is defined as direct or indirect. P-values less than 0.05 indicate significant differences. $n$, number; $\mathrm{p}$, $\mathrm{p}$-value]

\begin{tabular}{clc}
\hline \multicolumn{1}{c}{ Marsh type } & \multicolumn{1}{c}{ Factor } & p \\
\hline Fresh Marsh (n=70) & Hurricane influence & 0.0112 \\
& Year & 0.1644 \\
& Hurricane influence by year & 0.2089 \\
Brackish/Intermediate & Hurricane influence & 0.3124 \\
Marsh (n=70) & & \\
& Year & 0.7277 \\
& Hurricane influence by year & 0.7801 \\
\hline
\end{tabular}

cowpea) in 2006. Ludwigia leptocarpa is not considered a disturbance species because it generally occurs in undisturbed fresh and intermediate marshes, but $V$. luteola is considered a disturbance species. Neither of these species is typically dominant in fresh marsh. The CRMS0605 and CRMS0605-H sites, located west of Grand Lake, experienced storm surge from Hurricane Rita. At these sites, very little vegetation colonized in 2006 (fig. 15), and the species that did colonize (for example, S. patens, Distichlis spicata [seashore saltgrass], L. leptocarpa, Eleocharis parvula [dwarf spikesedge], Schoenoplectus robustus [sturdy bulrush], and Blutaparon vermiculare [silverhead]) are not considered disturbance species; however, most of these species do not occur in fresh marshes. In 2007, disturbance species were observed at CRMS0605 and CRMS0605-H, including Pluchea odorata (sweetscent) and Amaranthus australis (southern amaranth).

Live aboveground biomass at the end of growing seasons at fresh marsh sites was significantly lower in the directly impacted sites ( $309 \mathrm{~g}$ dry weight $\mathrm{m}^{-2}$ ) than in the indirectly impacted sites (576 g dry weight $\mathrm{m}^{-2}$; table 7; fig. 16). At fresh marsh sites, live aboveground biomass at the end of the growing season 2 years after the hurricanes (in 2007, $543 \mathrm{~g}$ dry weight $\mathrm{m}^{-2}$ ) was not significantly greater than in the first

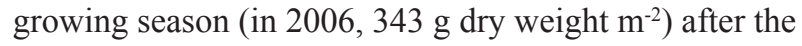
hurricanes. The interaction between year and hurricane impact was not statistically significant (table 7). Figure 16 shows that live aboveground biomass in fresh marsh at the end of growing seasons was lower in the first year after the hurricanes than in the second year, primarily because of the low level of fall biomass in the directly impacted plots. One year after the hurricanes, the average live biomass in the fall at directly impacted sites was greater than two standard deviations below the long-term (that is, 18-year) mean of values collected at three sites dominated by $P$. hemitomon (table 8 ). The low level of biomass occurring one growing season after the hurricanes has a 2.5 percent statistical probability of occurring normally because of interannual variation in fall biomass; however, it must be noted that not all study sites in fresh marsh were dominated by $P$. hemitomon prior to or after Hurricanes Katrina and Rita. Although the indirectly impacted sites had fall biomass that was below the long-term average, they were within one standard deviation and represent normal interannual variation in fall biomass. Two years after the hurricanes, fall biomass in the directly impacted sites was very similar to that in the indirectly impacted sites, and all sites had an average fall biomass within the range of normal interannual variation.

Of the sites with historical prestorm data, total aboveground biomass at the end of growing seasons after the hurricanes did not differ significantly from historically recorded values at any site except CRMS0605-H ( $p=0.0005$, fig. 17). Following the hurricanes of 2005, total and live aboveground biomass at CRMS0605-H decreased significantly from the values obtained at the end of the growing seasons in 2003 and 2004; however, the marked decrease in both live and total biomass in fall 2006 was not statistically different from the biomass measured in 2002 . Total aboveground biomass ranged from $102.67 \pm(13.92) \mathrm{g}$ dry weight $\mathrm{m}^{-2}$ at CRMS0605-H to $1,102.00 \pm(89.67) \mathrm{g}$ dry weight $\mathrm{m}^{-2}$ at CRMS0268-H. Some sites did experience a substantial reduction in the live component of aboveground biomass after the storms (CRMS0294-H, CRMS0128-H), but these differences were not statistically significant. As was observed with species dominance, there was not a consistent response among fresh marsh sites in total or live aboveground biomass before and after the storms. Peak biomass at

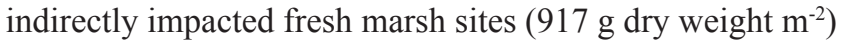
was significantly greater than at the directly impacted sites (424 g dry weight $\mathrm{m}^{-2}$ ). There was no significant difference in peak biomass between years or a significant interaction between year and type of hurricane influence in the fresh marsh sites (table 9; fig. 18). The hurricanes had a significant negative impact on biomass in the fresh marshes within the directly influenced area that lasted for at least two growing seasons after the hurricanes.

Estimates of aboveground and belowground biomass within specific vegetation types before and after Hurricanes Katrina and Rita are provided in table 8. According to estimates provided in the literature, live aboveground biomass at the end of the growing season in fall 2006 (first growing season after the storms) was lower than historical estimates but within the range of variability. In fall 2007, the mean value of live aboveground biomass increased and was within the range observed in other prestorm studies reported in the literature.

Total (live and dead) aboveground biomass at fresh marsh sites at the end of growing seasons ranged from 102.67 to $1,998.80 \mathrm{~g}$ dry weight $\mathrm{m}^{-2}$ in 2006 and 2007 . Mean values of total aboveground biomass among all fresh marsh sites averaged $802.50( \pm 127.94) \mathrm{g}$ dry weight $\mathrm{m}^{-2}$ in 2006 and increased to $904.06( \pm 124.10) \mathrm{g}$ dry weight $\mathrm{m}^{-2}$ in 2007 . In both growing seasons, total aboveground biomass at the end of growing seasons was greater at CRMS0268 than at all other fresh marsh sites (fig. 19). Similar trends in total aboveground 


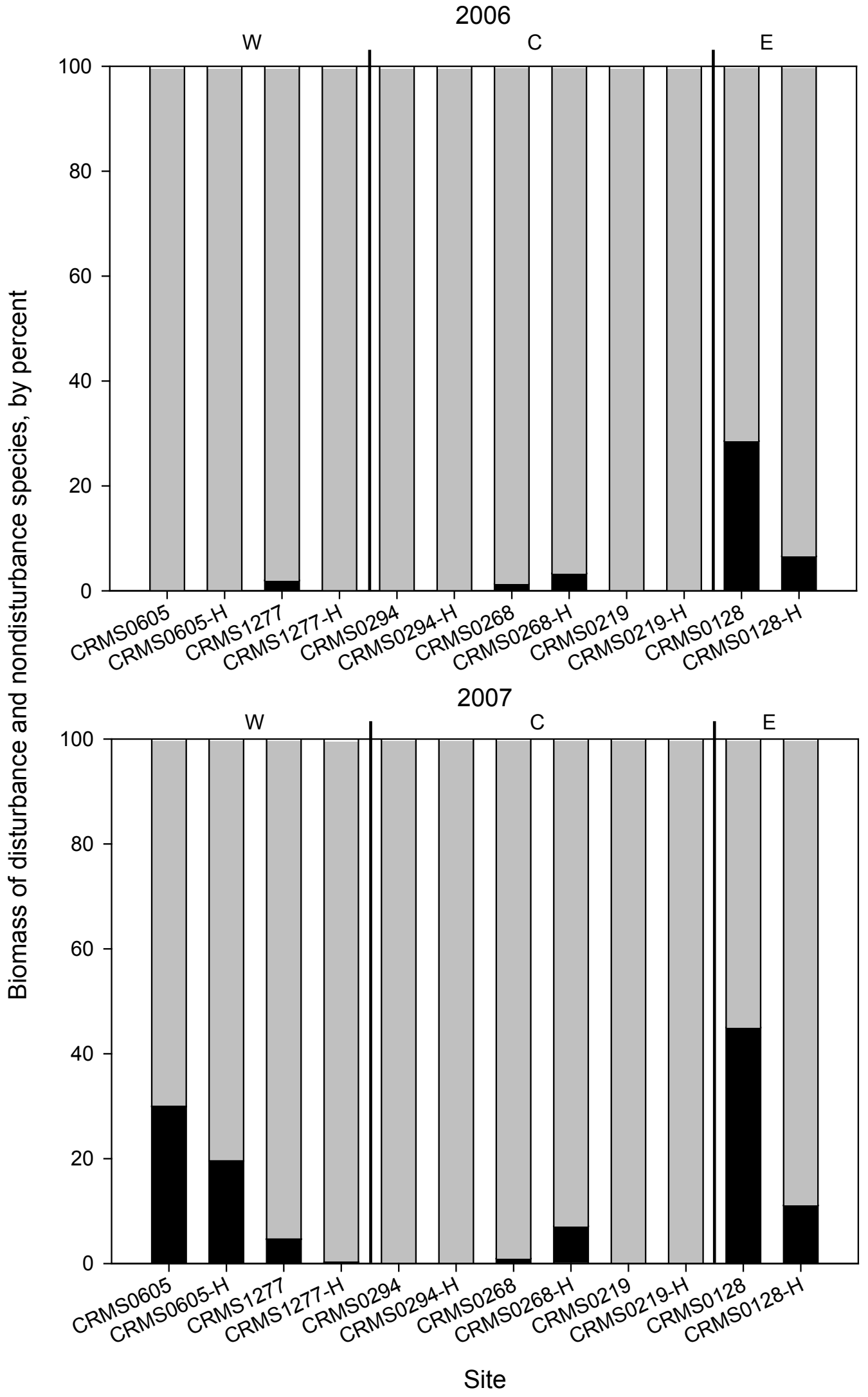

Figure 13. Percentages of biomass composed of disturbance (black bars) versus nondisturbance (gray bars) species at fresh marsh sites in 2006 and 2007. Sites with " $H$ " designations were historically sampled by various research projects, and sites without " $\mathrm{H}$ " designations are within the Coastwide Reference Monitoring System (CRMS). Western (W) and eastern (E) regions of Louisiana were affected by direct hurricane influence and the central (C) region by indirect influence. 


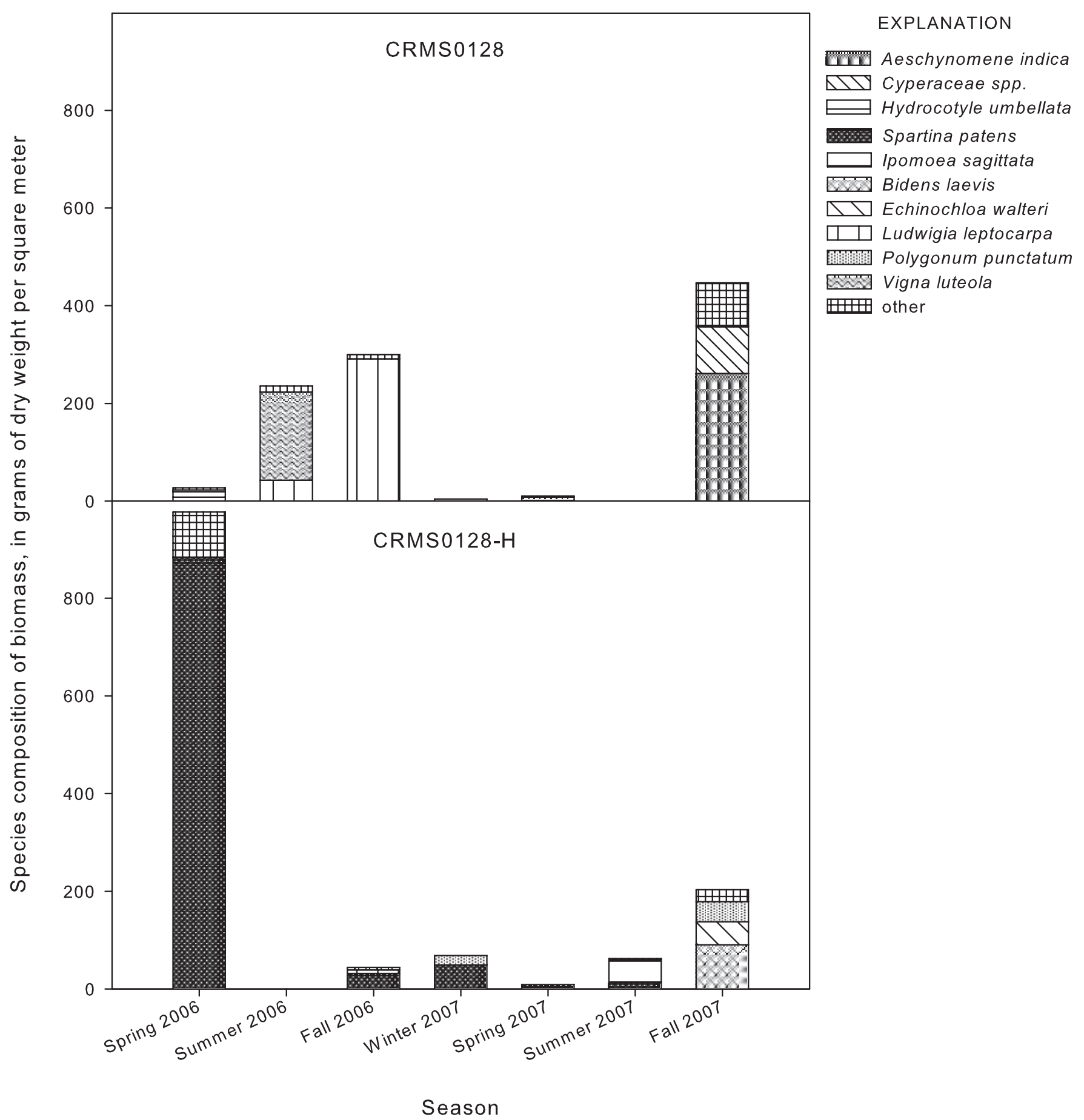

Figure 14. Species composition of biomass harvested at Coastwide Reference Monitoring System sites 0128 and $0128-\mathrm{H}$ by season. 


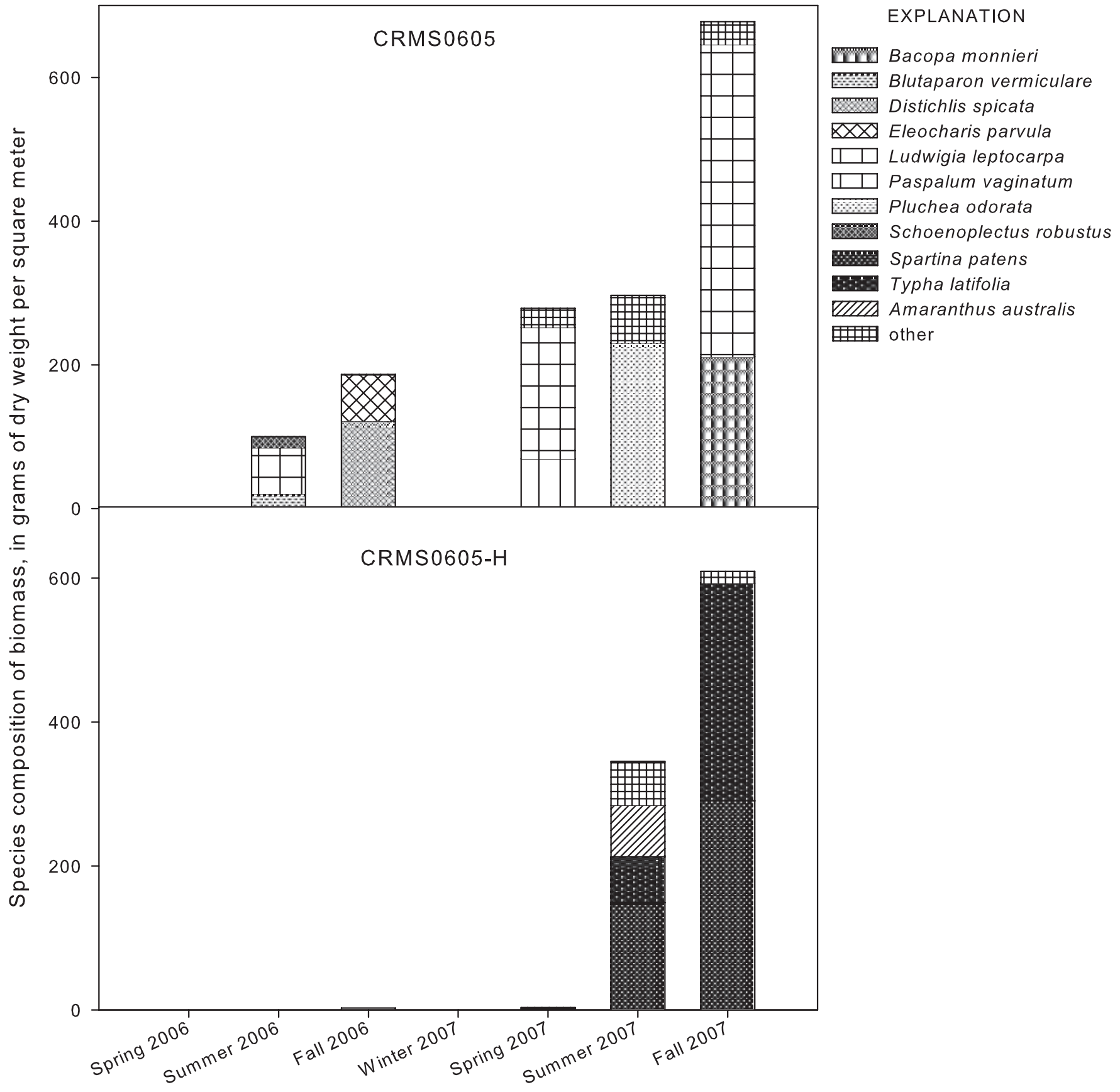

Season

Figure 15. Species composition of biomass harvested at sites CRMS0605 and CRMS0605-H by season. 
Table 7. Results of analysis of variance testing for live aboveground biomass at the end of growing seasons in fresh, brackish/ intermediate, and saline marsh types.

[Hurricane influence is defined as direct or indirect. P-values less than 0.05 indicate significant differences. $\mathrm{n}$, number; $\mathrm{p}$, $\mathrm{p}$-value]

\begin{tabular}{|c|c|c|}
\hline Marsh type & Factor & $\mathbf{p}$ \\
\hline \multirow[t]{2}{*}{ Fresh marsh $(n=72)$} & Hurricane influence & 0.0099 \\
\hline & Year & 0.0739 \\
\hline \multirow[t]{2}{*}{ Brackish/Intermediate marsh $(\mathrm{n}=72)$} & Hurricane influence & 0.0917 \\
\hline & Year & 0.0586 \\
\hline \multirow{2}{*}{ Saline marsh $(n=36)$} & Year & 0.3985 \\
\hline & Hurricane influence by year & 0.5037 \\
\hline
\end{tabular}

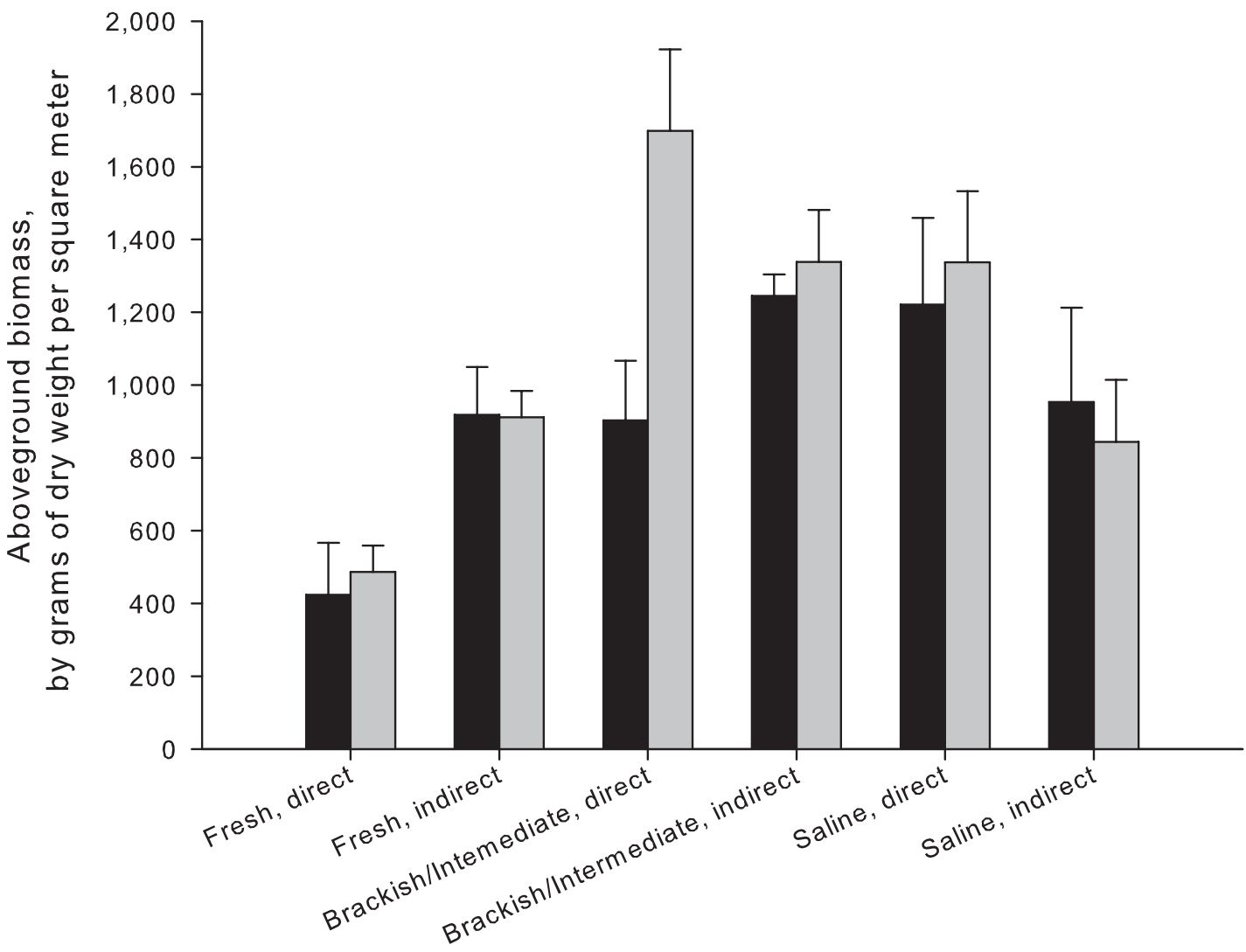

\section{Marsh type and hurricane influence}

Figure 16. Live aboveground biomass is displayed for each habitat type by level of hurricane influence and year. Mean values and standard errors are presented for the end of growing seasons in 2006 (black bars) and 2007 (gray bars). 
Table 8. Comparisons of aboveground and belowground biomass among different marsh types before and after Hurricanes Katrina and Rita.

[Unit of measurement for biomass is grams of dry weight per square meter. NA, not available; La., Louisiana; Ga., Georgia; SE, Standard error. Numbers listed in the "'study"' column denote the following studies: (1) Visser and others, 1996; (2) Schubauer and Hopkinson, 1984; (3) Darby and Turner, 2008;

(4) Turner and others, 2004; (5) Gross and others, 1991; (6) Swarzenski and others, 2008; (7) Hopkinson and others, 1978; (8) Moerschbaecher, 2008;

(9) this study]

\begin{tabular}{|c|c|c|c|c|c|c|}
\hline Marsh type & Dominant vegetation & $\begin{array}{l}\text { End-of-growing- } \\
\text { season live } \\
\text { aboveground } \\
\text { biomass } \\
\text { mean value (SE) }\end{array}$ & $\begin{array}{l}\text { End-of-growing- } \\
\text { season total } \\
\text { belowground } \\
\text { biomass } \\
\text { mean value (SE) }\end{array}$ & Location & Study & Notes \\
\hline \multirow[t]{3}{*}{ Fresh } & Panicum hemitomon & $845(285)$ & NA & La. & 1 & Prestorms \\
\hline & Panicum hemitomon & $538(31)$ & NA & La. & 6 & Prestorms, Barataria basin \\
\hline & $\begin{array}{l}\text { Panicum hemitomon, } \\
\text { Typha sp., Leersia } \\
\text { oryzoides }\end{array}$ & $403(78)$ & $5,242(341)$ & La. & 9 & $\begin{array}{l}\text { Poststorms, end of } \\
\text { growing season } 2006\end{array}$ \\
\hline \multirow[t]{5}{*}{$\begin{array}{l}\text { Brackish/ } \\
\text { Intermediate }\end{array}$} & Spartina patens & $835(374)$ & NA & La. & 1 & Prestorms \\
\hline & Spartina patens & 2,400 & NA & La. & 7 & $\begin{array}{l}\text { Prestorms, estimate } \\
\text { from graph }\end{array}$ \\
\hline & Spartina patens & 693 & NA & La. & 8 & $\begin{array}{l}\text { Poststorms, end of } \\
\text { growing season } 2006, \\
\text { estimate from graph }\end{array}$ \\
\hline & Spartina patens & $715(124)$ & $4,682(300)$ & La. & 9 & $\begin{array}{l}\text { Poststorms, end of } \\
\text { growing season } 2006\end{array}$ \\
\hline & Spartina patens & $1,321(213)$ & 4,804 (399) & La. & 9 & $\begin{array}{l}\text { Poststorms, end of } \\
\text { growing season } 2007\end{array}$ \\
\hline \multirow{4}{*}{ Saline } & Spartina alterniflora & 600 & 1,800 & La. & 4 & $\begin{array}{l}\text { Prestorms, estimate } \\
\text { from graph }\end{array}$ \\
\hline & Spartina alterniflora & $651(89)$ & NA & Ga. & 5 & $\begin{array}{l}\text { Prestorms, mean from } \\
\text { June, July, Aug., Sept., } \\
\text { Oct. and Mar. }\end{array}$ \\
\hline & Spartina alterniflora & $1,042(184)$ & $6,404(629)$ & La. & 9 & $\begin{array}{l}\text { Poststorms, end of } \\
\text { growing season } 2006\end{array}$ \\
\hline & Spartina alterniflora & $884(149)$ & $7,659(496)$ & La. & 9 & $\begin{array}{l}\text { Poststorms, end of } \\
\text { growing season } 2007\end{array}$ \\
\hline
\end{tabular}



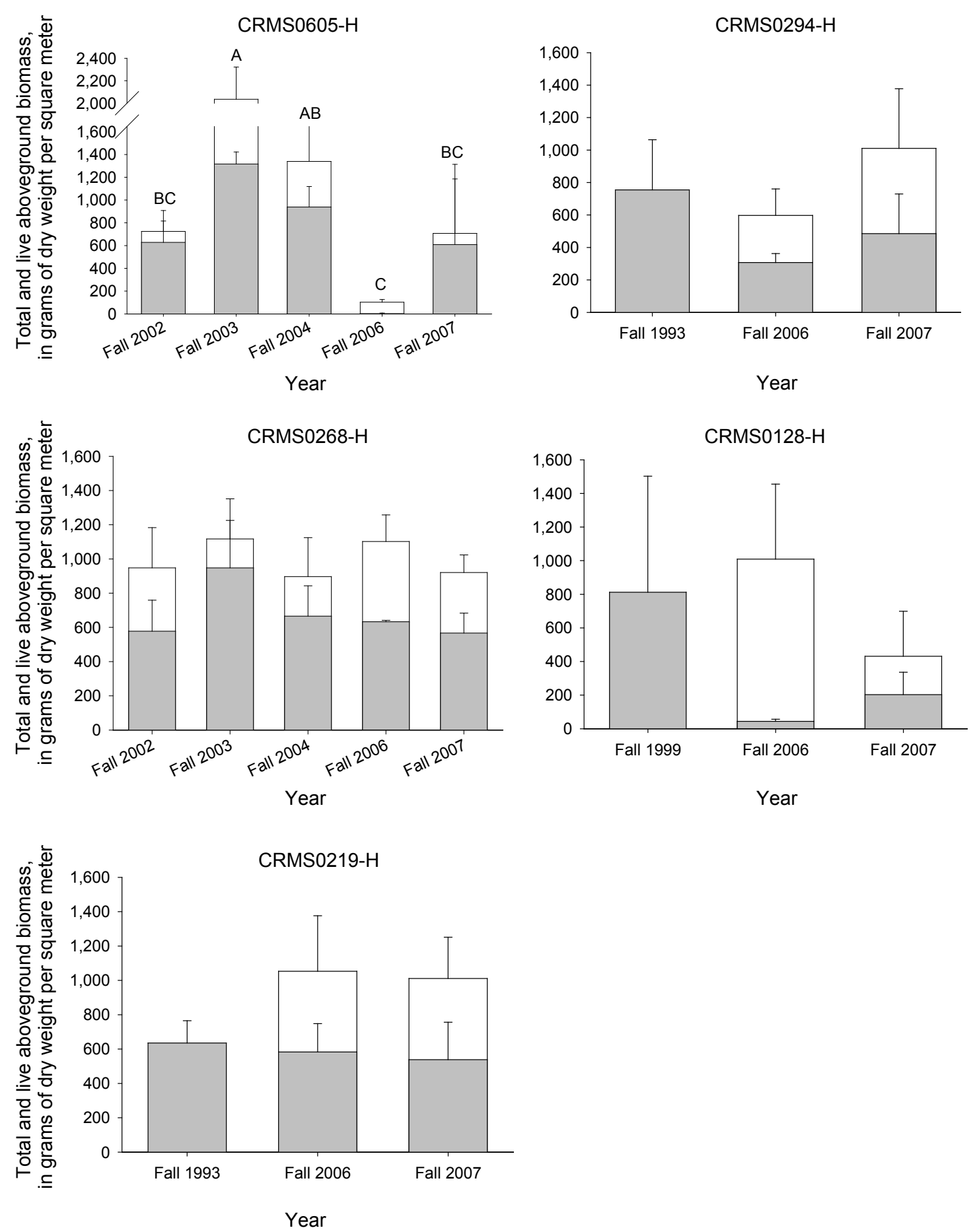

Figure 17. Total (white bars) and live (gray bars) aboveground biomass at fresh marsh sites for which historical data were compared with data from Coastwide Reference Monitoring System (CRMS) sites. Different letters indicate significant differences in total aboveground biomass $(p<0.05)$. Historical data are from Sasser and others, 1994; Holm, 2006; and Twilley and Nyman, 2000. 
Table 9. Results of analysis of variance testing for peak aboveground biomass in fresh, brackish/intermediate, and saline marsh types. [Hurricane influence is defined as direct or indirect. P-values less than 0.05 indicate significant differences. $n$, number; $\mathrm{p}$, $\mathrm{p}$-value]

\begin{tabular}{lll}
\hline \multicolumn{1}{c}{ Marsh type } & \multicolumn{1}{c}{ Factor } & p \\
\hline Fresh marsh $(\mathrm{n}=24)$ & Hurricane influence & 0.0005 \\
& Year & 0.8001 \\
& Hurricane influence by year & 0.7542 \\
Brackish/Intermediate marsh (n=24) & Hurricane influence & 0.9781 \\
& Year & 0.1849 \\
& Hurricane influence by year & 0.2909 \\
Saline marsh (n=12) & Hurricane influence & 0.1688 \\
& Year & 0.9909 \\
& Hurricane influence by year & 0.6659 \\
\hline
\end{tabular}

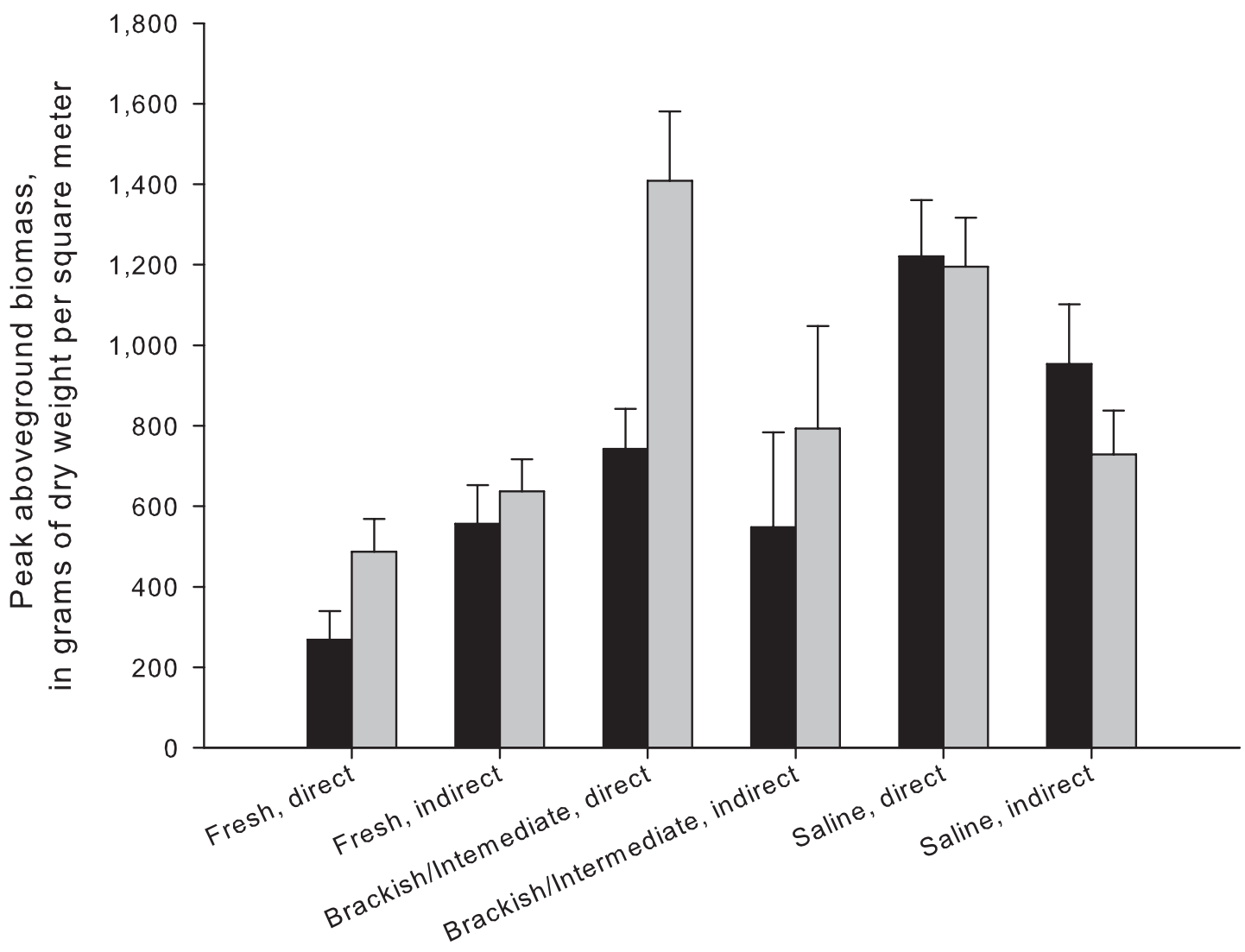

Marsh type and hurricane influence

Figure 18. Peak aboveground biomass at the end of growing seasons in 2006 and 2007 for each habitat type by hurricane influence (direct versus indirect) and year. Mean values and standard errors are presented for 2006 (black bars) and 2007 (gray bars). 

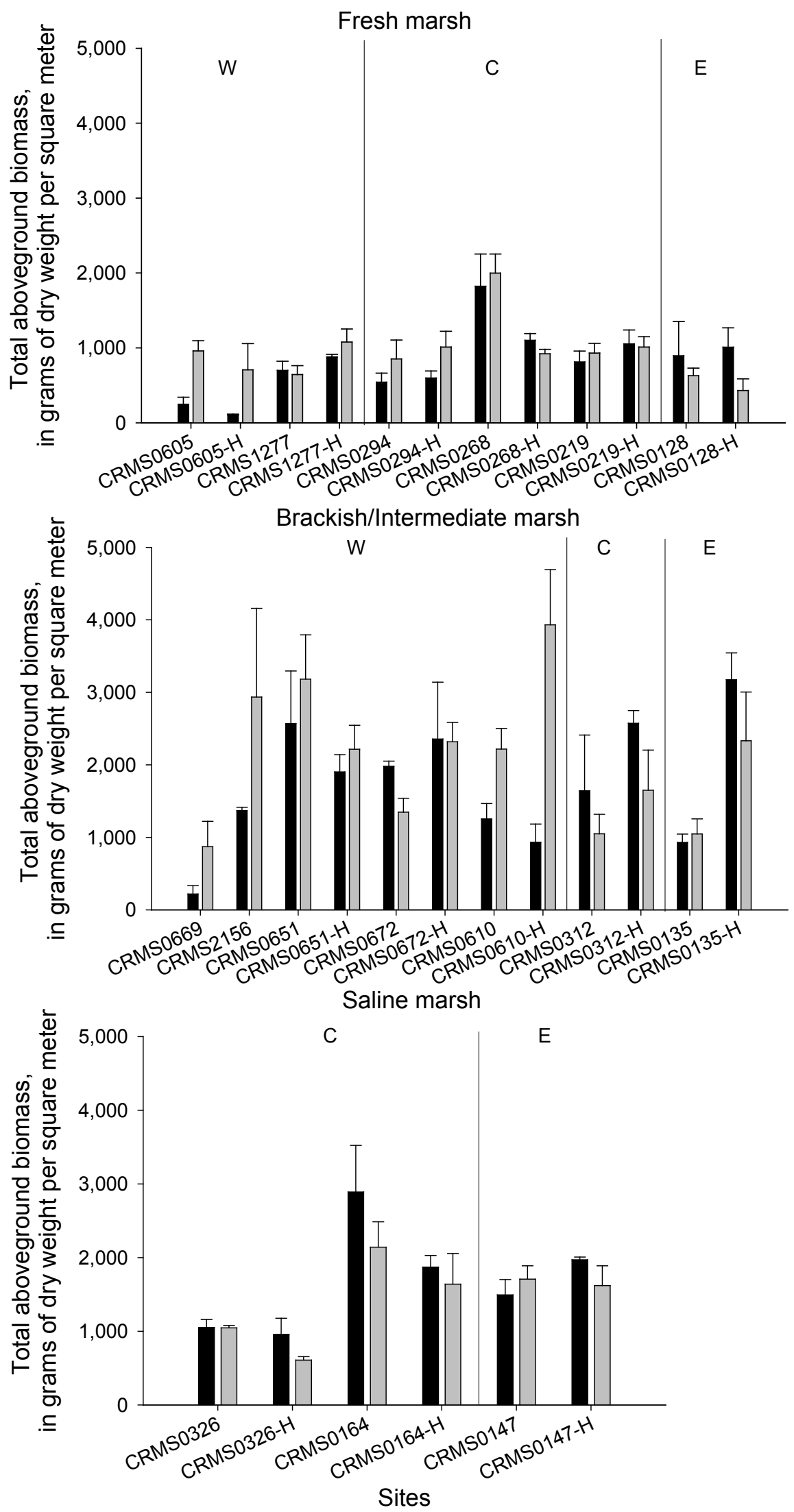

Figure 19. Total aboveground biomass (see standard error bars) at the end of growing seasons in 2006 (black bars) and 2007 (gray bars) at fresh, brackish/intermediate, and saline marsh sites. Sites with " $\mathrm{H}$ " designations were historically sampled by various research projects, and sites without " $\mathrm{H}$ " designations are within the Coastwide Reference Monitoring System (CRMS). Western (W), central (C), and eastern (E) regions of Louisiana are represented. 
biomass and total vegetation cover were observed at individual fresh marsh sites between fall 2006 and fall 2007, except at CRMS0128 where total biomass decreased in 2007 while cover increased. In 2006, CRMS0128 had multiple layers of aboveground biomass with a substantial amount of dead biomass, but by 2007 the aboveground dead biomass was much lower (about 33 percent) than in 2006.

Total belowground biomass at fresh marsh sites at the end of growing seasons ranged from 3,494.09 to 9,080.65 $\mathrm{g}$ dry weight $\mathrm{m}^{-2}$ in 2006 and 2007 (fig. 20). In 2006, total belowground biomass at the end of the growing season averaged 5,242.75 $( \pm 341.29) \mathrm{g}$ dry weight $\mathrm{m}^{-2}$, while in 2007 it increased slightly to 5,862.13 $( \pm 503.87) \mathrm{g}$ dry weight $\mathrm{m}^{-2}$. Belowground biomass at fresh marsh sites at the end of growing seasons differed significantly by hurricane influence, with directly influenced sites having less biomass $\left(6,653.41 \pm 433.44 \mathrm{~g}\right.$ dry weight $\left.\mathrm{m}^{-2}\right)$ than indirectly influenced sites $\left(8,250.26 \pm 766.24 \mathrm{~g}\right.$ dry weight $\left.\mathrm{m}^{-2}\right)$ (table 10, fig. 21). There was no significant difference in belowground biomass at the end of growing seasons by year or by the interaction of hurricane influence and year. Of all of the fresh marsh sites, CRMS0605 had the lowest amount of belowground biomass in 2006, which increased only slightly in 2007. Overall, the central region tended to have greater biomass in 2007 than the other regions; however, biomass at CRMS0219 and CRMS0219-H in 2007 was similar to the western and eastern regions. The decrease in fall-season belowground biomass between 2006 and 2007 at CRMS0128 and CRMS0128-H is consistent with the decrease observed in aboveground biomass. These sites (CRMS0128 and CRMS0128-H) were subjected to storm surge greater than 4 $\mathrm{m}$ from Hurricane Katrina and were located in an area where massive soil upheaval and erosion caused by this hurricane produced new open-water areas (Barras, 2006). The new open-water areas are exposed to increased inundation, which may explain the decrease in S. patens after Hurricanes Katrina and Rita. Increased inundation can reduce the productivity of S. patens (Burdick and Mendelssohn, 1987; Spalding and Hester, 2007) or may limit its reestablishment.

Belowground biomass at the end of growing seasons before and after the storms was compared at three fresh marsh study sites where available historical data exists for total and live belowground biomass (fig. 22). It is important to note that historical estimates of belowground biomass were from studies conducted with different methods than those presented in the current study. At CRMS0219-H and CRMS0294-H, historical measurements were made from 0 - to $25-\mathrm{cm}$ deep, while this study included measurements of the top $24 \mathrm{~cm}$. At CRMS0268-H, the historical measurements were made from 0 - to $15-\mathrm{cm}$ deep, and the current study included measurement of the top $16 \mathrm{~cm}$. Because the depth profiles included in the previous studies were within $1 \mathrm{~cm}$ of our measurements, we decided to present the comparisons (fig. 22). After the hurricanes, live belowground biomass at the end of growing seasons at these sites ranged from 738 to $3,601 \mathrm{~g}$ dry weight $\mathrm{m}^{-2}$. The lowest and highest estimates of live belowground biomass after the storms occurred at CRMS0219-H, illustrating the site-specific, interannual variability that can occur with belowground biomass data. Live and total belowground biomass estimates from before and after the hurricanes were similar among all three study sites $(\mathrm{p}>0.05)$. Although the mean value of live belowground biomass decreased between fall 2006 and fall 2007 at CRMS0219-H and CRMS0294-H, the differences were not statistically significant. Data from these sites indicated that belowground biomass was not significantly influenced by the hurricanes of 2005. There was evidence, however, of localized losses in belowground biomass from CRMS0605-H (see case study 1).

\section{Brackish/Intermediate Marsh Sites}

Porewater salinity at the end of growing seasons generally decreased from 2006 to 2007 at all brackish/ intermediate marsh sites except CRMS0651 and CRMS0672-H, where salinity was slightly greater in 2007 (fig. 10). There was no significant difference in mean values of porewater salinity at the end of growing seasons between $2006(12.1 \pm 0.9)$ and $2007(9.5 \pm 1.0)$ or by hurricane influence or the interaction of year and hurricane influence (fig. 9, table 4). Changes in porewater salinity from 2006 to 2007 varied by site, with the greatest difference occurring at CRMS0669 (that is, a decrease of 8.9 between 2006 and 2007). Porewater salinities were typically greater in the western region as compared to the eastern and central; however, the majority of brackish/intermediate marsh sites were in the western region. The largest deviations from historical values of porewater salinity occurred in brackish/ intermediate marsh. At the end of the growing season in 2007, five brackish/intermediate marsh sites exhibited porewater salinities greater than one standard deviation above historical estimates (table 5).

The mean value of total cover by live vegetation was greater in fall $2007(89.58 \pm 5.05 \%)$ than in fall 2006 $(67.72 \pm 8.82 \%)$ among all brackish/intermediate marsh sites but did not differ statistically (fig. 11). At sites monitored by CWPPRA in 2003 and 2004, live cover was 78.4 percent at all intermediate sites and 75.4 percent at all brackish marsh sites. Based on these historical CWPPRA data, live cover after Hurricanes Katrina and Rita was greater in the second growing season than before the hurricanes. At our study sites, the greatest difference between the vegetation cover at the end of growing seasons in 2006 and 2007 was observed at CRMS0672-H, where it increased by 85 percent. The only sites that decreased in live cover from 2006 were CRMS0610 and CRMS0312-H. Overall, the largest differences between values estimated at the end of growing season occurred in the western region of Louisiana. These large differences could be attributed to the persistence of salinity stress during the 2006 growing season and a subsequent decrease in salinity in 2007 (appendix figs. 1-11 and 1-13) in the western sites. There were no statistical differences in total live cover at the end of growing season between years, hurricane influence, or the interaction of years and hurricane influence $(\mathrm{p}>0.05)$. 

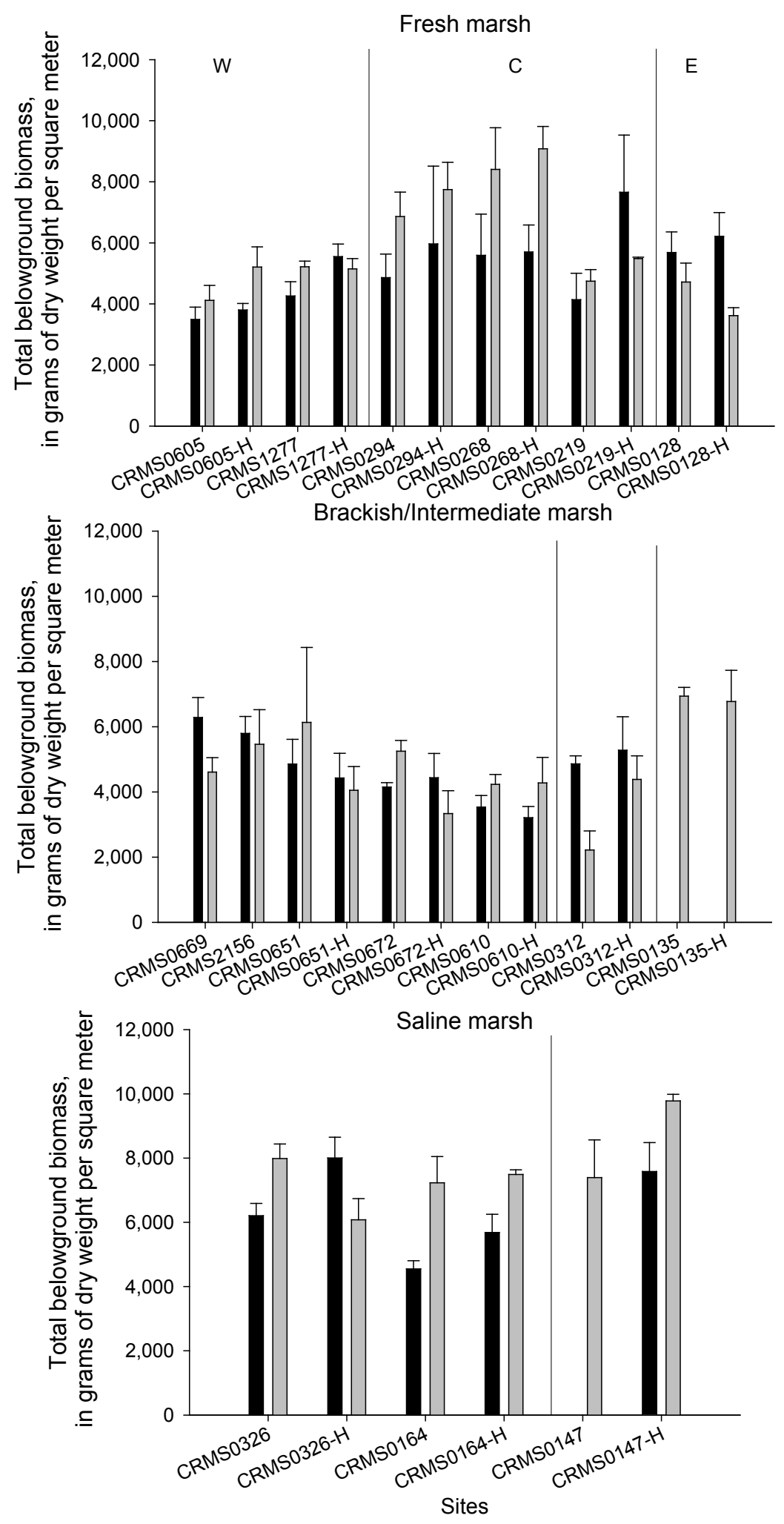

Figure 20. Total belowground biomass (see standard error bars) at the end of growing seasons in 2006 (black bars) and 2007 (gray bars) at fresh, brackish/intermediate, and saline marsh sites. Sites with " $\mathrm{H}$ " designations were historically sampled by various research projects, and sites without " $\mathrm{H}$ " designations are within the Coastwide Reference Monitoring System (CRMS). Western (W), central (C), and eastern (E) regions of Louisiana are represented. 
Table 10. Results of analysis of variance testing for total belowground biomass at the end of growing seasons in fresh, brackish/ intermediate, and saline marsh types.

[Hurricane influence is defined as direct or indirect. P-values less than 0.05 indicate significant differences. Belowground biomass was the dependent variable for $p$-values. n, number; $p$, p-value]

\begin{tabular}{|c|c|c|}
\hline Marsh type & Factor & $\mathbf{p}$ \\
\hline \multirow[t]{2}{*}{ Fresh marsh $(n=72)$} & Hurricane influence & 0.0044 \\
\hline & Year & 0.2286 \\
\hline Brackish/Intermediate marsh $(n=66)$ & Hurricane influence & 0.3092 \\
\hline \multirow[t]{3}{*}{ Saline marsh $(n=33)$} & Hurricane influence & 0.1511 \\
\hline & Year & 0.2773 \\
\hline & Hurricane influence by year & 0.9650 \\
\hline
\end{tabular}

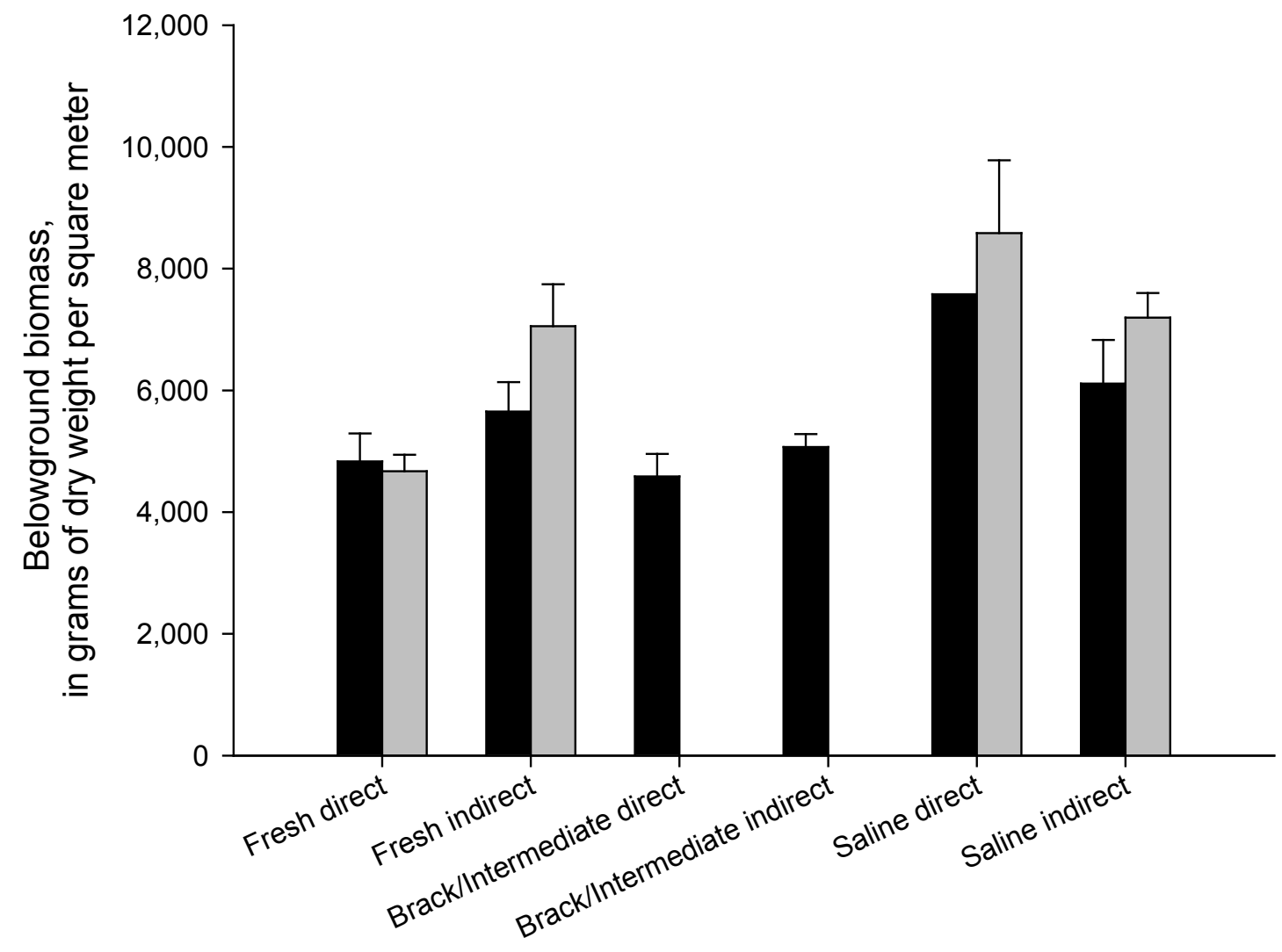

Marsh type by hurricane Influence

Figure 21. Mean values of belowground biomass (see standard error bars) for each marsh type by hurricane influence (direct or indirect) and year. Values are for the end of growing seasons in 2006 (black bars) and 2007 (gray bars). 


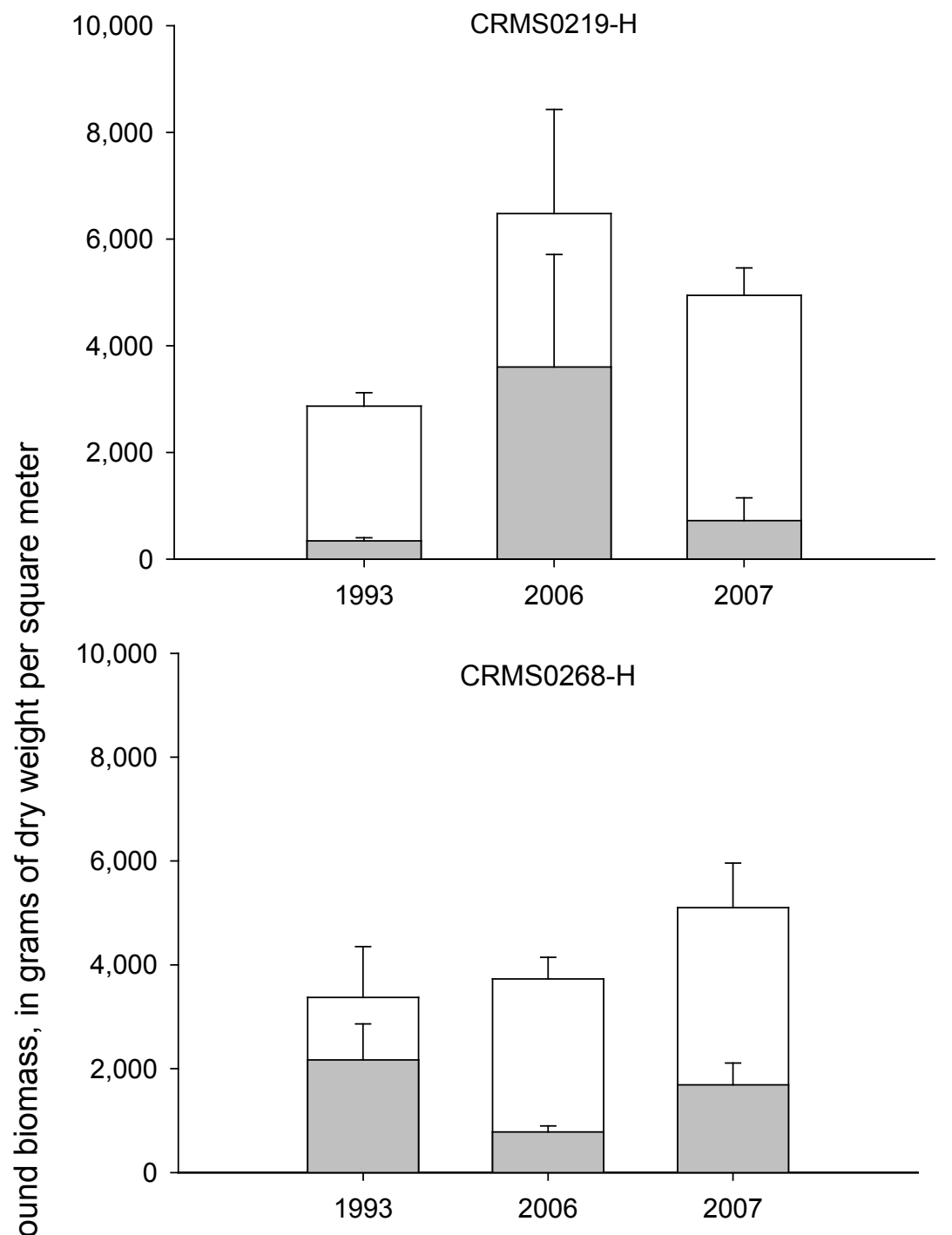

Figure 22. Total (white bars) and live (gray bars) belowground biomass at fresh marsh sites at the end of growing seasons. Sites within the Coastwide Reference Monitoring System (CRMS) were selected based on availability of historically sampled data (sites with "H" designations) from Sasser and others, 1994. Historical measurements were taken at $0-25-\mathrm{cm}$ depths at CRMS0219-H and CRMSO294- $\mathrm{H}$, while our measurements at these sites in 2006 and 2007 were made at $0-24-\mathrm{cm}$ depths. At CRMSO268-H, historical measurements were made at $0-15 \mathrm{~cm}$, while our measurements in 2006 and 2007 were made at $0-16-\mathrm{cm}$ depths. 
In fall 2006, the relative cover of disturbance taxa relative to nondisturbance taxa was 10.12 percent, slightly greater than in fall 2007 at 8.95 percent. Although the mean value of cover by disturbance taxa relative to nondisturbance taxa was greater at the end of the growing season in 2006 than at the end of the growing season in 2007, there was an increase in the number of sites exhibiting disturbance taxa in 2007 (fig. 23). Sites with disturbance taxa occurred in both the directly and indirectly influenced areas. At the end of the growing season in both years, CRMS0135 had the greatest percentage of cover by disturbance taxa (that is, greater than 50 percent) when compared to all brackish/intermediate marsh sites (see case study 2 for additional information).

In brackish/intermediate marshes, we detected no significant impact of hurricanes or year on the percentage of disturbance taxa observed in live aboveground biomass (table 6). On average, 5 percent of the brackish/intermediate marsh biomass consisted of disturbance species; however, CRMS0135, a site in the center of the Breton Sound that received the full force of Hurricane Katrina, had much greater levels of disturbance species, with 70 percent of the biomass contributed by disturbance species in 2006 and 40 percent in 2007 (fig. 24). The CRMS0135 site, which was an intermediate marsh site before Hurricane Katrina, was almost completely denuded of vegetation after the storm, with most of the biomass in the spring of 2006 consisting of A. australis (fig. 25). In contrast, the nearby site CRMS0135-H was not denuded, and most of the vegetation in the spring of 2006 consisted of $S$. patens. This dominance of $S$. patens is typical of brackish and some intermediate marshes. The difference between these two sites illustrates the patchiness of physical disturbance from a hurricane (Barras, 2006), probably due to local wind eddies as well as the relative vigor of the site affected. In the fall of 2007, CRMS0135 was still dominated by species other than $S$. patens, the typical dominant species of intermediate/brackish marshes.

We detected no significant impact from the hurricanes related to live biomass at the end of growing seasons in the brackish/intermediate marsh (table 7). This lack of influence may be due to the experimental design, which has only two indirectly impacted sites that were less productive compared to other brackish/intermediate marsh sites (table 8). Overall, biomass was slightly greater in the second year after the storm (fig. 16); however, the difference between years was not statistically significant, probably because of the large variation in fall biomass among sites.

In the brackish/intermediate marsh, no significant differences were detected for peak biomass as a result of the variables hurricane impact, year, or the interaction of the two (table 9). Figure 18 shows that there was a great deal of variation in peak biomass, especially in the indirectly impacted sites. Because only two sites are classified as indirectly impacted, the uncertainty around the estimate is high, making it more difficult to detect statistical differences. In general, the directly impacted sites had lower peak biomass the first year after the storms than the indirectly impacted sites. In contrast, the peak biomass in the second year after the storms was greater in the directly impacted sites than in the indirectly impacted sites.

Total (live and dead) aboveground biomass at the end of growing seasons ranged from 218.67 to $3,931.63 \mathrm{~g}$ dry weight $\mathrm{m}^{-2}$ in 2006 and 2007. The mean value of total aboveground biomass among all sites averaged 1,741.83 $( \pm 244.68) \mathrm{g}$ dry weight $\mathrm{m}^{-2}$ in 2006 and increased to 2,090.95 $( \pm 273.11)$ g dry weight $\mathrm{m}^{-2}$ in 2007 (fig. 19). The greatest change between estimates at the end of growing seasons occurred at CRMS0610-H, where total biomass increased more than fourfold between the two growing seasons. Changes in total aboveground biomass at the end of growing seasons were inconsistent, with some sites having increased biomass at the end of the growing season in 2007 and some having decreased biomass. For example, the mean value of total biomass decreased between fall 2006 and fall 2007 at 5 of the 12 brackish/intermediate marsh sites (fig. 19).

Among all brackish/intermediate marsh sites, belowground biomass at the end of growing seasons averaged $4,682.55( \pm 300.28) \mathrm{g}$ dry weight $\mathrm{m}^{-2}$ in 2006 and 4,804.32 $( \pm 399.36) \mathrm{g}$ dry weight $\mathrm{m}^{-2}$ in 2007 (fig. 20). Sites within areas directly and indirectly influenced by the hurricanes had similar values in 2006 and 2007 (table 10, fig. 21). The largest within-site change was observed at CRMS0312, with biomass decreasing from 4,857.33 to 2,220.11 g dry weight $\mathrm{m}^{-2}$ between 2006 and 2007. At the site level, no consistent pattern in belowground biomass was observed between the two growing seasons.

Live aboveground biomass in brackish/intermediate marshes at the end of the growing season in fall 2007 was greater than prestorm literature values (table 8), suggesting that there was no negative influence from Hurricanes Katrina and Rita in these marsh types. Aboveground biomass estimates are, however, sensitive to dominant vegetation taxa and site-specific heterogeneity (for example, streamside versus interior marsh and impaired versus healthy marsh) and are highly variable across landscapes (Ellison and others, 1986). Furthermore, historical data collected before the hurricanes were limited, thus limiting comparisons of conditions before and after the storms. We caution, therefore, that broad conclusions regarding the influence of the hurricanes on aboveground biomass should not be drawn based on these limited data.

\section{Saline Marsh Sites}

Porewater salinity at saline marsh sites at the end of growing seasons was significantly greater in $2006(21.3 \pm 1.6)$ than in 2007 (15.7 \pm 1.9$)$ (fig. 10, table 4). Interestingly, sites within the area of direct hurricane influence had significantly lower porewater salinity $(12.4 \pm 2.5)$ than those in areas of indirect influence $(21.2 \pm 1.2)$ (fig. 9). The interaction of variables year and hurricane influence was also statistically significant. This significance is likely due to the influence of freshwater from the Mississippi River upon salinity at the only 

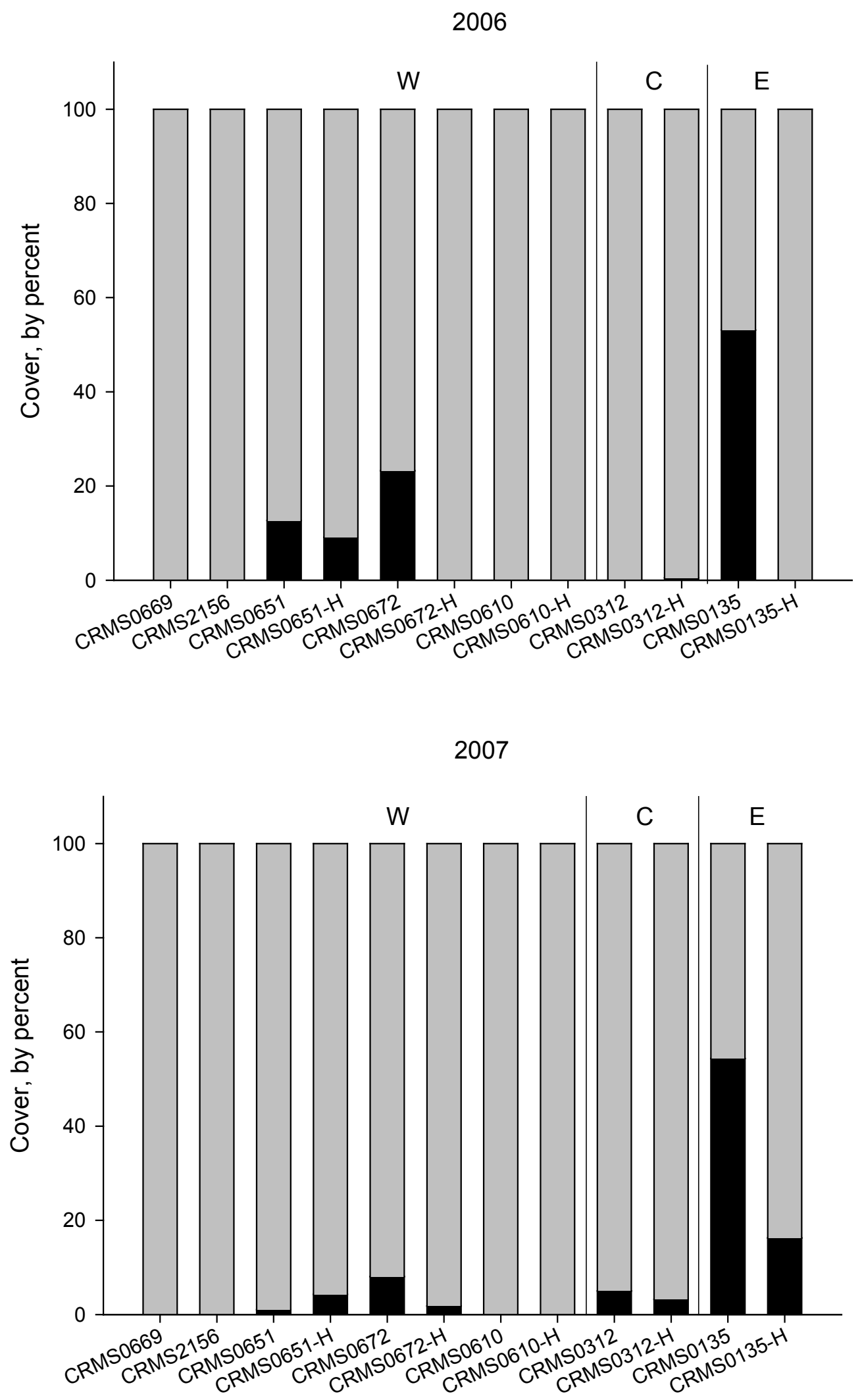

Sites

Figure 23. Cover of disturbance (black bars) taxa relative to nondisturbance taxa (gray bars) in emergent vegetation at brackish/ intermediate marsh sites at the end of growing season in 2006 and 2007. Sites with "H" designations were historically sampled by various research projects, and sites without " $\mathrm{H}$ " designations are within the Coastwide Reference Monitoring System (CRMS). Western (W), central (C), and eastern (E) regions of Louisiana are represented. 


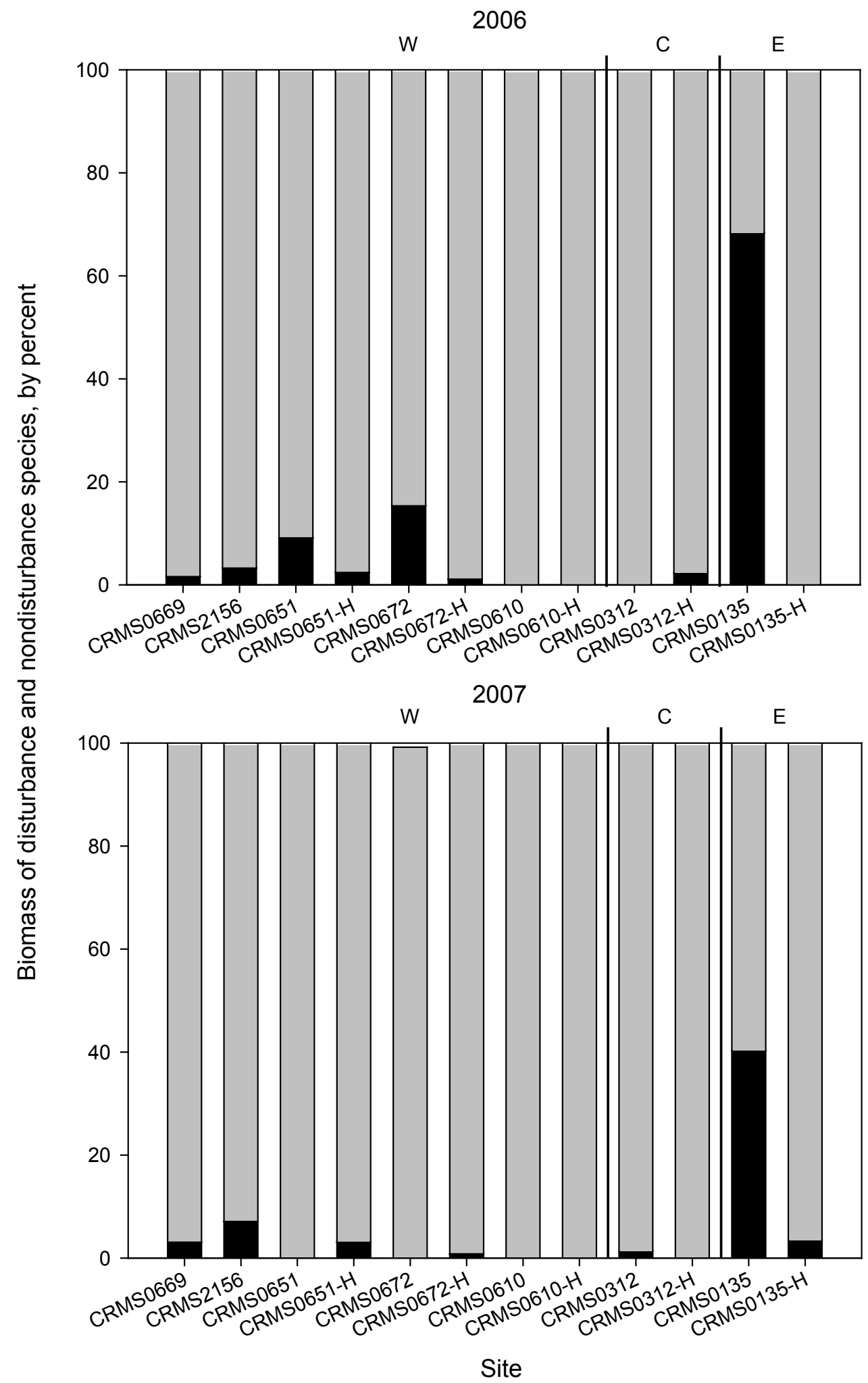

Figure 24. Percentages of biomass in disturbance (black bars) versus nondisturbance (gray bars) species at brackish/intermediate marsh sites for 2006 and 2007.

Sites with " $\mathrm{H}$ " designations were historically sampled by various research projects, and sites without " $\mathrm{H}$ " designations are within the Coastwide Reference Monitoring System (CRMS). Western (W) and eastern (E) regions of Louisiana were affected by direct hurricane influence and the central $(\mathrm{C})$ region by indirect influence. 


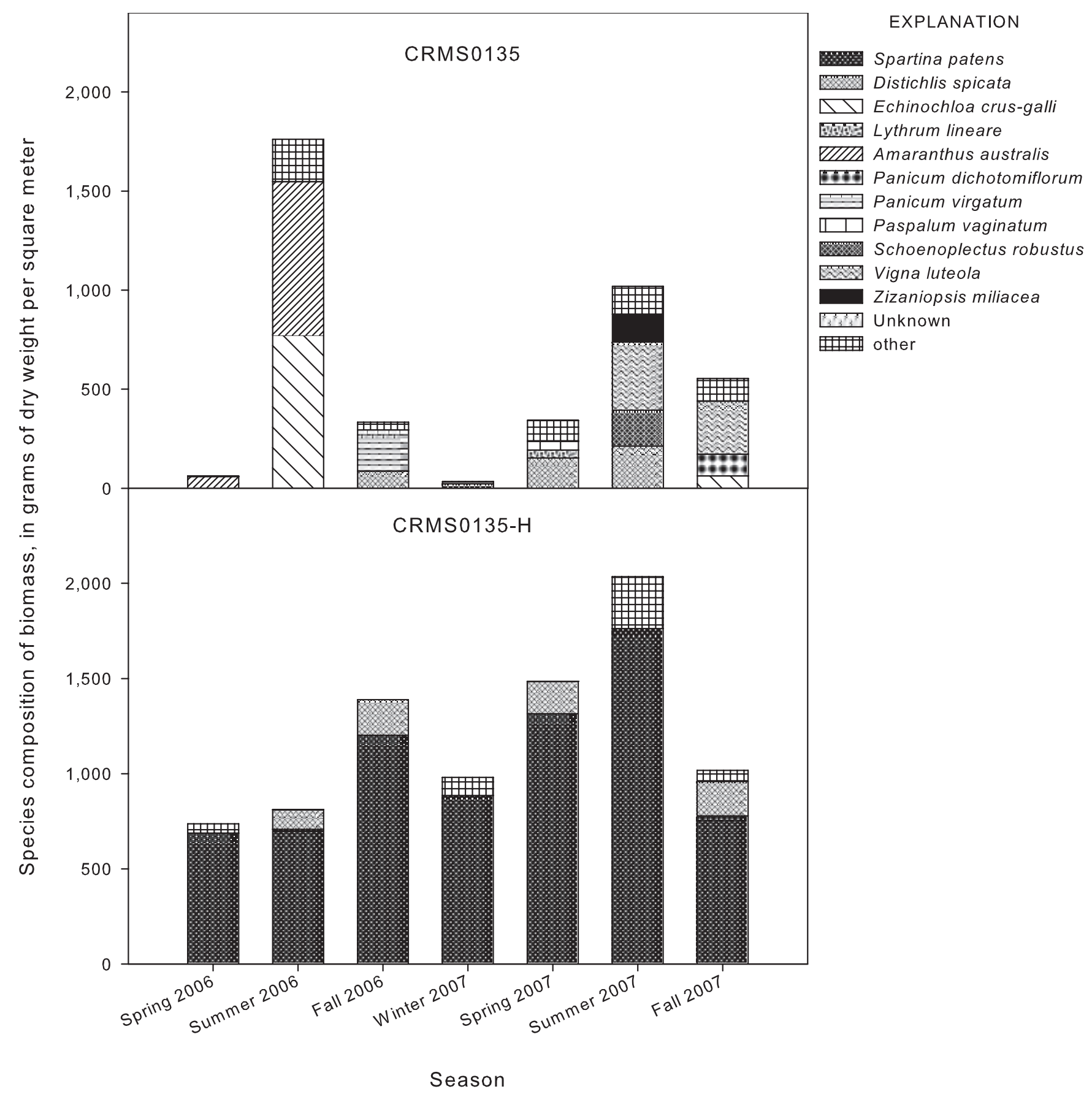

Figure 25. Species composition of biomass harvested at Coastwide Reference Monitoring System (CRMS) sites 0135 and 0135-H by season.

pair of saline marsh sites directly affected by the hurricanes (CRMS0147 and CRMS0147-H) (Wiseman and others, 1990). Of the six saline marsh sites, porewater salinity was greatest at CRMS0164 and CRMS0164-H at the end of both growing seasons after the hurricanes. At CRMS0164- $\mathrm{H}$, mean values for salinity at the end of the growing season in 2007 were greater than two standard deviations above the porewater salinity estimates for saline habitats observed by Chabreck (1972) (table 5). In fall 2007, porewater salinity at the remaining sites was typical of saline marsh habitats.
Total vegetation cover at the end of growing seasons was greater than 60 percent at all saline marsh sites in both 2006 and 2007 (fig. 11). The lowest value for cover the end of a growing season was observed at CRMS0326 (65 percent) in fall 2006, but in fall 2007 all saline marsh sites had total cover greater than or equal to 85 percent. Little change was observed in total cover at saline marsh sites throughout the study period. (See the case studies section of this report for specific details related to CRMS0164-H and CRMS0326-H.) The total cover consistently comprised taxa typical of saline 
habitats. No disturbance taxa were observed at any of the saline marsh sites during any sampling period throughout the study (fig. 26).

In the saline marsh sites, live aboveground biomass at the end of growing seasons was significantly greater in the directly impacted sites $\left(1,208 \mathrm{~g}\right.$ dry weight $\left.\mathrm{m}^{-2}\right)$ (that is, eastern region) than in the indirectly impacted sites (841 g dry weight $\mathrm{m}^{-2}$; table 7 ; fig. 16). No significant difference among years was observed, and the interaction between variables of hurricane influence and year was also not significant. This lack of statistical difference is probably due to the small sample size. Biomass in the directly impacted sites was approximately one standard deviation above the long-term average for S. alterniflora sites in the Leeville area, located within the indirectly influenced area. This indicates that the hurricanes had a positive effect on saline marshes in terms of plant biomass, and this effect lasted for at least 2 years after the storms; however, only two of the six saline marsh sites were in the zone of direct influence (eastern region). The positive effects on plant biomass may be explained by the deposit of sediments onto the saline marsh during the hurricanes (Turner and others, 2006).

Total aboveground biomass at the end of growing seasons ranged from $957.3( \pm 377.7)$ to $2,889.3( \pm 1,096.1) \mathrm{g}$ dry weight $\mathrm{m}^{-2}$, with the greatest values at CRMS0164 in fall 2006 and the lowest at CRMS0326-H in fall 2007 (fig. 19). In both growing seasons, CRMS0164 produced the greatest biomass. Sites in both the directly and indirectly influenced areas produced similar aboveground biomass, as was reflected in the peak biomass (fig. 18).

Hurricanes Katrina and Rita did not influence site-specific species dominance or total aboveground biomass at the two study sites with available historical data (CRMS0164-H or CRMS0326-H). The dominant vegetation species was S. alterniflora before and after the storms at both sites, and there were no significant differences between prestorm and poststorm calculations of total aboveground biomass at the end of growing seasons. At both these saline marsh sites, the mean value of total aboveground biomass was greater at the end of the growing season in 2006 than in 2007, and the difference was not statistically significant.

Belowground biomass at the end of growing seasons increased from 6,404.74 ( \pm 659.64) $\mathrm{g}$ dry weight $\mathrm{m}^{-2}$ in 2006 to $7,659.06$ $( \pm 496.23) \mathrm{g}$ dry weight $\mathrm{m}^{-2}$ in 2007 among all saline marsh sites (fig. 20). No significant differences occurred in belowground biomass by
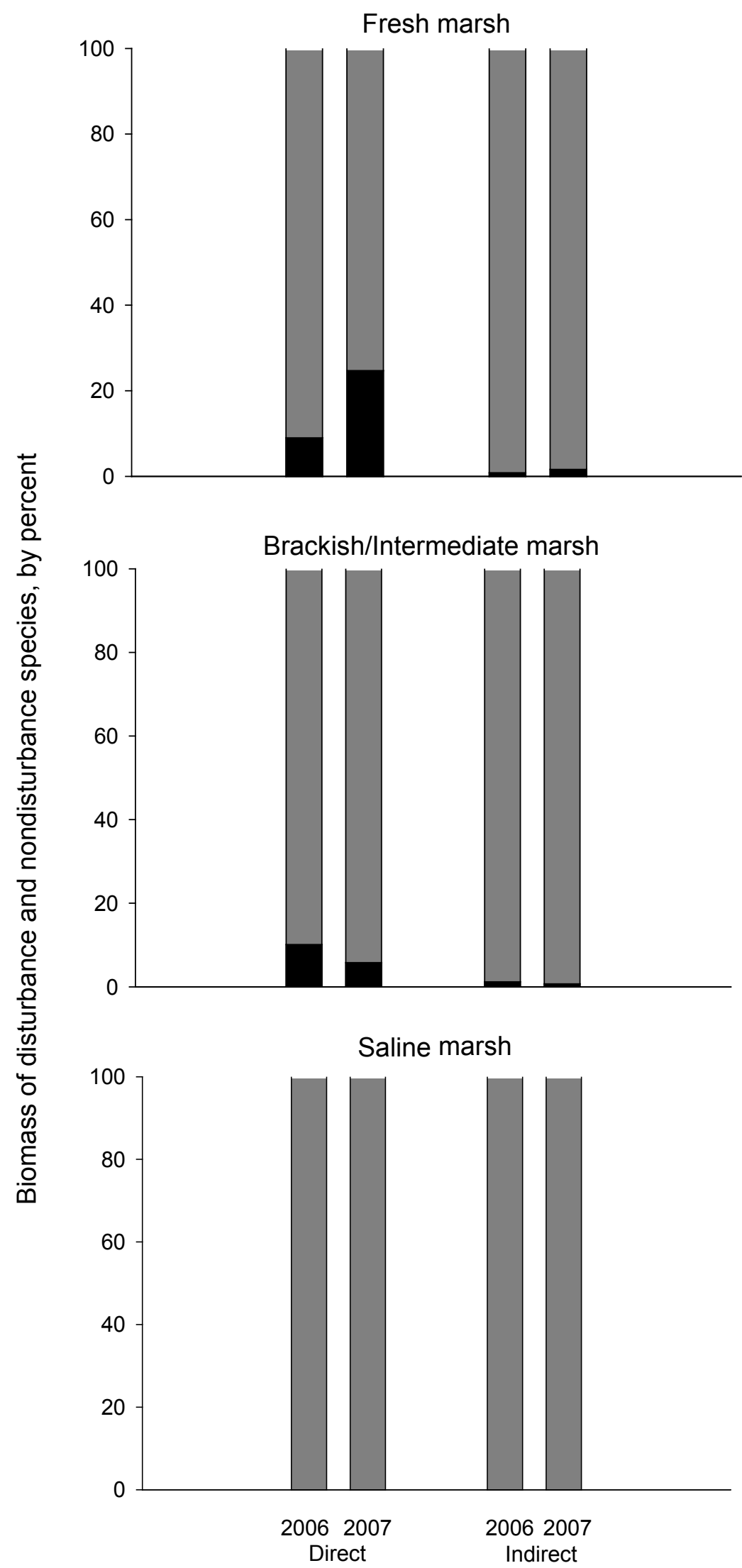

Figure 26. Percentages of biomass from disturbance (black bars) and nondisturbance (gray bars) species in 2006 and 2007 for each marsh type by hurricane influence (direct or indirect). 
variables of year, hurricane influence area, or the interaction of year and hurricane influence area (table 10, fig. 21). With the exception of CRMS0326-H, belowground biomass increased at all sites in the second growing season. Total belowground biomass at saline marsh sites at the end of growing seasons was greater after the storms than before, according to the published prestorm values (table 8). Although prestorm and poststorm estimates were all collected in marshes dominated by $S$. alterniflora, site-specific heterogeneity (for example, streamside versus interior marsh and impaired versus healthy marsh) may explain the variability between our study and previously published estimates.

\section{Case Studies}

This section includes a series of case studies for specific study sites. Site selection for case studies was based on habitat type, hurricane influence, and availability of historical data. We included CRMS0605-H and CRMS1277-H, which are located in fresh marsh habitats within the chenier plain (for definitions of the Louisiana chenier and deltaic plains, see Saucier, 1994). The CRMS0605-H site was directly influenced by Hurricane Rita and was exposed to a prolonged period of elevated salinities after the hurricanes, resulting in changes to the species composition of emergent vegetation. For both sites, there was availability of historical vegetation and salinity data. The CRMS1277-H site is located in proximity to the path of Hurricane Rita and was classified as being in the area of direct hurricane influence, but it was only marginally impaired by the storm because changes in species composition and elevations in salinity were not observed at the site. Within brackish/intermediate marshes, CRMS0135 and CRMS0672-H are presented. Both sites were directly influenced by physical-biological disturbances associated with Hurricanes Katrina and Rita. Although no historical data were available from the exact location of these sites, hydrologic and vegetation data were available from sites located within proximity to these locations (paired sites). Saline marsh sites CRMS0326-H and CRMS0164-H were indirectly influenced by the hurricanes, and there were site-specific historical data for both sites, allowing for comparisons of data acquired before and after the hurricanes.

\section{Case Study 1: CRMS0605-H and CRMS1277-H}

\section{Overall Site Description}

The CRMS0605-H and CRMS1277-H sites are located in freshwater marshes near the Mermentau River and Grand Lake and have highly organic soils that are relatively isolated from freshwater exchange with the river and the lake (fig. 27). Instead, the semi-impounded hydrology of these marshes, which naturally arises from chenier confinement and a variable degree of artificial hydrologic management, is controlled by local rainfall (Gammill and others, 2001).
Short-term, periodic introduction of the Mermentau River to the marshes south of Lake Misere and north of Little Chenier has been observed when canal plugs are removed for oil and gas exploration (G. Holm, oral commun.). Otherwise, these marshes are typically blackwater areas with limited connection to Grand Lake and the Gulf Intracoastal Waterway.

An interesting attribute of freshwater marshes in the chenier plain is their extensive plant coverage and the absence of significant areas of open water, save small potholes and narrow trenasses (Davis, 1976). Panicum hemitomon (maidencane) often forms uninterrupted, densely vegetated prairie. This species tolerates periodic fire and a broad range of water levels, but it has practically no tolerance for salt (Holm and Sasser, 2008). The largest, robust stands of maidencane occur in purely freshwater areas of the chenier plain.

Prior to Hurricanes Katrina and Rita, CRMS0605-H was a freshwater herbaceous marsh dominated by $P$. hemitomon, with interspersed patches of Morella cerifera (wax myrtle), Schoenoplectus tabernaemontani (softstem bullrush), and Phragmites australis (common reed) (Holm and others, 2003; Holm, 2006). Some of the marsh was buoyant (a 1.0-cm vertical adjustment of marsh water level corresponded to 0.86 -cm vertical adjustment of marsh mat), but there was high spatial variability because some areas were attached to a clay lens occurring at depth of $90 \mathrm{~cm}$ (Holm and others, 2003). The transition between attached and detached marsh was gradual, such that the mat was not separated or fragmented.

\section{Salinity Before and After the Storms}

Based on continuous water-level and salinity records from 2001 to early 2005, surface salinity never exceeded 0.5 ; however, anecdotal evidence suggests that low-level salt exposure to this site occurred during the 1999-2000 drought. Before Hurricane Rita, from July to September 2005 surface salinity increased and reached 9.2 on September 13, 2005, when a point sample was collected (the gage record was not complete for this time period) (fig. 28). The surfacewater salinity increase was due to an opening of a water control structure on the Mermentau River above the Catfish Locks during an intense, localized drought in the summer of 2005. The introduction of saltwater to the marshes was a management measure to reduce noxious growth of submerged aquatic plants (R. Vincent, oral commun., 2005). Peak salinity associated with the Hurricane Rita is unknown. Two full years after the storms, salinity remained elevated $(>1.5)$ compared to the original background levels $(<0.5)$ at this site.

\section{Plant Biomass Before and After the Storms}

Before Hurricane Rita, the vegetation community at CRMS0605-H, which was dominated by P. hemitomon, had a total aboveground biomass of $1,340 \mathrm{~g}$ dry weight $\mathrm{m}^{-2}$ in 2003 and 2,035 $\mathrm{g}$ dry weight $\mathrm{m}^{-2}$ in 2004. Live belowground biomass within the upper $15 \mathrm{~cm}$ (measured with in-growth cores) was $807 \mathrm{~g}$ dry weight $\mathrm{m}^{-2}$ in 2003 and $962 \mathrm{~g}$ dry weight 


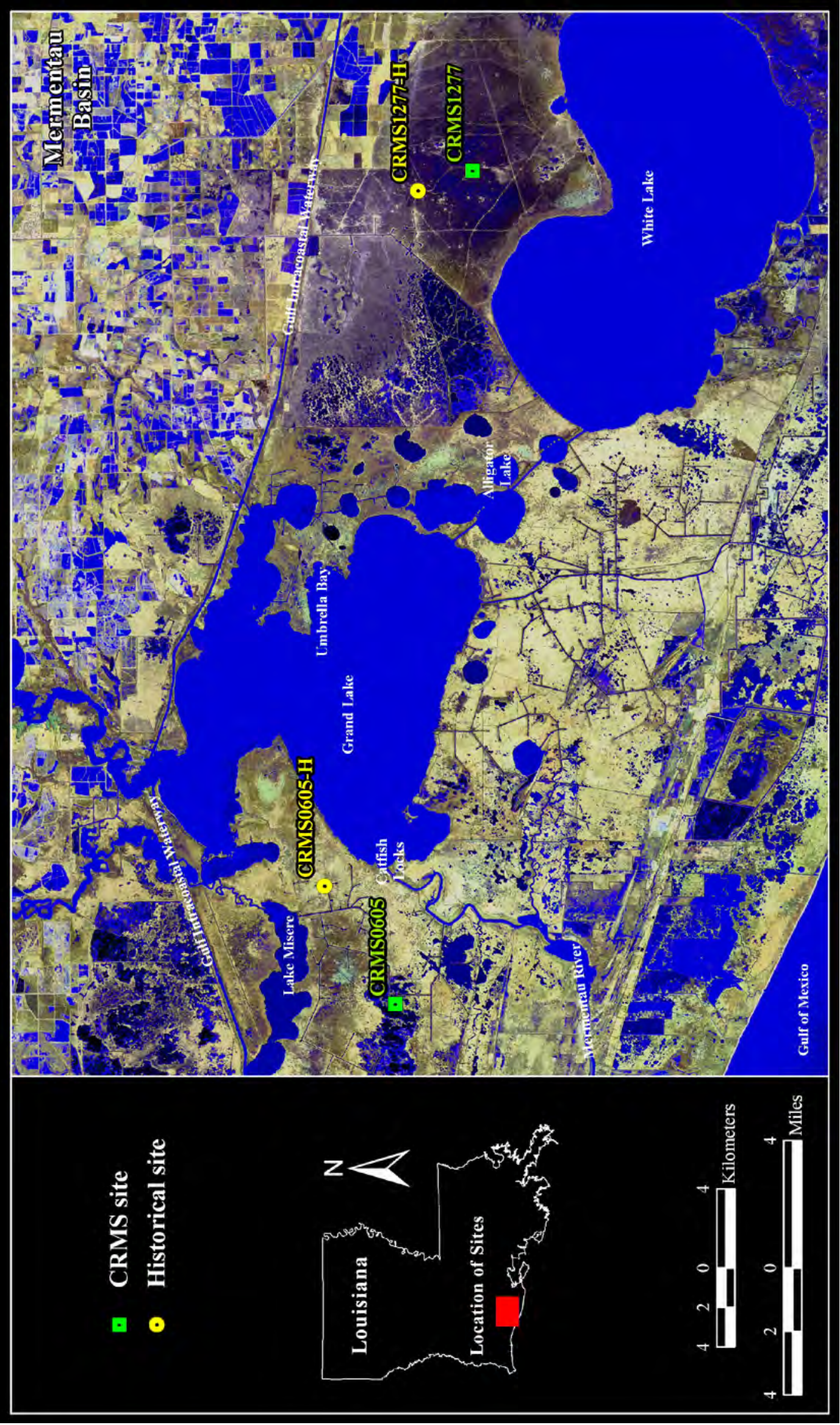

$\stackrel{9}{10}$

क

बूँ

范

3 步

$\stackrel{2}{x}$

둥

要 嗀

$\stackrel{\omega}{\underline{\omega}}$

$\sum^{\infty} \frac{\Phi}{\square}$

西

त

$\infty \sum^{\infty}$

品. 壱

$\sum_{0} \stackrel{0}{E}$

ज.

焉

. 든

药

츠음

즘

등 음

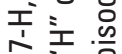

칭

둥ㅎㅁ

吅

工

的 都

응 등

造高

की $\frac{0}{2}$ 금

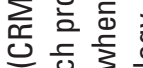

틈 흥흐

फे

के के व

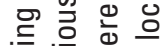

家

흥ㅎㅁ

$\sum$ 的

은 능

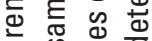

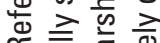

제

을 은 흔

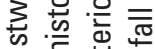

잉.

访要

क क क ज

㼛

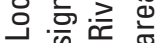

. 造 层

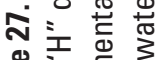

言言焉 


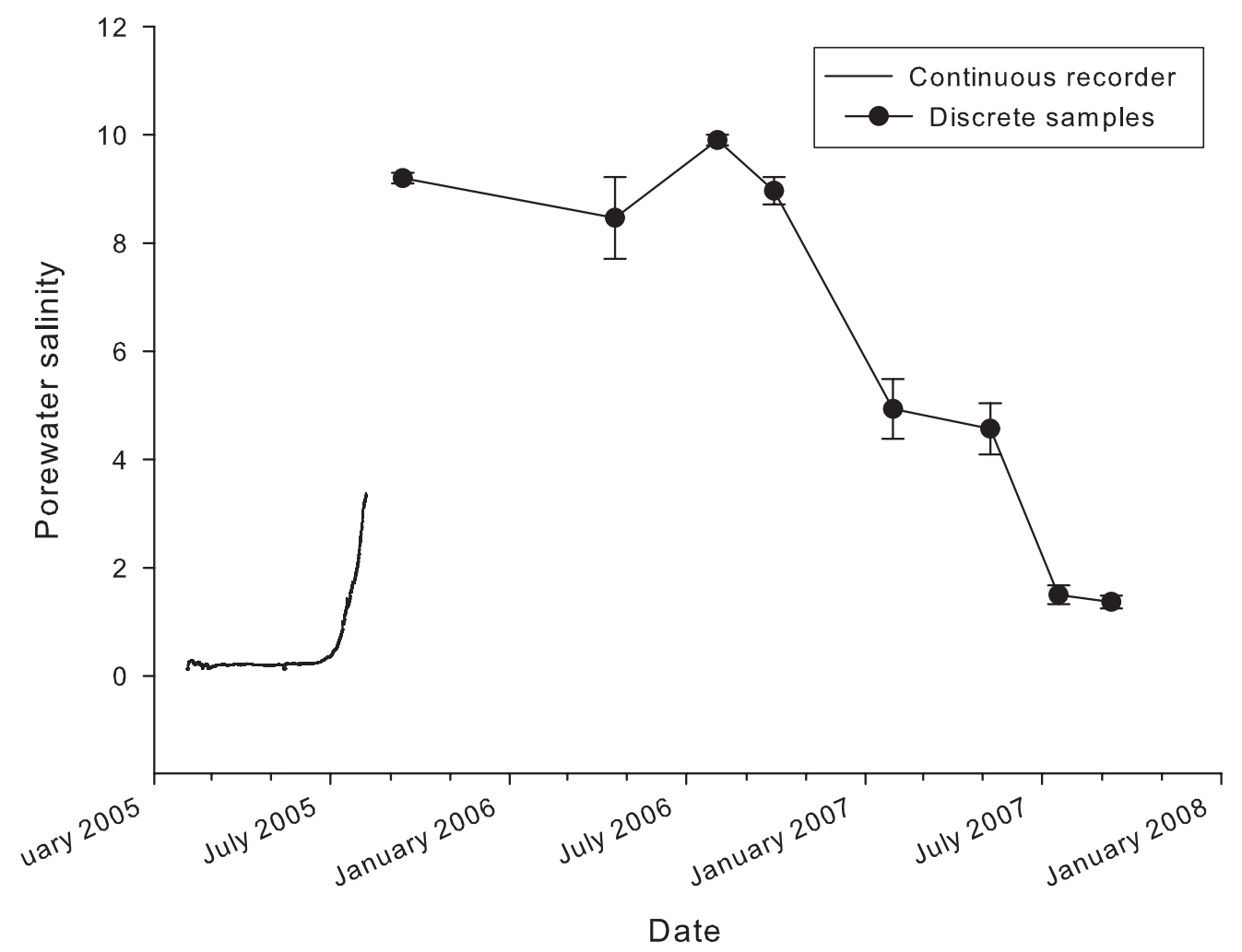

Figure 28. Continuous and discrete samples of porewater salinity taken from $30 \mathrm{~cm}$ deep at Coastwide Reference Monitoring System (CRMS) site 0605-H from 2005 to 2007. Data from before August 2005 was collected with a continuous recorder that quit working; subsequent measurements are discrete. The first discrete measurement of elevated porewater salinity (9.2) was collected on September 13, 2005, approximately 11 days before Hurricane Rita made landfall. Prior to the storm, a local drought was developing, and the typically freshwater marshes of Lake Misere (see fig. 27) were exposed to high salinity because of the opening of a water control structure on the Mermentau River above Catfish Locks.

$\mathrm{m}^{-2}$ in 2004. Complete mortality of the plant community had occurred throughout fall and winter 2005 , such that by spring 2006, a bare mat of peat was exposed with only some dead plant stubble remaining (fig. 29). By the end of the second growing season after Hurricanes Katrina and Rita (in fall 2007), live aboveground and belowground biomass were approximately one-half that before the storms (figs. 30 and 31).

The delayed colonization and poor plant growth following Hurricane Rita resulted in a potentially significant loss of organic matter to the soil. We used two other sites dominated by $P$. hemitomon to calculate the potential loss of organic matter to the soil, the premise being that these sites were comparable in dominant-species composition and provide an estimate of the potential loss in plant production that occurred at CRMS0605-H. We chose an adjacent site in the chenier plain that was within the region of direct hurricane influence, as defined by this study, but was only marginally impaired by Hurricane Rita (White Lake, CRMS1277-H), and a deltaic plain site (Lake Boeuf, CRMS0268-H) that was indirectly affected by Hurricane Rita in the central region of the study area. These two sites were selected based on our historical understanding of the stability of their communities (Holm, 2006). Comparisons of seasonal, live aboveground and belowground biomass among these sites were used to calculate potential organic matter deficits. The potential organic matter deficit was calculated by summing seasonal differences between the highly impacted site (CRMS0605-H) and the two other sites (CRMS0268-H and CRMS1277-H). We estimated a deficit of aboveground biomass at CRMS0605-H ranging between 2,091 and 2,915 g dry weight $\mathrm{m}^{-2}$ (figs. 32 and 33) and a belowground biomass deficit ranging between 3,385 and $8,814 \mathrm{~g}$ dry weight $\mathrm{m}^{-2}$ (figs. 34 and 35). Given the long interval of minimal plant production, a cumulative deficit of live biomass over the 2 years of storm recovery was estimated to be between 5,400 and $11,700 \mathrm{~g}$ dry weight $\mathrm{m}^{-2}$.

A potential loss of live belowground biomass over this period (calculation based on 5,400 $\mathrm{g}$ dry weight $\mathrm{m}^{-2}=$ organic matter deficit; soil density $=0.1 \mathrm{~g} \mathrm{~cm}^{-3} ; 32-\mathrm{cm}$ soil depth) 

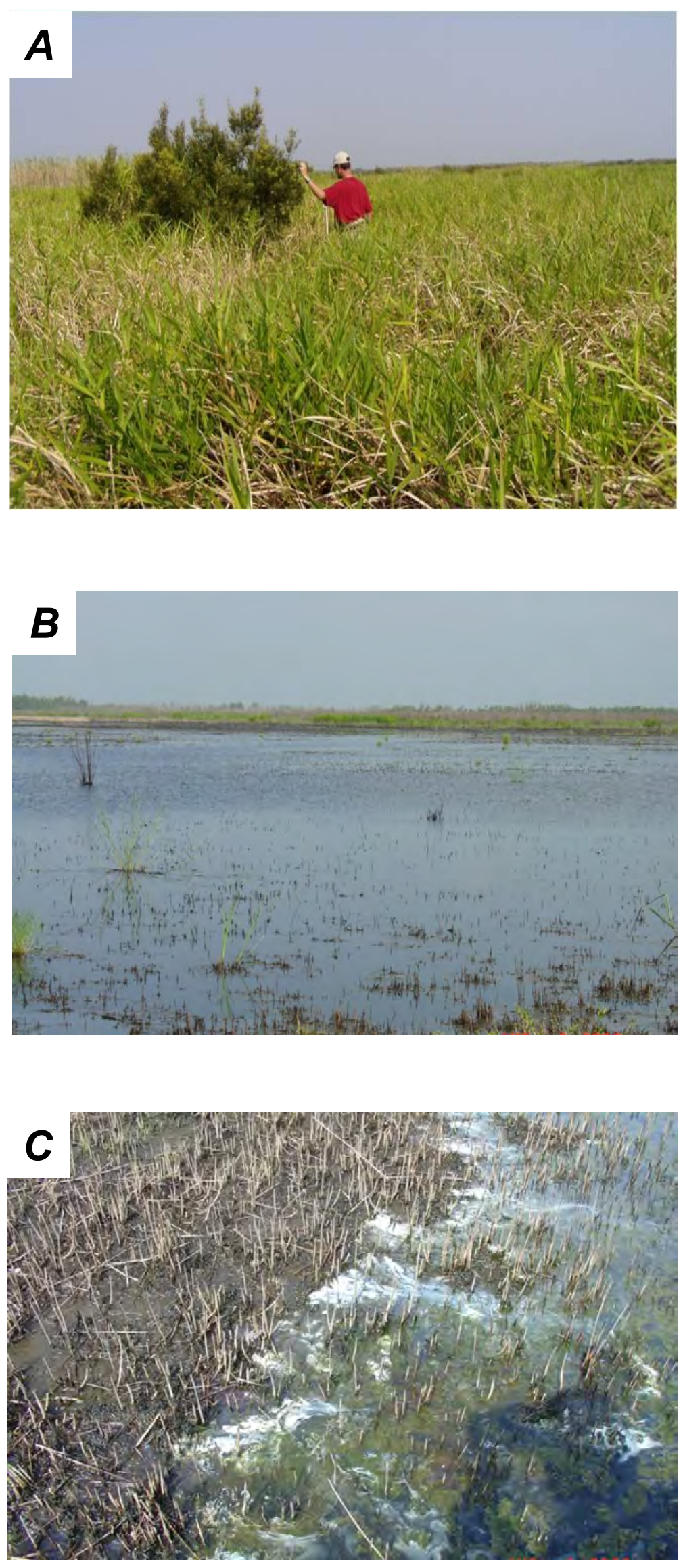

Figure 29. The plant community at Coastwide Reference Monitoring System (CRMS) site 0605-H before and after Hurricane Rita. A, Before Hurricane Rita the site was dominated by Panicum hemitomon (maidencane) which created a productive prairie that was mostly bouyant. Wax myrtle (Morella cerifera) and common reed (Phragmites australis) created moderate size patches. Clonal, salt intolerant species typically comprised the freshwater interior marsh community of the chenier plain (for definition, see Saucier, 1994). B, One year after Hurricane Rita there was extensive mortality of the marsh and limited plant recolonization due to a relatively high and lengthy residence of salt in the marsh peat. C, There was a potential loss of plant biomass over time. Limited plant recolonization resulted in a cumulative deficit of aboveground and belowground organic matter to the marsh over two years which is conservatively estimated at greater than 5,400 grams of dry weight per square meter. 

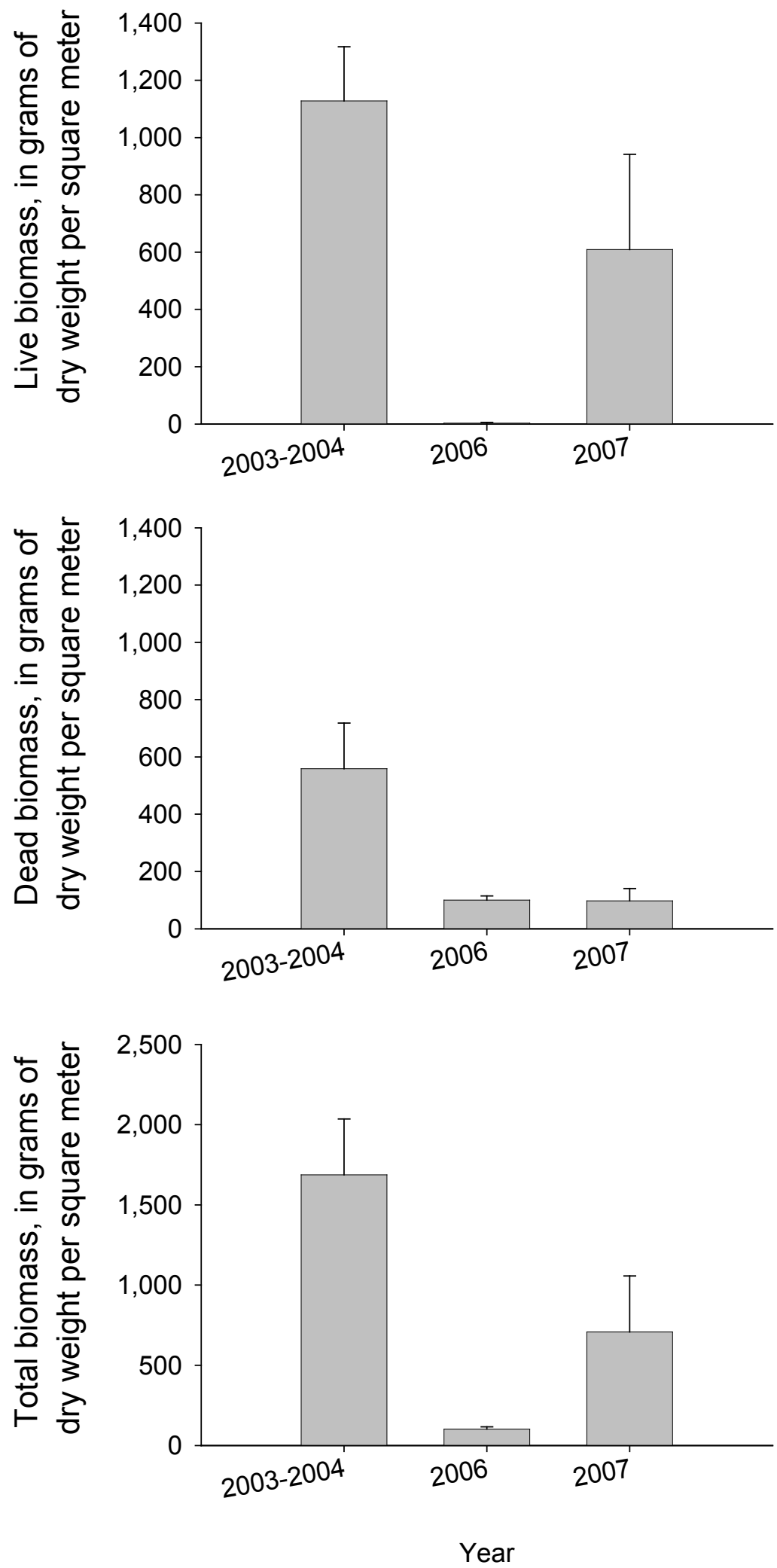

Figure 30. Aboveground live, dead, and total biomass (see standard error bars) at the end of growing seasons at Coastwide Reference Monitoring System (CRMS) site 0605-H before Hurricanes Katrina and Rita (mean values for 2003-4) and two years thereafter (in 2006 and 2007). There was complete mortality of the plant community at the study site vicinity shortly after the passage of Hurricanes Katrina and Rita from August to September 2005. Total biomass production by the end of 2007 was half that measured in 2003-4 before the storms. 


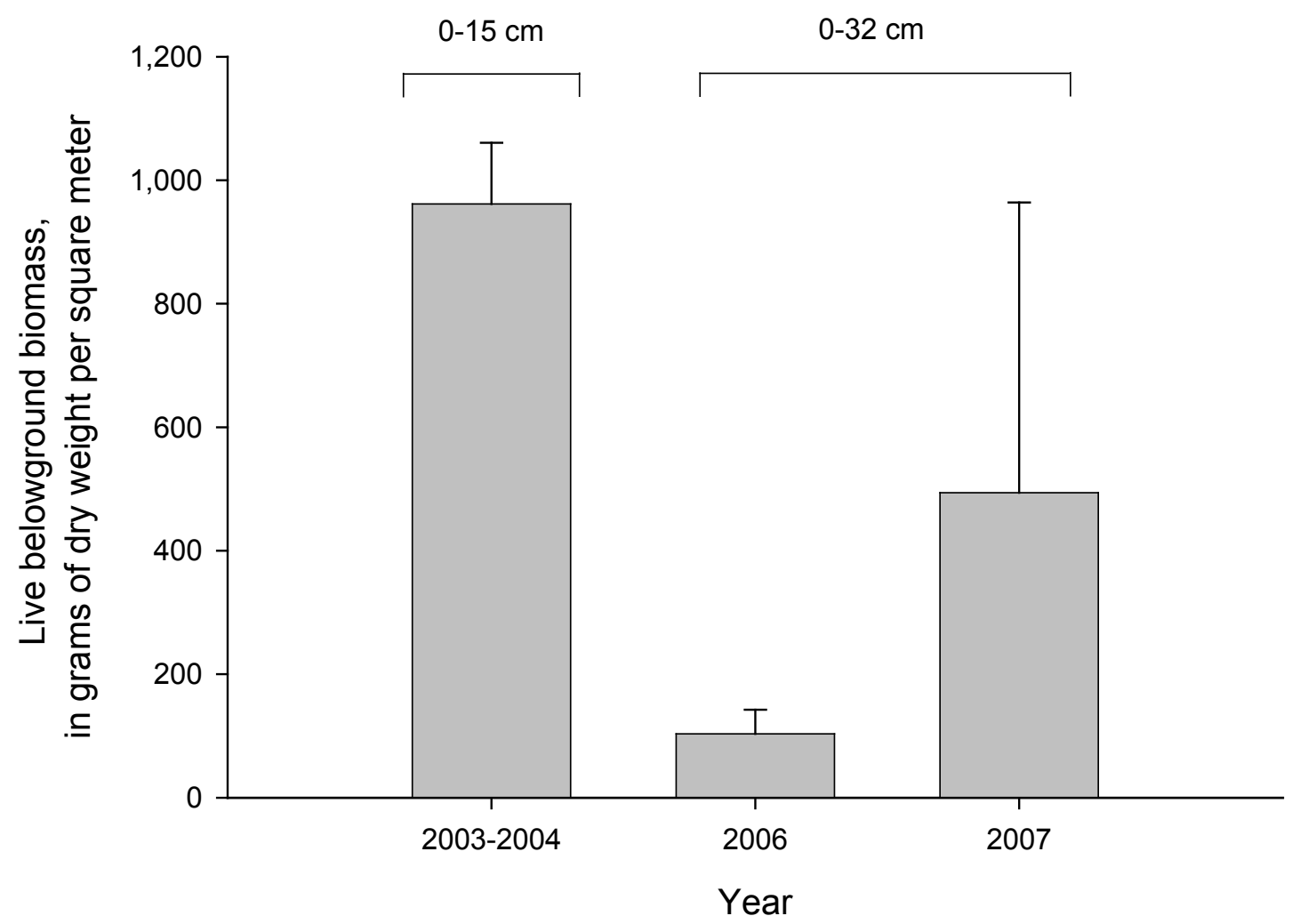

Figure 31. Live belowground biomass (see standard error bars) for Coastwide Reference Monitoring System (CRMS) site 0605-H at the end of growing seasons before Hurricane Rita (mean values for 2003-4) and two years thereafter (2006 and 2007). Prestorm data were based on the upper $15 \mathrm{~cm}$ of the soil, whereas poststorm data were based on the upper $32 \mathrm{~cm}$.

constitutes an 11 percent loss of soil mass, which corresponds to a vertical loss of soil elevation of approximately $3 \mathrm{~cm}$. This potential decrease in soil elevation, if the mat looses buoyancy in the future, has immediate and longer term implications for vegetation community change.

\section{Plant Community Change After the Storms}

Prior to Hurricane Rita, CRMS0605-H had a relatively rich plant community with about 18 herbaceous species in the general site area (300-m radius) (Holm and others, 2003). The most common species were $P$. hemitomon, Thelypteris palustris (eastern marsh fern), and M. cerifera. There were also patchy, discrete stands of $P$. australis and Schoenoplectus californicus (California bulrush). A few small $\left(<0.25 \mathrm{~m}^{2}\right)$ patches of $S$. patens were noted during the 2001-5 period; however, this species was never considered a significant component of the community. Based on harvest data over three years, $P$. hemitomon composed greater than 70 percent of the live biomass (Holm, 2006).

At the end of the first growing season after the storms, there was no plant recolonization of our pre-established harvest plots (fig. 36). This lack of recolonization was also reflected at the larger landscape level in the site-specific departure of $-0.19( \pm 0.05)$ from the average NDVI score, indicating that there was a decrease in vegetation vigor from the baseline condition. Also at the larger landscape level, however, the aforementioned sparse patches of $S$. patens were noticeably expanding. This was a rare opportunity to observe the guerrilla growth pattern of this species into a bare area with little competition. Clonal expansion advanced as long culms ( $>1.5 \mathrm{~m}$ ) lodged on the water/soil surface, followed by adventitious root and ramet sprouting at culm nodes (fig. 37). At the end of this first growing season after Hurricanes Katrina and Rita, small patches of Typha domingensis (southern cattail) and Paspalum vaginatum (seashore paspalum) were also expanding.

During winter 2007, we surveyed ten discrete patches of three species (S. patens, Typha spp., and P. vaginatum) to estimate clonal expansion rates. These patches were marked and their diameters measured along two right-angle transects during the February 2007 and May 2007 sampling periods. In most cases, the edge of the patch where culm bases met bare soil was fairly abrupt. By the 2007 summer sampling, edges of the patches had become sufficiently obscured by newly emerged seedlings, which precluded any further accurate measurements. Spartina patens and T. domingensis had similar rates of clonal expansion, such that within 70 days an increase of $10 \mathrm{~m}^{2}$ in area was observed, while Panicum vaginatum remained more compact and only increased by $3 \mathrm{~m}^{2}$ during this same time period (table 11). 


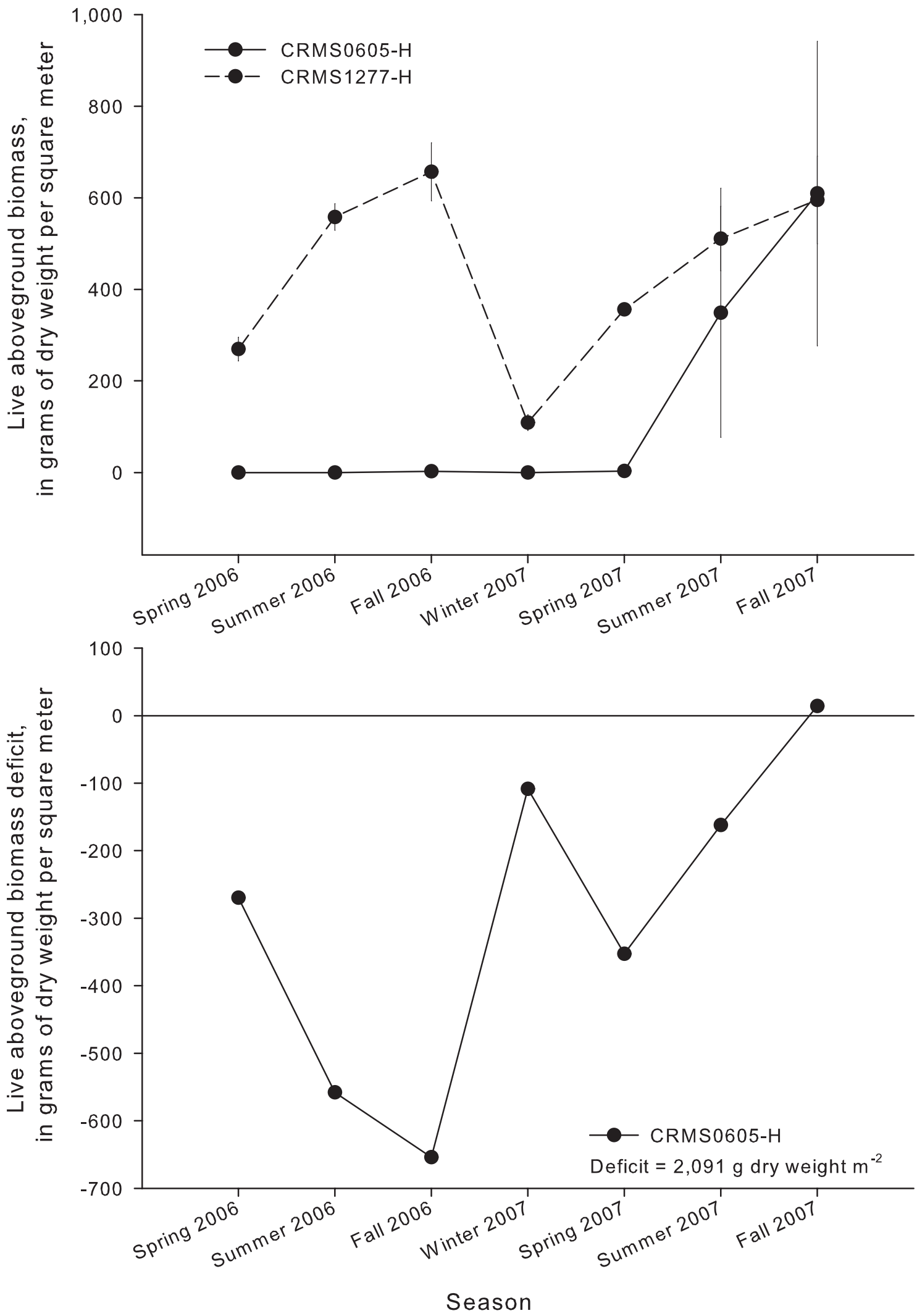

Figure 32. Live aboveground biomass at Coastwide Reference Monitoring System (CRMS) sites 1277-H and 0605-H. The CRMS1277-H site was exposed to marginally direct effects from Hurricane Rita, and CRMS0605-H was exposed to direct effects. The upper panel shows the seasonal time course of live aboveground biomass, with standard errors. The lower panel shows the seasonal deficit of live aboveground biomass at CRMS0605-H compared to CRMS1277- $\mathrm{H}$. Comparative recovery of aboveground biomass at CRMS0605-H took two full growing seasons. 

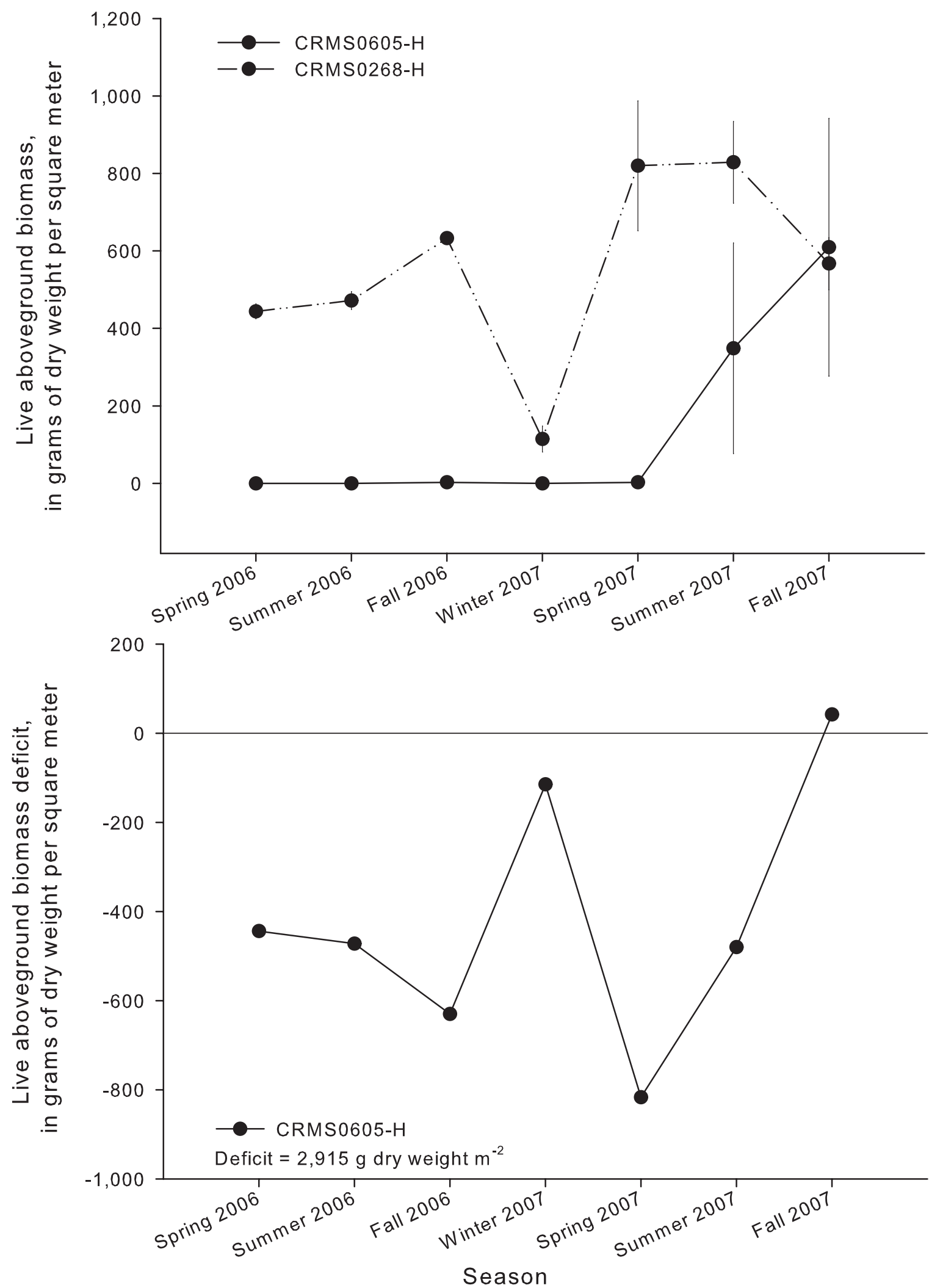

Figure 33. Live aboveground biomass at Coastwide Reference Monitoring System (CRMS) sites 0605-H and 0268- H. The CRMS0605-H site was exposed to direct effects of Hurricane Rita, and CRMS0268-H was exposed to indirect effects. The upper panel shows the seasonal time course of live aboveground biomass, with standard errors. The lower panel shows the seasonal deficit of live aboveground biomass at CRMS0605-H compared to CRMS0268- $\mathrm{H}$. Comparative recovery of the aboveground biomass at CRMS0605- $\mathrm{H}$ took two full growing seasons. 

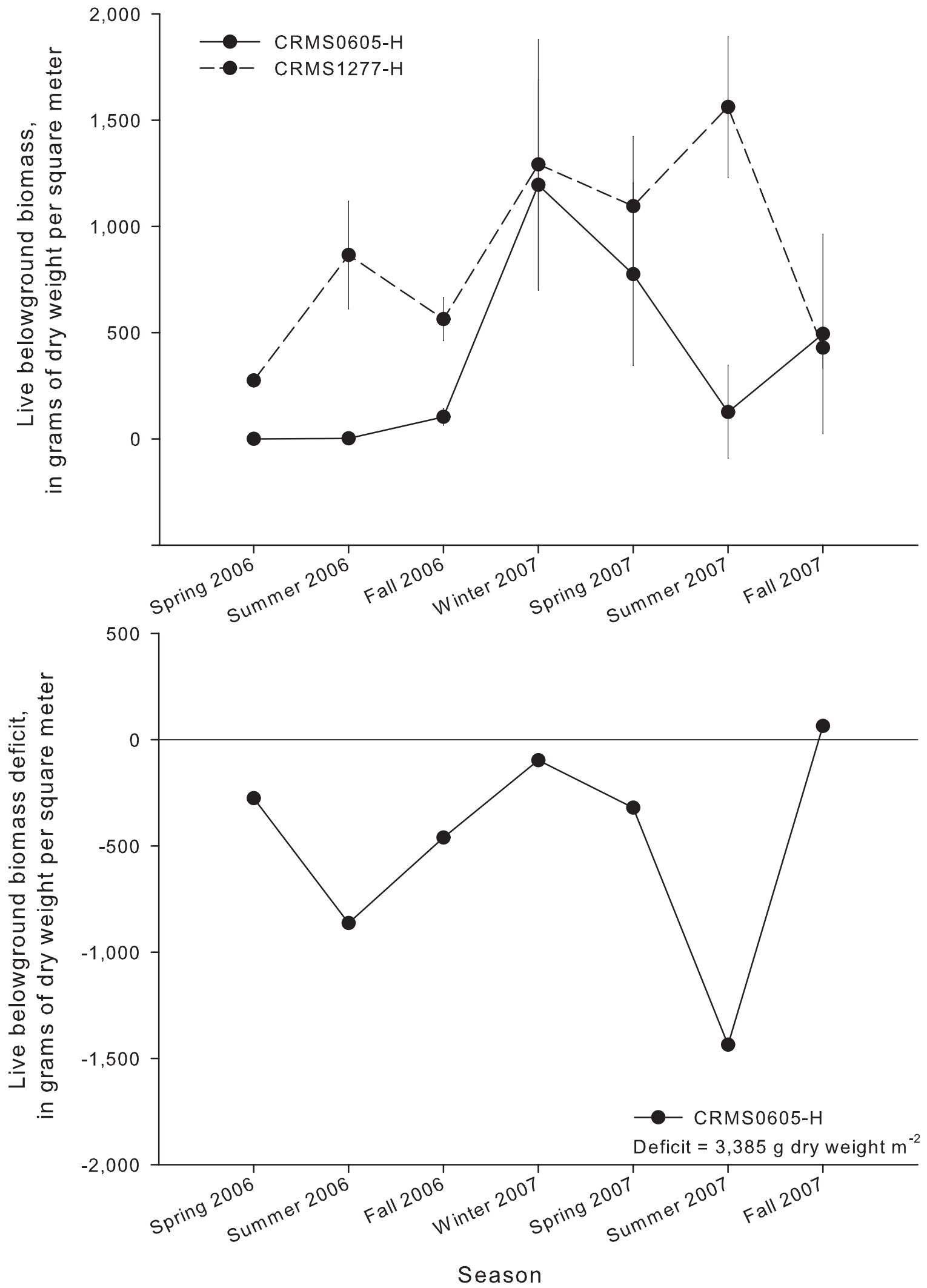

Figure 34. Live belowground biomass at Coastwide Reference Monitoring System (CRMS) sites 0605-H and 1277-H. The CRMS0605-H site was exposed to direct effects of Hurricane Rita, and CRMS1277-H was exposed to marginally direct effects. The upper panel shows the seasonal time course of live belowground biomass, with standard errors. The lower panel shows the seasonal deficit of live belowground biomass at CRMS0605- $\mathrm{H}$ compared to CRMS1277- $\mathrm{H}$. 


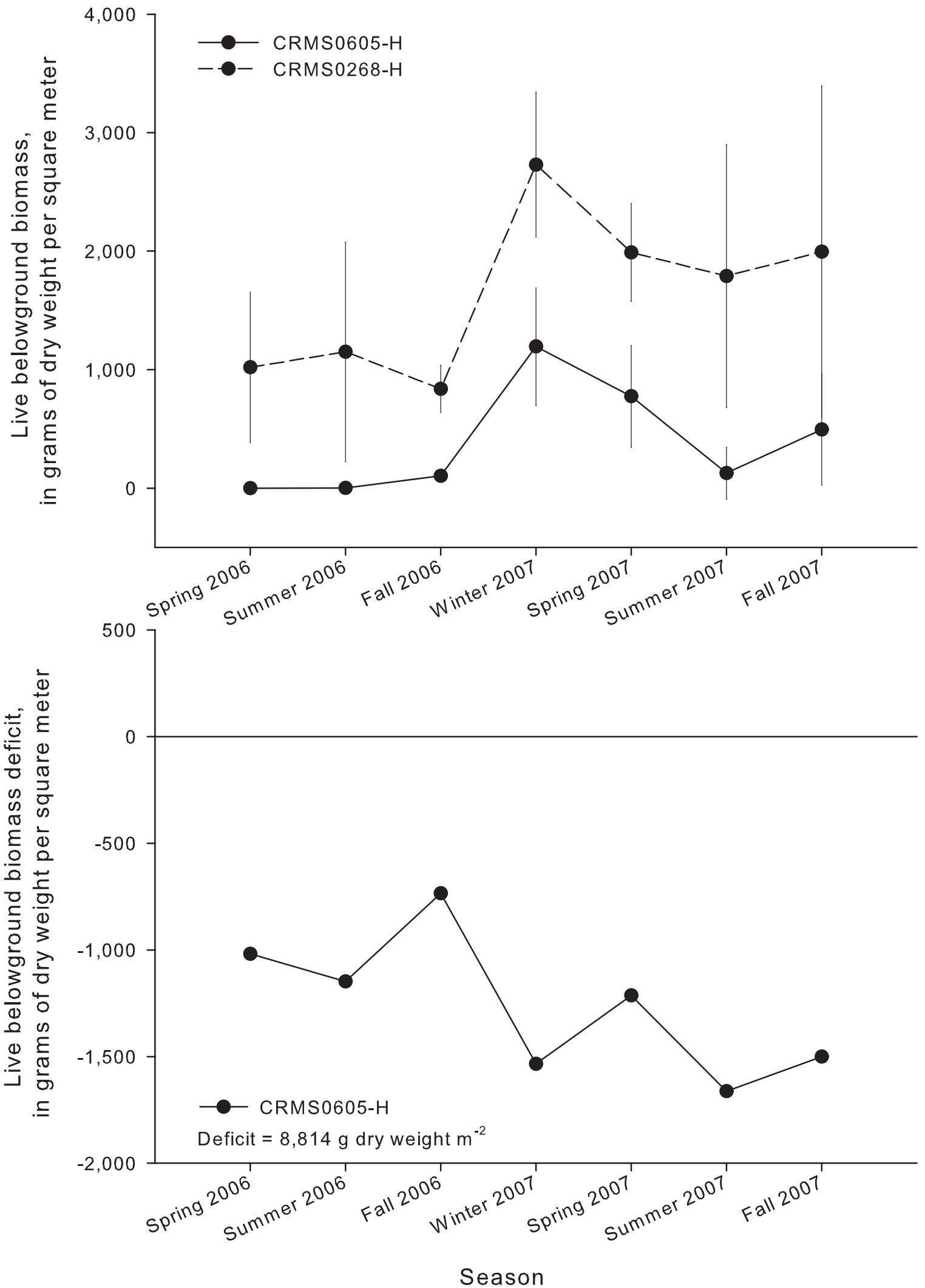

Figure 35. Live belowground biomass at Coastwide Reference Monitoring System (CRMS) sites 0605-H and 0268-H. The CRMS0605-H site was exposed to direct effects of Hurricane Rita, and CRMS0268-H was exposed to indirect effects. The upper panel shows the seasonal time course of live belowground biomass, with standard errors. The lower panel shows the seasonal deficit of live belowground biomass at CRMS0605-H compared to CRMS0268-H. 

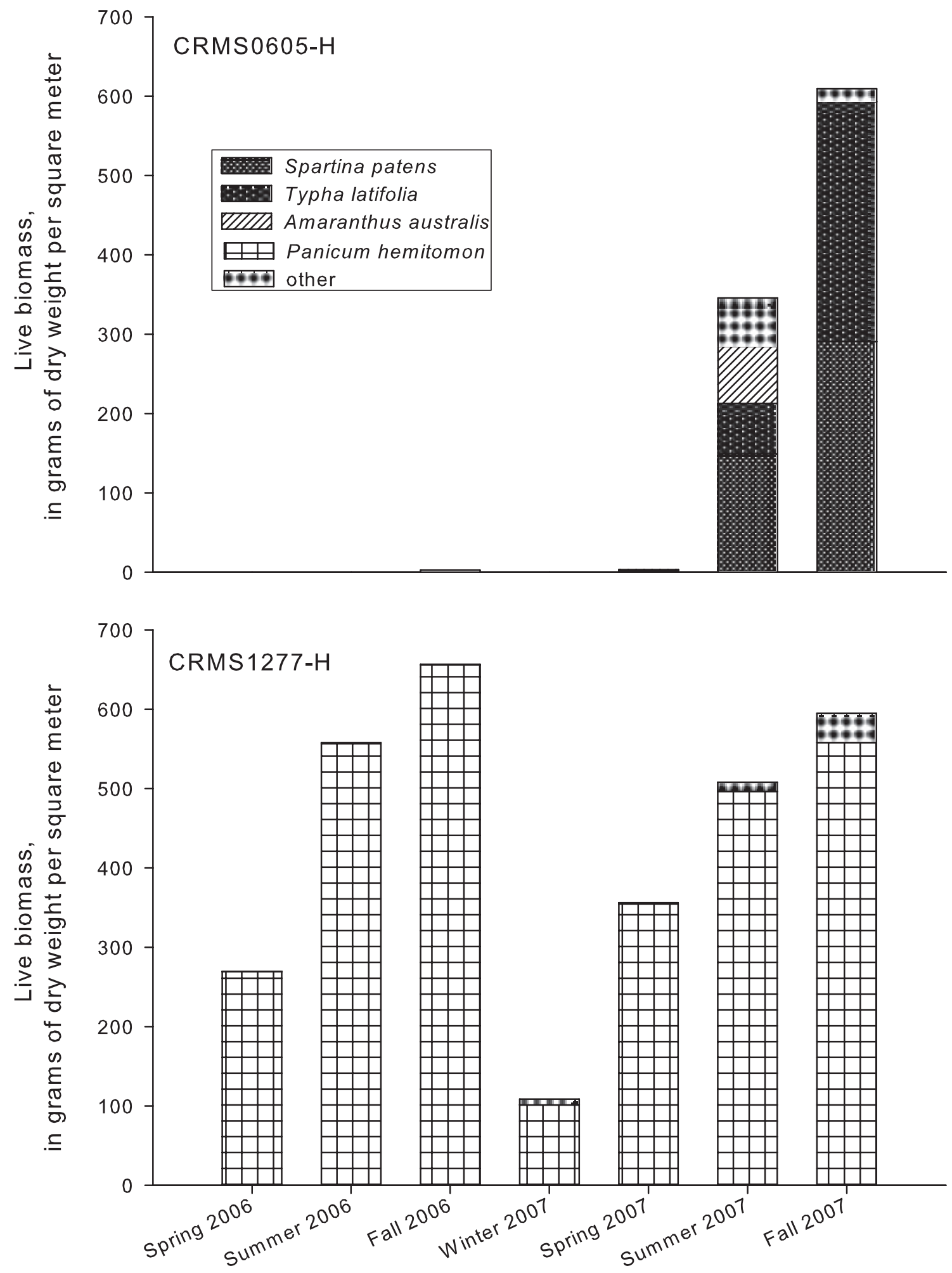

Season

Figure 36. Live aboveground biomass and species composition by season two years after Hurricane Rita. The upper panel shows Coastwide Reference Monitoring System (CRMS) site 0605-H, and the lower panel shows CRMS1277-H. The CRMS1277-H site serves as a comparison of low-level, short-duration salinity exposure associated with Hurricane Rita. Before the storm, these sites were comparable in terms of plant dominance and biomass of Panicum hemitomon. 

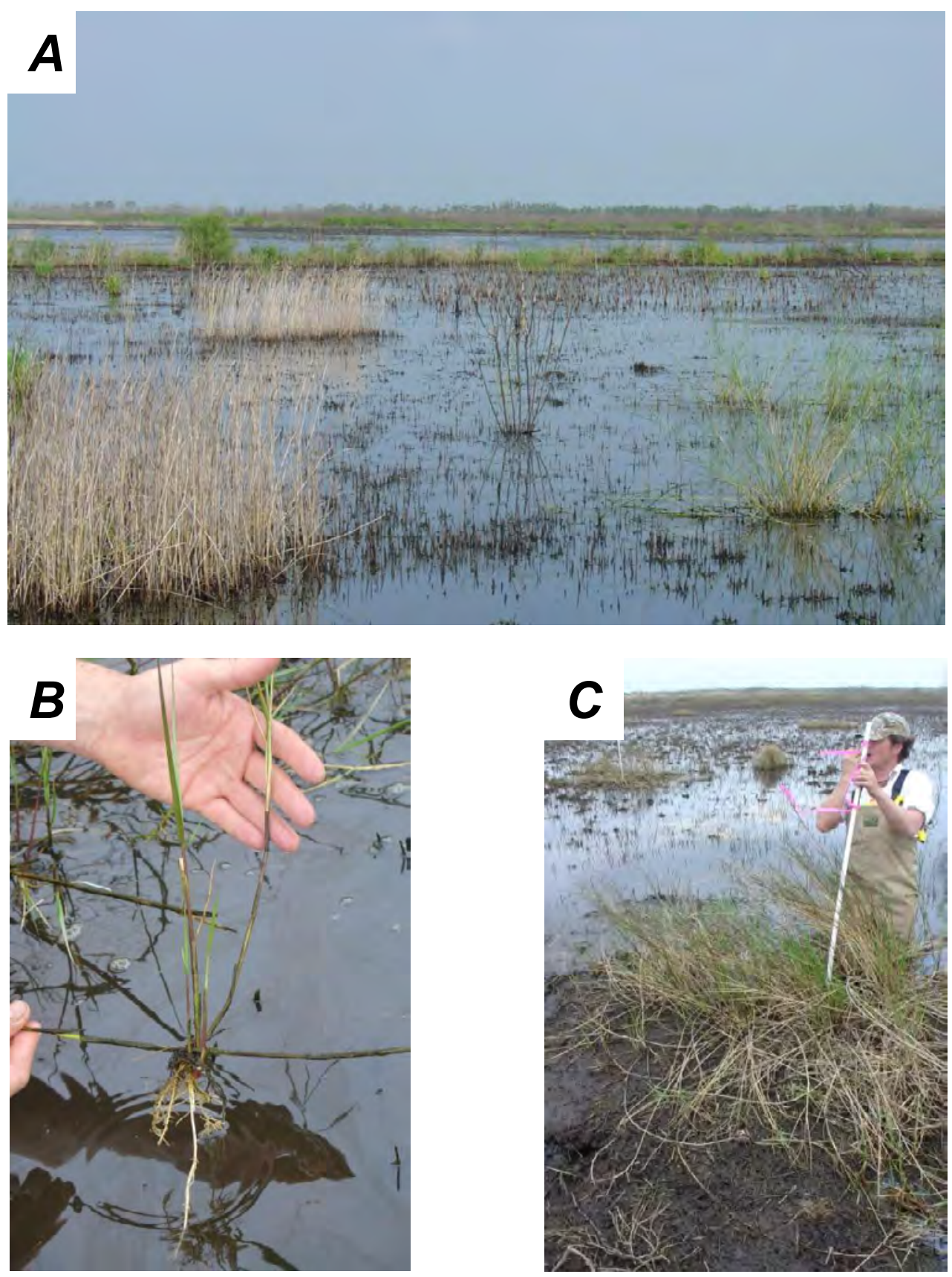

Figure 37. Characteristics of initial plant recolonization by clonal, patch-forming species prior to the seedbank release of annual species at Coastwide Reference Monitoring System (CRMS) site 0605-H. A, Early phase of marsh recolonization. The clonal species responsible for initial site recolonization consisted mostly of Spartina patens, Typha domingensis, and Paspalum vaginatum (photo is from early August 2006). B, Spartina patens. Given its salt tolerance, this species was capable of rapid expansion in bare areas. Unlike its characteristic tussock growth form, Spartina patens initiated a guerrilla growth pattern where culms lodged in open water, sprouted adventitious roots and daughter ramets at its nodes, and created self-sustaining plantlets over one meter away from the parent plant. $C$, Measuring clonal expansion rates. We followed the expansion rates of three different clonal species that formed discrete patches. In approximately 2 months, Spartina patens and Typha domingensis increased by an average of $10 \mathrm{~m}^{2}$ in coverage (table 11). 
Table 11. Changes in clonal expansion of ten monospecific patches of three species observed at Coastwide Reference Monitoring System 0605-H on February 28 and May 9, 2007. The area was estimated by patch diameter on two right-angle axes. By summer 2007 sampling, almost complete coalescence among patches had occurred, indicating an exponential expansion of both clonal growth and widespread seedbank germination.

$\left[\mathrm{m}^{2}\right.$, square meter; NA, not appicable]

\begin{tabular}{lcccccc}
\hline \multicolumn{1}{c}{ Species } & $\begin{array}{c}\text { Feb. 28 area } \\
\left(\mathbf{m}^{2}\right)\end{array}$ & $\begin{array}{c}\text { May } \mathbf{9} \text { area } \\
\left(\mathbf{m}^{2}\right)\end{array}$ & $\begin{array}{c}\text { Increase in } \\
\text { area }\left(\mathbf{m}^{2}\right)\end{array}$ & $\begin{array}{c}\text { Increase in } \\
\text { area }(\%)\end{array}$ & $\begin{array}{c}\text { Mean increase } \\
\left(\mathbf{m}^{2}\right)\end{array}$ & $\begin{array}{c}\text { Mean increase } \\
(\%)\end{array}$ \\
\hline Typha domingensis & 3.3 & 16.0 & 12.7 & 378 & $\mathrm{NA}$ & NA \\
& 7.8 & 15.0 & 7.2 & 91 & 9.9 & 235 \\
Spartina patens & 6.5 & 18.5 & 12.0 & 184 & $\mathrm{NA}$ & NA \\
& 3.9 & 13.7 & 9.7 & 250 & $\mathrm{NA}$ & $\mathrm{NA}$ \\
& 1.9 & 9.5 & 7.6 & 411 & $\mathrm{NA}$ & $\mathrm{NA}$ \\
& 3.8 & 12.9 & 9.1 & 235 & $\mathrm{NA}$ & $\mathrm{NA}$ \\
& 10.2 & 21.2 & 11.0 & 107 & $\mathrm{NA}$ & NA \\
& 5.8 & 18.1 & 12.3 & 213 & 10.3 & 234 \\
\end{tabular}

The summer of 2007 (23 months after Hurricane Rita) marked a threshold when visual landscape recovery was discernable (fig. 38). Widespread germination of the seed bank, in addition to an apparent exponential rate of clonal expansion, contributed to extensive plant coverage. The primary factors facilitating this rapid recolonization during the second growing season included (1) time since storm disturbance, which increased the likelihood of new seed recruitment/dispersal; (2) decreasing porewater salinity; (3) the onset of the growing season; and (4) subaerial emergence of peat mat as it became bouyant.

\section{Discussion}

In this case study, we documented the early stages of community succession following protracted salt exposure to a freshwater community. The widespread mortality of the plant community and its slow recovery serves as an extreme point in a continuum of storm impacts due to salt exposure. After 18 months of bare peat exposure, we found that neither community composition nor the standing stock of live biomass had returned to prestorm conditions. We observed a predictable shift to a more salt-tolerant assemblage. Predicting the trajectory of the future recovery for these wetland types is highly speculative. Nonetheless, it is worthwhile to discuss possible outcomes based on our knowledge of similar historical impacts.

After Hurricane Audrey in 1957, Valentine (1976) conducted a long-term, poststorm plant survey of marshes just north of Lake Misere, which is in the general vicinity of CRMS0605-H. His yearly surveys were done from 1958 to 1967 and again in 1972 and 1974. Direct comparisons concerning the prestorm community in relation to poststorm community changes are not appropriate between this study and Valentine's, because there was a lack of specific community information for his study area. We only know it was a freshwater marsh impacted by salt exposure. At the beginning of his survey in July 1958, one year after the storm, Valentine observed that, the marsh appeared devoid of vegetation, which translated into an open water/bare soil estimate of 86 percent across 5,900 m of transect lines. After 5 years, the open water/ bare soil coverage had dramatically decreased to 18 percent (fig. 39). Sagittaria lancifolia (bulltongue) was the species responsible for recolonization of Valentine's study area. Interestingly, he never documented the presence of Typha spp. in his surveys. By the end of 1974, the community largely represented a freshwater, wet-prairie assemblage, including species capable of withstanding moderately deep flooding like Eleocharis quadrangulata (squarestem spikerush), Eleocharis equisetiodes (jointed spikerush), Pontederia cordata (pickerelweed), and two species within the family Nymphaeaceae.

Valentine largely attributed the demise of C. mariscus ssp. jamaicense (Jamaica sawgrass) in southwestern Louisiana to salt exposure from Hurricane Audrey (1957) and the subsequent 5 years of local drought. Within the past 10 years, Jamaica sawgrass has made a noticeable re-expansion in many of the freshwater areas of the chenier plain. To what degree the landscape loss of Jamaica sawgrass can be correlated with the saltwater impacts from Hurricane Audrey is uncertain. It is plausible, however, that major events like hurricanes can radically change a community, such that the possibility of its return to pre-event condition is unlikely or indefinitely extended (fig. 40). Major climate events such as tropical storms and local drought (Visser and others, 2002) may act as 


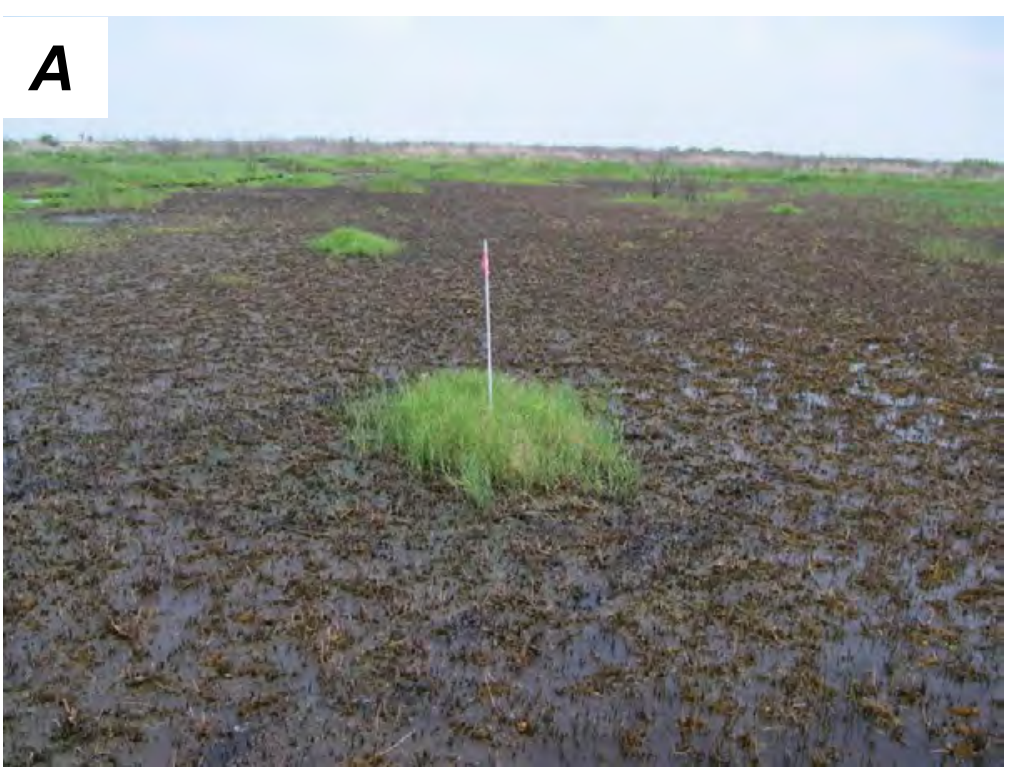

B
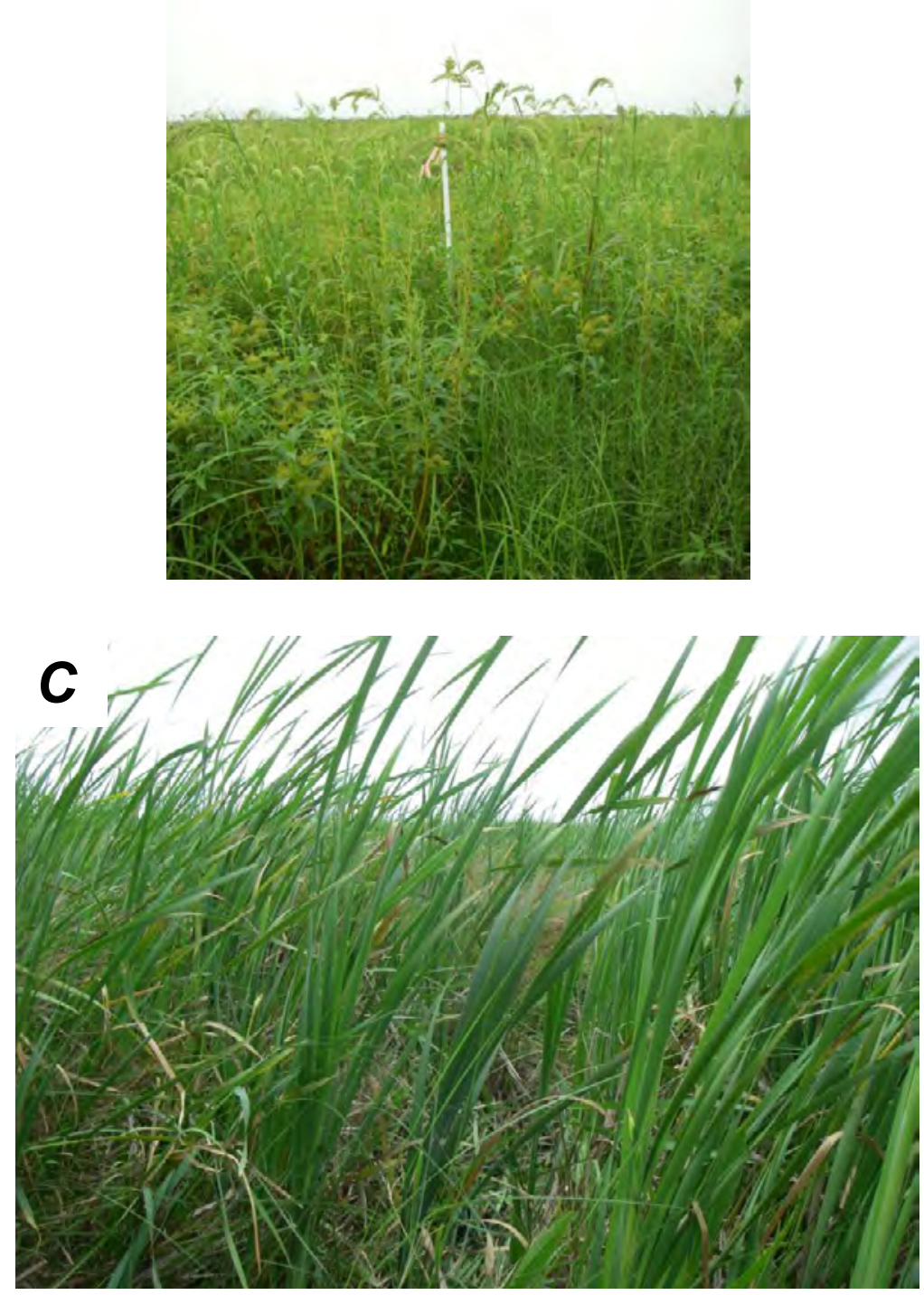

Figure 38. A description of plant community change at Coastwide Reference Monitoring System (CRMS) site 0605-H following Hurricane Rita. A, Sequence of community change. Beginning in the spring 2007, small patches of clonal species began the noticeable expansion across the bare peat surface (photo from early May 2007). B, Release of the seedbank. By summer 2007, an immense response of the seedbank was evident, such that most of the bare peat was colonized; at this time the peat mat had emerged from the water surface. Seedbank species included Echinochloa walteri, Cyperus spp., Eleocharis spp., Amaranthus spp., and Typha domingensis (photo from late June 2007). The delay in seedbank response was likely due to the combination of elevated salinity, mat submergence, and dispersal limitation. C, Community development. By spring 2008, seedbank annuals were replaced by Typha domingensis and Typha latifolia. At a landscape scale, the fresh to intermediate marsh community zones of the chenier plain (for definition, see Saucier, 1994) have been invaded by these two species, which has taken three years. These community types are subject to relatively rapid change and may be considered ephemeral alternate states. The possibility exists that such massive disturbances preclude a return to an original state. 


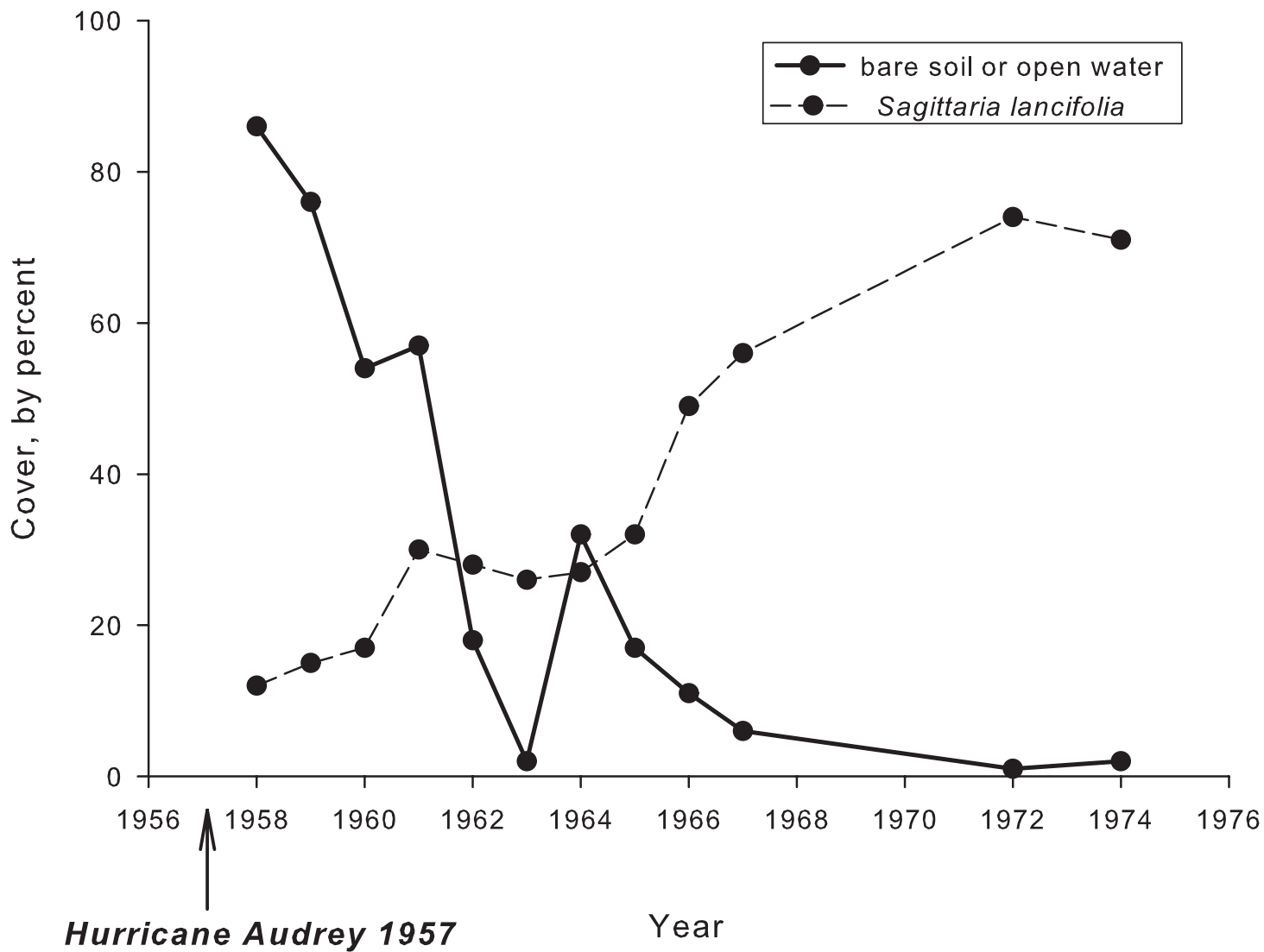

Figure 39. Vegetation in marshes north of Lake Misere (see fig. 27), near Coastwide Reference Monitoring System (CRMS) site 0605$\mathrm{H}$, based on the research of Valentine (1976), who conducted plant surveys after Hurricane Audrey (1957). One year after Hurricane Audrey, Valentine noted that the marsh was devoid of vegetation. The return to a relatively stable plant assemblage occurred within 5-8 years, when the perennial Sagittaria lancifolia became the dominant plant. Other species observed along the 5,900 $\mathrm{m}$ of transect plots exemplify a wet prairie community made up of floating-leaved aquatics (Nymphaeaceae), Eleocharis quadrangulata, and Eleocharis equisetoides.

the primary control on long-term wetland community change, while the type and intensity of hydrologic manipulation is likely the secondary control that determines the rates of community recovery during the intervening periods between episodic events. The CRMS0605-H site may serve as an important ongoing study site to understand how freshwater communities may recover over longer time periods and how resilient they are to future disturbance events.

\section{Case Study 2: CRMS0135}

\section{Overall Site Description}

The CRMS0135 site is located in middle Breton Sound approximately halfway between Oak River to the west and Bayou Terre Aux Boeufs to the east (N 29 41.193', W89 $9^{\circ} 45.628^{\prime}$, fig. 41). The site is south of Shell Lake and north of Lake Fausan, on a relic of a natural bayou. The closest town, Delacroix Island, is approximately $8.8 \mathrm{~km}$ northwest of the site. The marsh in this area is fragmented, with an abundance of natural bayous and oil and gas canals traversing the area. The site is less than $0.3 \mathrm{~km}$ west of an oil and gas canal that runs directly from Lake Lery to Bay Gardene through Grand Point Bay. Water is freely exchanged, with no impoundments or weirs nearby. The CRMS0135 site was classified as being in the direct area of impacts from Hurricanes Katrina and Rita because the eye of Hurricane Katrina passed approximately $14 \mathrm{~km}$ east of the site, and storm surge in the area was estimated at $5.2 \mathrm{~m}$ (Federal Emergency Management Agency, 2006). When sampling began in spring 2006, there were visible signs of physical disturbance to the marsh surface. In some locations, wrack and multiple layers of vegetation and soil were stacked on top of each other, and in other locations the vegetation had been removed, leaving divots or holes in the marsh surface. In July 2005, prior to 

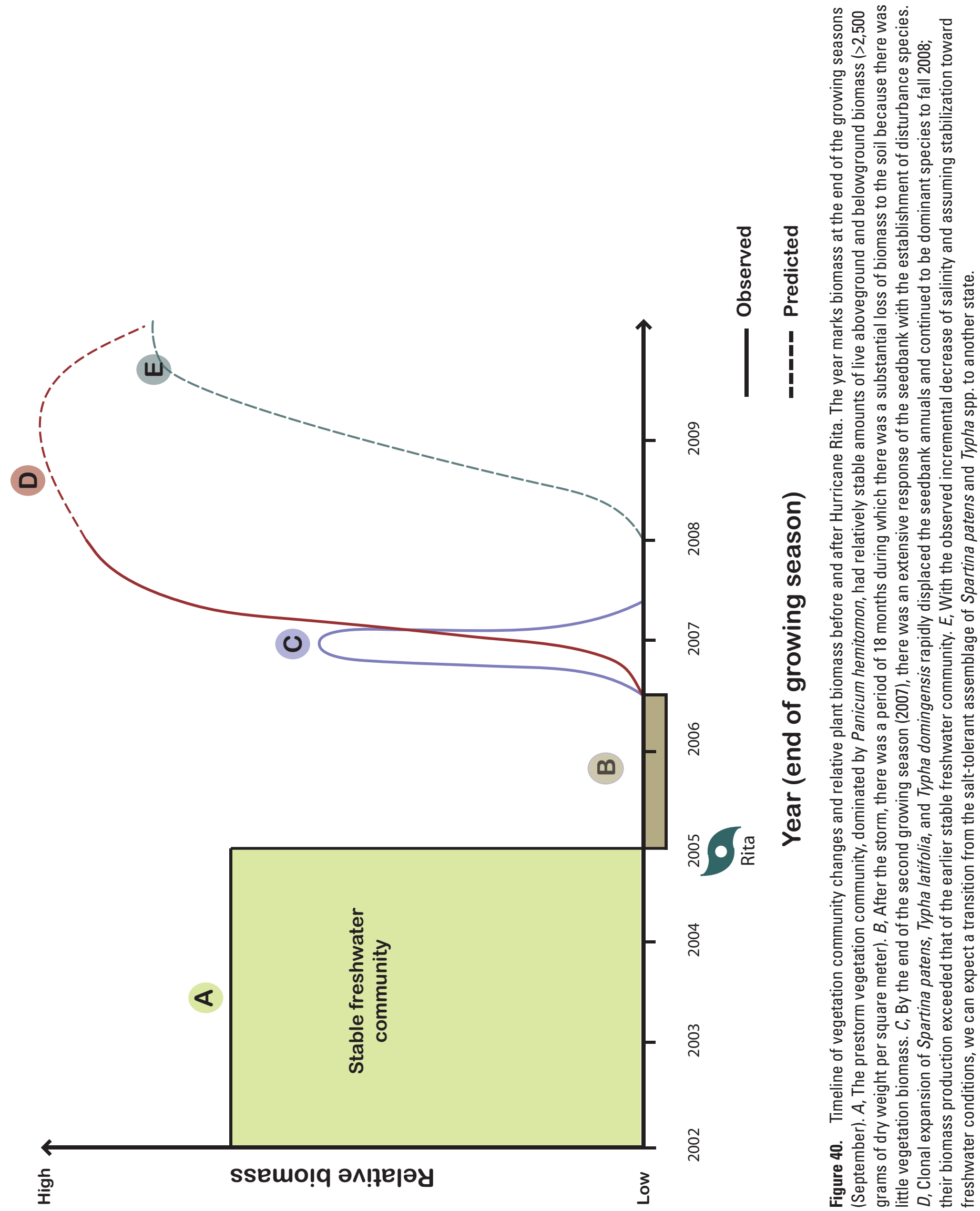

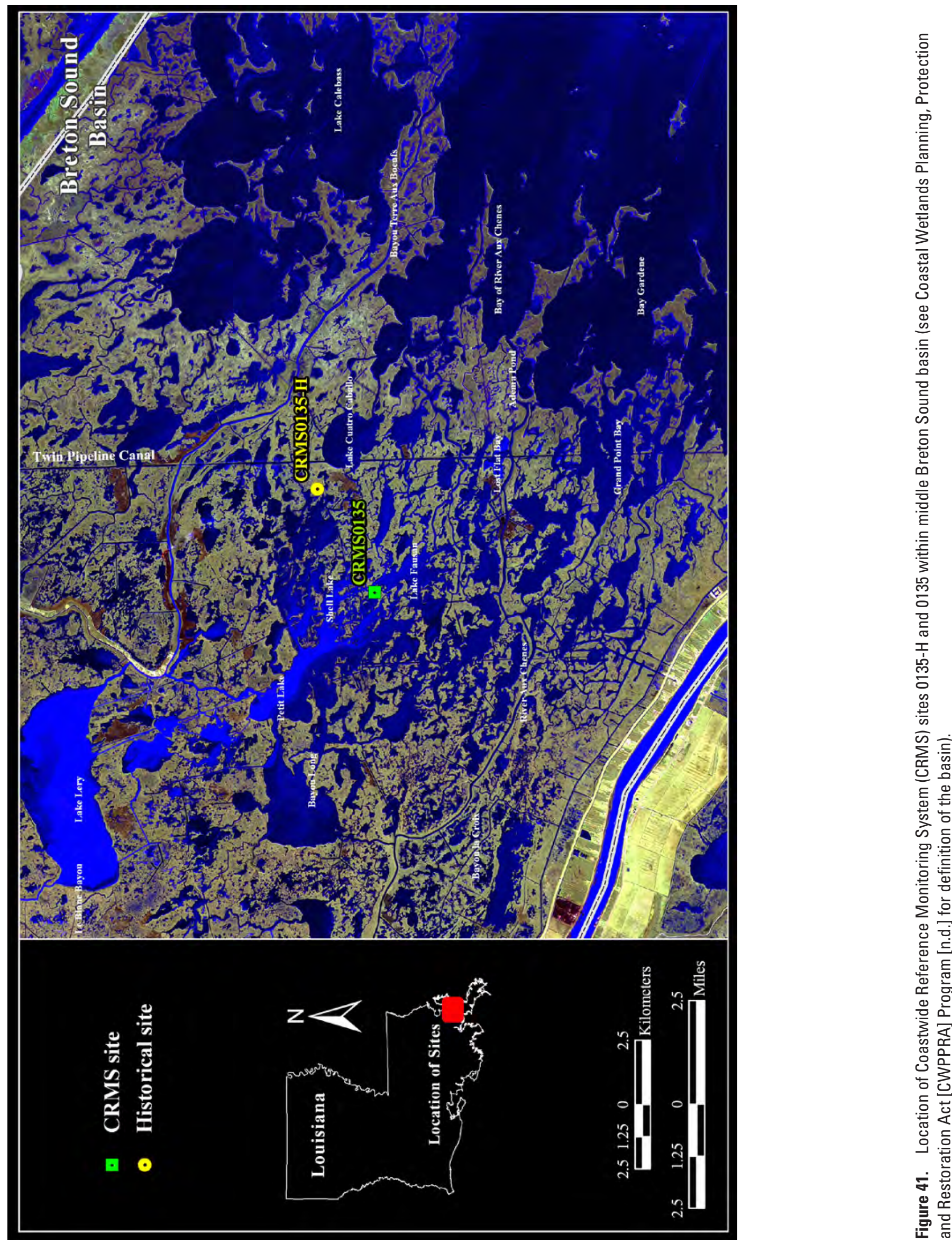
Hurricane Katrina, the site was dominated by S. patens and V. luteola (CRMS Preliminary Site Visit Report, unpub. data); however, in spring 2006, the dominant vegetation species was A. australis, an annual that colonizes disturbed areas (table 5). This site is part of the CRMS network; therefore, additional data beyond our samplings were incorporated into this report. The CRMS supplementary data (unpublished) include continuous hourly hydrographic data, discrete porewater data, vegetation survey data, and photo documentation acquired before the hurricanes. Estimates of aboveground biomass at the end of growing seasons in 2000 and 2001 were provided by Dr. John Day of Louisiana State University from a nearby study site (written commun.).

The CRMS0135 site was classified as brackish/ intermediate marsh habitat. In July 2005, the site had consolidated soils typical of that marsh type and fairly complete vegetation cover. When this study began in spring 2006, the marsh was covered with multiple layers of wrack and storm-deposited material, and minimal live vegetation was present other than single-stemmed annuals (fig. 42).

\section{Surface-Water and Porewater Salinities}

Surface-water salinity throughout the study was typical of brackish/intermediate marshes and ranged from 0.2 to 13.9. Average surface-water salinity in the bayou adjacent to CRMS0135 was $2.82( \pm 0.12)$ and was greatest from summer through fall 2006 and lowest from winter through summer 2007 (fig. 43). The only time the marsh surface was flooded $(2 \mathrm{~cm})$ during the quarterly sampling visits was in spring 2007 . Although continuous hydrographic data are available for the site, marsh elevation data are not currently available, so depth, duration, and frequency of marsh-surface flooding could not be included.

Porewater salinity ranged from 1.2 to 10.1 throughout the study, averaging $5.47( \pm 0.55)$. In late October 2006, porewater salinity was elevated for this habitat type, measuring 10.1, which is greater than the mean value reported for brackish marsh salinity (8.2) by Chabreck (1972) and significantly greater than all other sampling periods $(\mathrm{p}<0.0001)$. By spring 2007, porewater salinity decreased to ranges typically found in brackish/intermediate marshes. Elevated porewater salinity, in addition to hurricane-induced physical disturbance of the marsh, likely contributed to the changes in vegetation species composition at CRMS0135, which are described below.

\section{Vegetation Cover}

Live vegetation cover was lowest in spring 2006 and winter 2007 (fig. 44). In addition to the low cover (55 percent) in spring 2006, the species present were largely disturbance species, A. australis and V. luteola (fig. 44). Cover of these two species remained high through summer 2006, composing 95 percent of the total live cover. Disturbance species

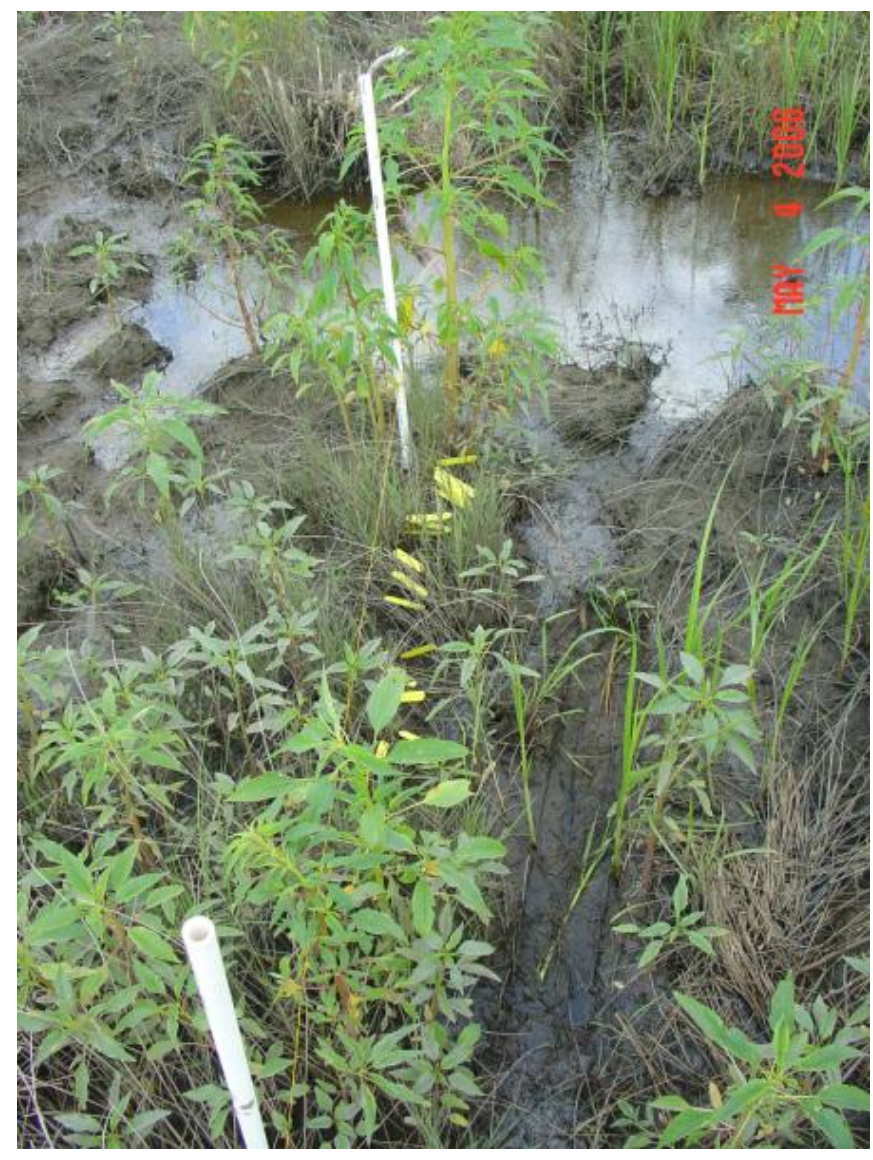

Figure 42. Coastwide Reference Monitoring System (CRMS) site 0135 on May 4, 2006, after Hurricanes Katrina and Rita. Multiple layers of wrack and storm deposited material, and single-stemmed annual vegetation colonized the area.

continued to contribute substantially to the total live cover through fall 2007. The initial large contribution of A. australis to the total cover during the first growing season after Hurricanes Katrina and Rita was replaced with an increase in $V$. luteola in the second growing season after the hurricanes. By fall 2007, S. patens, the dominant species before the hurricanes, comprised 35 percent of the total cover, although 65 percent of the total cover remained composed of disturbance species.

Minimal live vegetation was observed at the site during construction of the CRMS project in early November 2005 (fig. 45). Some of the dieback is assumed to be related to seasonal changes, but one would expect some living and standing dead vegetation to remain in early November in a typical growing season of marsh dominated by $S$. patens. We believe the lack of live vegetation was likely related to hurricane-induced physical disturbance and salt stress that remained 2 months after Hurricane Katrina (see fig. 43 


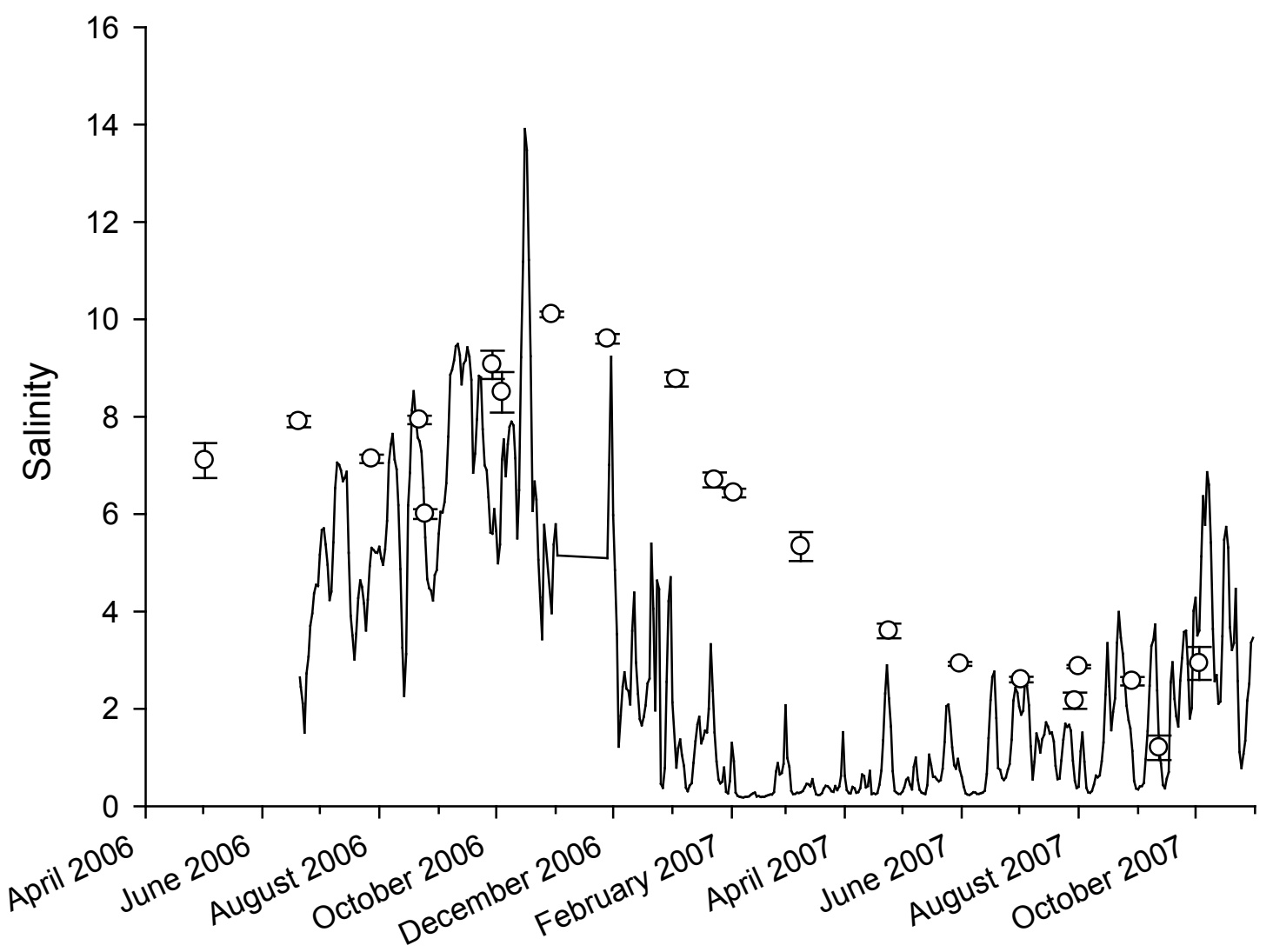

Figure 43. Mean values of daily surfacewater (solid line) salinity and discrete porewater (open circles) salinity at $30 \mathrm{~cm}$ deep from April 2006 to November 2007 at Coastwide Reference Monitoring System (CRMS) site 0135.

\section{Date}

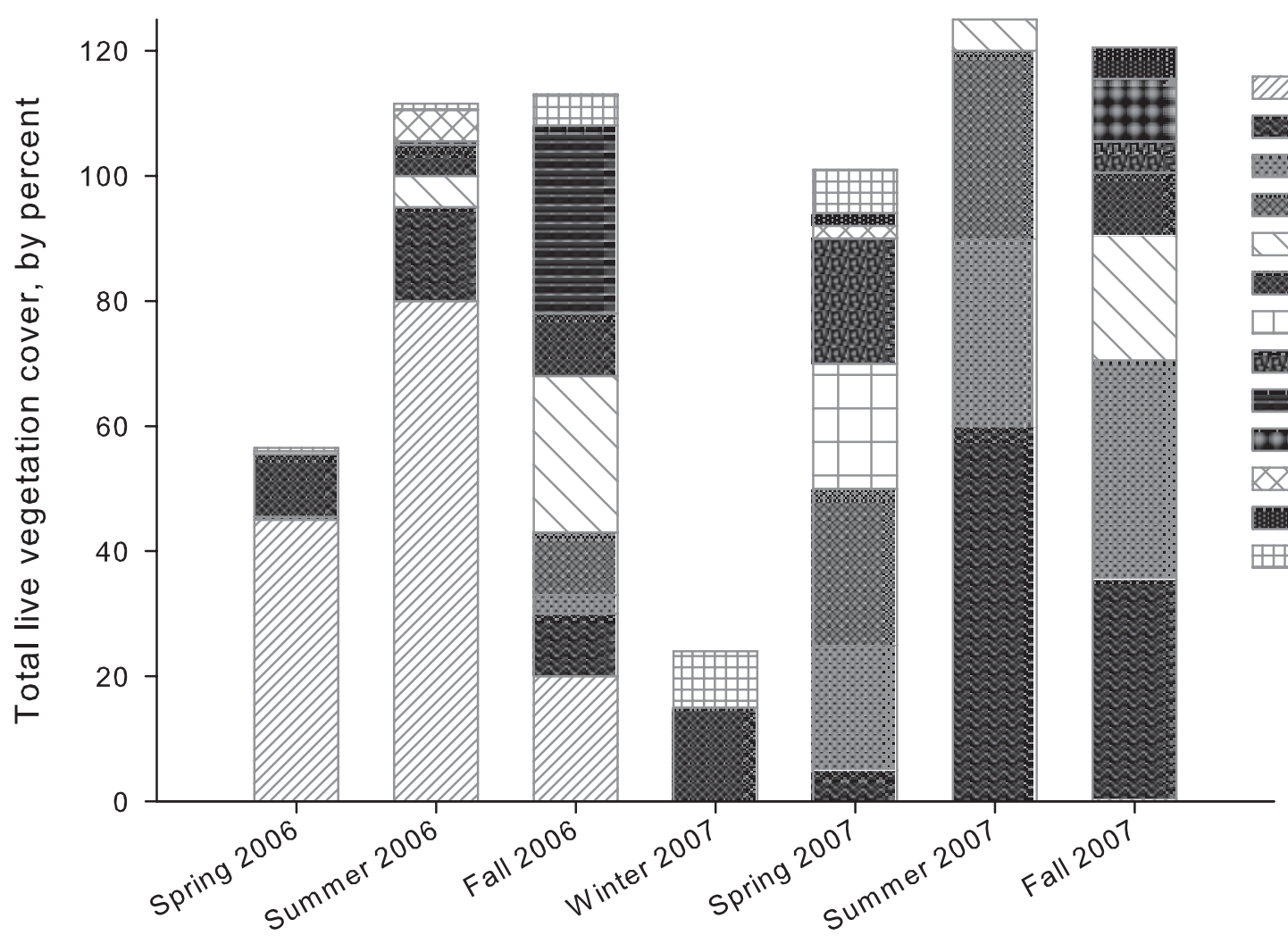

EXPLANATION

IIII Amaranthus australis

Vigna luteola

Spartina patens

Schoenoplectus robustus

Echinochloa spp.

Distichlis spicata

Paspalum vaginatum

Lythrum lineare

Panicum virgatum

Panicum dichotomiflorum

Eleocharis spp.

Polygonum spp.

Other

Figure 44. Seasonal species composition of total live vegetation cover at Coastwide Reference Monitoring System (CRMS) site 0135. 


\section{A}
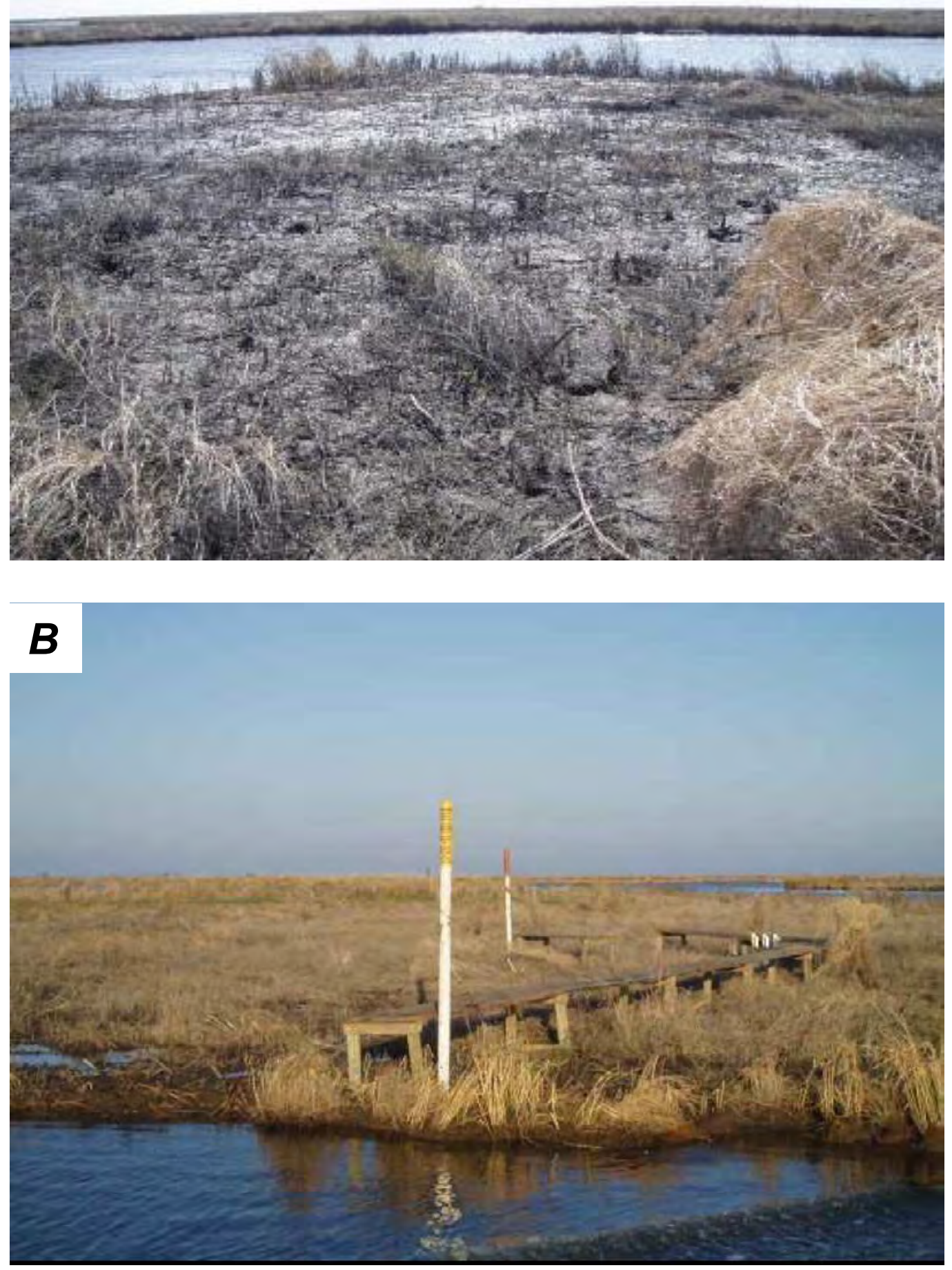

Figure 45. Coastwide Reference Monitoring System (CRMS) site 0135 after Hurricanes Katrina and Rita. $A$, Photograph taken on October 25, 2005. B, Photograph taken on November 8, 2005, of the boardwalk and surrounding marsh. 
for salinity data). By the initiation of our study in spring 2006, live vegetation was present but was largely composed of disturbance species rather than S. patens (fig. 46). The presence of disturbance species continued throughout the study period.

\section{Aboveground and Belowground Biomass}

Before Hurricanes Katrina and Rita, measurements of biomass were collected approximately $5 \mathrm{~km}$ northeast of CRMS0135 at the end of growing seasons during fall 2000 and 2001 (J. Day and others, unpub. data, 2007). The historical site (sampled by Day; N29.7006 ${ }^{\circ}, \mathrm{W} 89.7102^{\circ}$ ) is located in the marsh near the northwest corner of Lake Cuatro Caballo (locally known as Four Horse Lake; see fig. 41) and adjacent to the northern intersection of the twin pipeline canal and Four Horse Lake. The mean value of live biomass at the end of growing seasons was $981.6( \pm 411.2)$ dry weight $\mathrm{m}^{-2}$ in 2000 and 1,233.2 ( \pm 150.1$) \mathrm{g}$ dry weight $\mathrm{m}^{-2}$ in 2001 (fig. 47). In fall 2006 live biomass at the end of the growing season was significantly lower at CRMS0135 than at the historical site before the hurricanes ( $\mathrm{p}=0.0117$, fig. 47$)$; however, in fall 2007 live biomass was similar to fall 2000.
Throughout the course of this study, aboveground biomass followed seasonal trends, with decreased live biomass in winter and increased live biomass in summer and fall (fig. 48). Live aboveground biomass increased greatly from spring 2006 to summer 2006, but this increase was due to the presence of two disturbance species, A. australis and Echinochloa crus-galli (barnyard grass) (figs. 49 and 50). Both of these species are annuals, and A. australis can produce large amounts of biomass in one growing season (Wunderlin and Hansen, 2003). In the second growing season after the hurricanes, A. australis was not present, but two other disturbance species, $V$. luteola and Panicum dichotomiflorum (fall panic), were present, albeit in less quantity. The presence of $S$. patens in summer 2007 was the first sign that species composition was returning to conditions that existed before Hurricanes Katrina and Rita; however, it was not present in the sampled plots at the end of the growing season in 2007. Spartina patens was present at the site in fall 2007 but not in the plots sampled for aboveground biomass (fig. 44). Species composition was dynamic at this site and continued to change throughout the study period, partially because of the patchy distribution of species and the relatively small area harvested each period.

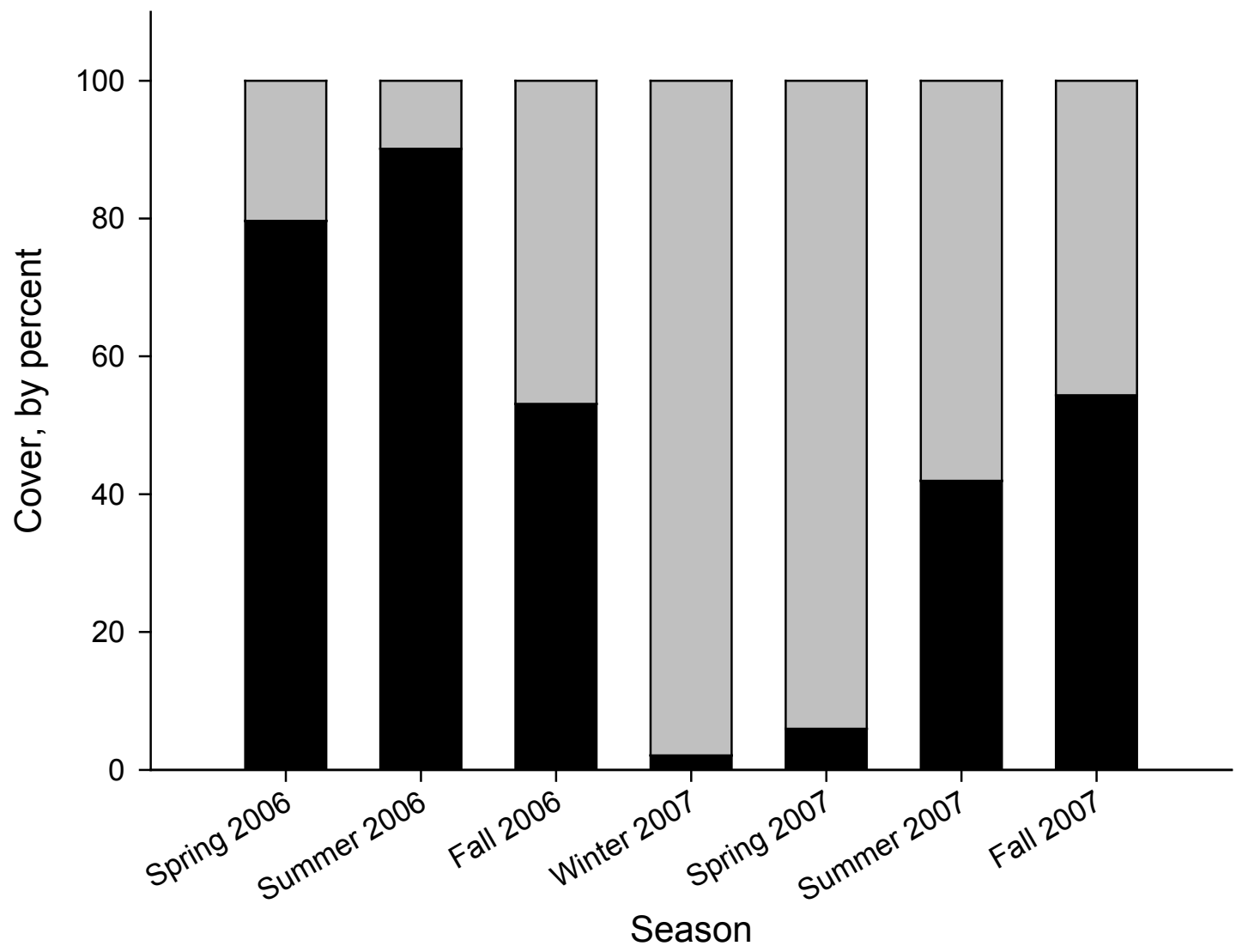

Figure 46. Seasonal coverage of disturbance (black bars) taxa relative to nondisturbance (gray bars) taxa at Coastwide Reference Monitoring System (CRMS) site 0135

\section{Season}



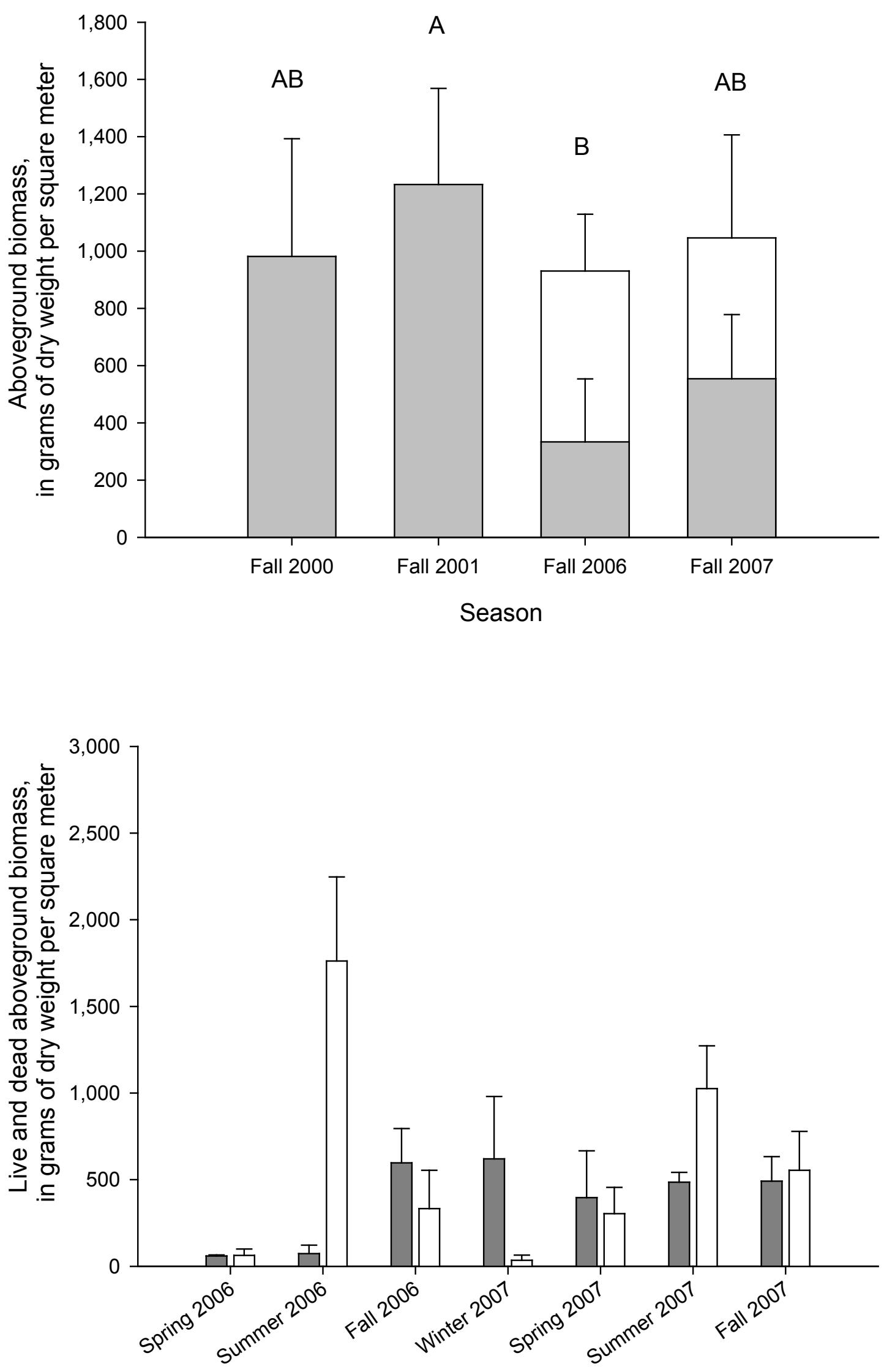

Figure 47. Total (white bars) and live (gray bars) aboveground biomass at a historically sampled site near Lake Cuatro Caballo (see fig. 41) at the end of growing seasons in fall 2000 and 2001 and at Coastwide Reference Monitoring System (CRMS) site 0135 at the end of growing seasons in fall 2006 and 2007. No estimates of total biomass were available for fall 2000 and 2001. Differing letters indicate statistical differences for live biomass only $(p=0.0117)$.
Figure 48. Live (white bars) and dead (gray bars) aboveground biomass (see standard error bars) by season at Coastwide Reference Monitoring System (CRMS) site 0135 . 


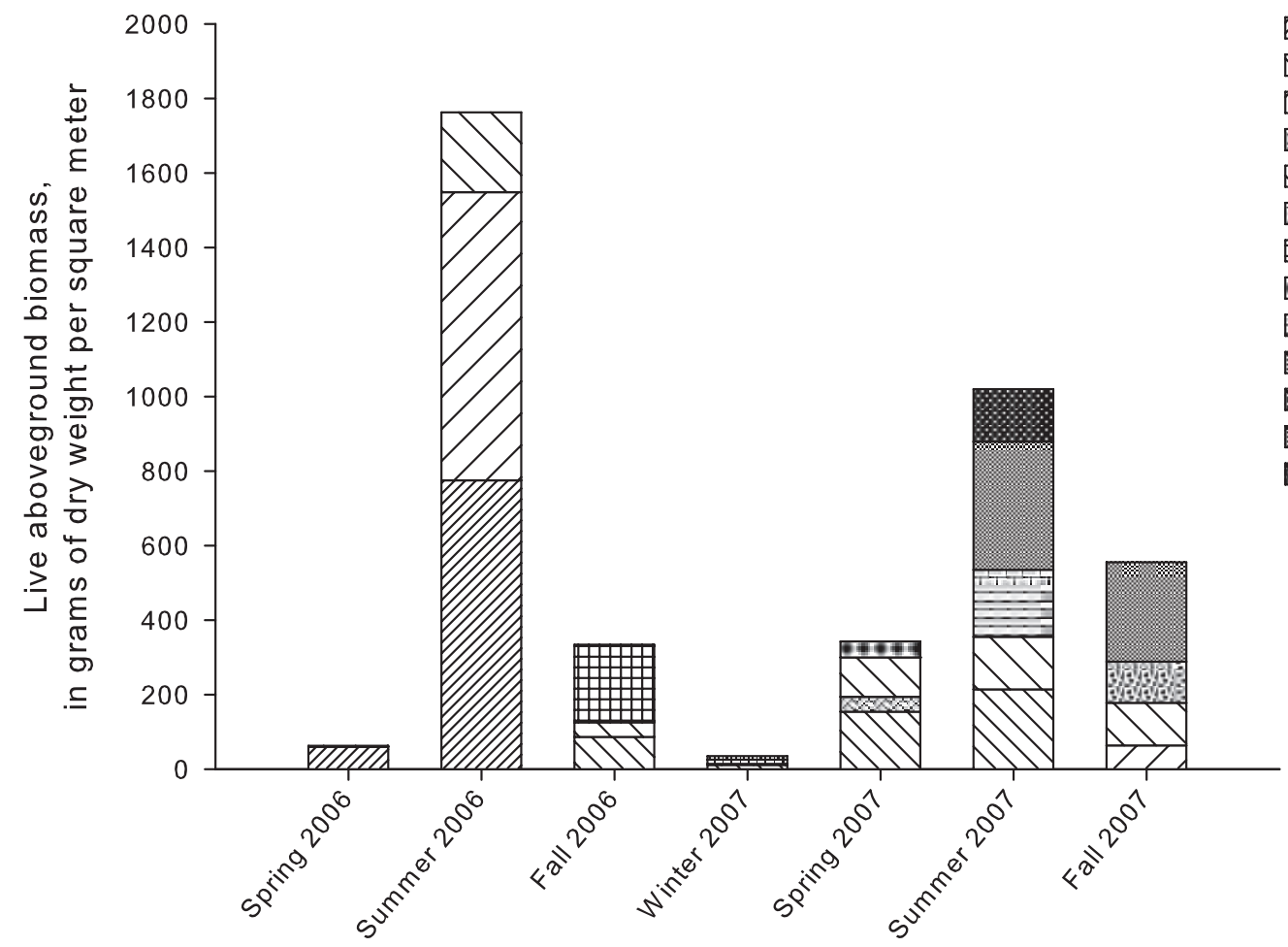

EXPLANATION

$217 \pi$ Amaranthus australis $\triangle \backslash$ Distichlis spicata

$\square$ Echinochloa crus-galli Lythrum lineare $\triangle>$ Other

Wajid Panicum dichotomiflorum 車 Panicum virgatum $\$ 980$ Paspalum vaginatum

Schoenoplectus robustus

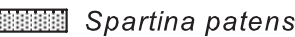

Wnknown

Vigna luteola

\%izaniopsis miliacea

Figure 49. Species composition of live aboveground biomass by season at Coastwide Reference Monitoring System (CRMS) site 0135 .

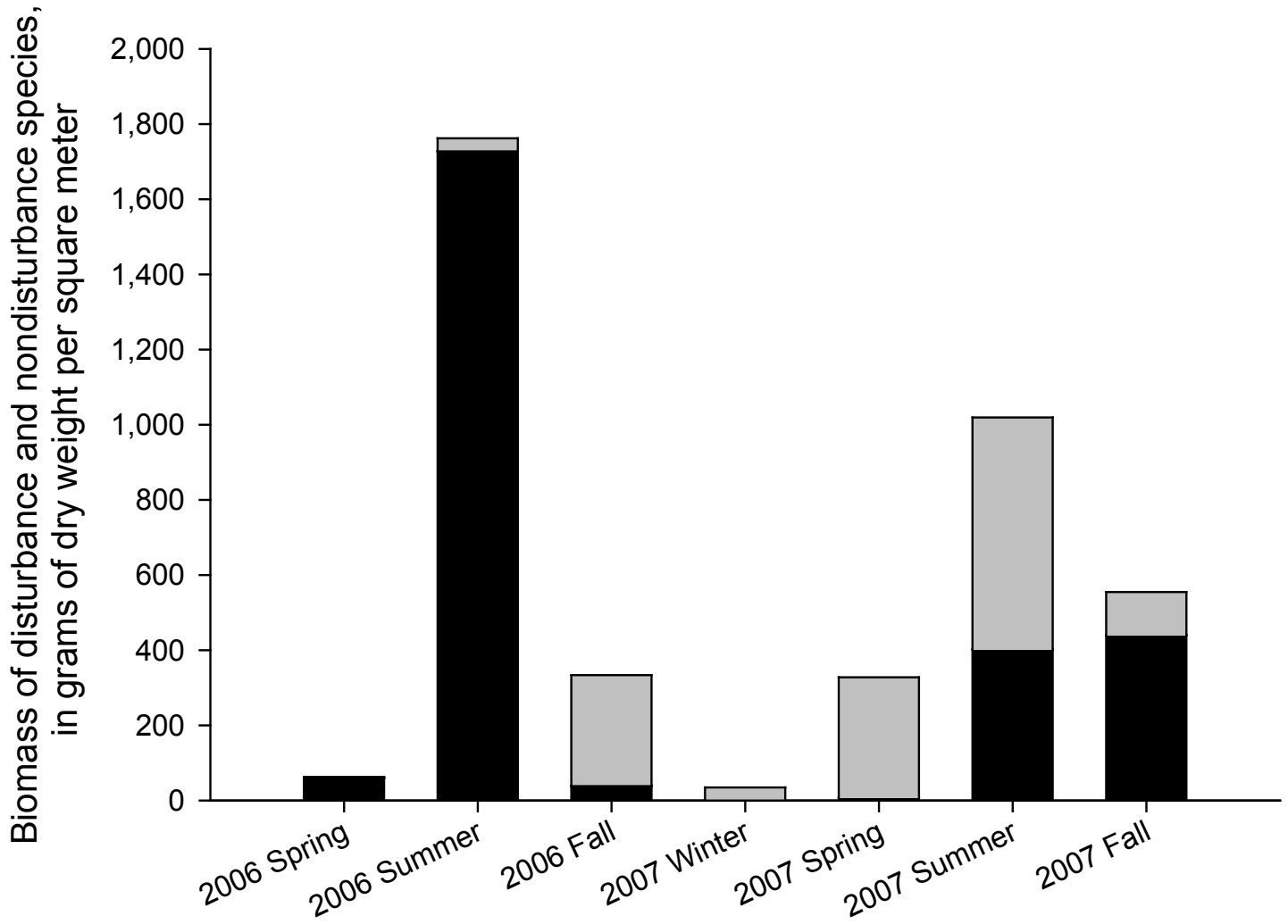

Season

Figure 50. Seasonal aboveground biomass of disturbance (black) and nondisturbance (gray) taxa at Coastwide Reference Monitoring System (CRMS) site 0135. 
Total aboveground biomass ranged from $122.6( \pm 32.5)$ to $1,835.3( \pm 487.9) \mathrm{g}$ dry weight $\mathrm{m}^{-2}$, while total belowground biomass ranged from 5,670.9 $( \pm 1606.9)$ to $7,877.3( \pm 1,328.5)$ $\mathrm{g}$ dry weight $\mathrm{m}^{-2}$ (fig. 51). Minimal changes in total belowground biomass were observed from spring 2006 to fall 2007, with the lack of significant change likely due to the dominance by annual species at this site. The expected trend of increased belowground biomass in spring, prior to an increase in aboveground biomass in summer, and subsequent decrease in belowground biomass found by Darby and Turner (2008) was not observed at this site. However, as is typical of Louisiana's coastal marsh systems, the belowground component to vegetation biomass was far greater than the aboveground component (Gross and others, 1991; Darby and Turner, 2008). Live belowground biomass was greatest in winter 2007 but did not account for more than 20 percent of the total belowground biomass throughout the study period (fig. 52).

\section{Sediment Characterization, Accretion, and Elevation}

The average bulk density taken from two cores at CRMS0135 was $0.25( \pm 0.02) \mathrm{g}$ dry weight $\mathrm{cm}^{-3}$ from 0 to $48 \mathrm{~cm}$ deep (fig. 53). In the bulk density profile, a strong mineral signal was present between -26 and $-32 \mathrm{~cm}$, depending on the core. In addition, the bulk density profile in core two shows a mineral signal peaking between -2 and $-4 \mathrm{~cm}$. The same signal is present in two archived cores taken for the CRMS project at the same site location (fig. 54). Because of its location in the profile (that is, in surface sediment) and the proximity with which Katrina passed in relation to CRMS0135, it is possible that this mineral sediment was deposited by Hurricane Katrina.

Two cores analyzed for caesium-137 showed clear peaks of caesium activity at approximately $31 \mathrm{~cm}$ deep (fig. 54). This depth is assumed to correspond to the 1963 level. The strong mineral signal between 26 and $32 \mathrm{~cm}$ deep occurs above (after) the 1963 level; therefore, it is probably from the passage of Hurricane Betsy in 1965. Betsy was a category 4 hurricane that passed approximately $71 \mathrm{~km}$ west of CRMS0135 and produced marsh scouring in Breton Sound (J. Barras, personal commun., 2007).

Accretion since 1963 was calculated as $0.72 \mathrm{~cm} \mathrm{yr}^{-1}$, which is within the range (from 0.59 to $0.95 \mathrm{~cm} \mathrm{yr}^{-1}$ ) reported for brackish/intermediate marshes in Louisiana (Hatton, 1983; Smith and others, 1983; Chmura and Kosters, 1994; Nyman and others, 2006).

From our limited data (three sampling periods over 3 years) on elevation and short-term accretion, we estimated elevation change at $0.19 \mathrm{~cm} \mathrm{yr}^{-1}$ and vertical accretion at 0.49 $\mathrm{cm} \mathrm{yr}^{-1}$ (appendix fig. 2-1). It appears that the site-specific vertical accretion is not fully contributing to elevation change; therefore, shallow subsidence is $0.30 \mathrm{~cm} \mathrm{yr}^{-1}$. With estimates of RSLR at $0.92 \mathrm{~cm} \mathrm{yr}^{-1}$ in this area, these data suggest that this site is not building sufficient elevation to prevent increased tidal elevation and stress related to RSLR. Care should be taken when interpreting these data because estimates of elevation change and shallow subsidence improve over longer time periods (Cahoon and others, 2002b), and data from one site cannot be generalized for the region. The bulk density profile (fig. 53, core 2) does reflect a mineral pulse indicative of sediment recently incorporated into the site, likely from Hurricane Katrina. Hurricane-induced subsidies have been shown to contribute to substantial elevation change and can be beneficial to the sustainability of coastal systems (Cahoon, 2003; Nyman and others, 1995; Turner and others, 2006).

\section{Summary of the Classification of Impacts}

Vegetation cover and species composition data, paired with observational findings, indicate that the hurricaneinduced impacts at this site were largely caused by physical disturbance of the marsh surface, likely from a combination of wind and storm surge. Physical disruption to the marsh surface was obvious from the divots, marsh balls, lack of live vegetation, and irregularity of the marsh surface (beyond typical surface heterogeneity) when sampling began. As the study progressed, the abundance of disturbance species that colonized the site provided further evidence of a marsh directly influenced by the storms. The porewater salinity was within the normal range anticipated for brackish/intermediate marshes, and there was not a shift in species composition to more salt-tolerant species. Both observations offer further support for the occurrence of physical disturbance rather than salinity-induced impacts. In the fall of 2005, the site-specific departure from average was $-0.55( \pm 0.04)$ from the NDVI value, indicating that there was a major decrease in vegetation vigor from the baseline condition. This departure from average was validated by the lack of live vegetation present in fall 2005 when the CRMS site was constructed. By fall 2006, the departure from average NDVI score increased to -0.16 $( \pm 0.08)$, indicating that plant vigor at the site did improve in the first growing season after Hurricanes Katrina and Rita, as was reflected in our aboveground biomass estimates, but remained below the baseline average.

\section{Case Study 3: CRMS0672-H}

\section{Overall Site Description}

The CRMS0672-H site (N29.83343 ${ }^{\circ}$, W93.4091 $)$ is located within the East Mud Lake Marsh Management project area (CWPPRA project CS-20), located in the Calcasieu/ Sabine basin in Cameron Parish, La. (Castellanos and others, 2007) (fig. 55). The hydrology in this 3,222-ha project area is influenced by the fact that the project area is isolated by levees and roads. The project area is divided into Conservation Treatment Units (CTU). CRMS0672-H is located within CTU-2 and is actively managed by using variable crest culverts with flapgates, gated culverts, and variable-crest 


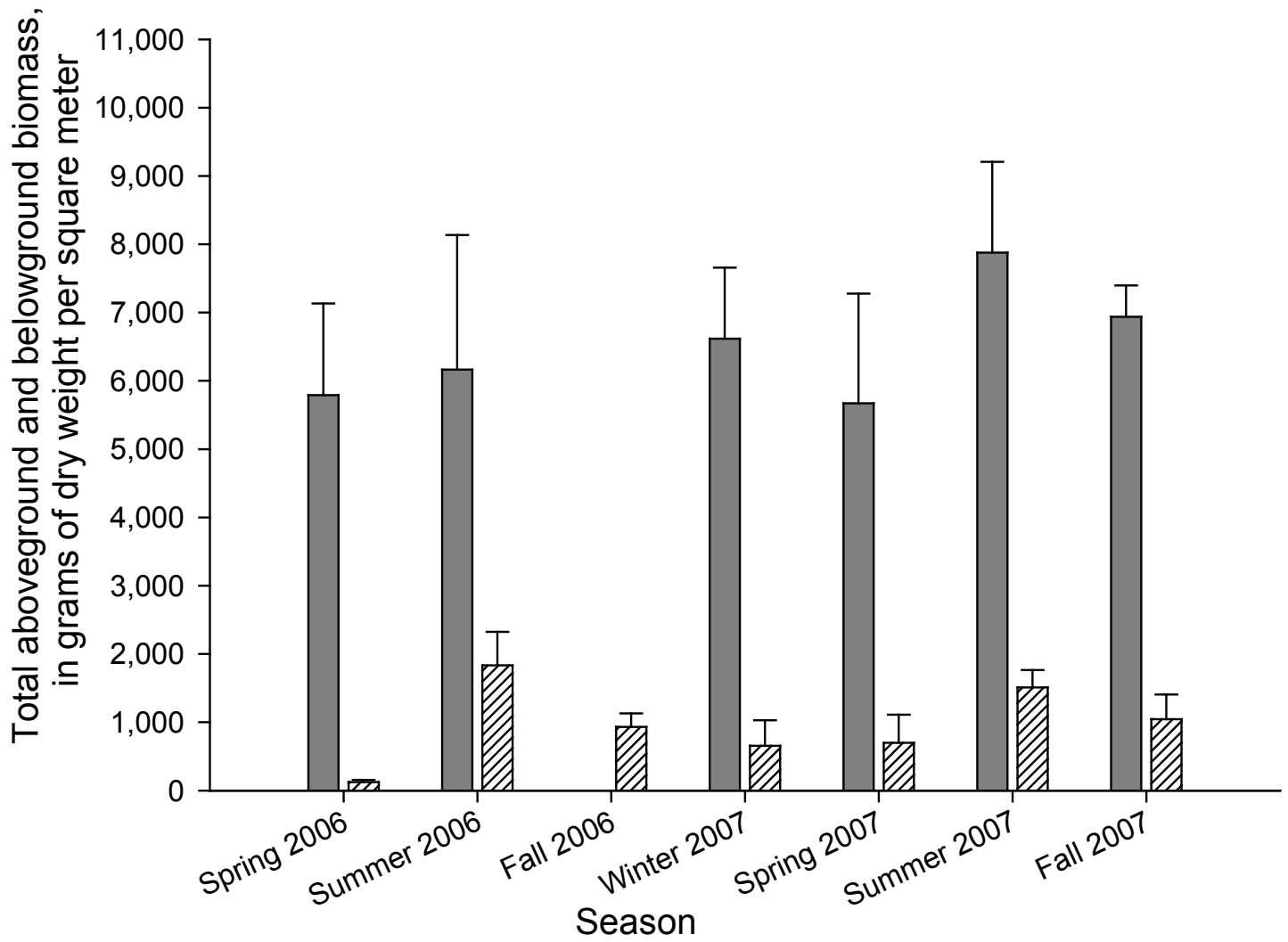

Figure 51. Seasonal above and belowground biomass at Coastwide Reference Monitoring System (CRMS) site 0135. Total belowground biomass is represented by gray bars and total aboveground biomass by hatched bars.

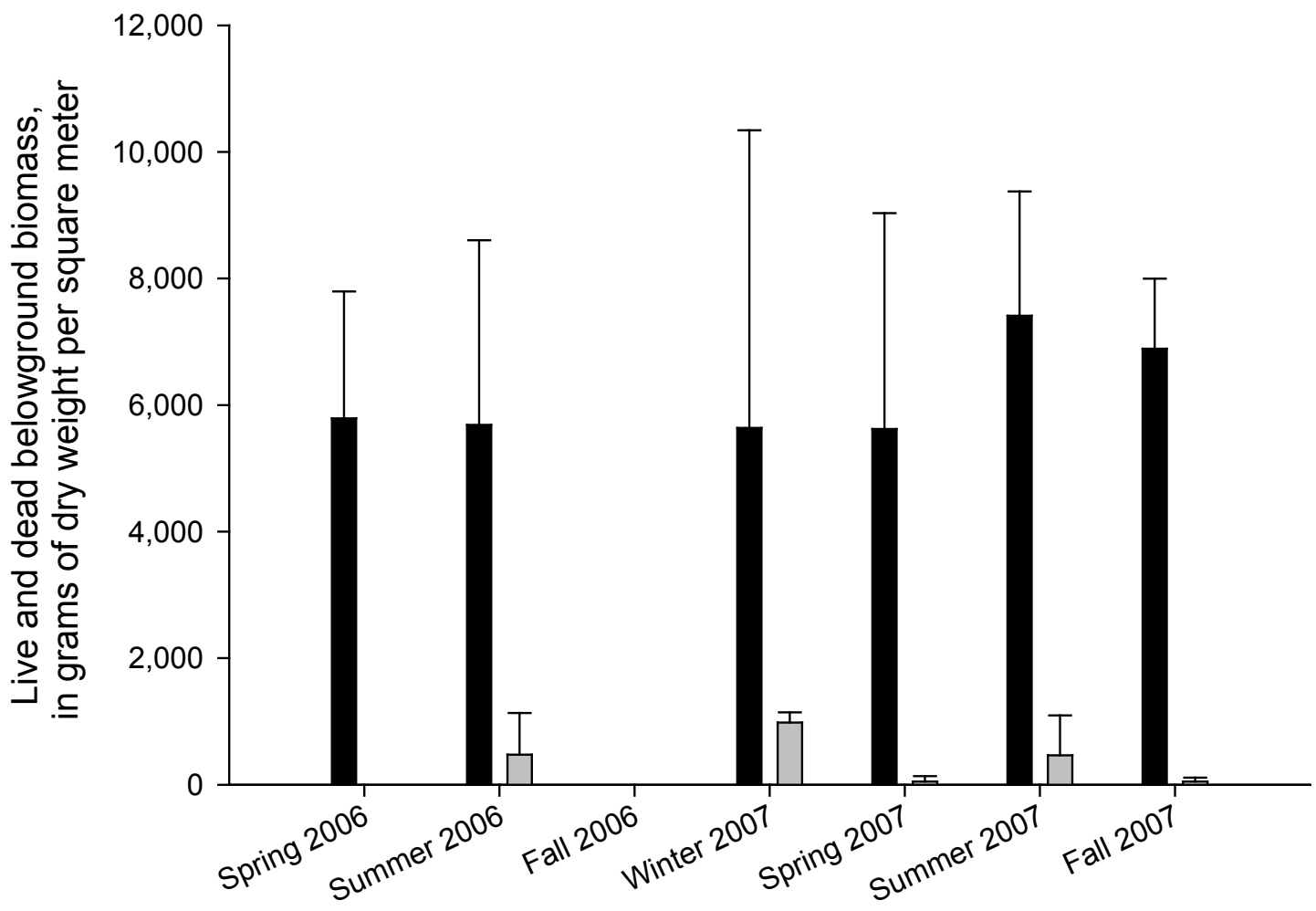

Figure 52. Seasonal belowground biomass (see standard error bars) of dead (black) and live (gray) components at Coastwide Reference Monitoring System (CRMS) site 0135. 


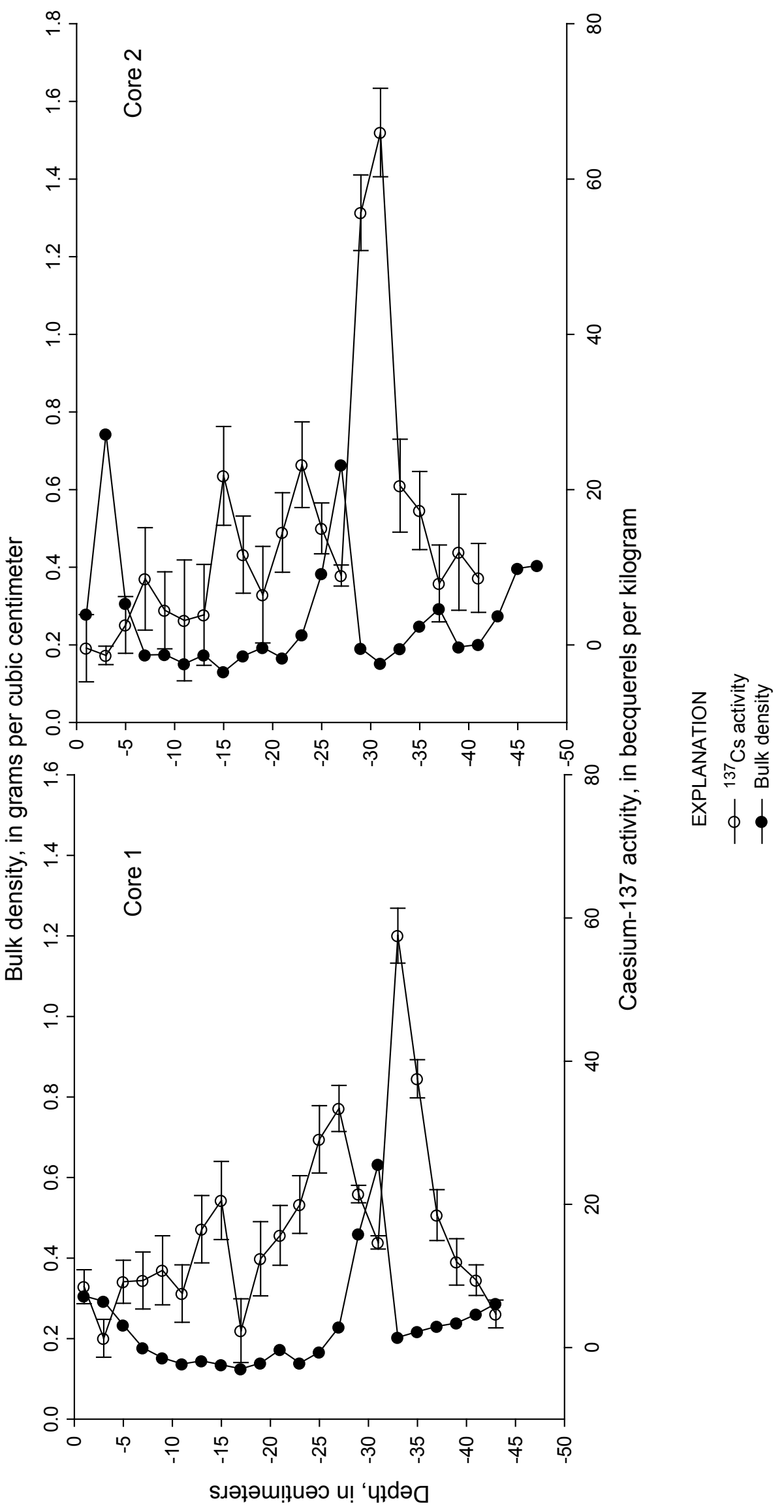

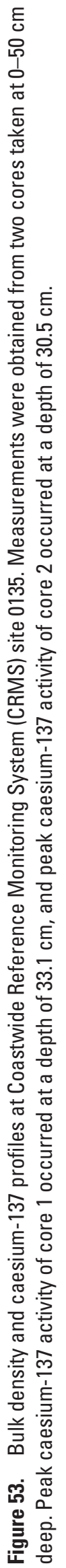



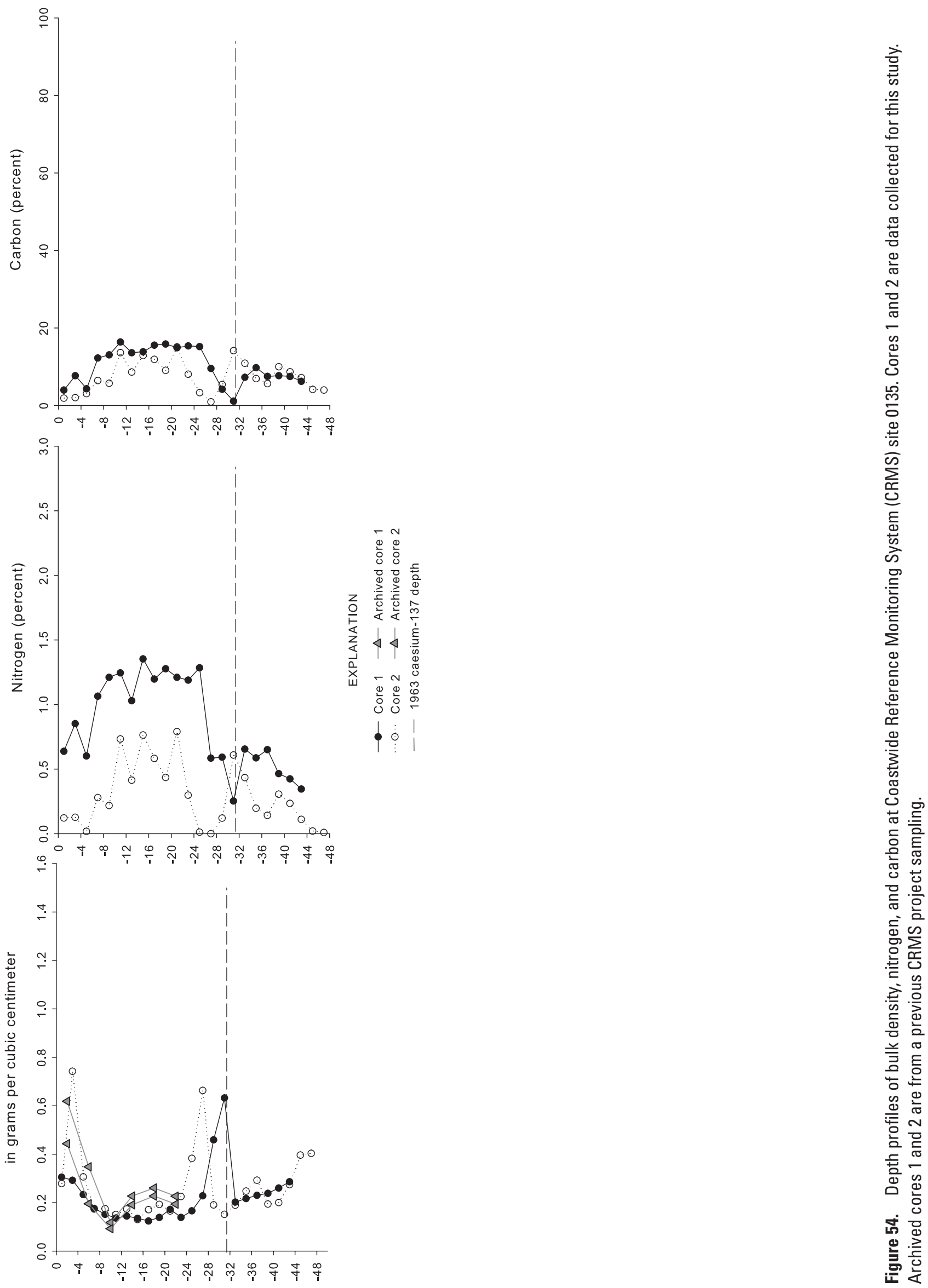


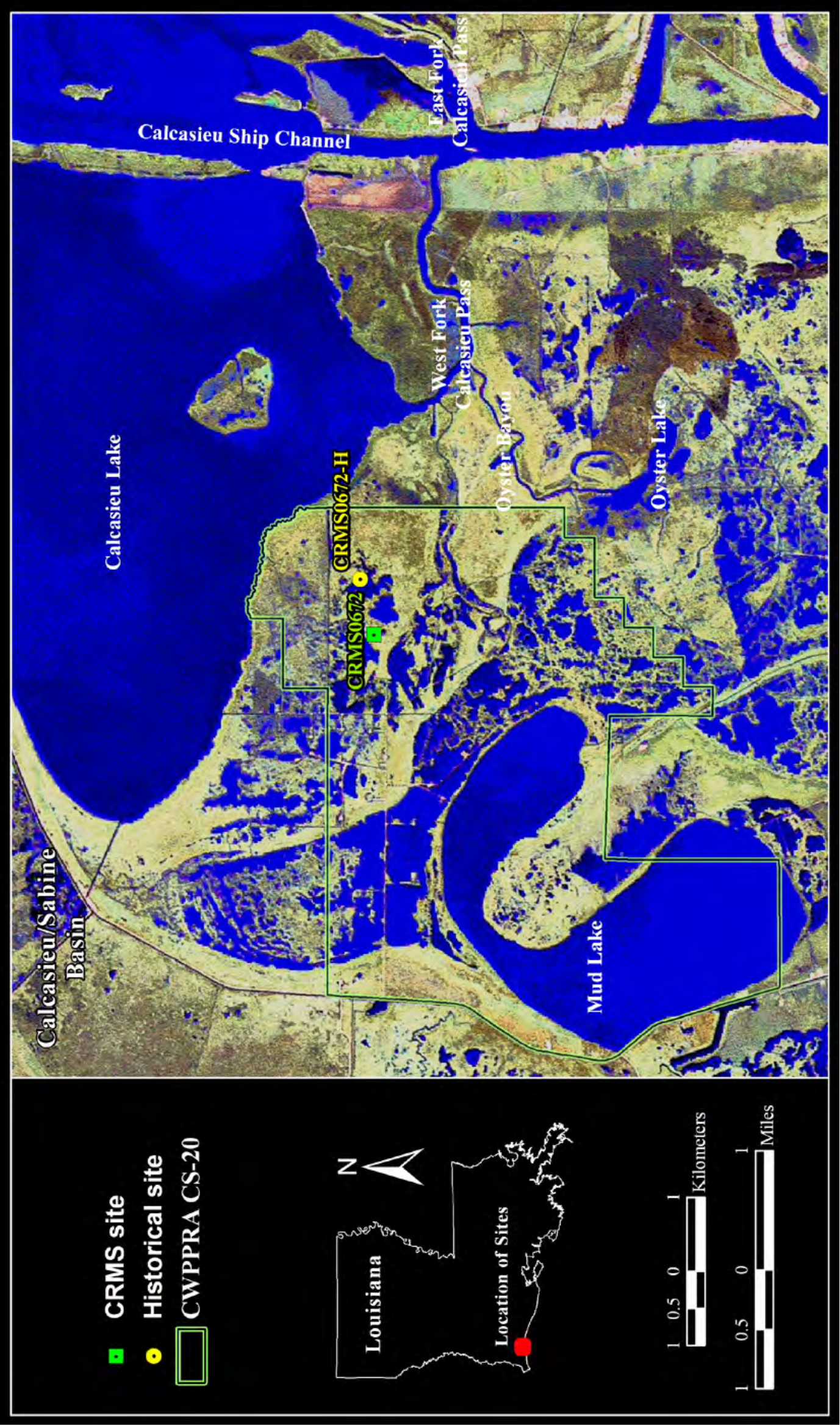

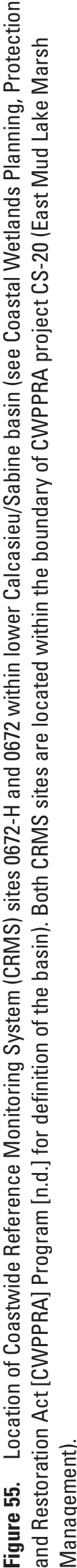


box structures. East Mud Lake Marsh Management project construction was completed in April 1996. The manipulation of water-control structures is designed to alleviate prolonged flooding of the marsh resulting from impoundment and to better control the rapid movement of high-salinity water (that is, >15) into the CWPPRA CS-20 project area via West Cove Bay, Oyster Bayou, and Mud Bayou. The Calcasieu Ship Channel, a navigation channel 15-m deep by 122-m wide and located $1.6 \mathrm{~km}$ east of the project area, is the primary source of high-salinity water.

In surveys conducted by Chabreck and Linscombe in $1968,1978,1988,1997$, and 2001, the habitat at CRMS0675-H was classified as brackish marsh, supporting flora and fauna typically adapted to surface salinities ranging from 5 to 18 (Chabreck, 1970). Marsh loss in this area has been minimal since 1978, and land change analyses from 1994 to 2000 suggest increases in marsh within the entire CTU-2 (Castellanos, 2005). The site is located on Creole soils (Natural Resource Conservation Service, n.d.), a poorly drained mineral soil that has a fluid, mucky surface layer and underlying material of clay, sand, and loam.

The dominant vegetation species at this site historically has been $S$. patens and D. spicata. Vegetation cover data from this site (CWPPRA station CS20-40) are available from 1995, 1997, 1999, 2003, 2005, and 2006 (Louisiana Office of Coastal Protection and Restoration, 2010) and were used to evaluate changes in vegetation communities after Hurricanes Katrina and Rita. Additionally, we used historical surfacewater salinity data from a nearby CWPPRA station (CS20-03) to investigate salinity effects on vegetation. CRMS0672-H was classified as brackish/intermediate for the purposes of this study and was within the area directly impacted by Hurricane Rita, which passed within $37 \mathrm{~km}$ of the site. The study area received 1.8-2.4 $\mathrm{m}$ of storm surge (Coastal Emergency Risks Assessment, 2008).

\section{Surface-Water and Porewater Salinity}

There was very little surface water at CRMS0672-H during the study period, and the marsh surface was dry and cracked at the spring 2006 sampling. The seasonal mean values of porewater salinity ranged from $10.7( \pm 1.0)$ in 2007 to $16.3( \pm 1.3)$ in 2006 and were significantly greater in summer 2006 and fall 2007 than in summer 2007 ( $\mathrm{p}=0.014$, fig. 56). The salinity values are within the range of variability found in brackish marsh (Chabreck, 1970). Continuous data on surface-water salinity from station CS20-03 show that salinities remained above 20 from February through July 2006, during which time drought conditions were prevalent (fig. 57). Damage to the salinity gage from Hurricane Rita prohibited measurements from September 2005 until February
2006. Salinity conditions in 2007 were lower and appear to be associated with a return to normal precipitation patterns. The salinity patterns poststorms are on the high end of the typical brackish marsh salinity range; however, they are not as high as during the 1999-2000 drought, when mean value for daily salinity exceeded 20 for much of the period from August 1999 to December 2000, peaking at 39 at station CS20-03 (Castellanos, 2005).

\section{Vegetation Cover}

The initial sampling of CRMS0672-H in spring 2006 indicated that 95 percent of the cover was dead vegetation, primarily $S$. patens, with only 5 percent live cover comprising S. patens and D. spicata (fig. 58). Distichlis spicata was the dominant plant species throughout the study and tended to increase in cover from spring 2006 to fall 2007, whereas S. patens showed little recovery until spring 2007. The disturbance species, $A$. australis, comprised only 5 percent cover in summer 2006, but it accounted for 33 percent of the total cover at the site (figs. 58 and 59), and it was very abundant outside our sampling area in all seasons in 2006. During fall 2006 and fall 2007, Paspalum vaginatum was also codominant but did not occur in sample plots during other sampling times of the year. This species has been prevalent during low-water conditions in the study area and occurs along marsh-water interfaces (Castellanos, 2005). Overall, live cover values increased only slightly (from 5 to 20 percent) throughout 2006, but during 2007 the site fully recovered, with 100 percent cover by fall 2007 .

The influence of the hurricanes at this site was very apparent from observations in spring 2006 because there was near complete dieback of $S$. patens within and outside this site and minimal live vegetation cover. The four vegetation surveys conducted at this site before the hurricanes (that is, as part of the CS-20 project in 1995, 1997, 1999, and 2003) reported cover values between 40 and 100 percent, with dominant species of $S$. patens and D. spicata (Louisiana Office of Coastal Protection and Restoration, 2010). Interestingly, the survey in July 1997 after the 2006 drought revealed a pattern similar to that observed in our study, in which $S$. patens almost completely died back and $A$. australis composed the total live cover (40 percent), but by the July 1999 survey $S$. patens was the dominant species again. It appears that after a large disturbance event, whether hurricane or drought, dominant perennials in this brackish marsh are initially set back during the first growing season after the event, and disturbance species become opportunistic. If stressful conditions do not persist, the dominant perennials can outcompete the disturbance species and reestablish typical values of vegetation cover. 


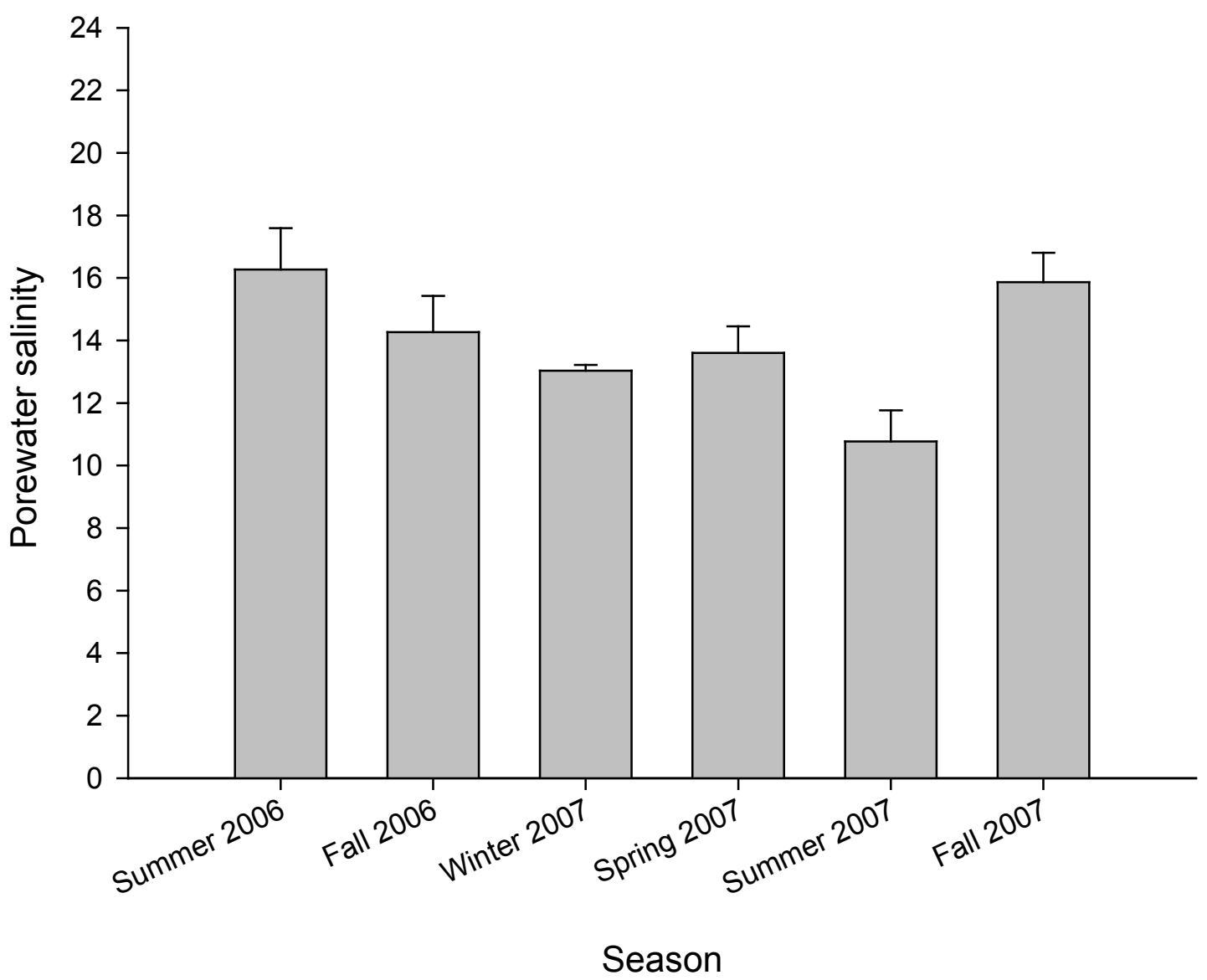

Figure 56. Seasonal discrete porewater salinity (see standard error bars) at Coastwide Reference Monitoring System (CRMS) site 0672-H, sampled at a depth of $30 \mathrm{~cm}$.

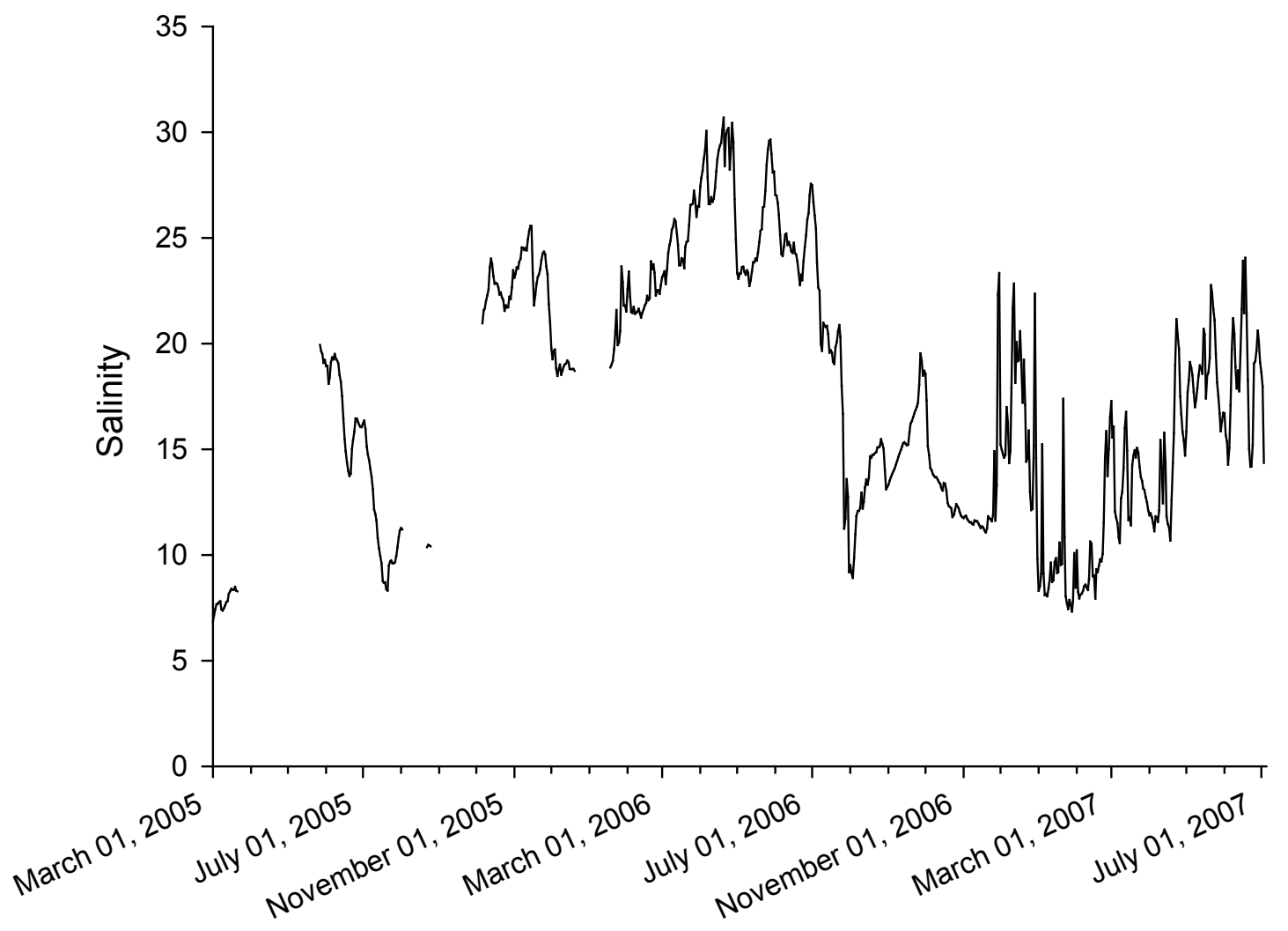

Figure 57. Average daily surface-water salinity from a sampling station (CS20-03) within the CS20 project of the Coastal Wetlands Planning, Protection and Restoration Act (CWPPRA) from January 2005 to July 2007. 


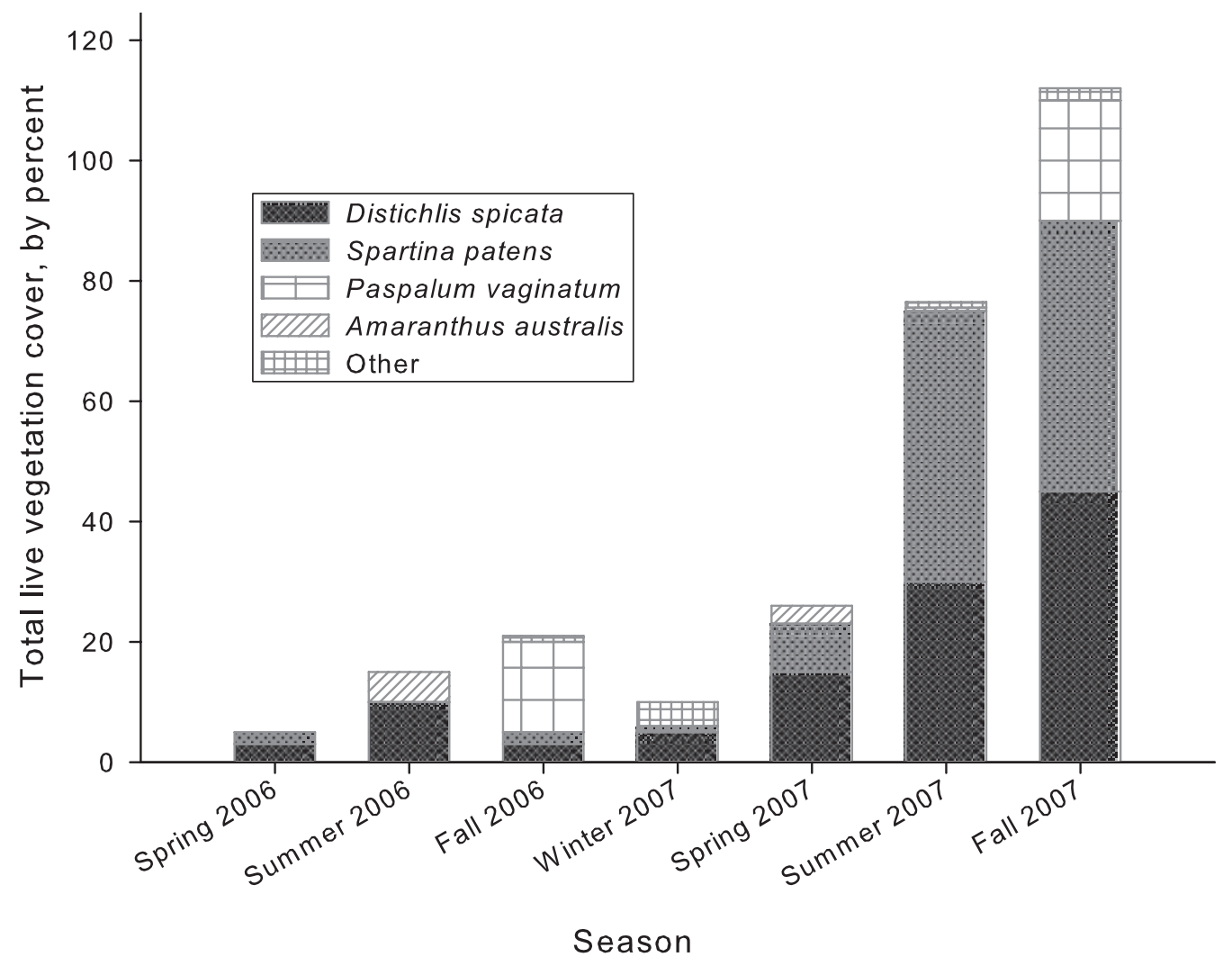

Figure 58. Seasonal species composition of total live vegetation cover at Coastwide Reference Monitoring System (CRMS) site 0672-H.

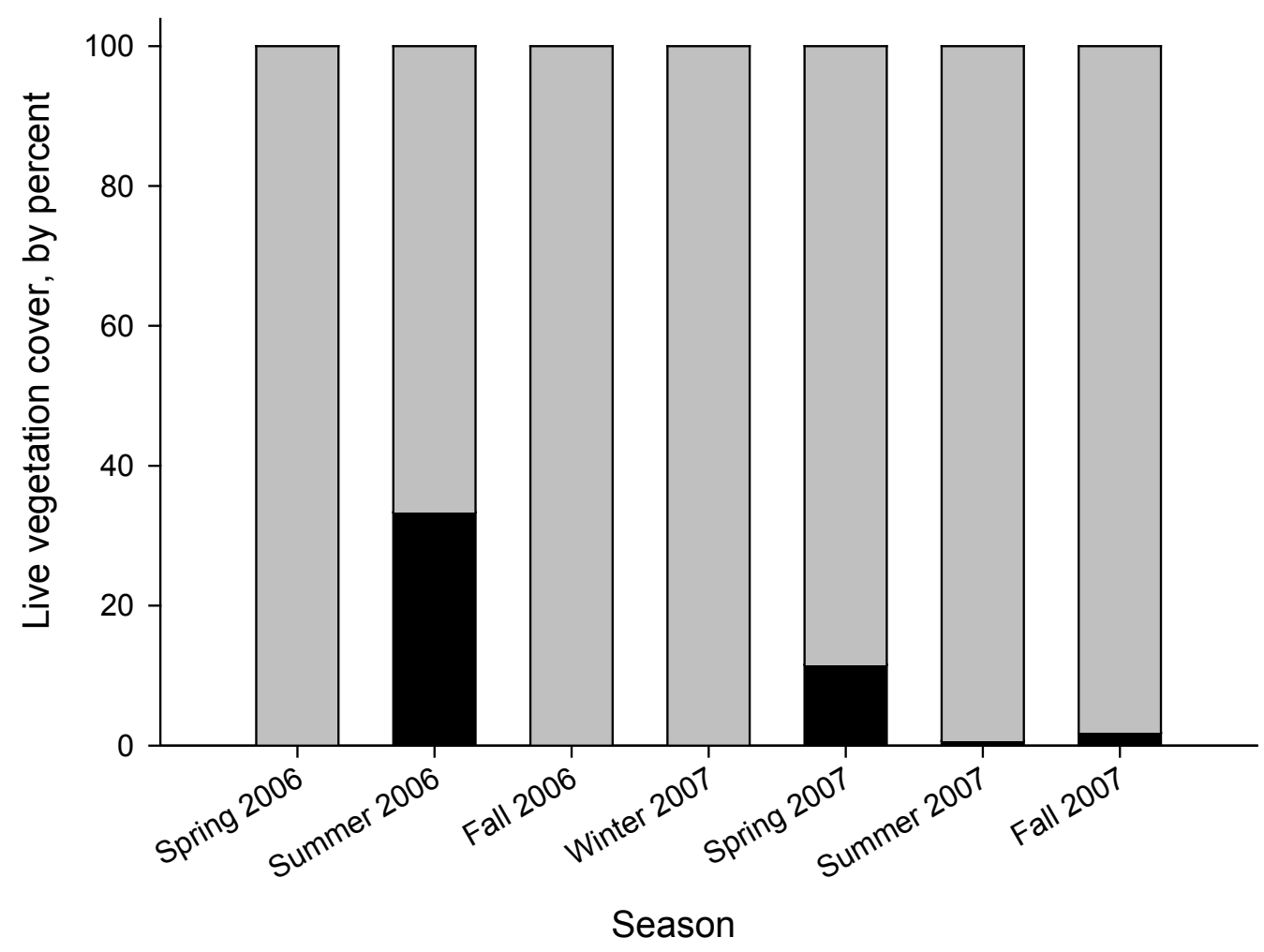

Figure 59. Live vegetation cover of disturbance (black bars) taxa relative to nondisturbance (gray bars) taxa by season at Coastwide Reference Monitoring System (CRMS) site 0672-H. 


\section{Aboveground and Belowground Biomass}

The pattern of live aboveground biomass was similar to that of vegetation cover (percent). Very low levels of live aboveground biomass were observed in spring 2006 $\left(255.33 \pm 19.22 \mathrm{~g}\right.$ dry weight $\left.\mathrm{m}^{-2}\right)$, then trended higher through the end of the study, with peak values of $1,927.02$ ( \pm 276.96$) \mathrm{g}$ dry weight $\mathrm{m}^{-2}$ in fall 2007 (fig. 60). The live aboveground biomass in fall 2007 was nearly twice that of fall 2006. The species that comprised the live aboveground biomass were the same as those found in the $4-\mathrm{m}^{2}$ plot used to measure vegetation cover; however, there was a much greater abundance of Paspalum vaginatum, which was dominant from fall 2006 until fall 2007 (fig. 61). The amount of dead aboveground biomass was very high from spring 2006 to spring 2007, with values exceeding 1,250 g dry weight $\mathrm{m}^{-2}$ (fig. 60). The dead aboveground biomass decreased during the 2007 growing season as the amount of live aboveground biomass increased. Observations from summer and fall 2007 suggest that the large reduction in dead aboveground biomass is due to decomposition and incorporation of dead material in the soil substrate. White and others (1978) found that 24 percent of dead plant material from $D$. spicata and 36 percent from $S$. patens remained in litter bags after one year.
The mean value for total belowground biomass was greater during the growing season in 2006 than in 2007 but not significantly (fig. 62). The pool of dead biomass was significantly larger than the pool of live biomass (fig. 63). The live biomass was only a small component of the total during the study, with contributions of 7 percent in fall 2006 and 6 percent in winter 2007. Although live biomass did occur throughout the entire $32-\mathrm{cm}$ core depth, the largest amount of live root and rhizome biomass was found in the upper $16 \mathrm{~cm}$ of the substrate, $6 \mathrm{~cm}$ deeper than Gross and others (1991) observed for S. alterniflora.

It is difficult to estimate the effects of Hurricane Rita on the basis of the biomass measured in this study alone because no prestorm data were available. Although the range of reported aboveground biomass estimates from Louisiana brackish marshes varies greatly over time and space, live biomass at this study site at the end of the growing season in fall $2007\left(1,927 \mathrm{~g}\right.$ dry weight $\left.\mathrm{m}^{-2}\right)$ was at the high end of the reported range. Louisiana Offshore Oil Port (LOOP) monitoring data from 1979 to 1997 indicated that aboveground biomass (that is, $S$. patens) in brackish marsh ranged from 441 to $1,750 \mathrm{~g}$ dry weight $\mathrm{m}^{-2}$ (Visser and others, 1996).

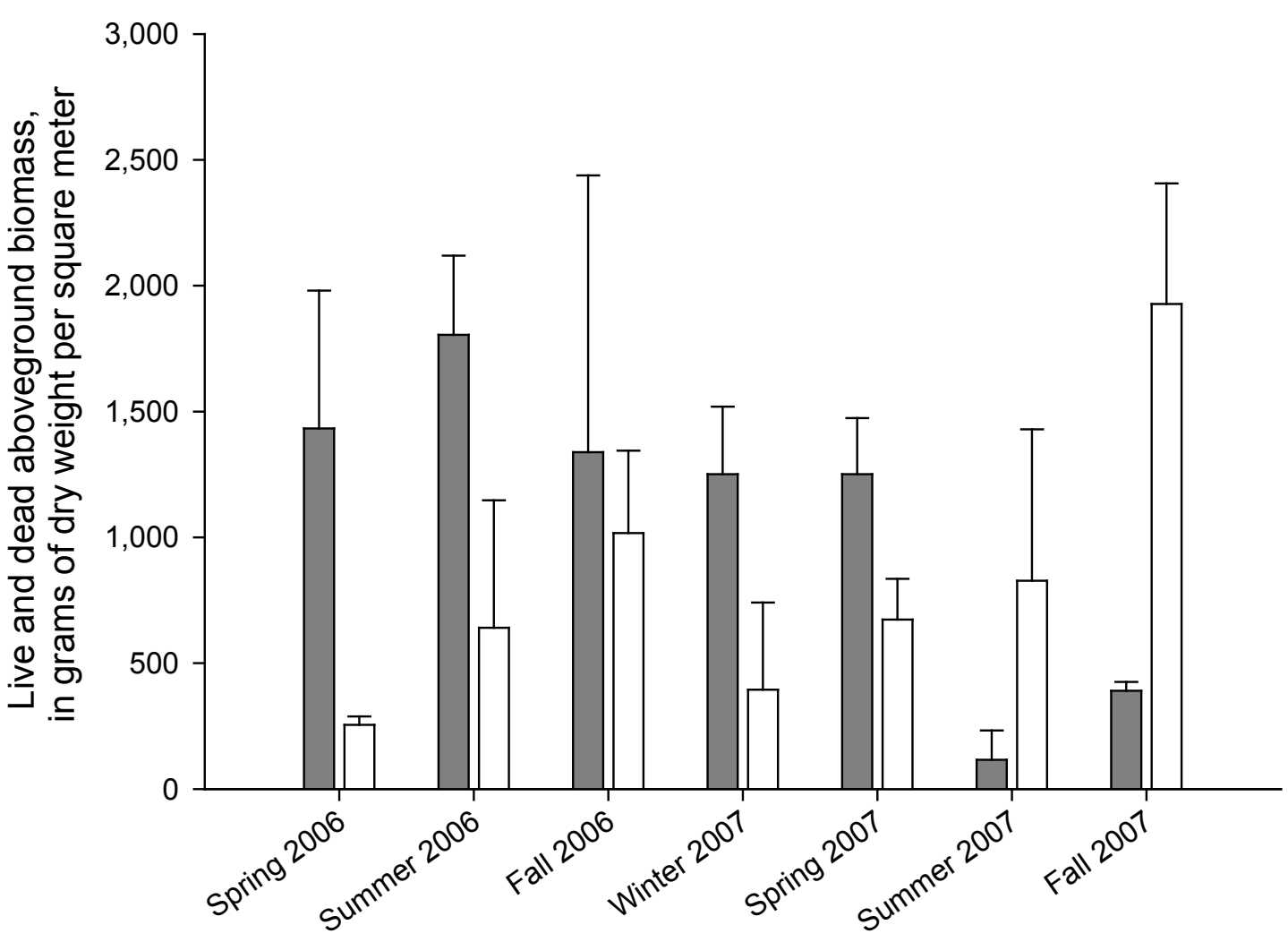

Figure 60. Live (white bars) and dead (gray bars) aboveground biomass (see standard error bars) by season at Coastwide Reference Monitoring System (CRMS) site 0672-H.

\section{Season}



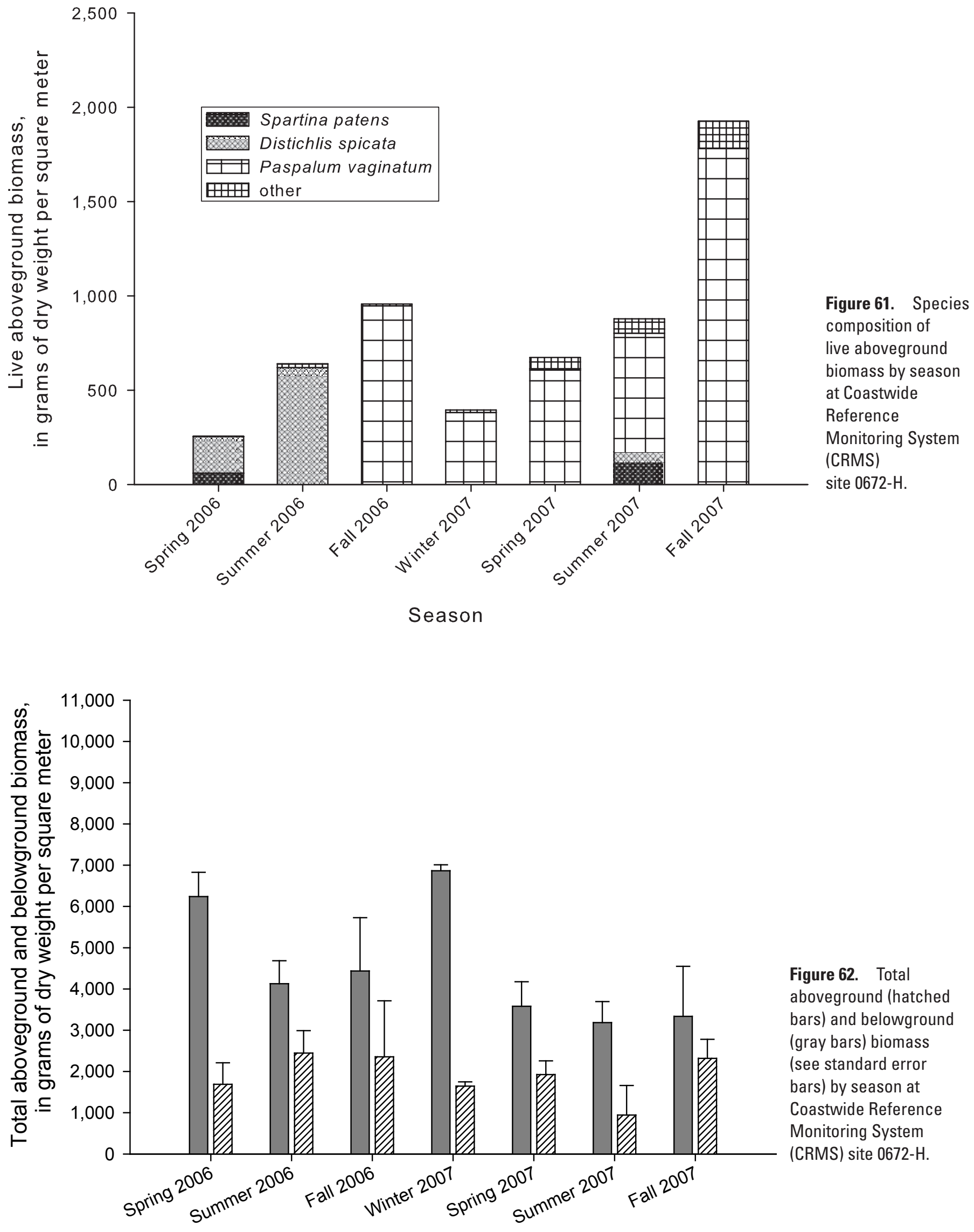

Figure 62. Total aboveground (hatched bars) and belowground (gray bars) biomass (see standard error bars) by season at Coastwide Reference Monitoring System (CRMS) site 0672-H. 


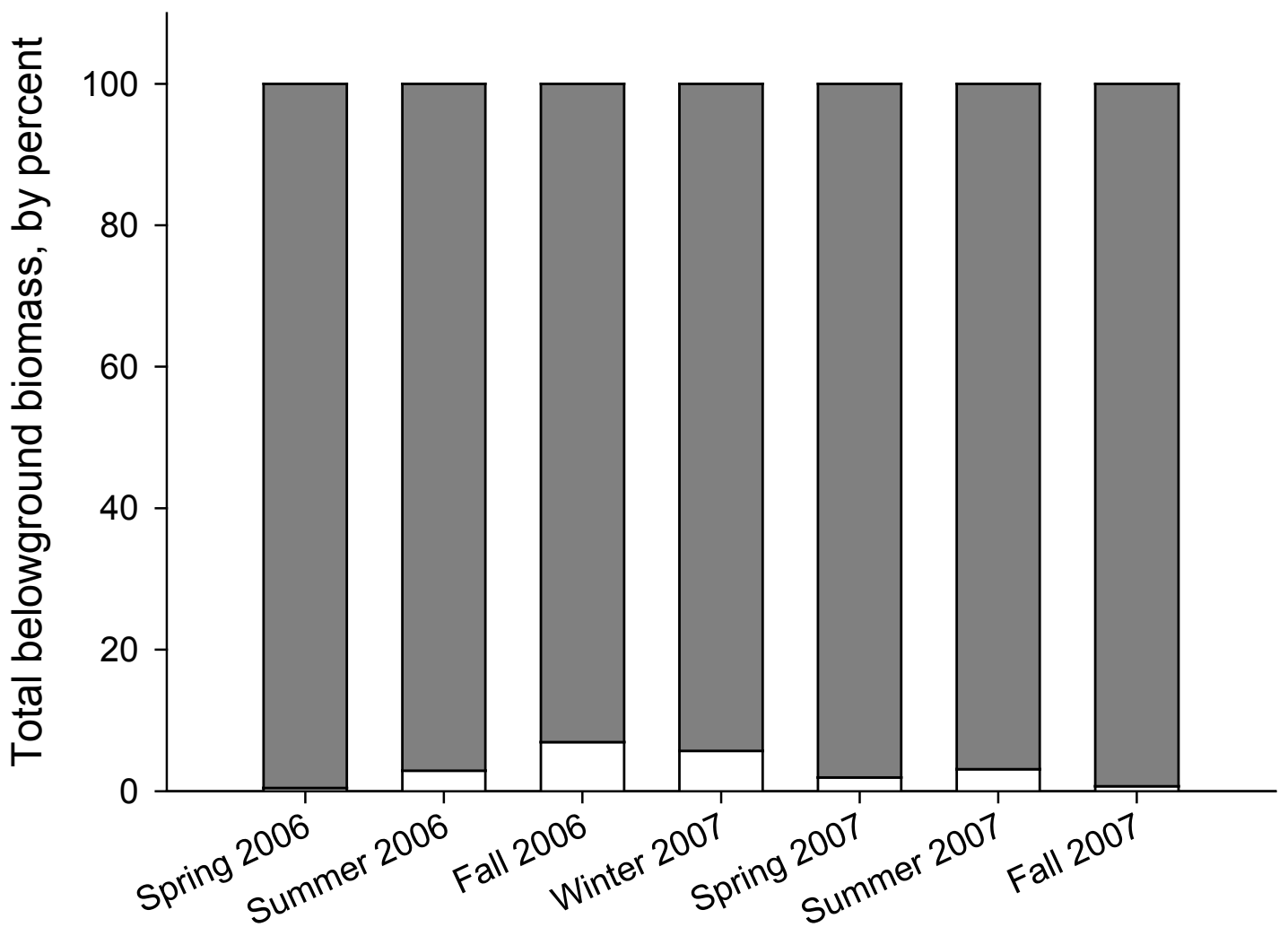

Figure 63. Live (white bars) and dead (gray bars) components of total belowground biomass by season at Coastwide Reference Monitoring System (CRMS) site 0672-H.

Season

\section{Sediment Characterization, Accretion, and Elevation}

The bulk density, percentage of nitrogen, and percentage of carbon profiles are presented in figure 64. Average bulk density was $0.54( \pm 0.05) \mathrm{g} \mathrm{cm}^{-3}$ throughout the entire profile. The caesium-137 peak occurred at $-14.3 \mathrm{~cm}$ depth (table 5), which is assumed to correspond to the 1963 level. The mean value of bulk density above the 1963 level was $0.22( \pm 0.02) \mathrm{g} \mathrm{cm}^{-3}$, but bulk density is noticeably greater within the top $4 \mathrm{~cm}$ of the core. The high bulk density in the surface portion of the core is potentially due to a subsidy of mineral sediments brought in by Hurricanes Katrina and Rita (Steyer, 2008). Low-water conditions at the time of sampling exposed sediments that had accumulated on the dead plants, facilitating observations that sediments had been recently redistributed and deposited. The carbon and nitrogen contents of the soils were low compared to nonimpounded soils in the region (Steyer, 2008). The depth profiles reflect that carbon and nitrogen contents are positively related to the amount of organic matter, which is consistent with the findings of Craft and others (1993).

The calculated accretion rate since 1963 was 0.33 $( \pm 0.03) \mathrm{cm} \mathrm{yr}^{-1}$. This rate is below the range of typical accretion rates observed in brackish/intermediate marshes in Louisiana; however, we know that this site is hydrologically impounded and that impoundments can influence accretion (Foret, 2001; Phillips, 2002; Steyer, 2008). In Rockefeller State Wildlife Refuge and Game Preserve, Foret (2001) described average caesium-137 accretion rates of $0.50( \pm 0.04)$ $\mathrm{cm} \mathrm{yr}^{-1}$ in open reference sites, compared to $0.36( \pm 0.04)$ $\mathrm{cm} \mathrm{yr}^{-1}$ in manipulated sites (that is, mixed and impounded). Phillips (2002) also reported lower caesium-137 accretion rates in impounded marsh $\left(0.19 \pm 0.06 \mathrm{~cm} \mathrm{yr}^{-1}\right)$ compared to semi-impounded (that is, mixed) and open reference sites $\left(0.31 \pm 0.09 \mathrm{~cm} \mathrm{yr}^{-1}\right)$ in Rockefeller State Wildlife Refuge and Game Preserve. Within the Sabine basin, the only historical accretion rates for marshes dominated by $S$. patens are from feldspar plots in the CWPPRA CS-20 project area, where impounded sites CRMS0672 and CRMS0672-H are located. The CWPPRA CS- 20 project averaged $0.40 \mathrm{~cm} \mathrm{yr}^{-1}$ accretion from 1997 to 2003 and over $3.0 \mathrm{~cm} \mathrm{yr}^{-1}$ from 2003 to 2006, accounting for deposition from Hurricane Rita (Castellanos and others, 2007). The short-term accretion rates from CRMS0672-H (1.11 $\left.\mathrm{cm} \mathrm{yr}^{-1}\right)$ and CRMS0672 (0.67 $\left.\mathrm{cm} \mathrm{yr}^{-1}\right)$ measured for the current study in 2007 and 2008 (fig. 65) are greater than the rates recorded before Hurricanes Katrina and Rita. Large organic accumulations may be contributing to these greater accretion rates, as suggested by the high values of live biomass measured in fall 2007. 

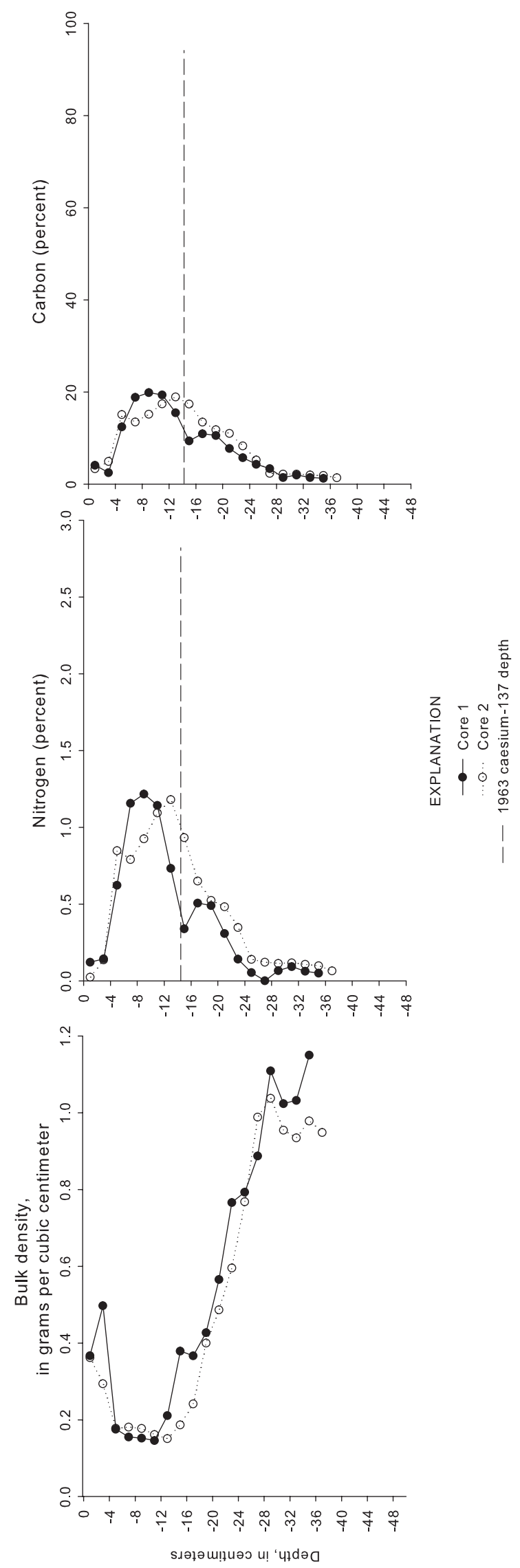
A

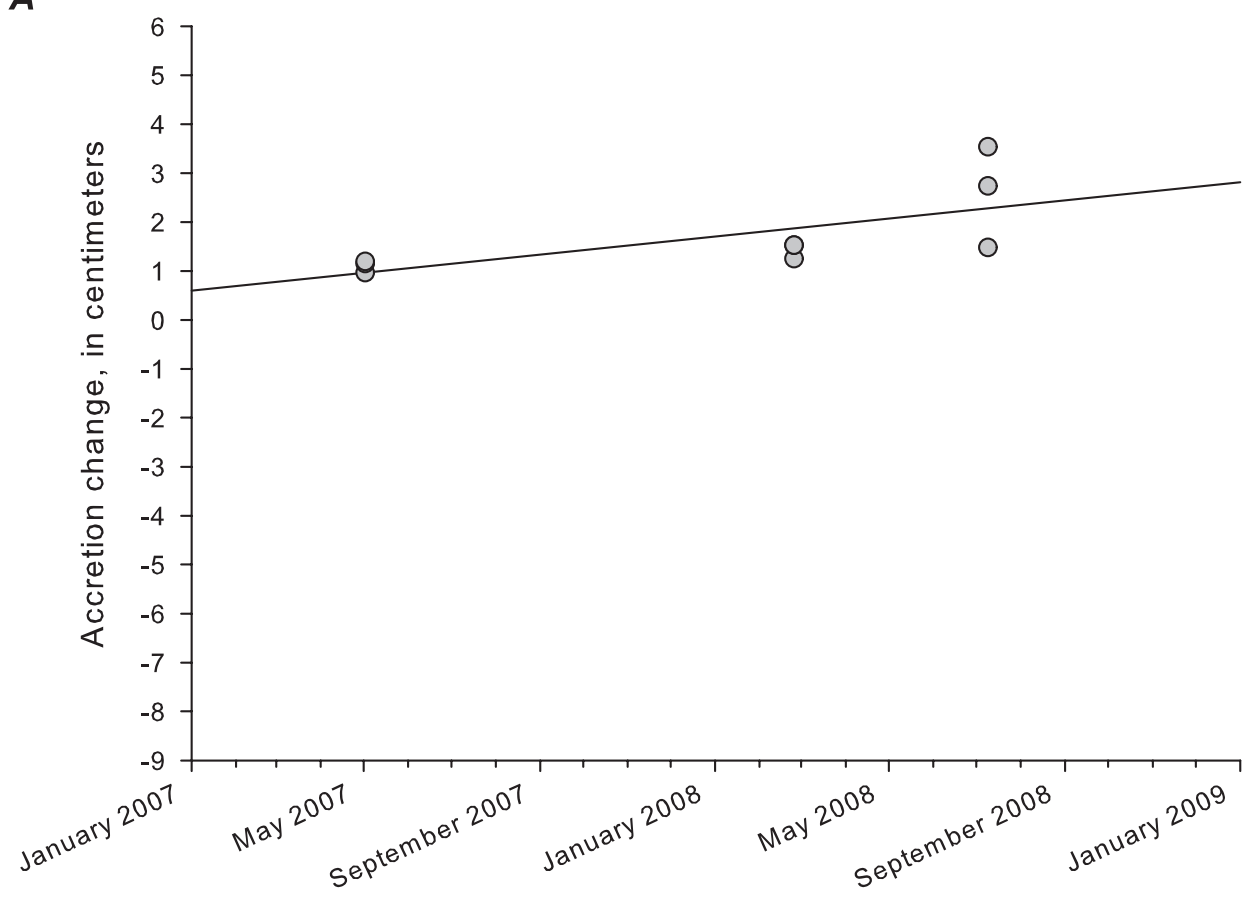

B

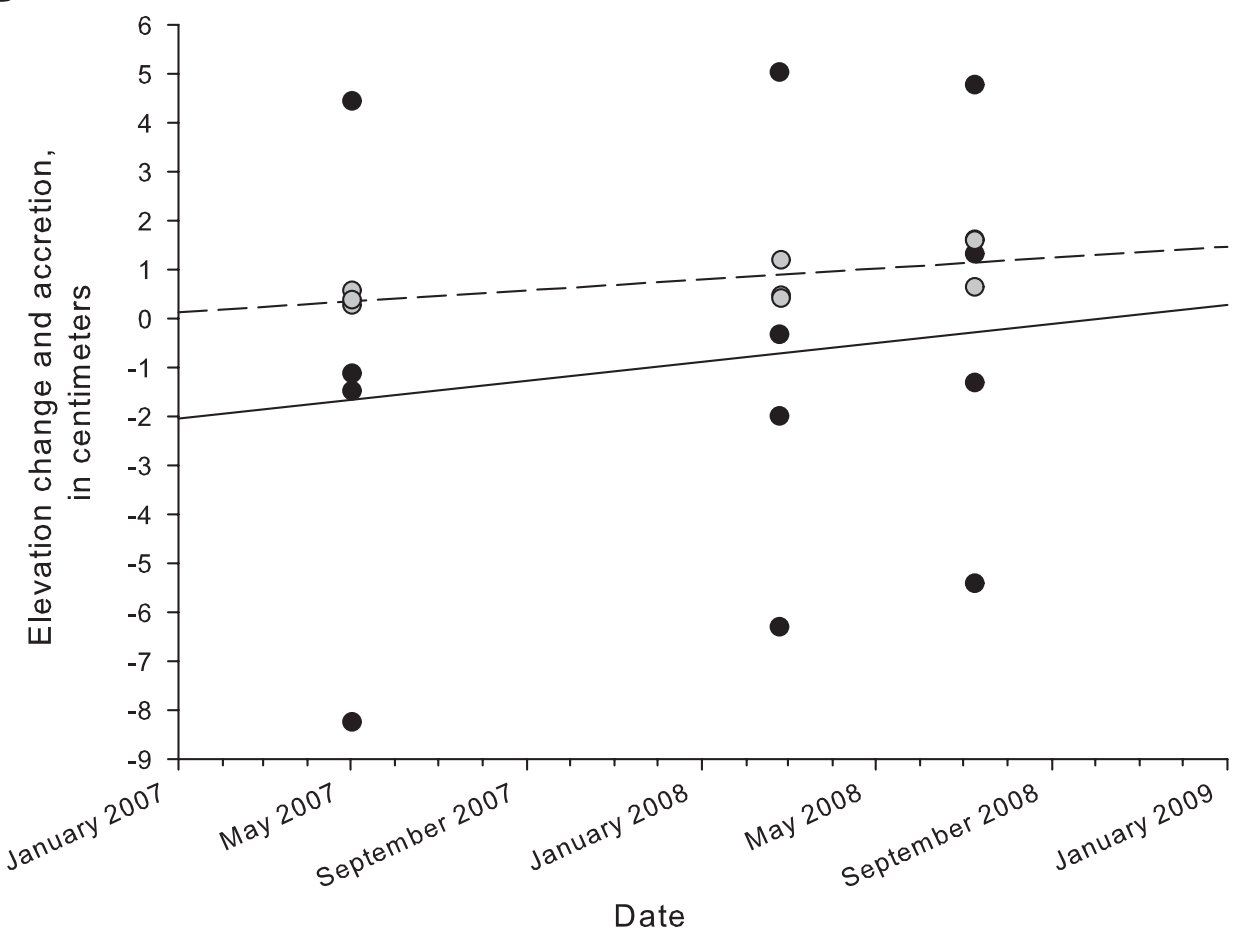

- Elevation

- Elevation regression

- Accretion

- - Accretion regression
Figure 65. Short-term accretion rates at Coastwide Reference Monitoring System (CRMS) site 0672- $\mathrm{H}$ and elevation and accretion change at CRMS0672. Estimates of site-specific elevation change, vertical accretion, and shallow subsidence (cm yr-1) are provided. $A$, There were no data on elevation change or shallow subsidence for CRMS0672-H. The rate of accretion $(y=-0.1924+0.0031 X ; r 2=0.46)$ was 1.11 centimeters per year $(\mathrm{cm}$ yr-1). B, At CRMS0672 the shallow subsidence was $-0.49 \mathrm{~cm} \mathrm{yr}-1$, and the relative sea level rise (RSLR) estimate was $0.57 \mathrm{~cm}$ yr- 1 . The rate of accretion $(y=-0.3523+$ $0.0018 X ; \mathrm{r} 2=0.44$ ) was $0.67 \mathrm{~cm} \mathrm{yr}-1$. The rate of elevation change $(y=$ $-2.9544+0.0032 X ; r 2=0.01$ ) was $1.16 \mathrm{~cm}$ yr-1. Elevation change at CRMS0672 is projected to be 0.59 cm yr-1 greater than RSLR. 
Vertical accretion is not necessarily equivalent to elevation gain (Cahoon, 2003). The accretion rate of $3.0-\mathrm{cm} \mathrm{yr}^{-1}$ from 2003 to 2006 was reported to result in $2.1 \mathrm{~cm} \mathrm{yr}^{-1}$ of elevation gain, suggesting sediment compaction of underlying soils from the combined weight of storm surge and mineral deposition associated with Hurricane Rita (Castellanos and others, 2007). The 2007 to 2008 elevation change of $1.16 \mathrm{~cm} \mathrm{yr}^{-1}$ at CRMS0672 (fig. 65) might be related to rebound from hurricane-induced compaction, changes in subsurface-water storage, or increases in root growth (Cahoon, 2003). Assuming a rate of 0.34 to $0.57 \mathrm{~cm} \mathrm{yr}^{-1}$ in RSLR in the Calcasieu/Sabine basin from two long-term tide gage stations (Penland and Ramsey, 1990), it appears that impounded sites CRMS0672-H and CRMS0672 are currently maintaining sufficient elevation to keep pace with projected estimates of RSLR.

\section{Summary of the Classification of Impacts}

Although we did not sample vegetation on the ground in fall 2005, the departure from the average NDVI value $(-0.19)$ at the end of the growing season in 2005 indicates that the plant vigor was below the baseline average. Such a decrease in vigor is expected following a hurricane, and ground observations of very little live vegetation and decreased aboveground biomass into spring 2006 illustrate the stressed nature of the vegetation. By fall 2006 the departure from the average NDVI score increased to -0.02 indicating improvement of the vegetative vigor in the first growing season after Hurricanes Katrina and Rita. Normalized difference vegetation index values provide an indication of plant vigor but cannot discriminate among species. In this case, the improved plant vigor can be attributed to an increase in coverage by disturbance species after the end of the first growing season.

From the soil bulk-density profiles and the data on accretion and elevation change, it appears that this area (including CRMS0672) received a subsidy of mineral sediment from the hurricanes. The increase in soil bulkdensity affected the upper $4 \mathrm{~cm}$ of the soil horizon and represented an approximate doubling of bulk density compared to the underlying soil. Given the proximity of this area to the path of Hurricane Rita, this storm likely contributed more mineral sediment to the area via storm surge than did Hurricane Katrina.

Storm impacts at CRMS0672-H and in the immediate vicinity were mixed. While the initial salinity pulse associated with the storm surge negatively influenced short-term plant productivity, there was some degree of enhanced sediment deposition to the marsh surface that may provide long-term benefits. Future data collections through the CRMS program may help clarify the storm-associated impacts, especially as they relate to the sediment record.

\section{Case Study 4: CRMS0326-H}

\section{Overall Site Description}

The CRMS0326-H site is located on Old Oyster Bayou $\left(\mathrm{N} 29^{\circ} 15.673^{\prime}, \mathrm{W} 91^{\circ} 05.685^{\prime}\right)$ in lower Terrebonne basin approximately $5.9 \mathrm{~km}$ north of the Gulf of Mexico (fig. 66; see Louisiana Coastal Wetlands Planning, Protection and Restoration Act Program [n.d.] for definition of the basin). Old Oyster Bayou is a navigable waterway connecting Old Oyster Bayou Lake to the east with Fourleague Bay to the west. Water is exchanged freely between Fourleague Bay (approximately $2.3 \mathrm{~km}$ west of the site) and the gulf through Oyster Bayou. No weirs or impoundments restrict water movement or tides from the gulf to CRMS0326-H. Old Oyster Bayou is approximately $14 \mathrm{~km}$ from the mouth of the Atchafalaya River. Historically, the site has been a healthy S. alterniflora marsh, likely because of its proximity to sediments, nutrients, and water from the Atchafalaya River. This site was characterized as being in the indirect area of hurricane impacts from Hurricanes Katrina and Rita.

The CRMS0326-H site was classified as saline marsh habitat with surface salinities typical of Louisiana saline marshes (8-29). The marsh surface was stable enough to walk upon, with sediment input available from the Atchafalaya River. Historically and throughout our study period, the dominant vegetation species at the site was $S$. alterniflora. The CRMS0326-H site was used in previous studies conducted by scientists at the U.S. Geological Survey National Wetlands Research Center with surface elevation table (SET) measurements dating back to 1992. For comparisons before Hurricanes Katrina and Rita, we present historical data on aboveground biomass at the end of growing seasons in 2001 and 2002, collected as part of a brown marsh study by scientists at the National Wetlands Research Center.

\section{Surface-Water and Porewater Salinity}

Measurements of surface-water and porewater salinity were taken quarterly from spring 2006 to fall 2007. Surface water was only present on the marsh surface in spring, summer, and fall 2007. During these three seasons, surfacewater depth averaged $4 \mathrm{~cm}$, and salinity ranged from 8.1 to 18.3 , with a mean salinity value of $13.2( \pm 4.28)$. Throughout the remainder of the study, the marsh was not inundated at the sampling times. Discrete porewater salinity did not vary greatly throughout the study period, ranging from 15.9 to 19.7 (mean $=18.3 \pm 1.1)($ fig. 67$)$.

In order to report data collected more frequently than the quarterly sampling intervals of this study, CRMS0326 was paired with CRMS0326-H. The CRMS0326 site is located $2.5 \mathrm{~km}$ north of CRMS0326-H in a similar saline marsh and 


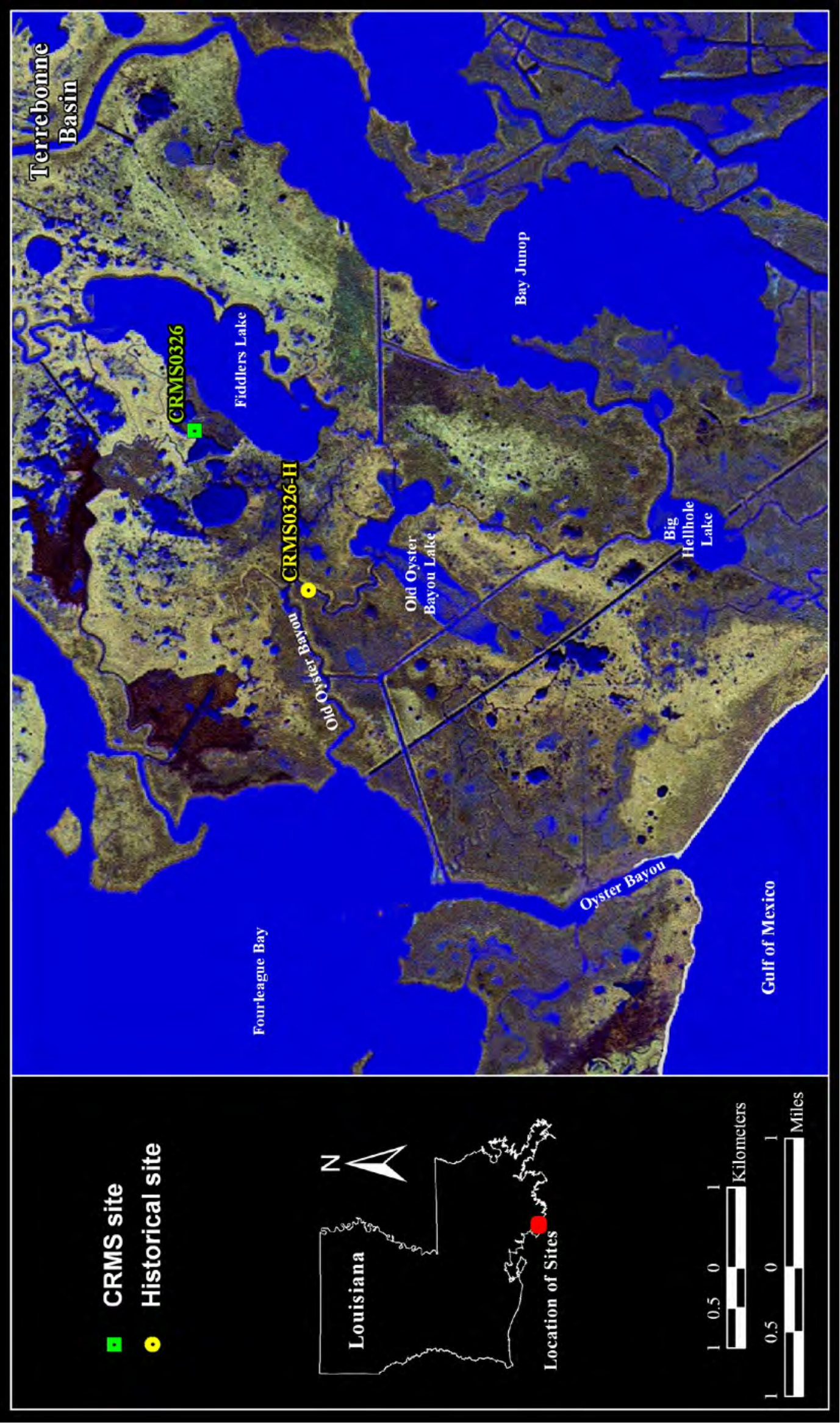

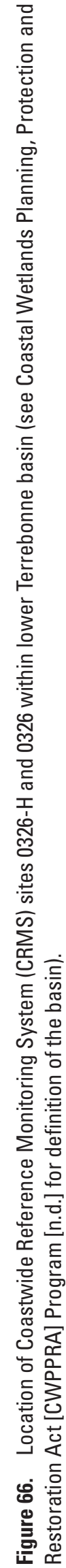




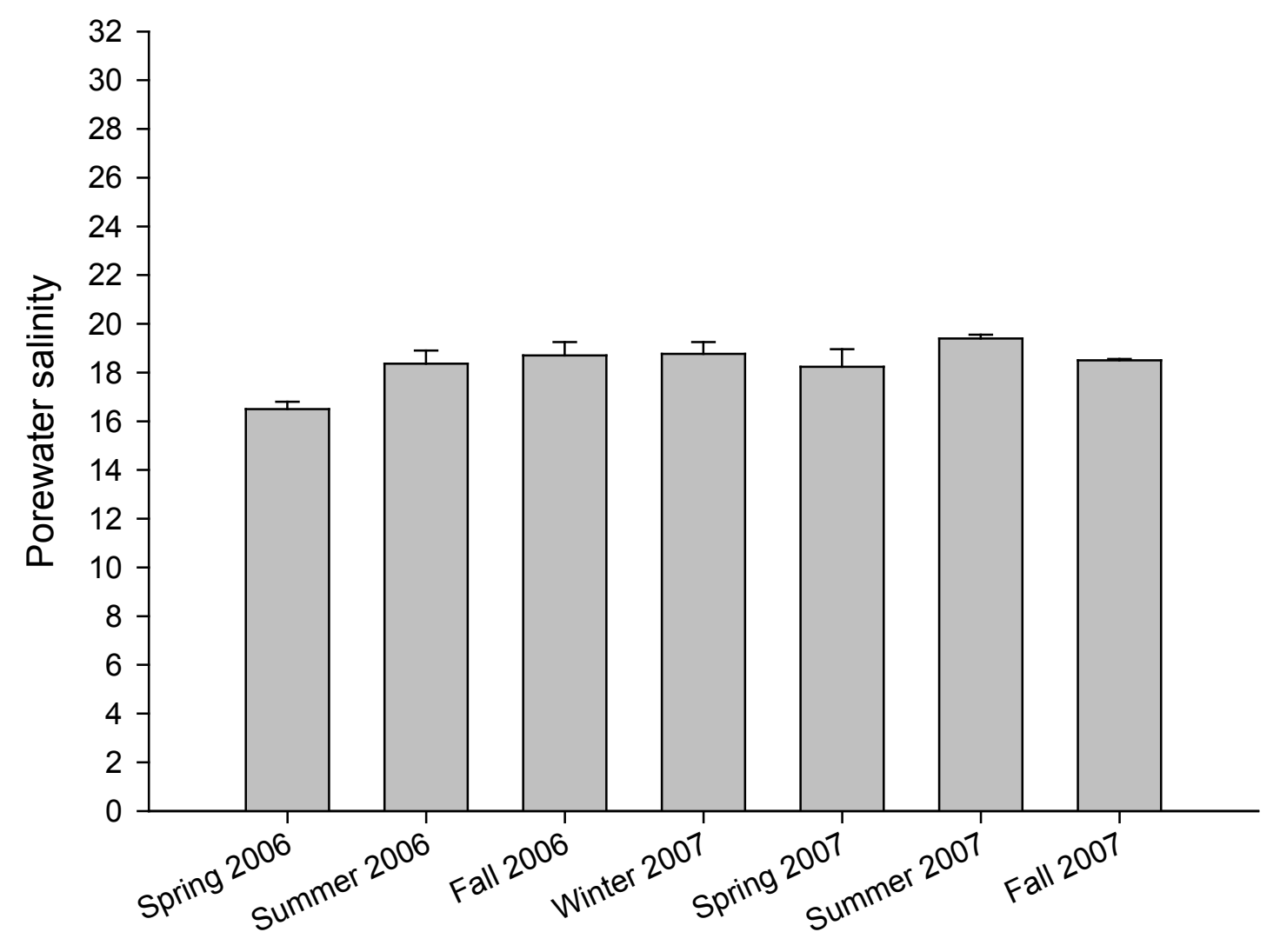

Figure 67. Discrete porewater salinity measured by season at $30 \mathrm{~cm}$ deep at Coastwide Reference Monitoring System (CRMS) site 0326-H.

\section{Season}

provided continuous hourly salinity data. At CRMS0326, surface-water salinity averaged 9.37 ( \pm 3.84$)$ from April 2006 to October 2007 (fig. 68). Throughout the same time period, discrete porewater salinity at CRMS0326 ranged from 10.4 to $18.2($ mean $=13.68 \pm 2.51)$, less than at CRMS0326-H $($ mean $=18.35 \pm 1.08)$. The greatest porewater salinity at CRMS0326 was observed in summer 2006.

Surface-water and porewater salinities at CRMS0326-H and CRMS0326 were typical of saline marsh environments. Surface-water salinities tended to decrease slightly throughout the study period, with seasonal increases in summer 2007 and fall 2006 and 2007. Porewater salinity at CRMS0326 was similar to that observed in saline marsh environments by Chabreck in 1972 (15.87 \pm 3.11$)$ (fig. 68). After Hurricanes Katrina and Rita, it appears that surface-water and porewater salinities have not been stressors to vegetation at CRMS0326 and CRMS0326-H because salinities have remained within typical ranges found in saline marsh habitats.

\section{Vegetation Cover}

Monospecific stands of $S$. alterniflora were present at this site from spring 2006 through fall 2007 (fig. 69). Live vegetation cover averaged $76.4( \pm 13.8)$ percent throughout the study period. Seasonal trends were observed, with the minimum cover (50 percent) occurring in winter 2007, when live cover is expected to be the lowest. The vegetation did not appear to be influenced by the hurricanes during the initial sampling period (spring 2006), and neither salt stress nor disturbance species were present throughout the study period (fig. 70).

\section{Aboveground and Belowground Biomass}

Live aboveground biomass ranged from 168.0 to $626.7 \mathrm{~g}$ dry weight $\mathrm{m}^{-2}$ (fig. 71). The peak value of live aboveground biomass occurred in fall 2006, while the lowest value occurred in winter 2007. The dead component of aboveground biomass tended to show trends that were the inverse of those of the live component; as live biomass increased dead biomass decreased. The peak value of dead aboveground biomass occurred in winter $2007\left(778.7 \pm 50.3 \mathrm{~g}\right.$ dry weight $\left.\mathrm{m}^{-2}\right)$. The live and dead aboveground biomass components were within published ranges for marshes dominated by S. alterniflora (Kaswadji and others, 1990; Visser and others, 2006; Darby and Turner, 2008). A marked decrease in biomass indicative of hurricaneinduced stress was not evident after Hurricanes Katrina and Rita. As was observed with vegetation cover, the live and 


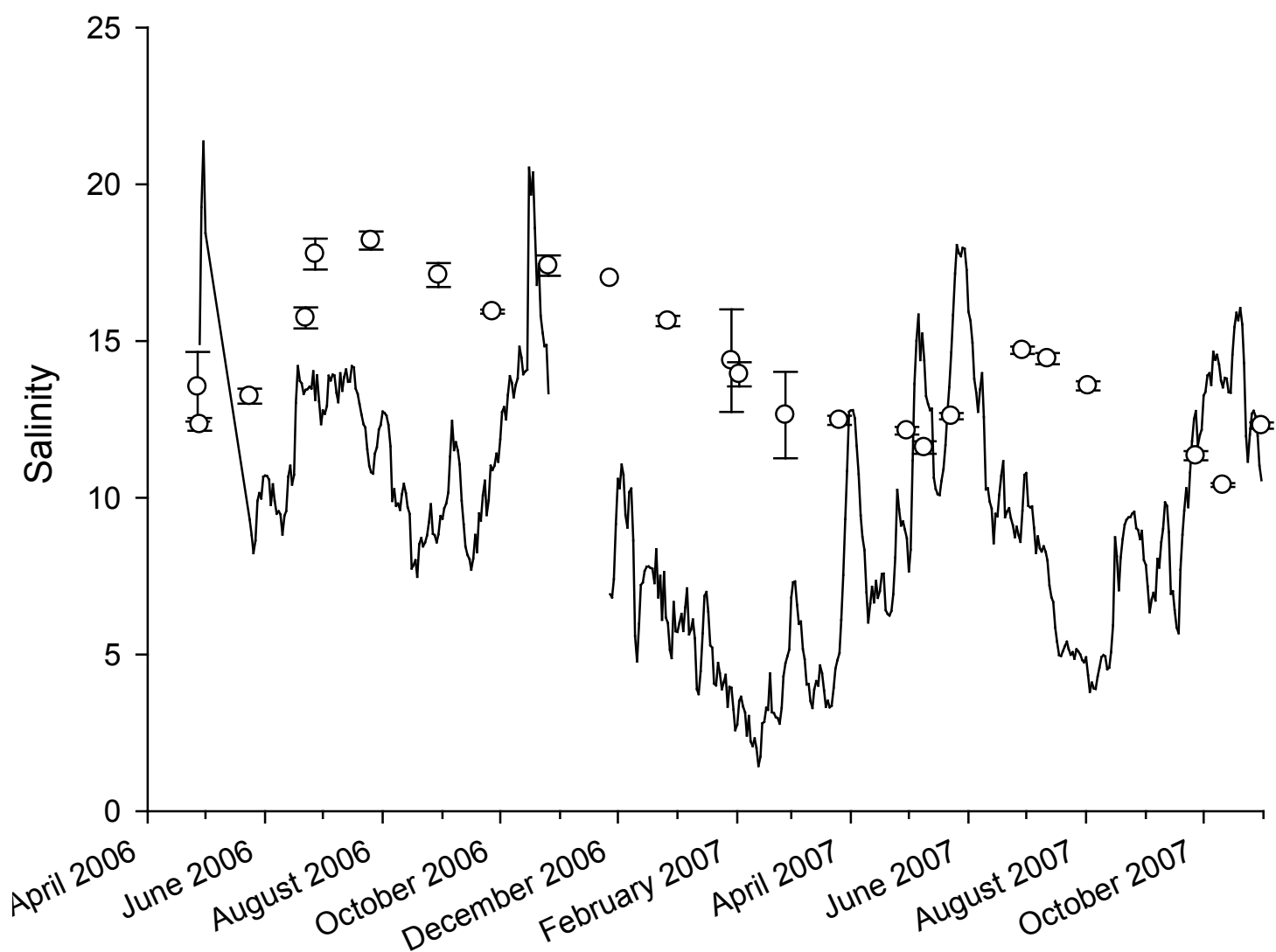

Figure 68. Mean values of daily surface-water salinity (solid line) and discrete porewater salinity (open circles) measured at $30 \mathrm{~cm}$ deep from April 2006 to November 2007 at Coastwide Reference Monitoring System (CRMS) site 0326.

\section{Date}

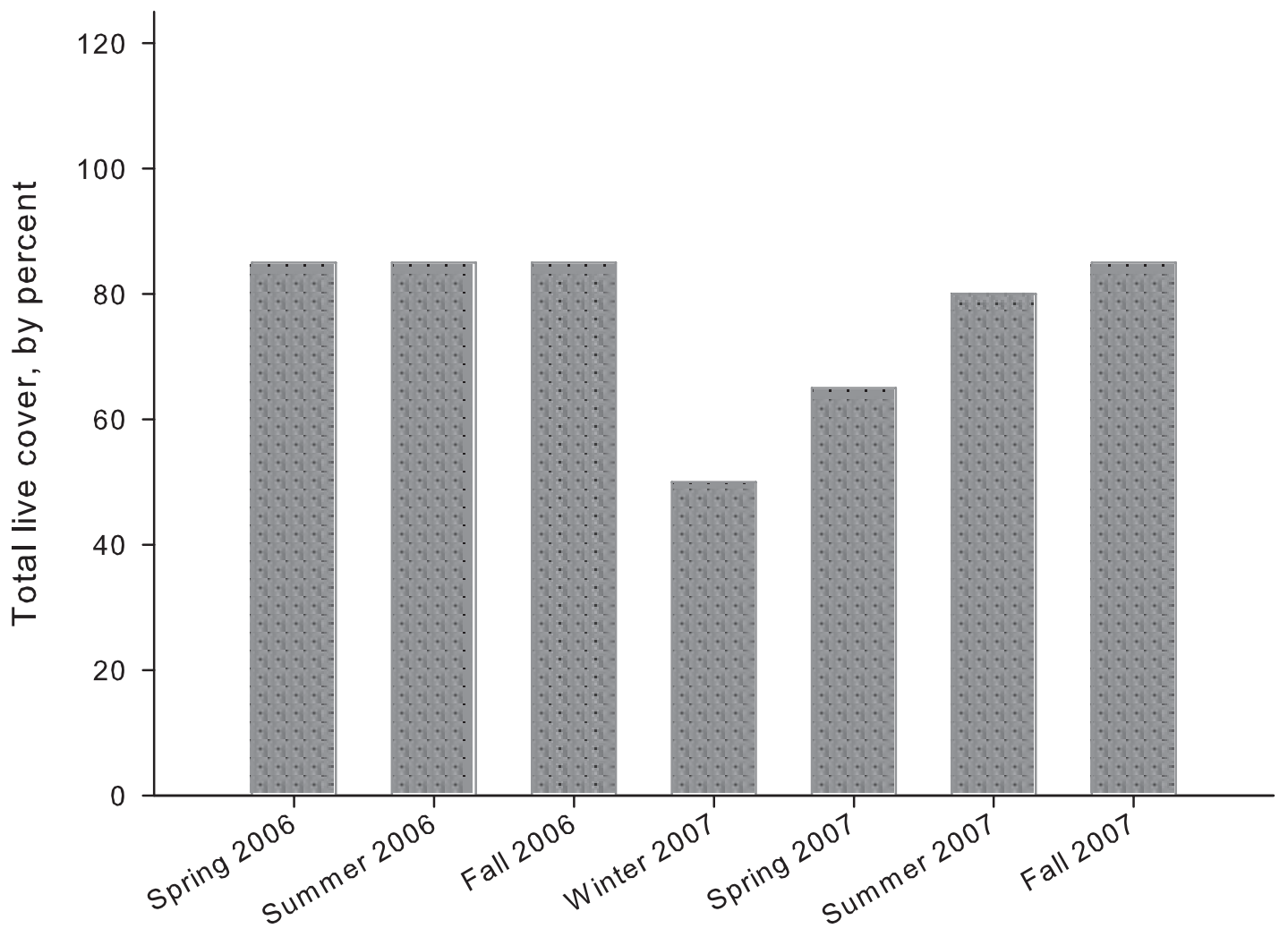

Figure 69. Species composition (all Spartina alterniflora) of total live vegetation cover by season at Coastwide Reference Monitoring System (CRMS) site 0326-H. 


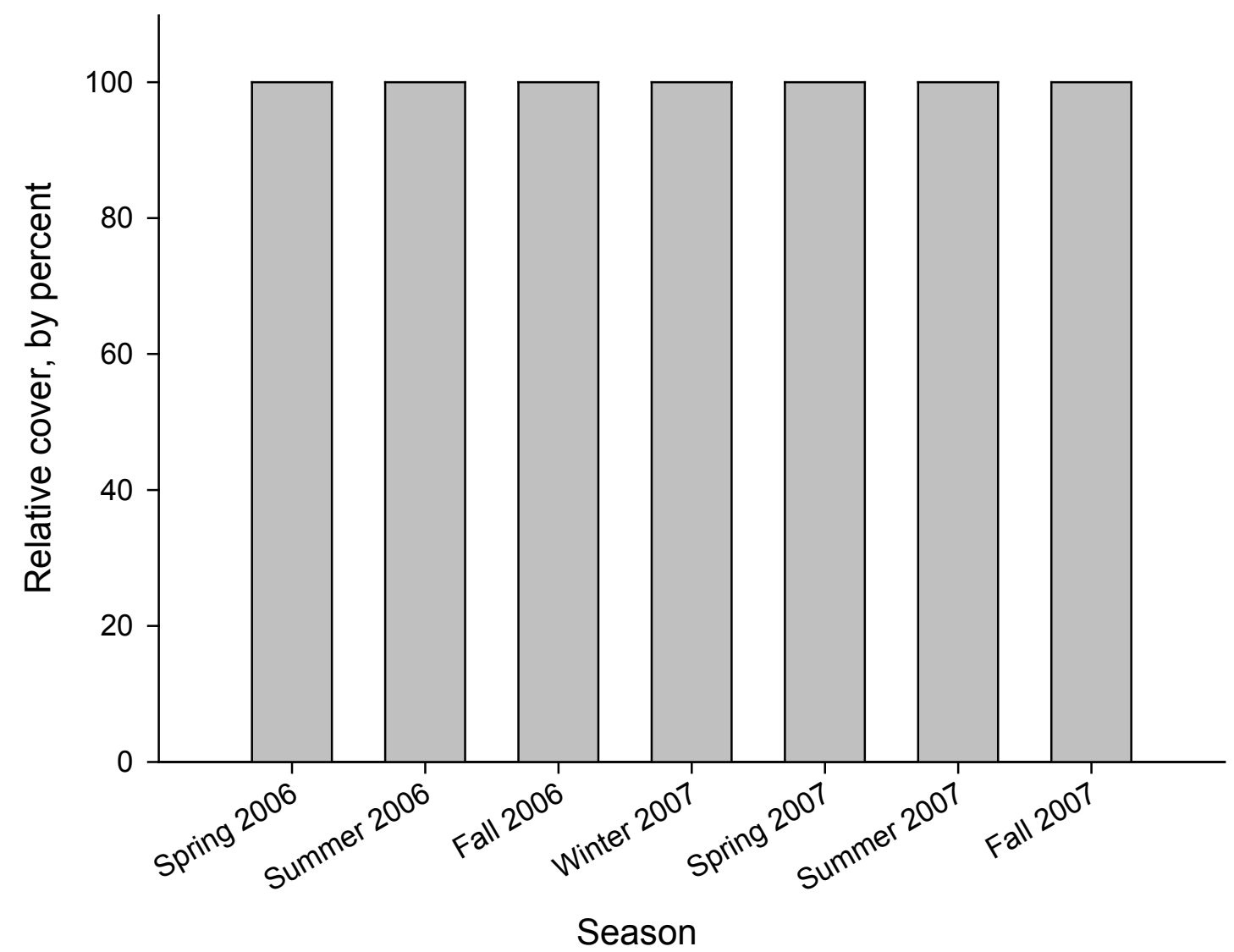

Figure 70. Seasonal cover of nondisturbance taxa at Coastwide Reference Monitoring System (CRMS) site 0326- H. There was no presence of disturbance taxa throughout the study period.

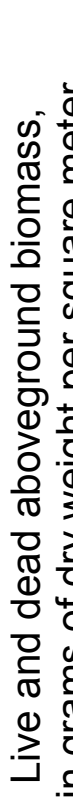

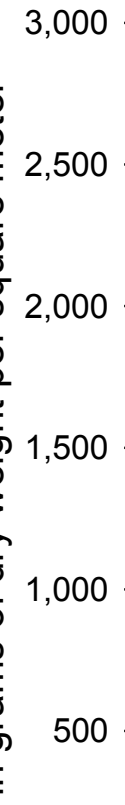
$-$

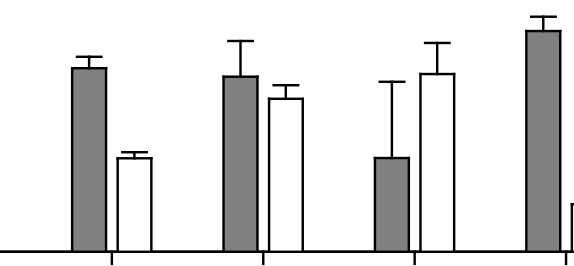

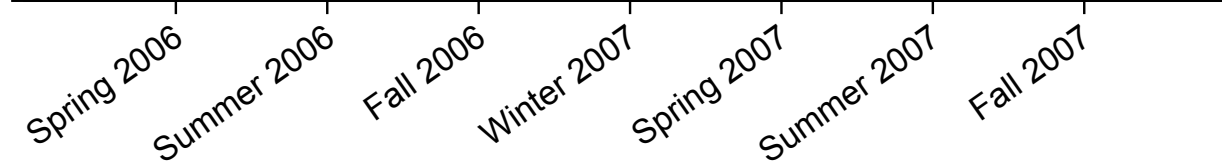

Figure 71. Live (white bars) and dead (gray bars) aboveground biomass (see standard error bars) by season at Coastwide Reference Monitoring System (CRMS) site 0326-H. 
dead components of aboveground biomass remained similar to historically observed conditions (fig. 72), with no significant difference between total aboveground biomass $(p=0.211)$ before and after the storms. Hurricanes

Katrina and Rita did not influence species dominance at the site because no vegetation taxa common to disturbance environments colonized the site (fig. 70). The stand remained monospecific to $S$. alterniflora throughout the study period and did not appear to be negatively influenced by the hurricanes.

Total and live aboveground biomass at the end of growing seasons was greater in fall 2006 than in fall 2001, 2002, and 2007 (fig. 72). Total aboveground biomass at the end of growing seasons ranged from 607.4 to $957.3 \mathrm{~g}$ dry weight $\mathrm{m}^{-2}$, while live aboveground biomass at the end of growing seasons ranged from 356.4 to $626.7 \mathrm{~g}$ dry weight $\mathrm{m}^{-2}$. As with total vegetation cover, total aboveground biomass at the end of growing seasons did not vary greatly throughout the study period; however, it was lower in fall $2007\left(\right.$ mean $=607.4 \pm 82.0 \mathrm{~g}$ dry weight $\mathrm{m}^{-2}$ ) than in any other season.

Total aboveground biomass ranged from $607( \pm 82)$ to $1,157( \pm 79) \mathrm{g}$ dry weight $\mathrm{m}^{-2}$, while the amount of total belowground biomass was approximately eight times greater, ranging from $6,077( \pm 1,142)$ to $9,114( \pm 570) \mathrm{g}$ dry weight $\mathrm{m}^{-2}$ (fig. 73). Both aboveground and belowground biomass estimates were similar to those reported by Darby and Turner (2008) from a similar marsh dominated by $S$. alterniflora within Terrebonne basin. Little seasonal variation occurred in total aboveground and belowground biomass throughout the study. Dead roots and rhizomes composed the majority of the belowground biomass for all seasons (fig. 74). Live belowground biomass was greatest in fall 2006 but never exceeded 25 percent of the total belowground biomass. There were discernable trends in the seasonal abundance, with live belowground biomass being greatest between fall 2006 and spring 2007. After the hurricanes, live belowground biomass was greater overall in the second growing season than in the first.

\section{Sediment Characterization, Accretion, and Elevation}

Mean values of soil bulk-density averaged 0.30 $( \pm 0.04) \mathrm{g} \mathrm{cm}^{-3}$ from 0 to $48 \mathrm{~cm}$ in depth (fig. 75). These values are similar to other estimates of soil bulk-density for saline marshes dominated by S. alterniflora in Louisiana, which range from 0.23 to $0.30 \mathrm{~g} \mathrm{~cm}^{-3}$ (Hatton and others, 1983; DeLaune and others, 1990; Nyman and others, 1993). Carbon accumulation was estimated at $154( \pm 20.7)$ $\mathrm{g} \mathrm{C} \mathrm{m}^{-2} \mathrm{yr}^{-1}$, and nitrogen accumulation was $7.1( \pm 0.8)$ $\mathrm{g} \mathrm{N} \mathrm{m}^{-2} \mathrm{yr}^{-1}$ (table 5). The mean value for depth of the peak

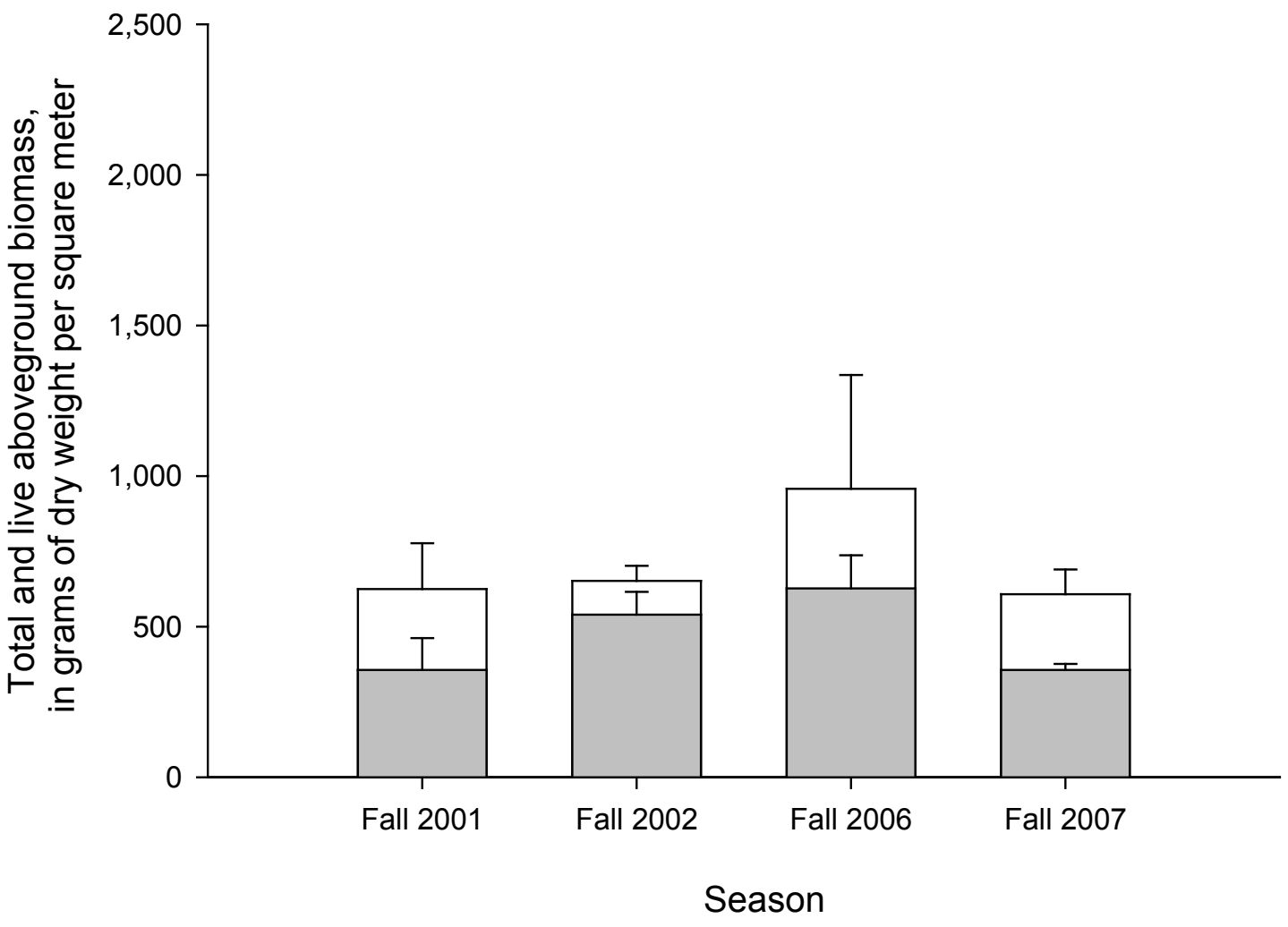

Figure 72. Total (white bars) and live (gray bars) aboveground biomass (see standard error bars) measured at the end of growing seasons at Coastwide Reference Monitoring System (CRMS) site $0326-\mathrm{H}$. 


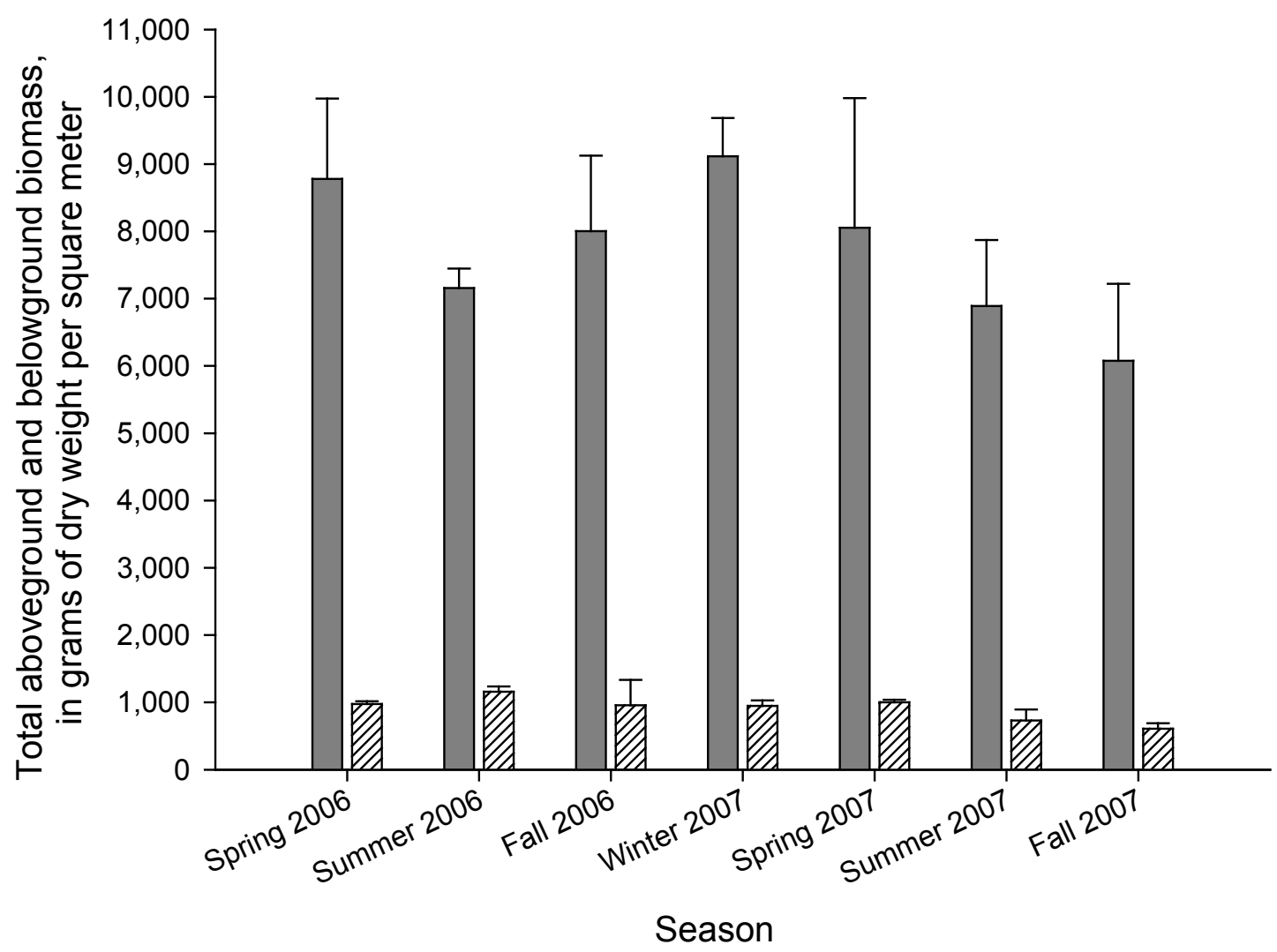

Figure 73. Total aboveground (hatched bars) and belowground (gray bars) biomass (see standard error bars) by season at Coastwide Reference Monitoring System (CRMS) site 0326-H.

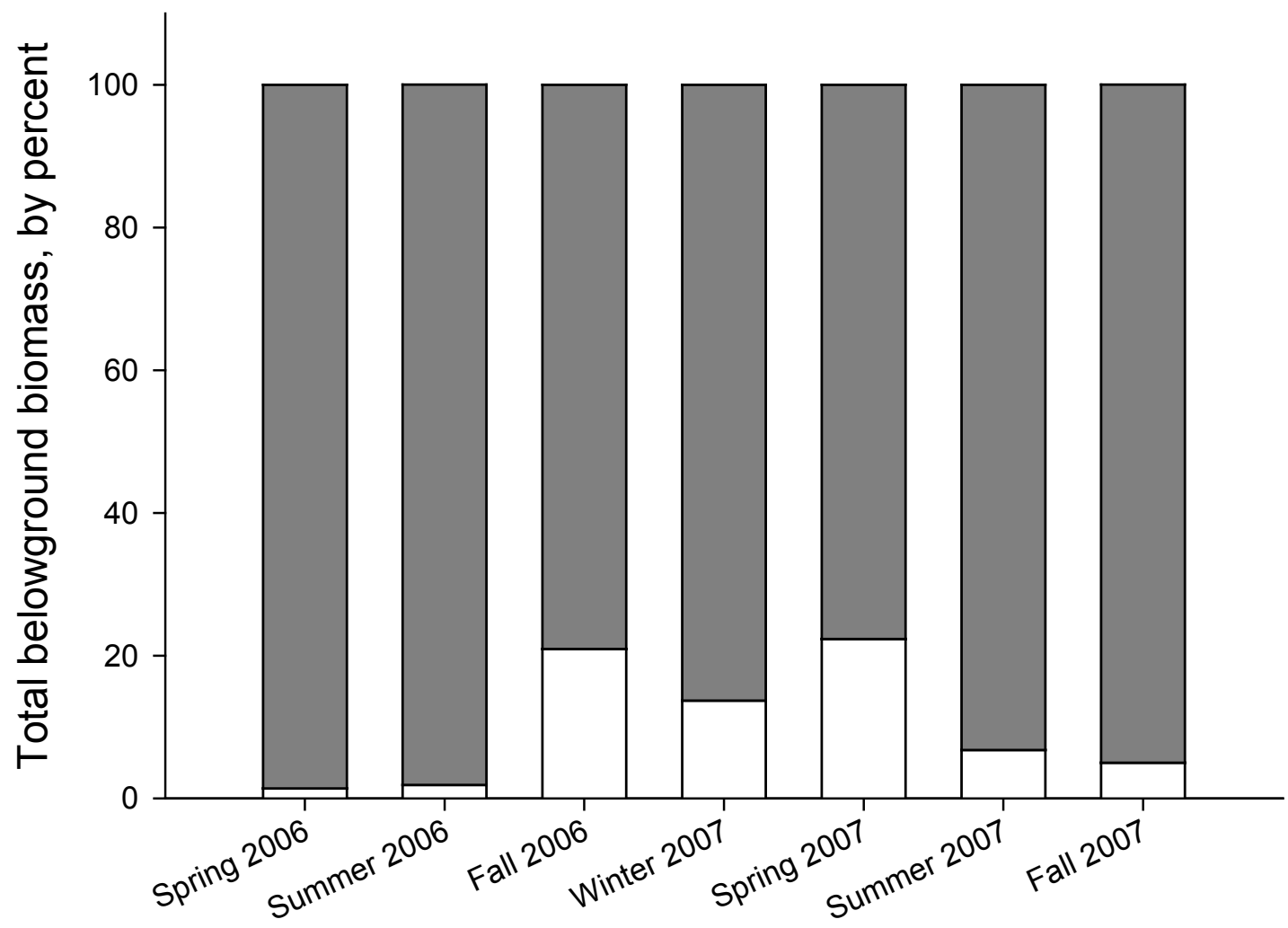

Figure 74. Live (white bars) and dead (gray bars) components of total belowground biomass by season at Coastwide Reference Monitoring System (CRMS) site 0326-H. 


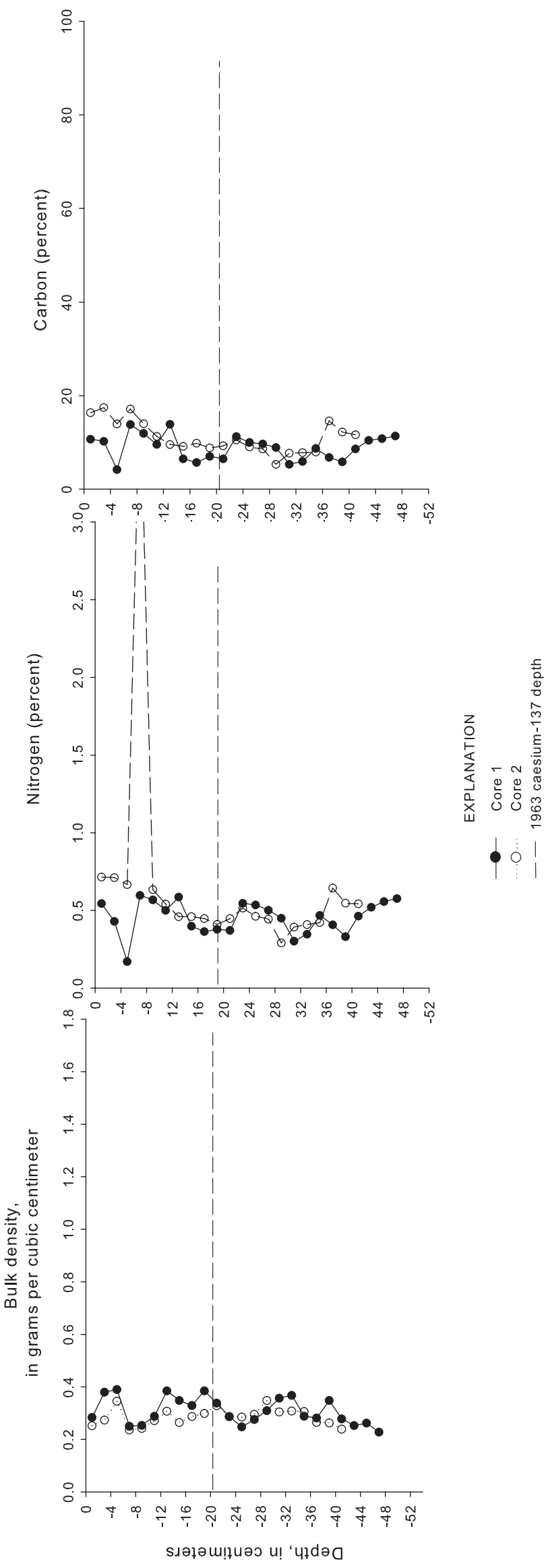


level of caesium-137 activity for two cores taken in fall 2006 was $20.9 \mathrm{~cm}$ (fig. 76). By these estimates, the accretion rate since 1963 has been $0.46 \mathrm{~cm} \mathrm{yr}^{-1}$, which is lower than rates published for other saline marshes in Louisiana, which range from 0.59 to $1.10 \mathrm{~cm} \mathrm{yr}^{-1}$ (Hatton and others, 1983; DeLaune and others, 1990; Nyman and others, 1993; Chmura and Kosters, 1994; Nyman and others, 2006).

Soil bulk-density since 1963 was calculated at 0.29 $( \pm 0.03) \mathrm{g} \mathrm{cm}^{-3}$, similar to the soil bulk-density estimate before 1963. The depth of the 1963 layer at this site was approximately 7 to $15 \mathrm{~cm}$ shallower than at the other saline marsh study sites in this study except at a site in lower Breton Sound (peak depth of caesium-137 activity $=17.2 \mathrm{~cm}$ at CRMS0147), where only one core was processed for caesium activity.

No short-term estimate of vertical accretion was possible because of poor sampling conditions. The feldspar marker horizon was only located during one sampling period in one feldspar plot; therefore, we could not analyze the feldspar data at this site. Site-specific processes dictate elevation and accretion changes, so it is not appropriate to assume that the rates calculated from the paired site (CRMS0326 over $2.5 \mathrm{~km}$ north) are identical to CRMS0326-H; however, the data from nine CRMS study sites are available in appendix 2 . The CRMS0326-H site is much closer to the gulf and on a major bayou, thereby receiving greater tidal inundation and suspended sediment than CRMS0326, which is located within an area of solid marsh separated by small bayous and marsh ponds. The long-term accretion rate calculated from the caesium-137 analysis of one core was $0.70 \mathrm{~cm} \mathrm{yr}^{-1}$, which is within the range of other Louisiana saline marshes (Hatton and others, 1983; DeLaune, 1990; Nyman and others, 1993; Chmura and Kosters, 1994; Nyman and others, 2006; Smith and others, 1983).

The short-term elevation change rate at CRMS0326- $\mathrm{H}$ (measured by RSET) was calculated at $0.23 \mathrm{~cm} \mathrm{yr}^{-1}$ during this study (fig. 77). With current estimates of RSLR, the site elevation change is $0.69 \mathrm{~cm} \mathrm{yr}^{-1}$, less than what would be required to keep pace with RSLR. The limited data from this study suggest that the site is not building sufficient elevation to prevent increased inundation and stress from longer frequency and duration of flooding associated with RSLR. Rates of short-term elevation change alone are not conclusive of a failure to compensate for projected sea level rise, unless they are interpreted with respect to the elevation of the site within the tidal frame.

\section{Summary of the Classification of Impacts}

The CRMS0326-H site did not appear to be negatively impacted by either Hurricanes Katrina or Rita. This lack of influence from the hurricanes was expected because the site is located greater than $140 \mathrm{~km}$ from the path of Hurricane Katrina and $280 \mathrm{~km}$ from that of Hurricane Rita. The storm surges at the site were estimated to be less than $1.5 \mathrm{~m}$, and because no impoundments exist in the area, the storm surge flushed in and out of the marsh quickly. The mechanical destruction of vegetation and the marsh surface that was observed at other sites was not present at CRMS0326-H. The site experienced mean values of porewater salinity greater than the mean value observed by Chabreck (1970) but within the range of historically observed values. The species at this site are adapted to fluctuations in salinity such as those observed during this study.

In fall 2005, immediately after Hurricanes Katrina and Rita, the departure from the average NDVI value was -0.21 , indicating some decrease in plant vigor from the baseline average. At the end of the second growing season after the storms, the departure from the average NDVI value increased to -0.07 , thereby indicating that the plant community had recovered somewhat but not to the baseline average. Our study does not include data on aboveground biomass or live cover from fall 2005 to validate the change in NDVI values; however, seasonal photography does illustrate the vegetative vigor in fall 2006. The monospecific stand of S. alterniflora appeared healthy throughout the study period.

\section{Case Study 5: CRMSO164-H}

\section{Overall Site Description}

The CRMS0164-H site is located in the saline marshes in southwestern Barataria basin (fig. 78; see Louisiana Coastal Wetlands Planning, Protection and Restoration Act Program [n.d.] for definition of the basin) in an area classified as being indirectly impacted by Hurricanes Katrina and Rita in 2005. Marshes in this general region of the coast are typically dominated by S. alterniflora with D. spicata, Juncus roemerianus (needlegrass rush), and, recently, Avicennia germinans (L.) L (black mangrove). The area includes numerous small ponds and shallow lakes within the marshes. The CRMS0164-H site is located near a small lake (locally known as Airplane Lake) in the marsh adjacent to Bayou Ferblanc, near larger water bodies Lake Palourde and Bay Macoin. These water bodies are part of the increasingly open estuarine system connected to Caminada Bay. There is no direct connection from CRMS0164-H to a navigation canal, although the Southwestern Louisiana Canal is located several kilometers north of the Airplane Lake area and is a major waterway connecting Bayou Lafourche at Leeville to Caminada Bay and Barataria Bay. The Southwestern Louisiana Canal further connects into Timbalier Bay to the west, providing a pathway for higher salinity waters from the bay to enter the marshes.

\section{Historical Datasets}

The CRMS0164-H site is an area with high historical data collection value. Several earlier studies included this general area for field research, dating back to the earliest studies by the Center for Wetland Resources at Louisiana State University. 
Bulk density, in grams per cubic centimeter

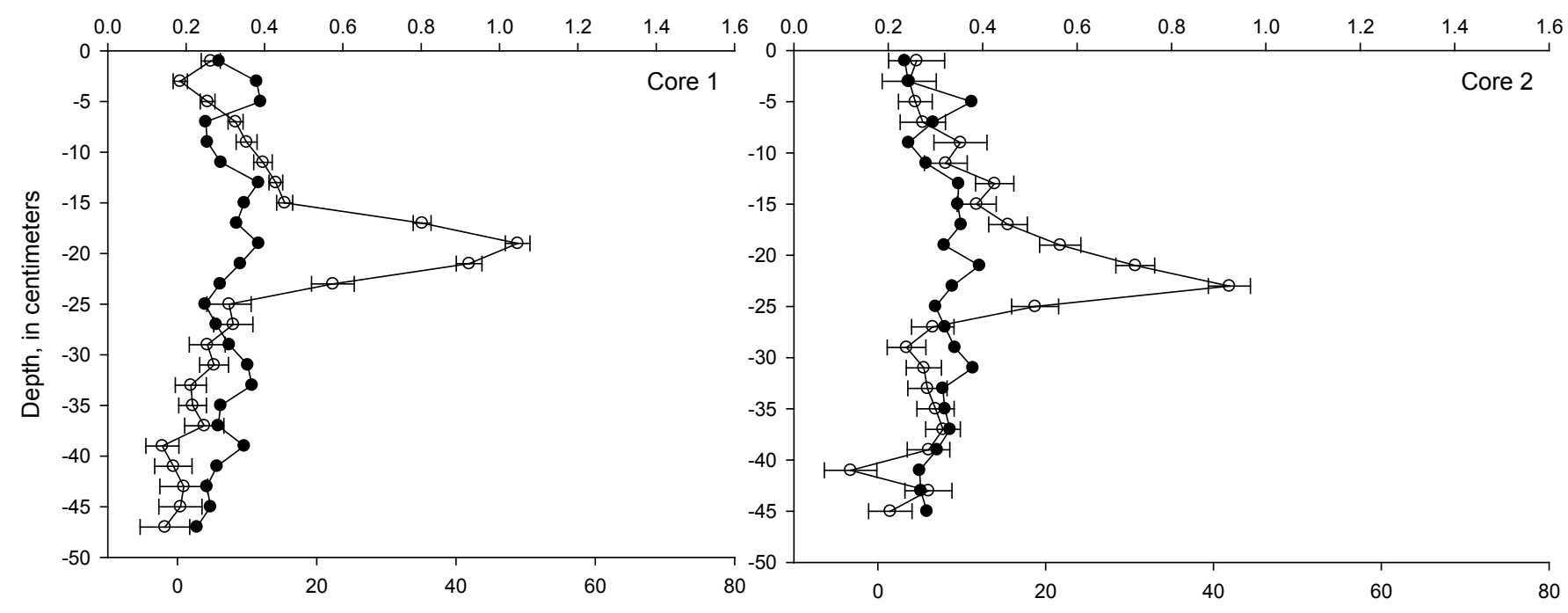

Caesium-137 activity, in becquerels per kilogram

EXPLANATION

${ }^{137}$ Cs activity

Bulk density

Figure 76. Bulk density and caesium-137 profiles at Coastwide Reference Monitoring System (CRMS) site 0326-H. Measurements were obtained from two cores taken at 0-50 cm deep. Peak caesium-137 activity for core 1 occurred at a depth of $19.1 \mathrm{~cm}$, and peak caesium-137 activity for core 2 occurred at a depth of $22.7 \mathrm{~cm}$.

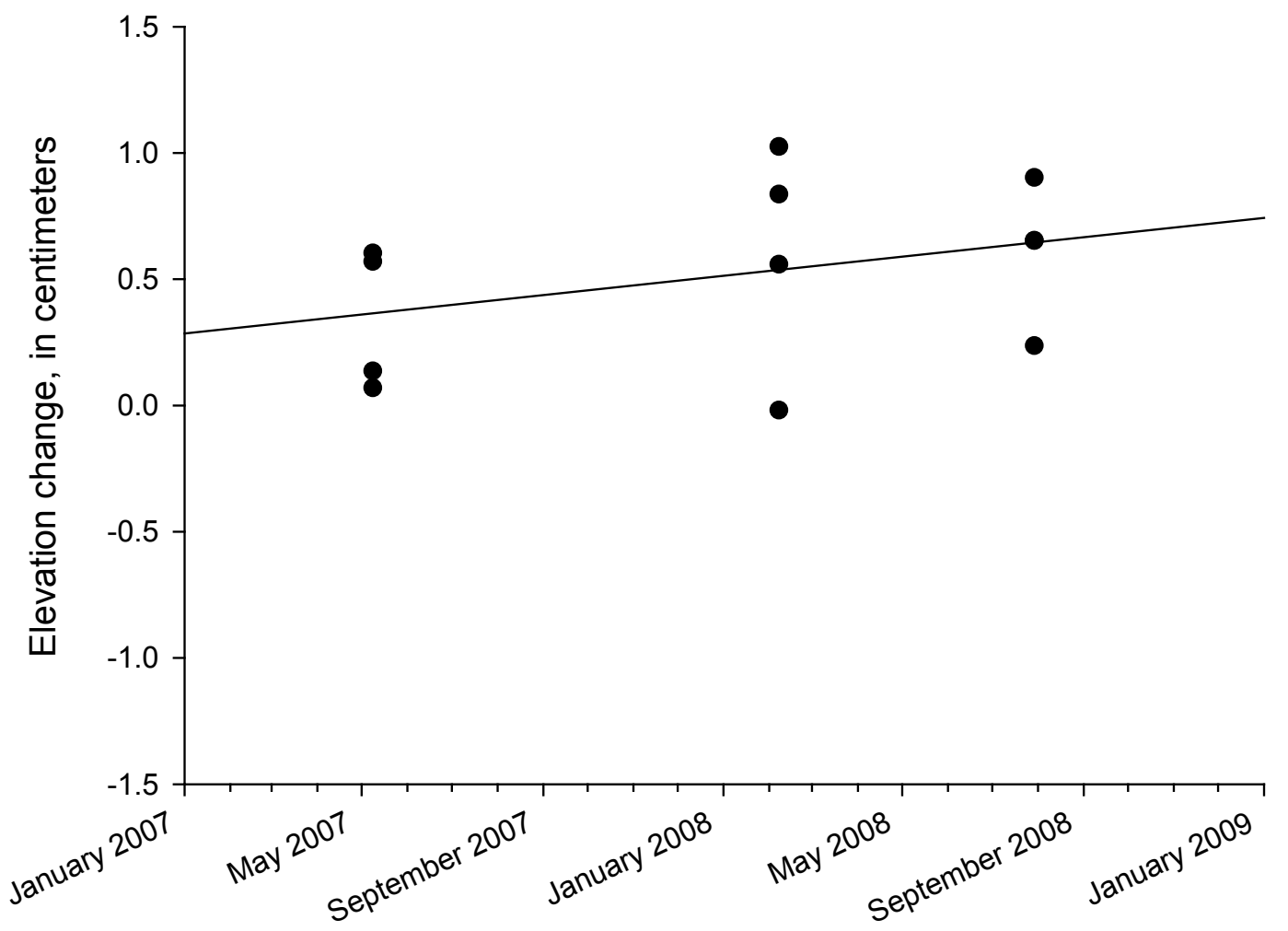

Figure 77. Rate of elevation change at Coastwide Reference Monitoring System (CRMS) site 0362-H. There were no data on vertical accretion or shallow subsidence at CRMSO362- $\mathrm{H}$. The rate of elevation change $(y=-2.1234+0.0006 x$; $r^{2}=0.12$ ) was 0.23 centimeters per year $(\mathrm{cm}$ $\left.\mathrm{yr}^{-1}\right)$, and the relative sea level rise (RSLR) was $0.92 \mathrm{~cm} \mathrm{yr}^{-1}$. Elevation change at CRMS0362- $\mathrm{H}$ is projected to be $0.69 \mathrm{~cm} \mathrm{yr}^{-1}$ less than RSLR. 

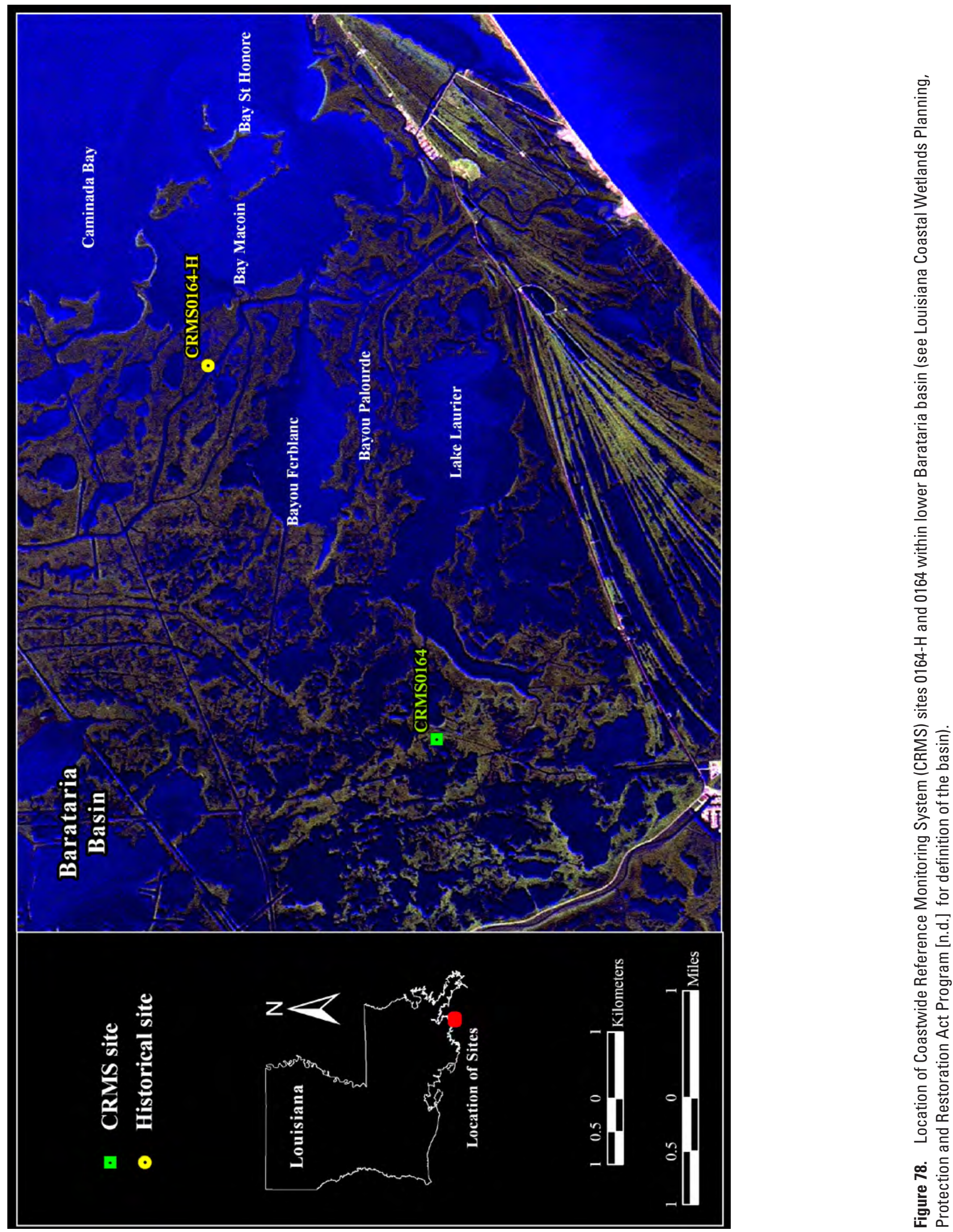
Several graduate students used data collected in this area to determine primary production values in saline marshes (Kirby and Gosselink, 1976; Kaswadji, 1982; Kaswadji and others, 1990). Historical field studies also include the LOOP baseline study for the original environmental impact work (Sasser and others, 1978). The baseline environmental impact study was followed by a long-term environmental monitoring program (that is, nearly 20 years) following construction of LOOP. The long term monitoring program (hereafter termed the LOOP study) included this site as a reference area.

\section{Monitoring Program for the Louisiana Offshore Oil Port}

The LOOP study included measurements of impacts from the LOOP and was conducted from 1978 through 1995, during which time vegetation biomass was harvested from $0.25-\mathrm{m}^{2}$ plots at the end of growing seasons (usually in September) at the CRMS0164-H site. At each site, the first plot on a transect was randomly selected. Subsequent plots were determined by orienting the transect perpendicular to the adjacent bayou and sampling at $20-\mathrm{m}$ intervals. If a plot was located in open water, the location was changed to the nearest vegetated area along the transect line. Biomass measurements for the LOOP study followed the same procedures as used in this study. The dominant plant species was $S$. alterniflora, with S. patens and D. spicata occasionally present. Another aspect of the LOOP study included two graduate theses that involved mapping wetlands and vegetation change within the southwestern Barataria basin (Dozier, 1983; Evers, 1991). The authors of both theses used a grid cell size of 0.25 ha. As reported in Dozier (1983), the wetland classification included a series of classes that combined both percentage and configuration of the water bodies within the marsh. Vegetation in the area was classified by Dozier (1983) for 1945, 1956, 1965, and 1980, by Evers and others (1992) for 1985, and by Visser and others (1996) for 1989 and 1995. The vegetation categories were based on dominant species to define marsh types for 1983 and 1995 (Evers and others, 1992).

In addition to the LOOP study, the Environmental Monitoring and Assessment Program (EMAP) funded by the Environmental Protection Agency included one site (BH3) that is in proximity (approximately $1 \mathrm{~km}$ ) to site CRMS0164-H. Aboveground and belowground sampling methods were the same as outlined above. The site was originally sampled in 1991 (Swenson and Turner, 1994) and then resampled in 1993 (Turner and others, 1998). Six replicates were taken in the fall each year and the study focused on aboveground vegetation, belowground components, and salinity. Aboveground vegetation indices measured included live, standing dead, and dead biomass; percentage of vegetation cover; and stem count, length and diameter. Soil properties included percentage of organic content, bulk density, and soil reduction. Surfacewater and soil salinities were also measured.

\section{Marsh Stability}

Land loss rates in the area have been relatively low since the 1950s. The saline marshes in the Airplane Lake area have been relatively stable, although in a relatively degraded condition (Evers, 1991). Sasser and others (1986) classified site CRMS0164-H as solid marsh in both 1945 and 1956, signifying that there was less than 10 percent open water within the marsh area. By 1969, the marsh area was classified as having 10-25 percent open water within the marsh. In 1980 and 1985, enough breakup had occurred within the marsh to account for 25-40 percent open water (Evers and others, 1992). From 1989 through 1995, CRMS0164-H was classified as degraded, with 40-60 percent open water, because of typical processes of marsh degredation (for example, subsidence and oil and gas activities) that commonly occur in Louisiana marshes.

\section{Surface-Water and Porewater Salinity}

Surface salinity was not collected at site CRMS0164-H because it was paired with site CRMS0164 that had a surface salinity recorder. Historical surface salinities were, however, available from EMAP for site $\mathrm{BH} 3$, which is located near the area of Airplane Lake. Mean values for surface-water salinity at site BH3 were 17.4 in 1991 and 15.2 in 1993 (Swenson and Turner, 1994; Turner and others, 1998).

Seasonal porewater salinities were significantly higher in the summer and fall of 2006 than in the same seasons in 2007 $(\mathrm{p}<0.0001$, fig. 79). Porewater salinities from the EMAP site averaged 17.7 in 1991 and 17.1 in 1993 (Swenson and Turner, 1994; Turner and others, 1998), which were lower than the values $(>20)$ obtained in the current study for site CRMS0164-H; however, all of the values reported here are within the typical salinity range of saline marsh.

\section{Vegetation Cover}

Throughout our study, the CRMS0164-H site always had greater than 80 percent vegetation cover and showed no observable difference before and after Hurricanes Katrina and Rita. Spartina alterniflora was the only species consistently found during every sampling within the plot used to measure vegetation cover (fig. 80); however, A. germinans was present in the general vicinity in summer 2007. Spartina alterniflora is a typical saline marsh species; therefore, no disturbance species were indicated by the vegetation cover data. Cover values at the end of growing seasons averaged 90 percent in 2006 and 95 percent in 2007.

\section{Aboveground and Belowground Biomass}

As in the vegetation cover data, S. alterniflora was the only species consistently present in the aboveground biomass data throughout the period of our study (fig. 81). Live aboveground biomass was greatest at the end of the growing season in 2006 (averaging 1,283 $\pm 49 \mathrm{~g}$ dry weight $\mathrm{m}^{-2}$ ) and 2007 (averaging 1,128 $\pm 240 \mathrm{~g}$ dry weight $\mathrm{m}^{-2}$ ). These values are slightly greater but similar to those reported for other marshes dominated by S. alterniflora (Visser and others, 1996; Darby and Turner, 2008). Total (live and dead) aboveground biomass ranged from 1,051 $( \pm 163)$ to 2,284 


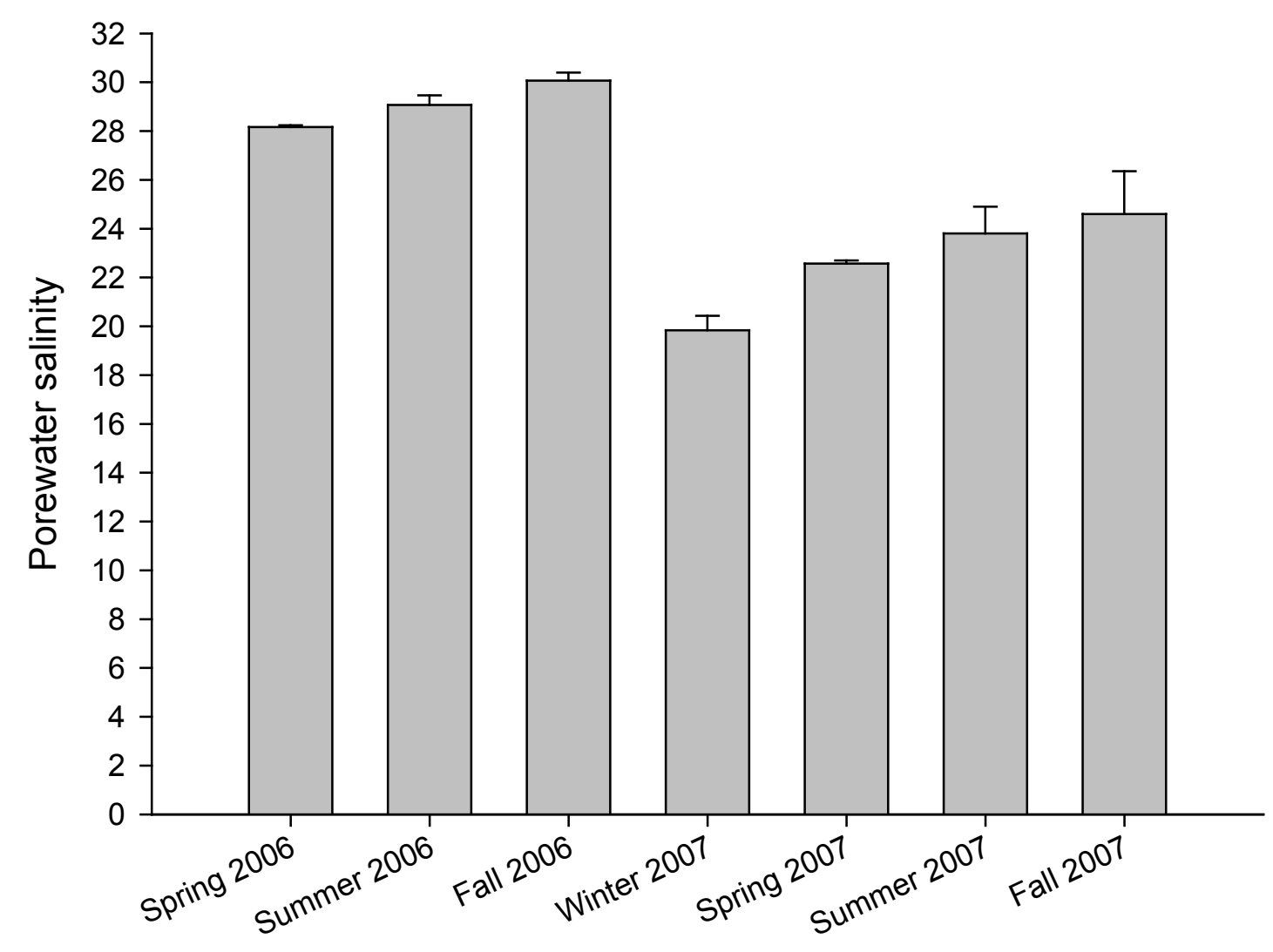

Figure 79. Discrete porewater salinity (see standard error bars) measured at 30 $\mathrm{cm}$ deep by season at Coastwide Reference Monitoring System (CRMS) site 0164-H.

\section{Season}

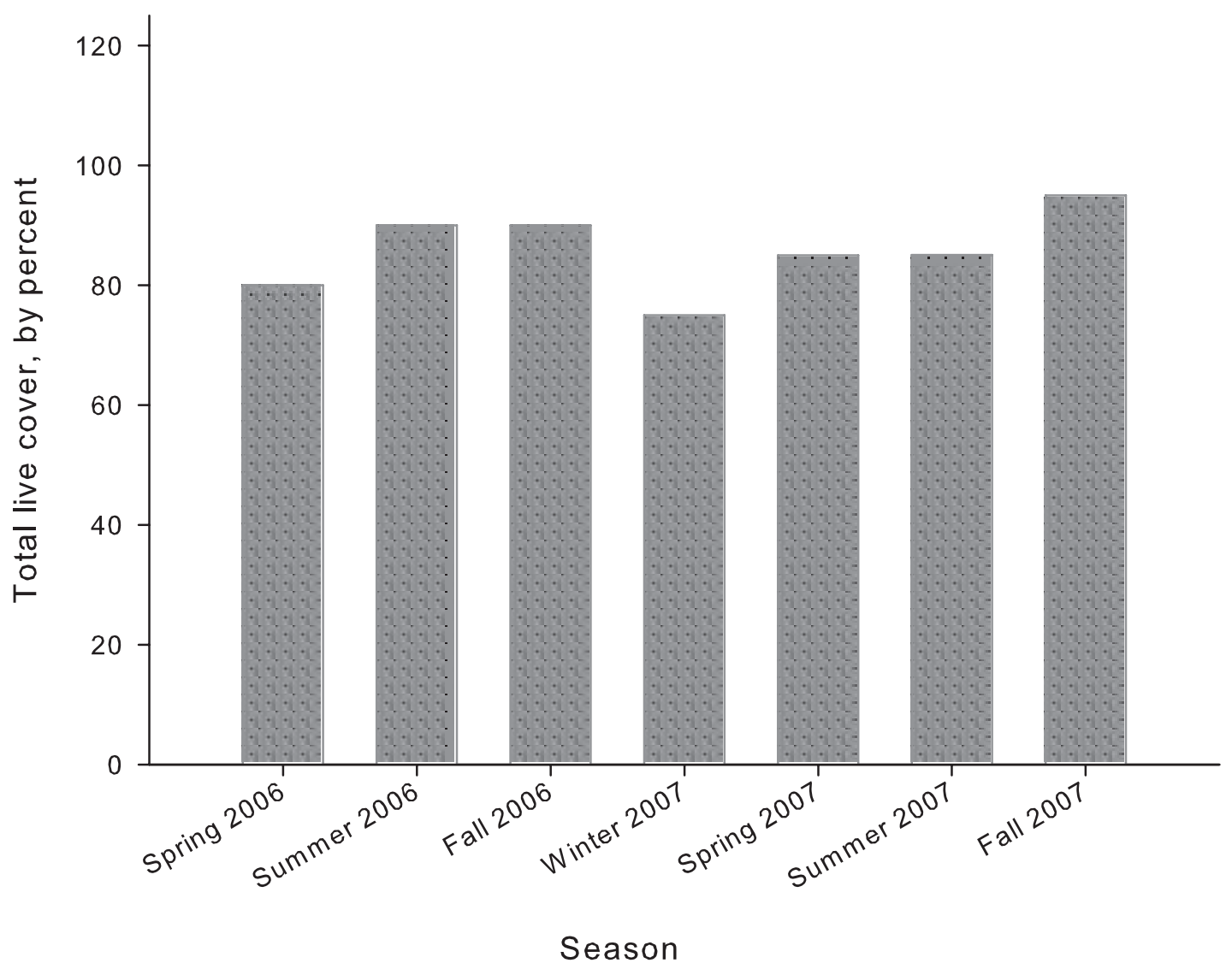

Figure 80. Species composition (all Spartina alterniflora) of total live vegetation cover by season at Coastwide Reference Monitoring System (CRMS) site 0164-H. 


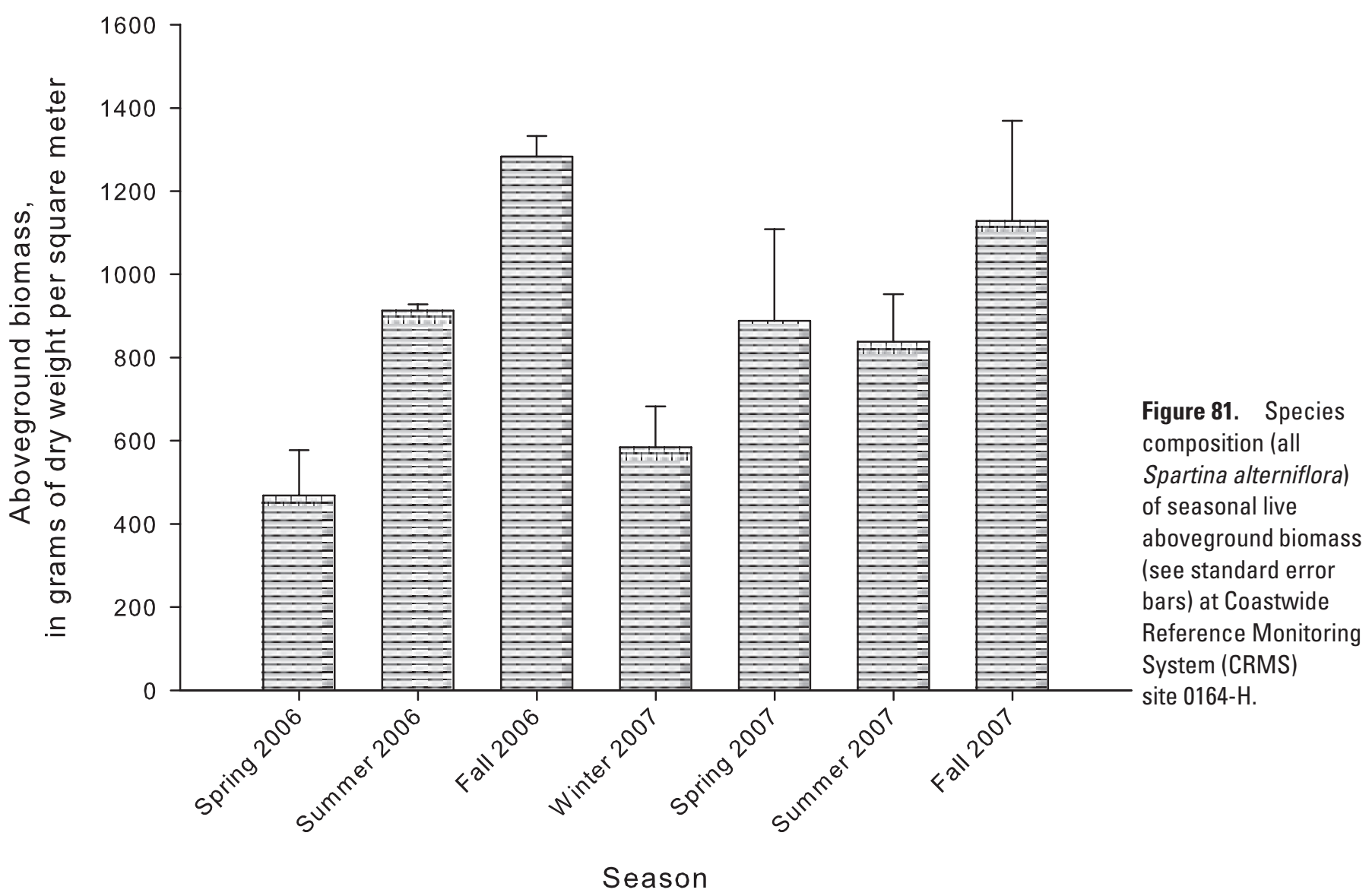

( \pm 544$) \mathrm{g}$ dry weight $\mathrm{m}^{-2}$, peaking in spring 2007 because the greatest amount of dead biomass was collected in that season. Avicennia germinans was also found in at least one sampling period in biomass plots (accounting for $<10$ percent of the biomass in spring 2007).

Total aboveground biomass was 1,870 $( \pm 158) \mathrm{g}$ dry weight $\mathrm{m}^{-2}$ at the end of the growing season in 2006 and 1,638 $( \pm 416) \mathrm{g}$ dry weight $\mathrm{m}^{-2}$ at the end of the growing season in 2007 (fig. 82). A comparison between total aboveground biomass at the end of growing seasons in 1994 and 1995 and at the end of growing seasons after Hurricanes Katrina and Rita showed no statistical difference $(p=0.0544)$. Comparable data were also obtained for this site for 1970 (Kirby and Gosselink, 1976), from 1978 through 1995 (Visser and other, 1996), for 1980 (Kaswadji and others, 1990), and from a nearby site for 1991 (Swenson and Turner, 1994) and 1993 (Turner and others, 1998). A comparison plot of these data (fig. 83) shows that all of the data within each of four datasets are within the range of the LOOP study data.

Visser and others (2006) included the LOOP study data as part of a database they compiled to test quantile regression as a tool to best explain interannual variation. They found that maximum biomass correlated positively with optimal nitrogen levels in surface water. They also concluded that the flooding index they employed was a poor predictor of $S$. alterniflora biomass, possibly because of the lack of elevation data at each plot sampled.

Slocum and others (2005) studied the effects of sediment addition to saline marshes and found a positive relationship between percentage of vegetation cover, canopy height, and aboveground biomass of $S$. alterniflora for the 2 years following a slurry enrichment program that added up to $30 \mathrm{~cm}$ of sediment onto the marsh surface. The trend weakened with passage of time.

Total belowground biomass ranged from 5,685 $( \pm 976)$ to $8,127( \pm 1,208) \mathrm{g}$ dry weight $\mathrm{m}^{-2}$ throughout the study period (fig. 84). These values are similar to those reported by Darby and Turner (2008). The dead component of belowground biomass was greater than the live component in every sampling period and was highly variable. The amount of variability in the data on dead belowground biomass is typical of these types of measurements. Both total and live belowground biomass peaked in the winter 2007 samples. 


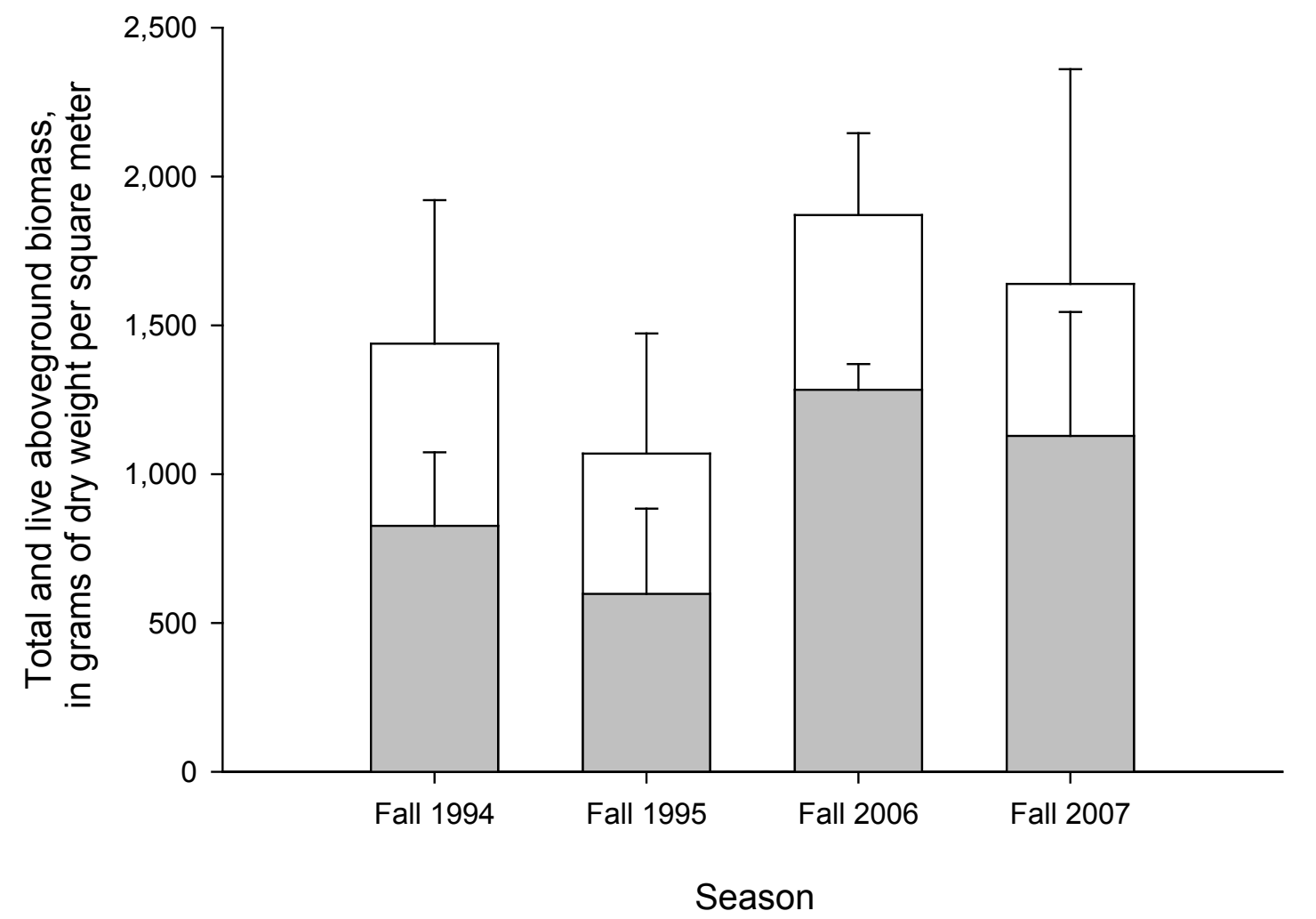

Figure 82. Total (white bars) and live (gray bars) aboveground biomass (see standard error bars) at the end of growing seasons at saline marsh sites with availability of historical data acquired before Hurricanes Katrina and Rita (historical data from Visser and others, 2006).

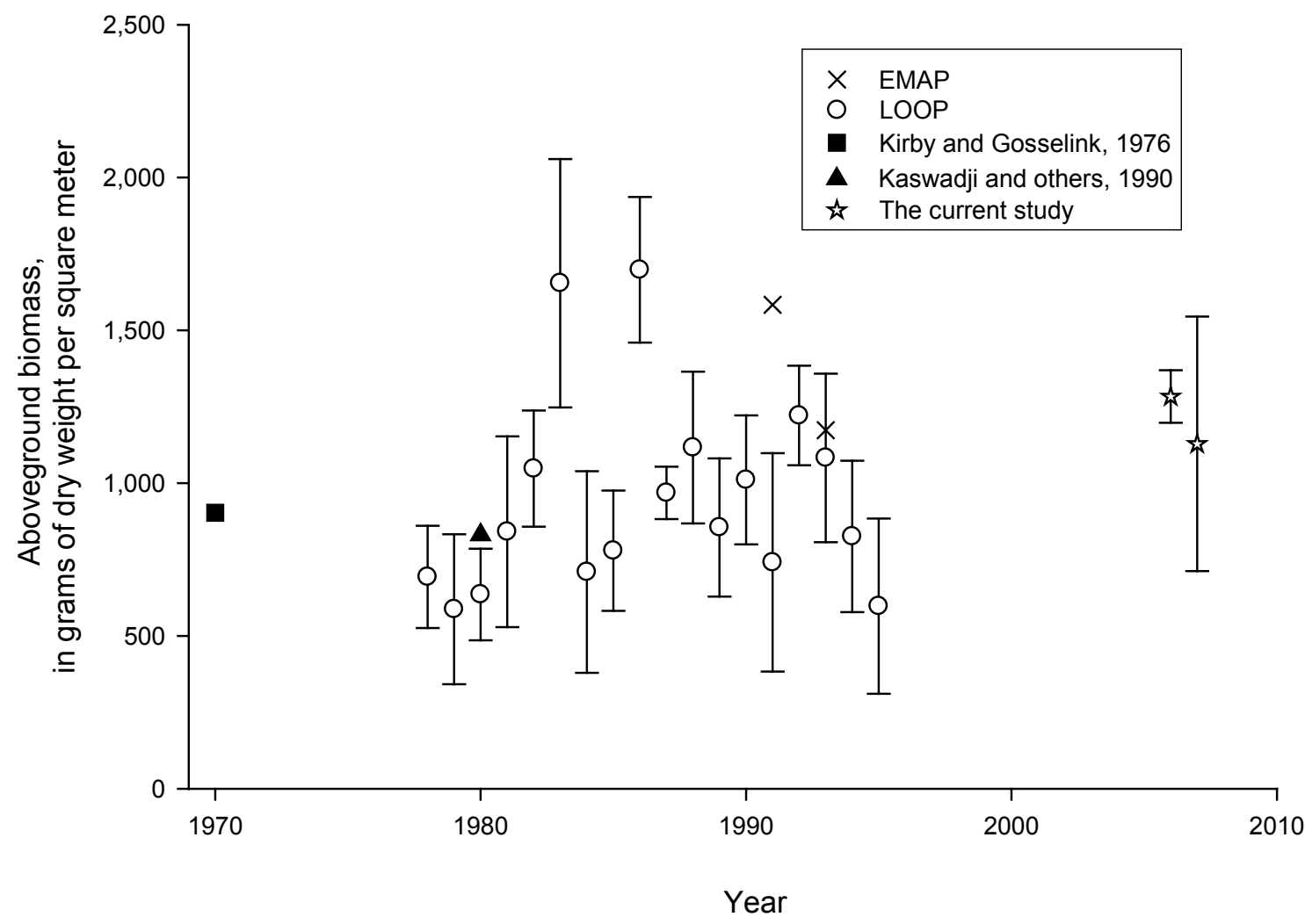

Figure 83. Aboveground biomass at the end of growing seasons as measured during various studies conducted in the vicinity of Coastwide Reference Monitoring System (CRMS) site 0164-H. Data from the Environmental Monitoring and Assessment Program (EMAP) were found in Swenson and Turner (1994) and Turner and others (1998). Data from the Louisiana Offshore Oil Port (LOOP) annual report can be found in Sasser and others, 1978. 


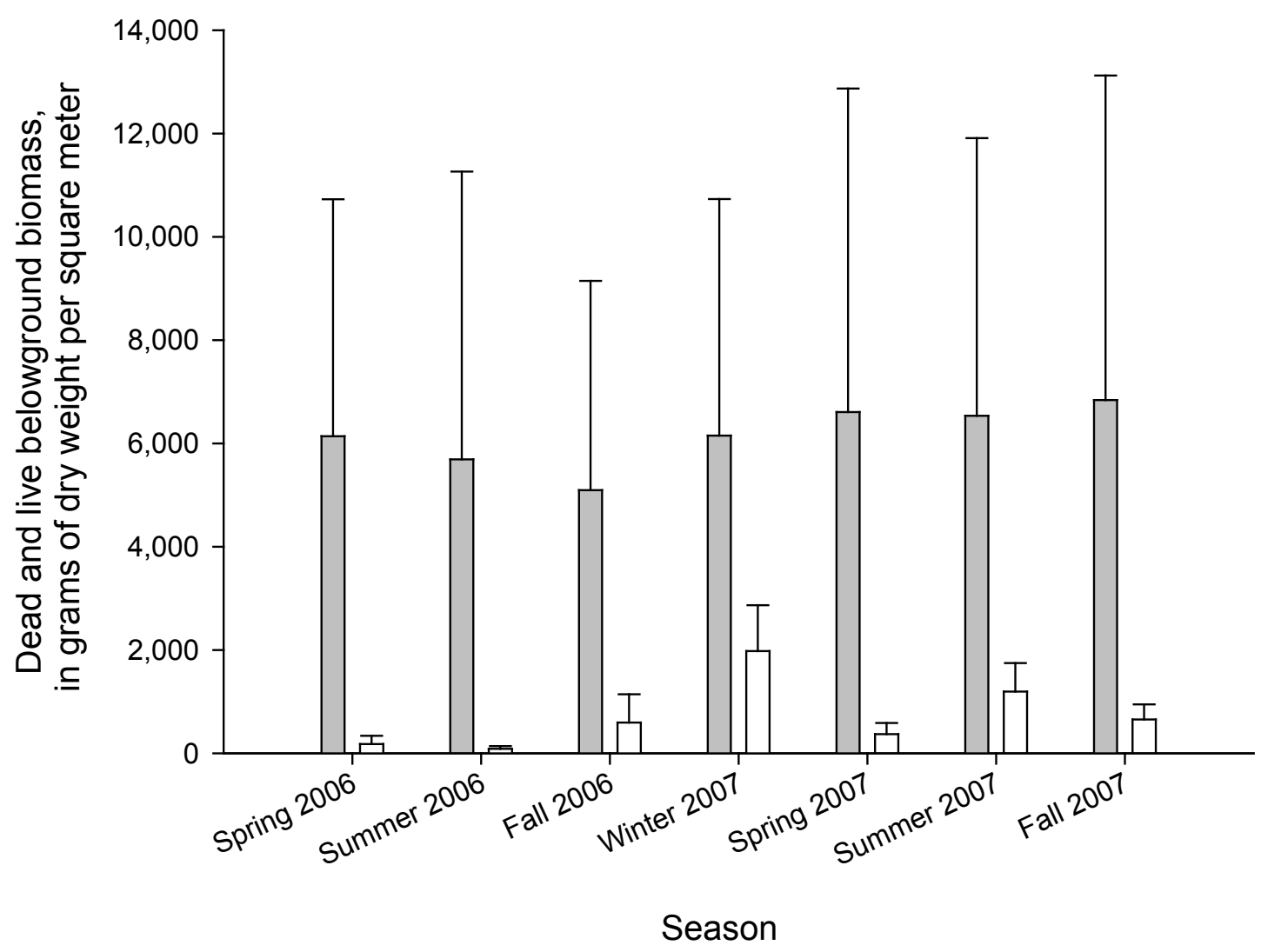

Figure 84. Live (white bars) and dead (gray bars) belowground biomass (see standard error bars) by season at Coastwide Reference Monitoring System (CRMS) site 0164-H.

\section{Sediment Characterization, Accretion, and Elevation}

Sediment bulk densities averaged $0.29 \mathrm{~g} \mathrm{~cm}^{-3}$ when computed above the 1963 horizon $(36.2 \mathrm{~cm}$ depth, figs. 85 and 86 , table 5). Above the 1963 horizon, bulk density is highest at the 2- to 4-cm depth $\left(0.36 \mathrm{~g} \mathrm{~cm}^{-3}\right)$, decreasing with depth to $34 \mathrm{~cm}$. Turner and others (2006) found the average bulk density in the newly deposited material after Hurricane Katrina to be $0.37 \mathrm{~g} \mathrm{~cm}^{-3}$. A noticeable decrease in bulk density is found at the $16-\mathrm{cm}$ depth, with bulk density averaging $0.32 \mathrm{~g} \mathrm{~cm}^{-3}$ for the 0 to $14-\mathrm{cm}$ depth and $0.24 \mathrm{~g} \mathrm{~cm}^{-3}$ in the 16- to $32-\mathrm{cm}$ depth. The highest bulk density was found at $36 \mathrm{~cm}$ in both replicate cores (fig. 85).

The caesium- 137 analysis indicated that the accretion rate since 1963 averaged $0.84 \mathrm{~cm} \mathrm{yr}^{-1}$ (individual core estimates of $0.87 \mathrm{~cm} \mathrm{yr}^{-1}$ and $0.81 \mathrm{~cm} \mathrm{yr}^{-1}$ ), which is a higher rate than the rate of $0.66 \mathrm{~cm} \mathrm{yr}^{-1}$ found at its paired site, CRMS0164. Samples taken in 1993 at a nearby site by Swenson and Turner (1994) had an average accretion rate of $0.88 \mathrm{~cm} \mathrm{yr}^{-1}$. After Hurricanes Katrina and Rita, Turner and others (2006) found accretion rates greater than $3 \mathrm{~cm}$ within the vicinity of this site. No elevation data were collected at this site because it was selected for its historical data and thus lacked an established RSET; however, feldspar data were collected. The short-term accretion rate was estimated at $2.69 \mathrm{~cm} \mathrm{yr}^{-1}$, which was the highest calculated accretion rate from all the study sites but was based on excellent feldspar coring (fig. 87). Note that this accretion was not due to the 2005 hurricanes, as the feldspar marker horizon was established after the hurricanes. Without the site-specific elevation data, it is not possible to predict how this accretion influenced overall soil elevation (see appendix 2 for elevation and accretion change information from the paired site CRMS0164).

\section{Summary of the Classification of Impacts}

The data obtained from the Airplane Lake area indicated little or no observable effects from the 2005 hurricanes on vegetative productivity. This site was approximately 50 $\mathrm{km}$ west of the track of Hurricane Katrina. The study site was then inundated with a $1.2-1.5-\mathrm{m}$ (4-5-ft) storm surge during Hurricane Rita (Federal Emergency Management 

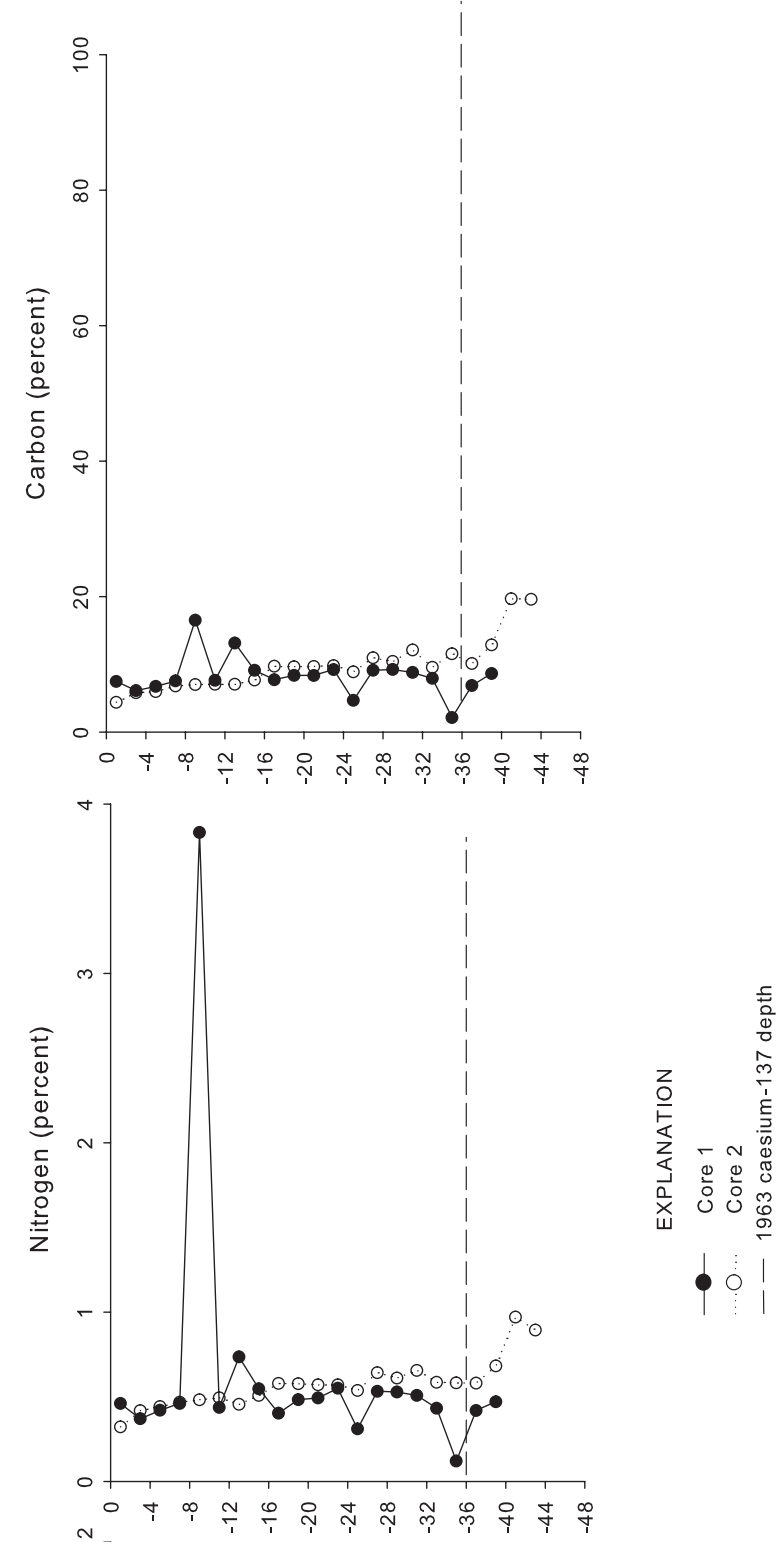
Bulk density, in grams per cubic centimeter

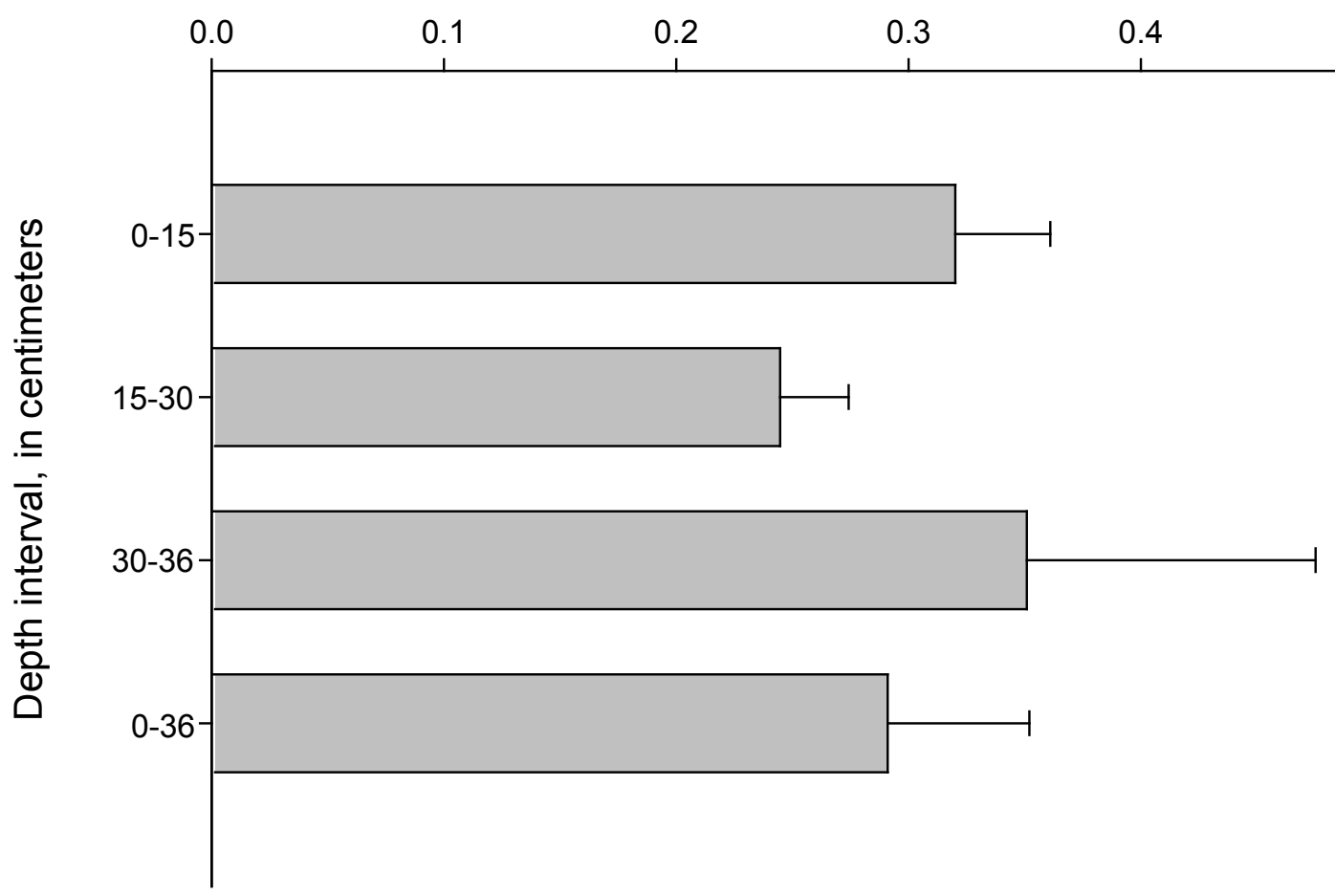

Figure 86. Mean values of bulk density by various depth intervals at Coastwide Reference Monitoring System (CRMS) site 0164-H.

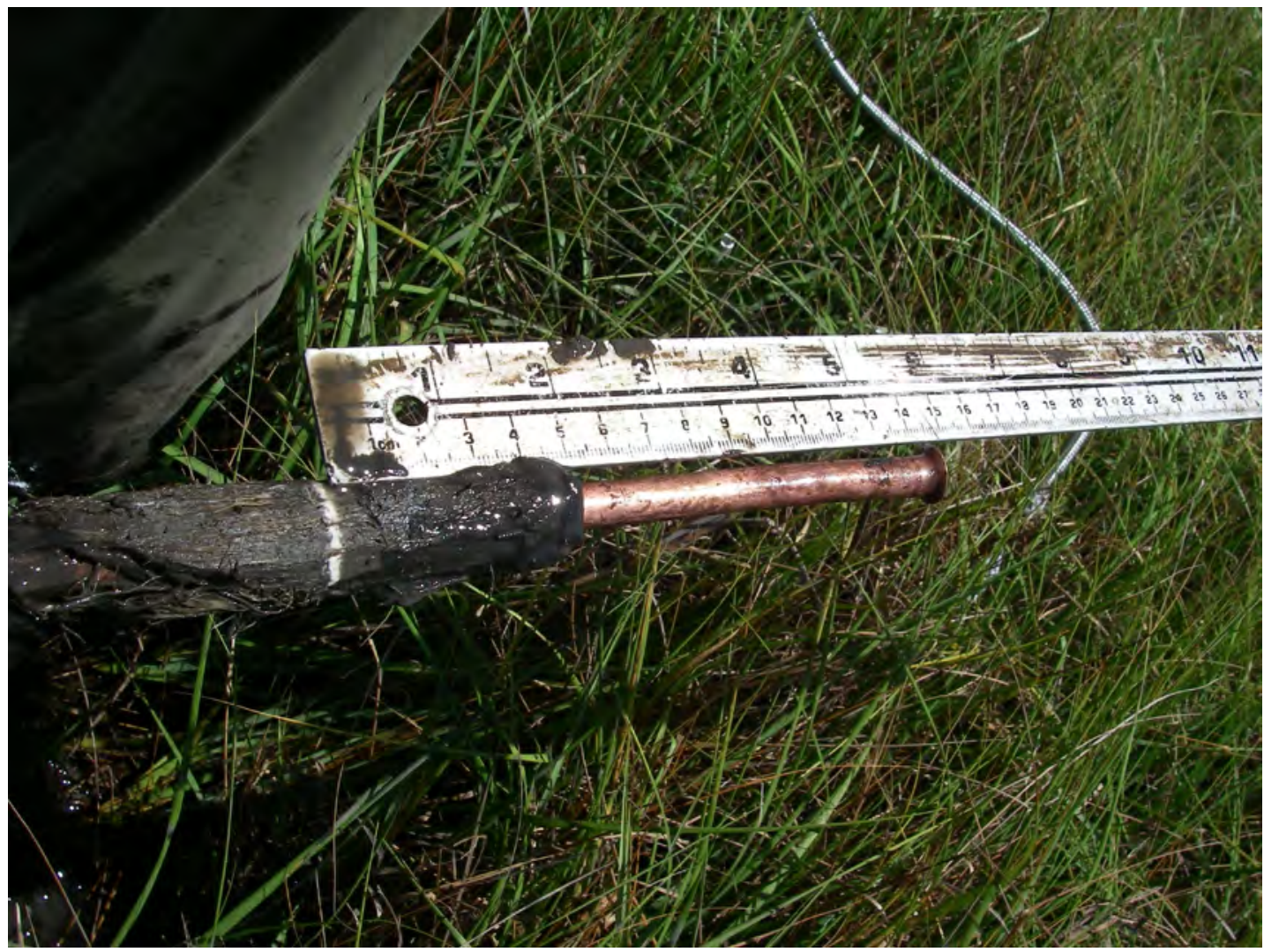

Figure 87. Feldspar marker horizon

(deployed July 13, 2006) and short-term accretion on July 10, 2008, at Coastwide Reference Monitoring System (CRMS) site 0164-H. 
Agency, 2006). Mineral sedimentation was greatest at this site compared to all other sites according to the shortterm accretion data. The greater mineral content and the nonbuoyancy of the vegetated mat of saline marsh allowed the storm surge to submerge the marsh, rather than uplifting it and subjecting it to the full force of wind waves at the surface, as occurred in the buoyant (fresh and intermediate) organic marshes that were in the path of Hurricanes Katrina and Rita.

\section{Soil Process Rates of Wetlands in the Chenier and Deltaic Plains of Louisiana}

We analyzed new soil accretion estimates from 30 sites across fresh, brackish/intermediate, and saline marshes of the chenier and deltaic plains of Louisiana. We investigated basic relationships of mineral and organic matter contribution to wetland soil development and provided estimates of nitrogen and carbon accumulation (burial) rates among these different marsh types. These new data build on existing information about saline and brackish marshes, but also fill knowledge gaps about freshwater areas.

General methods for the soils analysis and calculations exist in the methods section of this document. Data were summarized for general trends among marsh types (fresh, brackish/intermediate, and saline) and also divided among geological provinces (deltaic and chenier plains). Similar to the vegetation analyses, we combined the data from intermediate and brackish marshes dominated by $S$. patens to increase replication. Six hydrologically impounded sites in brackish marsh of the chenier plain were identified and separated from nonimpounded sites when examining vertical accretion rates. Otherwise, impounded sites were not distinguished in regression relationships for understanding the basic effects of mineral/organic contributions to vertical accretion of soil. To judge the relative strength of inference pertaining to an estimate, the number of sites with datable cores within a given marsh type and geologic province is provided in table 12. Site-specific information for all estimates of vertical accretion of soil and associated mineral/organic and nutrient accumulation rates are presented in table 5 .

\section{Results and Discussion}

\section{Accretion Rates Between the Chenier and Deltaic Plains}

Long-term accretion rates for freshwater marshes were $0.57( \pm 0.13) \mathrm{cm} \mathrm{yr}^{-1}$ for the deltaic plain and 0.57 $( \pm 0.25) \mathrm{cm} \mathrm{yr}^{-1}$ for the chenier plain (table 13). Accretion rates in nonimpounded brackish marshes were $0.72( \pm 0.14)$ $\mathrm{cm} \mathrm{yr}^{-1}$ for the deltaic plain and $0.65( \pm 0.23) \mathrm{cm} \mathrm{yr}^{-1}$ for the chenier plain. Under impounded conditions, accretion was appreciably lower than under nonimpounded conditions $\left(0.38 \pm 0.04 \mathrm{~cm} \mathrm{yr}^{-1}\right)$. Accretion in saline marshes of the deltaic plain was $0.64( \pm 0.16) \mathrm{cm} \mathrm{yr}^{-1}$; there were no cores from saline marshes in the chenier plain.

The estimated mean value of accretion in freshwater marshes $\left(0.57 \mathrm{~cm} \mathrm{yr}^{-1}\right)$ was below the range $(0.72-1.02$ $\mathrm{cm} \mathrm{yr}^{-1}$ ) of means reported by others (tables 12 and 13). There is good agreement, however, among data from this study on accretion in brackish marsh $\left(0.65\right.$ and $0.72 \mathrm{~cm} \mathrm{yr}^{-1}$, both geological provinces) and the range of other estimates of the

Table 12. Summary of mean values for long-term (since 1963) rates of soil accretion and organic/mineral accumulation in herbaceous marshes of the chenier and deltaic plains of Louisiana (for definitions, see Saucier [1994]).

[Mean values are provided with a standard error of plus or minus 1 unit. Numbers listed in the "study" column denote the following studies: (1) Nyman and others, 2006; (2) Holm, 2006; (3) Sasser and others, 2002; (4) DeLaune and Pezeshki, 2003; (5) Turner and others, 2001. No., number; cm yr ${ }^{-1}$, centimeters per year; $\mathrm{g} \mathrm{m}^{-2} \mathrm{yr}^{-1}$, grams per square meter per year]

\begin{tabular}{|c|c|c|c|c|c|c|}
\hline Marsh type & No. of cores & $\begin{array}{l}\text { Accretion } \\
\text { (cm yr-1) }\end{array}$ & $\begin{array}{c}\text { Organic } \\
\text { (g m-2 yr-1) }\end{array}$ & $\begin{array}{c}\text { Mineral } \\
\text { (g m-2 yr-1) }\end{array}$ & Study & Notes \\
\hline \multirow[t]{3}{*}{ Fresh } & 2 & 0.83 & 456 & 461 & 1 & deltaic; stable \\
\hline & 1 & 0.88 & 563 & 61 & 2 & deltaic; floating marsh \\
\hline & 1 & 1.02 & 488 & 621 & 1 & chenier; stable \\
\hline \multirow{2}{*}{ Brackish } & 2 & $0.72(0.07)$ & $349(66)$ & $523(405)$ & 3 & deltaic; deteriorating \\
\hline & 3 & $0.65(0.18)$ & $315(85)$ & $178(51)$ & 4 & deltaic; freshwater diversion \\
\hline \multirow[t]{2}{*}{ Saline } & 10 & $0.98(0.36)$ & $618(261)$ & $1,970(941)$ & 1 & deltaic; deteriorating \\
\hline & 12 & $0.59(0.14)$ & $424(82)$ & $1,928(898)$ & 1 & deltaic; stable \\
\hline
\end{tabular}


mean $\left(0.65-0.96 \mathrm{~cm} \mathrm{yr}^{-1}\right)$. A notable pattern is evident, with higher rates of accretion in nonimpounded versus impounded brackish marshes in the chenier plain (tables 12 and 13).

Saline marshes in the deltaic plain have remarkably consistent patterns of vertical accretion: $0.66 \pm 0.21 \mathrm{~cm} \mathrm{yr}^{-1}$ (52 cores, Turner and others, 2001); $0.59 \pm 0.14$ (12 cores, Nyman and others, 2006); and $0.64 \pm 0.16 \mathrm{~cm} \mathrm{yr}^{-1}$ ( 6 sites/10 cores, the current study) (tables 12 and 13).

\section{Contribution of Organic and Mineral Fractions to Soil Accretion}

For saline and brackish/intermediate marshes in Louisiana, there is agreement that rates of organic matter accumulation explain much of the variability associated with vertical accretion rates of marsh (Turner and others, 2001; Nyman and others, 2006). Data from our study support this strong relationship, such that 1.6 to $2.0 \mathrm{~mm} \mathrm{yr}^{-1}$ (salt and brackish, respectively) of vertical accretion increase is associated with every $100 \mathrm{~g}$ dry weight $\mathrm{m}^{-2} \mathrm{yr}^{-1}$ increase in organic matter accumulation (table 14). There has been a poor understanding of accumulation and accretion rates of mineral and organic matter in freshwater marshes because of limited data from these areas. While the general principle also holds for freshwater marshes that organic matter accumulation explains most of the variability in marsh vertical accretion, it also appears that 37 percent of the variability in vertical

Table 13. Mean values for long-term rates of soil accretion in three marsh types in the deltaic and chenier plains of Louisiana (for definitions, see Saucier [1994]). Accretion rates were determined by calculating the depth of peak activity of caesium-137, which marked the year 1963. Cores were collected during the spring or summer of 2006, after the passages of Hurricanes Rita and Katrina.

[Mean values are provided with a standard error of plus or minus 1 unit. no., number; $\mathrm{cm} \mathrm{yr}^{-1}$, centimeters per year; NA, not available]

\begin{tabular}{|c|c|c|c|c|}
\hline \multirow[b]{2}{*}{ Marsh type } & \multicolumn{2}{|c|}{ Deltaic plain } & \multicolumn{2}{|c|}{ Chenier plain } \\
\hline & Sites/Cores (no.) & "Accretion (cm yr'-1)" & Sites/Cores (no.) & "Accretion $\left(\mathrm{cm} \mathrm{yr}^{-1}\right)$ " \\
\hline Fresh & $8 / 15$ & $0.57(0.13)$ & $4 / 5$ & $0.57(0.25)$ \\
\hline Natural & $4 / 5$ & $0.72(0.14)$ & $2 / 3$ & $0.65(0.23)$ \\
\hline Impounded & NA & NA & $6 / 10$ & $0.38(0.04)$ \\
\hline
\end{tabular}

Table 14. Regression relationships between long-term rates of vertical accretion and accumulation of organic and mineral matter for three marsh types across Louisiana at research sites from the Coastwide Reference Monitoring System paired with sites that were historically sampled by Holm, 2006.

$\left[\mathrm{r}^{2}\right.$, coefficient of determination; $\mathrm{mm} \mathrm{yr}^{-1}$, millimeters per year; $\mathrm{g} \mathrm{m}^{-2} \mathrm{yr}^{-1}$, grams per square meter per year; $\mathrm{g} \mathrm{m}^{-2}$, grams per square meter]

\begin{tabular}{|c|c|c|c|c|}
\hline \multicolumn{2}{|c|}{ Variable } & \multirow[b]{2}{*}{ Slope } & \multirow[b]{2}{*}{ Intercept } & \multirow[b]{2}{*}{$\mathbf{r}^{2}$} \\
\hline Dependent & Independent & & & \\
\hline \multirow[t]{4}{*}{ Accretion } & Mineral & & & \\
\hline & Fresh & $0.38^{1}$ & 0.48 & 0.37 \\
\hline & Brackish & $0.11^{1}$ & 0.43 & 0.26 \\
\hline & Saline & $0.07^{1}$ & 0.52 & 0.18 \\
\hline \multirow[t]{4}{*}{ Accretion } & Organic & & & \\
\hline & Fresh & $0.9^{1}$ & 0.28 & 0.64 \\
\hline & Brackish & $2.0^{1}$ & -0.16 & 0.92 \\
\hline & Saline & $1.6^{1}$ & -0.007 & 0.88 \\
\hline \multirow[t]{4}{*}{ Organic } & Mineral & & & \\
\hline & Fresh & $32.5^{2}$ & 205 & 0.66 \\
\hline & Brackish & $5.0^{2}$ & 302 & 0.24 \\
\hline & Saline & $6.0^{2}$ & 309 & 0.37 \\
\hline
\end{tabular}

${ }^{1}$ Slope $=\mathrm{mm} \mathrm{yr}^{-1}$ vertical accretion $/ 100 \mathrm{~g} \mathrm{~m}^{-2} \mathrm{yr}^{-1}$ of mineral or organic matter.

${ }^{2}$ Slope $=\mathrm{g} \mathrm{m}^{-2}$ organic matter $/ 100 \mathrm{~g} \mathrm{~m}^{-2} \mathrm{yr}^{-1}$ mineral matter. 
accretion can be explained by mineral matter accumulation in freshwater areas, compared to lower values for brackish (26 percent) and salt (18 percent) (table 14). Moreover, 66 percent of the variance in organic accumulation rates can be explained by mineral accumulation rates for freshwater marshes, 24 percent for brackish marshes, and 37 percent for saline marshes. For illustration purposes in freshwater marshes, an increase of $100 \mathrm{~g}$ dry weight $\mathrm{m}^{-2} \mathrm{yr}^{-1}$ of mineral matter results in a concomitant increase of approximately $33 \mathrm{~g}$ dry weight $\mathrm{m}^{-2} \mathrm{yr}^{-1}$ of organic matter accumulation. In contrast to the rates applicable to freshwater marshes, in saline marshes an increase of $100 \mathrm{~g}$ dry weight $\mathrm{m}^{-2} \mathrm{yr}^{-1}$ of mineral matter results in an increase of $6.0 \mathrm{~g}$ dry weight $\mathrm{m}^{-2} \mathrm{yr}^{-1}$ of organic matter accumulation (table 14). These relationships suggest that freshwater marshes may react more positively (that is, with increased organic matter accumulation) than saline marshes, given an equivalent amount of mineral sedimentation.

\section{Organic, Mineral, and Nutrient Content in Relation to Accumulation Rates}

Across marsh types, mean values of organic matter content in sediment from within the upper $20 \mathrm{~cm}$ is comparable to $0.051 \mathrm{~g} \mathrm{~cm}^{-3}$ for fresh marsh, $0.068 \mathrm{~g} \mathrm{~cm}^{-3}$ for brackish marsh, and $0.065 \mathrm{~g} \mathrm{~cm}^{-3}$ for saline marsh (table 15). There are appreciable differences in mineral density, with $0.042 \mathrm{~g} \mathrm{~cm}^{-3}$ for fresh marsh, $0.150 \mathrm{~g} \mathrm{~cm}^{-3}$ for brackish marsh, and $0.300 \mathrm{~g} \mathrm{~cm}^{-3}$ for saline marshes (table 15). Nitrogen and carbon densities of these different marsh types mirror differences in organic content (table 15). All marsh types have carbon to nitrogen ratios below 20 (fig. 88), a threshold above which nitrogen immobilization is possible (Enriquez and others, 1993).

All three marsh types are capable of accumulating up to $200 \mathrm{~g} \mathrm{C} \mathrm{m}^{-2} \mathrm{yr}^{-1}$ (fig. 89 and table 5). The upper limit on the mean value for nitrogen accumulation for all marsh types appears to be between 10 and $14 \mathrm{~g} \mathrm{~m}^{-2} \mathrm{yr}^{-1}$. Mean values of organic matter accumulation tended to be lower in the chenier plain than in the deltaic plain for both freshwater and brackish marshes; however, variability within these estimates was high (table 16). All of the estimates of accumulation in mineral matter (across marsh types and basins) exhibited high variability, which may reflect spatial heterogeneity of mineral sedimentation associated with Hurricanes Katrina and Rita. For example, Turner and others (2001) showed high variability in mineral sedimentation $\left(1,354 \pm 899 \mathrm{~g} \mathrm{~m}^{-2} \mathrm{yr}^{-1}\right)$ for Louisiana saline marshes.

In our study, average rates of mineral sedimentation were approximately $1,800 \mathrm{~g}$ dry weight $\mathrm{m}^{-2} \mathrm{yr}^{-1}$ for saline marsh,

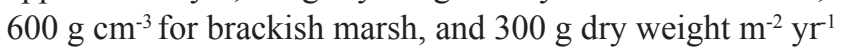
for fresh marshes of the deltaic plain (table 16). Since our sites were not under active river influence, these estimates do not represent upper limits of mineral sedimentation. Estimates of soil-building processes in active deltaic areas are lacking for coastal Louisiana.

\section{Overall Conclusions}

The influence of Hurricanes Katrina and Rita on coastal marsh communities was highly variable and site-specific. This study attempts to identify hurricane impacts by using new data collected across a broad landscape, with sites being subjected to various degrees of hurricane exposure. Documenting a new ecological baseline of coastal marshes is not straightforward, requiring adequate information to describe the spatially and temporally variable habitats that make up this dynamic ecosystem - an environment that is ever-changing, even under "normal" (nonstorm) conditions. Subsidence, sea level rise, erosion, sedimentation, and grazing are some of the processes that are always at work influencing the attributes of the system. Catastrophic storms such as Hurricanes Katrina and Rita create a range of effects, from marginal impacts to a total resetting of the system, such that one static baseline condition for the entire ecosystem is not totally appropriate. It may be more useful to think of coastal marshes as exhibiting dynamic baselines. Our overall assessment of changes resulting from Hurricanes Katrina and Rita contributes information relative to a new ecological baseline of the Louisiana coastal marshes. Generally, we found that fresh marshes experienced more negative effects from the hurricanes than did brackish/ intermediate and saline marshes.

Table 15. Mean values of organic, mineral, nitrogen, and carbon density in the upper $20 \mathrm{~cm}$ of soil in three marsh types. Values for the deltaic and chenier plains of Louisiana (for definitions, see Saucier [1994]) are combined. Cores were collected at research sites from the Coastwide Reference Monitoring System paired with sites that were historically sampled by Holm, 2006.

[Mean values are provided with a standard error of plus or minus 1 unit. $\mathrm{g} \mathrm{cm}^{-3}$, grams per cubic centimeter; mg cm ${ }^{-3}$, milligrams per cubic centimeter]

\begin{tabular}{lcccc}
\hline & \multicolumn{3}{c}{ Density } \\
\cline { 2 - 5 } Marsh type & Organic $\left(\mathrm{g} \mathrm{cm}^{-3}\right)$ & Mineral $\left(\mathrm{g} \mathrm{cm}^{-3}\right)$ & Nitrogen $\left.(\mathrm{mg} \mathrm{cm})^{-3}\right)$ & ${\mathrm{Carbon}\left(\mathrm{mg} \mathrm{cm}^{-3}\right)}$ \\
\hline Fresh & $0.051(0.001)$ & $0.042(0.003)$ & $1.78(0.04)$ & $29.5(0.7)$ \\
Brackish & $0.068(0.001)$ & $0.150(0.010)$ & $2.31(0.09)$ & $36.6(1.5)$ \\
Saline & $0.065(0.001)$ & $0.300(0.016)$ & $1.72(0.10)$ & $29.1(1.6)$ \\
\hline
\end{tabular}



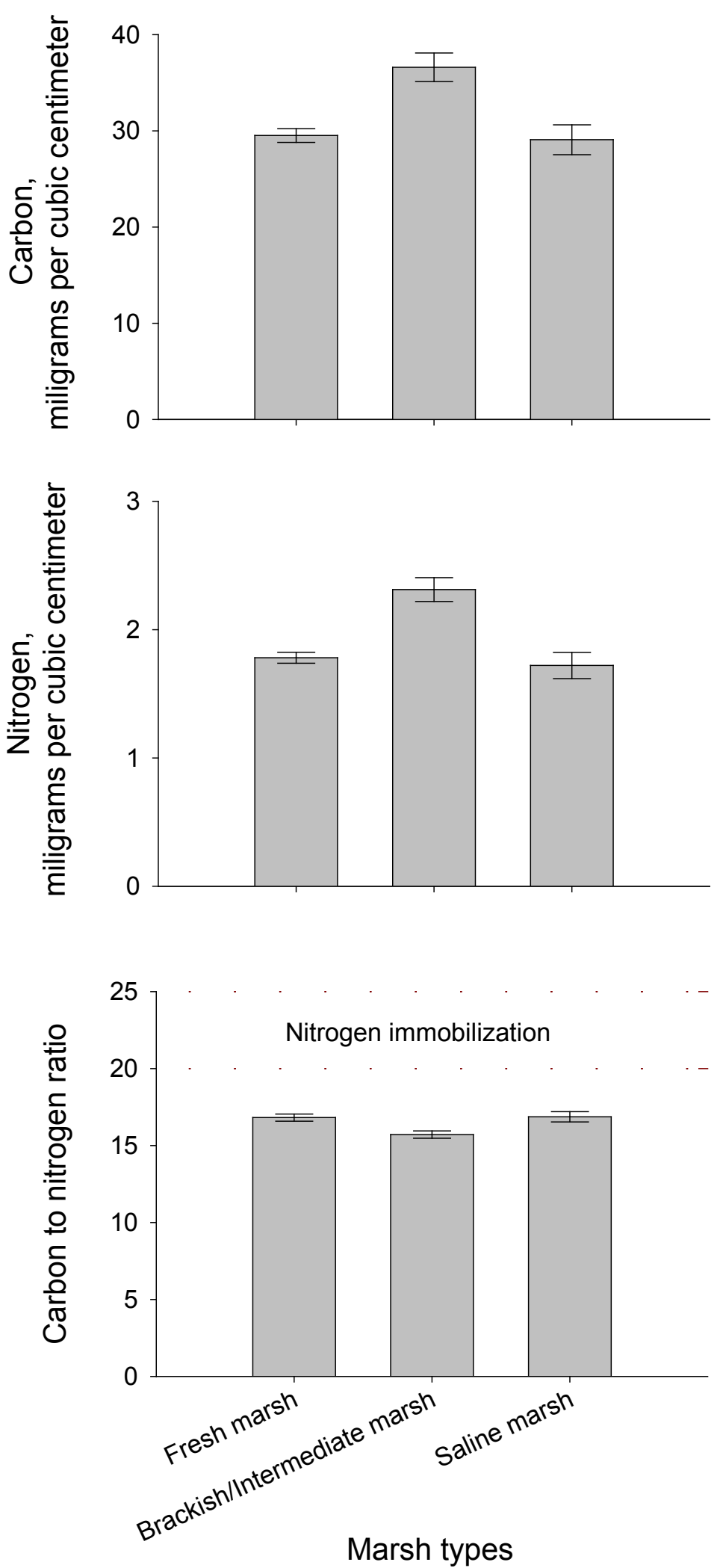

Figure 88. Carbon and nitrogen content in sediment (see standard error bars) and their ratios from the upper $20 \mathrm{~cm}$ of soil across different marsh types, with combined values from the Louisiana chenier and deltaic plains (for definitions, see Saucier [1994]). Carbon-to-nitrogen ratios above 20 are conducive to nitrogen immobilization.
Freshwater sites within areas directly influenced by Hurricanes Katrina (western region) and Rita (eastern region) shared the following characteristics when compared with indirectly influenced areas: (1) significantly higher porewater salinities at the end of seasons; (2) significantly lower values of live aboveground biomass at the end of seasons; (3) significantly lower values of peak biomass; (4) significantly greater contribution of disturbance species; and (5) significantly lower values of belowground biomass (table 17). All freshwater sites within the directly influenced area were not affected similarly. Specific location, dominant vegetation before Hurricanes Katrina and Rita, and surrounding hydrologic conditions likely influenced recovery from the storms. Two full growing seasons after Hurricanes Katrina and Rita, all freshwater sites had average values of aboveground biomass that were within the typical ranges; however, some sites exhibited shifts in dominant species towards disturbance or more salt-tolerant species. The longterm implications of changes in species composition cannot be determined with data from only two growing seasons because vegetation at many of the sites continues to undergo changes. At locations where site-specific data acquired before Hurricanes Katrina and Rita were available for comparison, the data indicate that these hurricanes had little effect on aboveground and belowground biomass.

Brackish/intermediate marsh sites experienced the largest deviations from historical data on porewater salinity; however, directly and indirectly influenced sites had statistically similar porewater salinities at the end of growing seasons. Among the brackish/intermediate marsh sites, there was no statistically significant influence from hurricane impacts on the following marsh characteristics: (1) live biomass at the end of growing seasons; (2) percentage of disturbance taxa; (3) peak values of aboveground biomass; or (4) belowground biomass at the end of growing seasons (table 17). It should be noted, however, that our study included only 2 of 10 sites in the zone of indirect influence. A few of the brackish/intermediate marsh sites that we studied did experience large changes in species composition after Hurricanes Katrina and Rita.

Saline marsh sites fared well after Hurricanes Katrina and Rita. A comparison of direct versus indirect hurricane influence showed that the directly impacted sites ( 2 of the 6 ) had significantly greater values of aboveground biomass at the end of growing season than did indirectly influenced sites, indicating that the hurricanes had a positive effect on plant biomass (table 17). Species composition remained consistent (S. alterniflora) at most sites, no disturbance taxa were observed, and live vegetation 


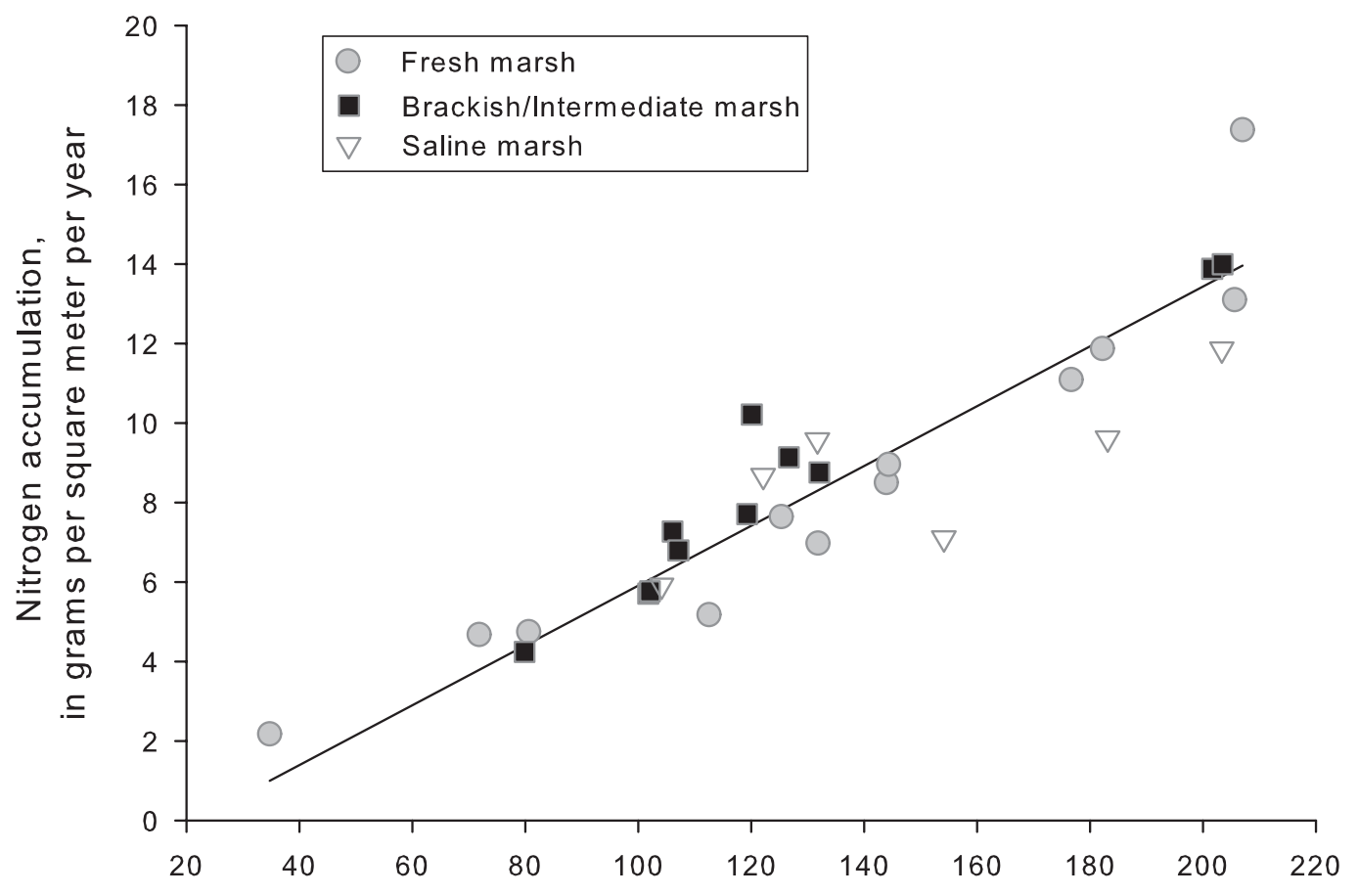

Carbon accumulation, in grams per square meter per year

Figure 89. The distribution of carbon and nitrogen accumulation in sediment across different marsh types, with combined values from the Louisiana chenier and deltaic plains (for definitions, see Saucier [1994].) Marsh types span a wide distribution of nutrient accumulation rates and exhibit similar upper limits of carbon (200 grams per square meter per year $\left[\mathrm{g} \mathrm{m}^{-2} \mathrm{yr}^{-1}\right]$ ) and nitrogen $\left(10-14 \mathrm{~g} \mathrm{~m}^{-2} \mathrm{yr}^{-1}\right)$ accumulation.

Table 16. Mean values of accumulation rates of organic, mineral, nitrogen, and carbon fractions in soil from three marsh types in the deltaic and chenier plains of Louisiana (for definitions, see Saucier [1994]). Measurements were obtained from sites in the Coastwide Reference Monitoring System that were paired with sites that were historically sampled by Holm, 2006. The number of sites and cores used for calculations follow those in table 13.

[Mean values are provided with a standard error of plus or minus 1 unit. $\mathrm{g} \mathrm{m}^{-2} \mathrm{yr}^{-1}$, grams per square meter per year]

\begin{tabular}{|c|c|c|c|c|c|}
\hline \multirow[b]{2}{*}{ Marsh type } & \multirow[b]{2}{*}{ Region } & \multicolumn{4}{|c|}{ Accumulation $\left(\mathrm{g} \mathrm{m}^{-2} \mathrm{yr}^{-1}\right)$} \\
\hline & & Organic & Mineral & Nitrogen & Carbon \\
\hline \multirow[t]{2}{*}{ Fresh } & Deltaic & $331(110)$ & $319(340)$ & $9.1(2.8)$ & $148(41)$ \\
\hline & Chenier & $246(192)$ & $263(420)$ & $7.4(6.8)$ & $109(73)$ \\
\hline \multirow[t]{2}{*}{ Brackish } & Deltaic & 447 (31) & $594(701)$ & $12.3(2.8)$ & 177 (44) \\
\hline & Chenier & $304(77)$ & $913(1,017)$ & $7.1(1.9)$ & $109(16)$ \\
\hline Saline & Deltaic & 415 (98) & $1,755(1,000)$ & $8.8(2.1)$ & $150(38)$ \\
\hline
\end{tabular}


Table 17. Comparison of study parameters for fresh, brackish/intermediate, and saline marsh types and sample year.

[Definitions: $\mathrm{cm} \mathrm{yr}^{-1}$, centimeters per year]

\begin{tabular}{|c|c|c|c|}
\hline & Fresh & Brackish/Intermediate & Saline \\
\hline Porewater salinity & $\begin{array}{l}2006>2007 ; \\
\text { direct impact }>\text { indirect } \\
\text { impact; decreasing during } \\
\text { study; overall } 0.7>1968 \\
\text { estimate }\end{array}$ & $\begin{array}{l}2006 \text { slightly }>2007 \text { though not } \\
\text { significant; no difference } \\
\text { between direct and indirect } \\
\text { impact; decreasing during } \\
\text { study; overall } 4.7>1968 \\
\text { estimate }\end{array}$ & $\begin{array}{l}2006>2007 \\
\text { direct }<\text { indirect impact; } \\
\text { decreasing during study; } \\
\text { overall } 2.7>1968 \text { estimate }\end{array}$ \\
\hline Live aboveground biomass & $\begin{array}{l}\text { End of growing season } \\
\qquad 2007>2006 \text {; direct } \\
\text { impact < indirect impact }\end{array}$ & $\begin{array}{l}\text { End of growing season } \\
2007 \text { > 2006; greatest } \\
\text { quantity increase during } \\
\text { study of all habitat type; } \\
\text { no difference between } \\
\text { direct vs. indirect impact }\end{array}$ & $\begin{array}{l}\text { End of growing season } \\
2006>2007 \text {; direct }>\text { indirect } \\
\text { impact }\end{array}$ \\
\hline Cover of disturbance taxa & $\begin{array}{l}2007>2006 ; \\
\quad \text { direct impact }>\text { indirect } \\
\text { impact; present throughout } \\
\text { entire study }\end{array}$ & $\begin{array}{l}2006>2007 \text { but not significant; } \\
\text { present throughout entire } \\
\text { study; number of sites with } \\
\text { disturbance taxa in } \\
2007>2006\end{array}$ & none present \\
\hline Organic accumulation rates & Chenier plain $<$ deltaic plain & Chenier plain $<$ deltaic plain & Estimate in deltaic plain only \\
\hline Mineral accumulation rates & $\begin{array}{l}\text { Highly variable across coast but } \\
\text { chenier plain }<\text { deltaic plain in } \\
\text { fresh marshes }\end{array}$ & $\begin{array}{l}\text { Highly variable across coast but } \\
\text { chenier plain }>\text { deltaic plain in } \\
\text { brackish/intermediate marshes }\end{array}$ & $\begin{array}{l}\text { Much greater in saline marsh } \\
\text { than fresh and brackish/ } \\
\text { intermediate }\end{array}$ \\
\hline Nitrogen accumulation rates & Chenier plain $<$ deltaic plain & Chenier plain $<$ deltaic plain & Estimate in deltaic plain only \\
\hline Carbon accumulation rates & Chenier plain $<$ deltaic plain & Chenier plain $<$ deltaic plain & Estimate in deltaic plain only \\
\hline
\end{tabular}


cover remained above 60 percent throughout the period of our study. Values of belowground biomass were also similar among all sites. Although saline marsh sites were closest to the coast and therefore most exposed to hurricane effects, the dominant vegetation is better adapted to salinity surges, and the storm surge was not impounded on these sites for any appreciable amount of time. Some sites may have received a sediment subsidy associated with the storms.

Our analysis of long-term rates of vertical accretion in the brackish marsh of the chenier plain suggests that accretion under impounded conditions is less than under nonimpounded conditions. Our data also support the results of previous studies that found rates of organic matter accumulation explain much of the variability associated with vertical accretion in brackish/intermediate and saline marshes. In fresh marshes, more of the variability associated with vertical accretion can be explained by mineral accumulation than in the other marsh types. All marsh types span a wide distribution of rates of nutrient accumulation but exhibit similar upper limits of carbon (200 $\left.\mathrm{g} \mathrm{C} \mathrm{m}^{-2} \mathrm{yr}^{-1}\right)$ and nitrogen (10-14 $\left.\mathrm{g} \mathrm{N} \mathrm{m}^{-2} \mathrm{yr}^{-1}\right)$ accumulation.

Our study provides extensive information that will help define baseline conditions in multiple marsh types after Hurricanes Katrina and Rita, not only for salinity and vegetation variables, but also for soil characteristics and accumulation rates. Paired with the data that will continue to be collected through the CRMS program, the current study provides information for resource managers and scientists that can be used for comparisons of environmental conditions following future landscape-scale disturbances and to support development of ecological models of landscape response.

In this study, we documented severe damage to marshes by Hurricanes Katrina and Rita, but the mechanism of damage was variable across the landscape. For example, in the chenier plain, saltwater surged into freshwater marshes and stayed much too long, effectively causing damage that reset the vegetation community, even though the physical damage to these marshes was not overwhelming. The future of these marshes is uncertain. Will freshening conditions over time facilitate the vegetation community to return to highly productive freshwater species that were present before the storm, or has the saltwater influence caused a shift to dominance by more salt-tolerant species? Figure 40 provides an appropriate conceptual representation of the new ecological baseline for this condition. Impacts to the deltaic coastal wetlands in the eastern area were different from those in the west, with the freshwater marshes heavily damaged physically (marsh mats ripped, flipped, and relocated) by strong winds and the churning currents associated with high storm surge. The future of these marshes is also uncertain; however, because the saltwater surge was not impounded in this area, as it was in the chenier plain, an eventual recovery is likely, given a continuation of freshwater conditions. Saline marshes were not severely impacted by the hurricanes. Species composition of the vegetation in saline marshes was not affected, and sediment deposition in saline marshes actually seems to have increased vegetative productivity. In the brackish/ intermediate marshes, disturbance species took advantage of the opportunity provided by physical and saltwater-induced perturbations. The observed shifts in species composition to include disturbance species is a significant baseline change, although probably temporary.

Further development of conceptual models for specific marsh types would support a better understanding of the factors that control how they function during average, nonstorm periods, as well as how storms and other stresssors might affect and change them. Some emphasis should be placed on understanding the differences in storm effects that are possible on managed versus nonmanaged areas (for example, differences in impounded versus nonimpounded wetlands). Data from this study suggest differences in response at managed versus nonmanaged areas, but more work will be necessary to verify and determine the implications. An important consideration is that management activities in the coastal landscape (for example, impoundments and canals) appear to have magnified the effect of stressors influencing the marshes. It is possible that some management actions may pre-establish how the coastal landscape responds to events such as catastrophic storms. This potential for dramatic human influence calls for a much better understanding of the implications of our management actions. For example, what are the implications of building impoundments in the coastal landscape to the overall productivity of the vegetation community occupying the marsh landscape? What are the physiological implications of impoundments and resulting hydrologic changes to productivity of belowground vegetation and its related soil composition, structure, and strength? Soil strength may be a robust indicator of vegetative productivity and marsh health, and studies to determine these relationships will be valuable to our ability to evaluate marsh conditions over a large landscape.

Understanding the variable effects of large storms on an expansive and complex ecosystem of coastal marshes such as the Mississippi River deltaic wetlands requires landscapescale studies to provide a proper evaluation of the impacts. The landscape configuration of the coastal wetlands of the gulf coast reflects influences, at any given time, from current and previous forces exerted on the ecosystem, including storms, subsidence, erosion, and active sedimentation processes. Large hurricanes such as Katrina and Rita influence vast areas of the coast. Most previous evaluations of hurricane impacts have focused on the immediate areas of visible physical impact; however, the scientific community is now recognizing - supported by the more extensive network of data collection stations available through CRMSthat high water levels and associated saltwater surge are influences that occur across very large areas. These effects could go virtually unreported without extensive efforts to collect data at the landscape scale in order to facilitate evaluation of coastwide impacts from episodic events, as well as other potential stressors. 


\section{References Cited}

Alexander, H.D., and Dunton, K.H., 2002, Freshwater inundation effects on emergent vegetation of a hypersaline salt marsh: Estuaries, v. 25, p. 1426-1435.

Barbour, M.G., 1978, The effects of competition and salinity on the growth of a salt marsh plant species: Oecologia, v. 37, p. 93-99.

Barras, J.A., 2006, Land area change in coastal Louisiana after the 2005 hurricanes - a series of three maps: U.S. Geological Survey Open-File Report 2006-1274.

Barras, J.A., 2007, Land area changes in coastal Louisiana after Hurricanes Katrina and Rita, in Farris, G.S., Smith, G.J., Crane, M.P., Demas, C.R., Robbins, L.L., and Lavoie, D.L., eds., Science and the storms - the USGS response to the hurricanes of 2005: U.S. Geological Survey Circular 1306, p. 97-112. (Also available at http://pubs.usgs.gov/ circ/1306.)

Baumann, R.H., Day, J.W., and Miller, C.A., 1984, Mississippi deltaic wetland survival - sedimentation versus coastal submergence: Science, v. 224, p. 1093-1095.

Boesch, D.F., Josselyn, M.J., Mehta, A.J., Morris, J.T., Nuttle, W.K., Simenstad, C.A., and Swift, D.J.P., 1994, Scientific assessment of coastal wetland loss, restoration and management in Louisiana: Journal of Coastal Research, Special Issue v. 20, no. 103, p. 1-103.

Bricker-Urso, S., Nixon, S.W., Cochran, J.K., Hirschberg, D.J., and Hunt, C., 1989, Accretion rates and sediment accumulation in Rhode Island salt marshes: Estuaries, v. 12, no. 4, p. 300-317.

Broome, S.W., Woodhouse, W.W., and Seneca, E.D., 1975, The relationship of mineral nutrients to growth of Spartina alterniflora in North Carolina-II. The effects of N, P, and Fe fertilizers: Soil Science Society of America Proceedings, v. 39, p. 295-301.

Burdick, D.M., and Mendelssohn, I.A., 1987, Waterlogging responses in dune, swale, and marsh populations of Spartina patens under field conditions: Oecologia, v. 74, no. 3, p. 321-329.

Cahoon, D.R., 2003, Storms as agents of wetland elevation change - their impact on surface and subsurface sediment processes, in Proceedings of the International Conference of Coastal Sediments 2003 CD-Rom: Corpus Christi, Tex., World Scientific Publishing Corporation and East Meets West Productions.

Cahoon, D.R., 2006, A review of major storm impacts on coastal wetland elevations: Estuaries and Coasts, v. 29, no. 6 A, p. $889-898$.
Cahoon, D.R., Reed, D.J., and Day, J.W., Jr., 1995, Estimating shallow subsidence in microtidal salt marshes of the southeastern United States-Kaye and Barghoorn revisited: Marine Geology, v. 128, p. 1-9.

Cahoon, D.R., Lynch, J.C., Hensel, P., Boumans, R., Perez, B.C., Segura, B., and Day, J.W., Jr., 2002a, A device for high precision measurement of wetland sediment elevation-I. Recent improvements to the sedimentationerosion table: Journal of Sedimentary Research, v. 72, no. 5, p. $730-733$.

Cahoon, D.R., Lynch, J.C., Perez, B.C., Segura, B., Holland, R., Stelly, C., Stephenson, G., and Hensel, P., 2002b, A device for high precision measurement of wetland sediment elevation-II. The rod surface elevation table: Journal of Sedimentary Research, v. 72, no. 5, p. 734-739.

Castellanos, D.L., 2005, Three-year comprehensive monitoring report East Mud Lake marsh management CS-20: Louisiana Department of Natural Resources, 108 p.

Castellanos, D.L., McGinnis, T., Landry, P., and Pontiff, D., 2007, Operations, Maintenance, and Monitoring Report for East Mud Lake Marsh Management (CS-20): Louisiana Department of Natural Resource, Coastal Restoration Division, Lafayette, Louisiana, $71 \mathrm{p}$.

Chabreck, R.H., 1970, Marsh zones and vegetative types in the Louisiana coastal marshes: Baton Rouge, Louisiana State University, Ph.D. dissertation, 124 p., 2 pls.

Chabreck, R.H., 1972, Vegetation, water, and soil characteristics of the Louisiana coastal region: Louisiana State University Bulletin 664, 72 p.

Chabreck, R.H., Joanen, T., and Palmisano, A.W., 1968, Vegetation type map of the Louisiana coastal marshes: Louisiana Wildlife and Fisheries Commission, scale 1:62,500.

Chabreck, R.H., and Palmisano, A.W., 1973, The effects of Hurricane Camille on the marshes of the Mississippi River Delta: Ecology, v. 54, p. 1118-1123.

Chabreck, R.H., and Linscombe, G., 1978, Vegetation type map of the Louisiana coastal marshes: New Orleans, Louisiana Department of Wildlife and Fisheries, scale 1:62,500.

Chabreck, R.H., and Linscombe, G., 1988, Vegetation type map of the Louisiana coastal marshes: New Orleans, Louisiana Department of Wildlife and Fisheries, scale 1:62,500.

Chabreck, R.H., and Linscombe, G., 1997, Vegetation type map of the Louisiana coastal marshes: New Orleans, Louisiana Department of Wildlife and Fisheries, scale 1:62,500. 
Chabreck, R.H., and Linscombe, G., 2001, Louisiana coastal marsh vegetation map: Baton Rouge, Louisiana State University and Louisiana Department of Natural Resources, scale 1:62,500.

Chamberlain, J.L., 1959, Influence of Hurricane Audrey on the coastal marsh of southwestern Louisiana: Baton Rouge, Louisiana State University, Coastal Studies Institute technical report no. 10. pt. B, 21 p.

Chmura, G.L., and Kosters, E.C., 1994, Storm deposition and $137 \mathrm{Cs}$ accumulation in fine-grained marsh sediments of the Mississippi Delta Plain: Estuarine, Coastal and Shelf Science, v. 39, p. 33-44.

Coastal Emergency Risks Assessment, 2008, Louisiana State University, accessed November 20, 2008 at http://www. cera.lsu.edu/cera/home/cerahome.html .

Craft, C.B., Seneca, E.D., and Broome, S.W., 1993, Vertical accretion in microtidal regularly and irregularly flooded estuarine marshes: Estuarine, Coastal and Shelf Science, v. 37, p. 371-386.

Crain, C.M., Silliman, B.R., Bertness, S.L., and Bertness, M.D., 2004, Physical and biotic drivers of plant distribution across estuarine salinity gradients: Ecology, v. 85, no. 9, p. 2539-2549.

Darby, F.A., and Turner, R.E., 2008, Below- and aboveground Spartina alterniflora production in a Louisiana salt marsh: Estuaries and Coasts, v. 31, p. 223-231.

Day, J.W., Jr., Pont, D., Henzel, P.E., and Ibanez, C., 1995, The impacts of sea level rise on the deltas in the Gulf of Mexico and the Mediterranean - the importance of pulsing events to sustainability: Estuaries, v. 18, no. 4, p. 637-647.

Davis, D.W., 1976, Trainasse: Annals of the Association of American Geographers, v. 66, p. 349-359.

Dean, W.E., 1974, Determination of carbonate and organic matter in calcareous sediments and sedimentary rocks by loss on ignition: comparison with other methods: Journal of Sedimentology and Petrology, v. 44, p. 242-248.

DeAngelis, D.L., 1980, Energy flow, nutrient cycling, and ecosystem resilience: Ecology, v. 61, p. 764-771.

DeLaune, R.D., Patrick, W.H., Jr., and Buresh, R.J., 1978, Sedimentation rates determined by $137 \mathrm{Cs}$ dating in a rapidly accreting salt marsh: Nature, v. 275, p. 532-533.

DeLaune, R.D., Reddy, C.N., and Patrick, W.H., Jr., 1981, Accumulation of plant nutrients and heavy metals through sedimentation processes and accretion in a Louisiana salt marsh: Estuaries, v. 4, p. 328-334.
DeLaune, R.D., Baumann, R.H., and Gosselink, J.G., 1983, Relationships among vertical accretion, coastal submergence, and erosion in a Louisiana Gulf Coast marsh: Journal of Sedimentary Petrology, v. 53, p. 147-157.

DeLaune, R.D., Patrick, W.H., Jr., Van Breemen, N., 1990, Processes governing marsh formation in a rapidly subsiding coastal environment: Catena, v. 17, p. 277-288.

DeLaune, R.D., Patrick, W.H., Jr., and Smith, C.J., 1992, Marsh aggradation and sediment distribution along rapidly submerging Louisiana Gulf Coast: Environmental Geology, v. 20 , no. 1 , p. $57-64$.

Delaune, R.D., and Pezeshki, S.R., 2003, The role of soil organic carbon in maintaining surface elevation in rapidly subsiding U.S. Gulf of Mexico coastal marshes: Water, Air, and Soil Pollution, v. 3, p. 167-179.

Douglas, B.C., and Peltier, W.R., 2002, The puzzle of global sea-level rise: Physics Today, v. 55, p. 35-40.

Doyle, T., Keeland, B., Gorham, L., and Johnson, D., 1995, Structural impact of Hurricane Andrew on the forested wetlands of the Atchafalaya Basin in south Louisiana: Journal of Coastal Research, v. 21, p. 354-364.

Doyle, T.W., Conner, W.H., Day, R.H., Krauss, K.W., and Swarzenski, C.M., 2007, Wind damage and salinity effects of Hurricanes Katrina and Rita on coastal baldcypress forests of Louisiana, in Farris, G.S., Smith, G.J., Crane, M.P., Demas, C.R., Robbins, L.L., and Lavoie, D.L., eds., Science and the storms - the USGS response to the hurricanes of 2005: U.S. Geological Survey Circular 1306, p. 163-168. (Also available at http://pubs.usgs.gov/ circ/1306.)

Dozier, M., 1983, Assessment of change in the marshes of southwestern Barataria basin, Louisiana, using historical aerial photographs and a spatial information system: Louisiana State University, Master's thesis, 102 p.

Dunton, K.H., Hardegree, B., and Whitledge, T.E., 2001, Response of estuarine marsh vegetation to interannual variations in precipitation: Estuaries, v. 24, p. 851-861.

Ebersole, B.A., Resio, D.T., and Westerink, J.J., 2007, A community approach to improved prediction and characterization of coastal storm hazards: Marine Technology Society Journal, v. 40, no. 4, p. 56-68.

Ellison, A.M., Bertness, M.D., and Miller, T., 1986, Seasonal patterns in the belowground biomass of Spartina alterniflora (Gramineae) across a tidal gradient: American Journal of Botany, v. 73, p. 1548-1554. 
Enriquez, S., Duarte, C.M., and Sand-Jensen, K., 1993, Patterns in decomposition rates among photosynthetic organisms - the importance of detritus C: N: P content: Oecologia v. 94, p. 457-471.

Ensminger, A.B., and Nichols, L.G., 1957, Hurricane damage to Rockefeller Refuge: Proceedings-Annual Conference of the Southeastern Association of Game and Fish Commission 11, p. 52-56.

Evers, D.E., 1991, Wetland and vegetation changes in southwestern Barataria Bay, Louisiana, 1945-1985: Baton Rouge, Louisiana State University, M.S. thesis, 76 p.

Evers, D.E., Sasser, C.E., Gosselink, J.G., and Hill, J.M., 1992, Wetland loss dynamics in southwestern Barataria basin, Louisiana (USA), 1945-1985: Wetlands Ecology and Management, v. 2, no. 3, p. 103-118.

Evers, D.E., Swenson, E.M., Stanton, L., and Sasser, C.E., 2007, Distribution and ecological characteristics of the marshes in the eastern Mississippi River Delta Plain, Louisiana and the impacts of Hurricane Katrina: U.S. Environmental Protection Agency, Water Quality Protection Division, $121 \mathrm{p}$.

Ewel, J., 1986, Invasibility-lessons from south Florida, in Mooney, H.A., and Drake, J.A., eds., Ecology of biological invasions of North America and Hawaii: New York, Springer-Verlag, p. 214-230.

Ewing, K., McKee, K.L., Mendelssohn, I.A., and Hester, M., 1995, A comparison of indicators of sublethal salinity stress in the salt marsh grass, Spartina patens (Ait.) Muhl.: Aquatic Botany v. 52, p. 59-74.

Federal Emergency Management Agency (FEMA), 2006, Hurricane Rita surge inundation limits: Washington, D.C., U.S. Department of Homeland Security, Federal Emergency Management Agency, accessed July 23, 2008 at http://www. fema.gov/hazard/flood/recoverydata/rita/rita_la_mmds. shtm\#sil.

Folse, T.M., and West, J.L., 2005, A standard operating procedures manual for the Louisiana Department of Natural Resource's Coastal Restoration Division-methods for data collection, quality assurance/quality control, storage, and products: Baton Rouge, Louisiana Department of Natural Resources, 226 p.

Foret, J.D., 2001, Nutrient limitation of tidal marshes on the Chenier Plain, Louisiana: Lafayette, University of Louisiana at Lafayette, Ph.D. dissertation, 99 p.
Gammill, S., Balkum, K., Duffy, K., Porthouse, J., Meselhe, E., Ramsey, E., and Walters, R., 2001, Hydrologic investigation of the Louisiana Chenier Plain. Report prepared for the Louisiana Coastal Wetland Planning, Protection and Restoration Act Task Force: Baton Rouge, Louisiana Department of Natural Resources.

Goni, M.A., Gordon, E.S., Monacci, N.M., Clinton, R., Gisewhite, R., Allison, M.A., and Kineke, G., 2006, The effect of Hurricane Lili on the distribution of organic matter along the inner Louisiana shelf (Gulf of Mexico, USA): Continental Shelf Research, v. 26, p. 2260-2280.

Gosselink, J.G., 1984, The ecology of delta marshes of coastal Louisiana - a community profile: U.S. Fish and Wildlife Service, FWS/OBS-84/09, 134 p.

Gross, M.F., Hardisky, M.A., Wolf, P.L., and Klemas, V., 1991, Relationship between aboveground and belowground biomass of Spartina alterniflora (smooth cordgrass): Estuaries, v.14, no. 2, p. 180-191.

Guntenspergen, G.R., Cahoon, D.R., Grace, J., Steyer, G.D., Fournet, S., Townson, M.A., and Foote, A.L., 1995, Disturbance and recovery of the Louisiana coastal marsh landscape from the impacts of Hurricane Andrew: Journal of Coastal Research, Special Issue, v. 21, p. 324-339.

Hackney, C.T., and de la Cruz, A.A., 1978, Changes in interstitial water salinity of a Mississippi tidal marsh: Estuaries, v. 1, p. 185-188.

Hatton, R.S., Delaune, R.D., and Patrick, W.H., Jr., 1983, Sedimentation, accretion, and subsidence in marshes of Barataria basin, Louisiana: Limnology and Oceanography, v. 28, no. 3, p. 494-502.

Hester, M.W., Mendelssohn, I.A., and McKee, K.L., 2001, Species and population variation to salinity stress in Panicum hemitomon, Spartina patens, and Spartina alterniflora - morphological and physiological constraints: Environmental and Experimental Botany, v. 46, p. 277-297.

Holm, G.O., Jr., 2006, Nutrient constraints on plant community production and organic matter accumulation of subtropical floating marshes: Baton Rouge, Louisiana State University, Ph.D. dissertation, 123 p.

Holm, G.O., Jr., Evers, D.E., Swenson, E.M., and Sasser, C.E., 2003, Vegetation, hydrologic, and substrate characteristics of the marshes in the Grand Lake area of the Chenier plain, Louisiana: Environmental Protection Agency, Water Quality Protection Division, 78 p. 
Holm, G.O., Jr., and Sasser, C.E., 2008, The management and ecology of the wetland grass maidencane: Journal of Aquatic Plant Management, v. 46, p. 51-60.

Hopkinson, C.S., Gosselink, J.G., and Parrondo, R.T., 1978, Aboveground production of seven marsh plant species in coastal Louisiana: Ecology, v. 59, no. 4, p. 760-769.

Howard, R.J., and Mendelssohn, I.A., 1999, Salinity as a constraint on growth of oligohaline marsh macrophytes. I. Species variation in stress tolerance: American Journal of Botany, v. 86, p. 785-794.

Jackson, L.L., Foote, A.L., and Balistrieri, L.S., 1995, Hydrological, geomorphological, and chemical effects of Hurricane Andrew on coastal marshes of Louisiana: Journal of Coastal Research, Special Issue, v. 21, p. 306-323.

Kaswadji, R.F., 1982, The estimation of primary production using five different methods in a Spartina alterniflora salt marsh in Barataria Bay, Louisiana: Baton Rouge, Louisiana State University, Master's thesis, 40 p.

Kaswadji, R.F., Gosselink, J.G., and Turner, R.E., 1990, Estimation of primary production using five different methods in a Spartina alterniflora salt marsh: Wetlands Ecology and Management, v. 1, no. 2, p. 57-64.

Keim, B.D., Muller, R.A., and Stone, G.W., 2007, Spatiotemporal patterns and return periods of tropical storm and hurricane strikes from Texas to Maine: Journal of Climate, v. 20, p. 3498-3509.

Kirby, C.J., and Gosselink, J.G., 1976, Primary production in a Louisiana gulf coast Spartina alterniflora marsh: Ecology, v. 57, no. 5, p. 1052-1059.

Knaus, R.M., and Cahoon, D.R., 1990, Improved cryogenic coring device for measuring soil accretion and bulk density: Journal of Sedimentary Petrology, v. 60, p. 622-623.

LaPeyre, M.K.G., Grace, J.B., Hahn, E., and Mendelssohn, I.A., 2001, The importance of competition in regulating plant species abundance along a salinity gradient: Ecology, v. 82 , p. $62-69$.

Latham, P.J., Pearlstine, L.G., and Kitchens, W.M., 1994, Species association changes across a gradient of freshwater, oligohaline, and mesohaline tidal marshes along the lower Savannah River: Wetlands, v. 14, p. 174-183.

Louisiana Coastal Wetlands Planning, Protection and Restoration Act Program, n.d., Coastal Louisiana basins: Louisiana Coastal Wetlands Planning, Protection and Restoration Act Program Web site, accessed November 9, 2010, at http://lacoast.gov/new/About/Basins.aspx.
Louisiana Office of Coastal Protection and Restoration, 2010, Strategic Online Natural Resource Information System (SONRIS) database: accessed May 01, 2010 at http://dnr. louisiana.gov/crm/coastres/monitoring.asp.

McCaffrey, R.J., and Thomson, J., 1980, A record of the accumulation of sediment and trace metals in a Connecticut salt marsh: Advances in Geophysics, v. 22, p. 165-236.

McGee, B.D., Tollett, R.W., and Goree, B.B., 2007, Monitoring Hurricane Rita inland storm surge, in Farris, G.S., Smith, G.J., Crane, M.P., Demas, C.R., Robbins, L.L., and Lavoie, D.L., eds., Science and the storms - the USGS response to the hurricanes of 2005: U.S. Geological Survey Circular 1306, p. 257-263. (Also available at http://pubs. usgs.gov/circ/1306.)

McKee, K.L., Mendelssohn, I.A., and Hester, M.W., 1988, Reexamination of pore water sulfide concentrations and redox potentials near the aerial roots of Rhizophora mangle and Avicennia germinans: American Journal of Botany, v. 75 , no. 9 , p. 1352-1359.

McKee, K.L., and Mendelssohn, I.A., 1989, Response of a freshwater marsh plant community to increased salinity and increased water level: Aquatic Botany, v. 34, p. 301-316.

Meeder, J.F., 1987, Variable effects of hurricanes on the coast and adjacent marshes - a problem for land managers, in Brodtmann, N.V., ed., Fourth Water Quality and Wetlands Conference Proceedings, New Orleans, Louisiana p. 337-374.

Mitsch, W.J., and Gosselink, J.G., 2000, Wetlands (3d ed.): New York, John Wiley \& Sons, Inc., 920 p.

Moerschbaecher, M.K., 2008, The impact of the Caernarvon diversion on above- and belowground marsh biomass in the Breton Sound Estuary after Hurricane Katrina: Baton Rouge, Louisiana State University, Master's thesis, 64 p.

Morgan, J.P., Nichols, L.G., and Wright, M., 1958, Morphological effects of Hurricane Audrey on the Louisiana coast: Baton Rouge, Louisiana State University, Coastal Studies Institute technical report no. 10, 53 p.

Morris, J.T., Sundareshwar, P.V., Nietch, C.T., Kjerve, B., and Cahoon, D.R., 2002, Responses of coastal wetlands to rising sea level: Ecology, v. 83, p. 2869-2877.

National Climatic Data Center. 2009, State precipitation data: National Oceanic and Atmospheric Administration, National Climatic Data Center, accessed August 03, 2008, at http:// www1.ncdc.noaa.gov/pub/data/cirs/state.README. 
Nyman, J.A., DeLaune, R.D., and Patrick, W.H., Jr., 1990, Wetland soil formation in the rapidly subsiding Mississippi River deltaic plain - mineral and organic matter relationships: Estuarine, Coastal and Shelf Science, v. 31, p. 57-69.

Nyman, J.A., Chabreck, R.H., DeLaune, R.D., and Patrick, W.H., Jr., 1993, Submergence, salt-water intrusion, and managed gulf coast marshes, in Magoon O.T., Coastal Zone '93- Proceedings of the Eighth Symposium on Coastal and Ocean Management, New Orleans, Louisiana: New York, American Society of Civil Engineers, p. 1690-1704.

Nyman, J.A., Crozier, C.R., and DeLaune, R.D., 1995, Roles and patterns of hurricane sedimentation in an estuarine marsh landscape: Estuarine, Coastal and Shelf Science, v. 40, p. 665-679.

Nyman, J.A., Walters, R.J., DeLaune, R.D., and Patrick, W.H., Jr., 2006, Marsh vertical accretion via vegetative growth: Estuarine, Coastal and Shelf Science, v. 69, p. 370-380.

Odum, W.E., and Hoover, J.K., 1988, A comparison of vascular plant communities in tidal freshwater and saltwater marshes, in Hook, D.D., and others, eds., The ecology and management of wetlands: London, Croom Helm, p. $526-534$.

Penfound, W.T., and Hathaway, E.S., 1938, Plant communities in the marshlands of southeastern Louisiana: Ecological Monographs, v. 8, p. 4-56.

Penland, S., and Ramsey, K.E., 1990, Relative sea-level rise in Louisiana and the Gulf of Mexico-1908-1988: Journal of Coastal Research, v. 6, p. 323-342.

Perez, B.C., Day, J.W., Jr., Rouse, L.J., Shaw, R.F., and Wang, M., 2000, Influence of Atchafalaya River discharge and winter frontal passage on suspended sediment concentration and flux in Fourleague Bay, Louisiana: Estuarine, Coastal and Shelf Science, v. 50, no. 2, p. 271-290.

Phillips, L.A., 2002, Vertical accretion and marsh elevation dynamics on the Chenier Plain, Louisiana: Lafayette, University of Louisiana at Lafayette, Master's thesis, 132 p.

Reed, D.J., 2002, Sea-level rise and coastal marsh sustainability - geological and ecological factors in the Mississippi Delta Plain: Geomorphology, v. 48, p. 233-243.

Rejmanek, M., Sasser, C.E., and Peterson, G.W., 1988, Hurricane-induced sediment deposition in a Gulf Coast marsh: Estuarine, Coastal and Shelf Science, v. 27, p. 217-222.
Sasser, C.E., Fuller, D., and Gosselink, J.G., 1978, Environmental monitoring program: Louisiana Offshore Oil Port Pipeline Annual Report, 145 p.

Sasser, C.E., Dozier, M.D., Gosselink, J.G., and Hill, J.M., 1986, Spatial and temporal changes in Louisiana's Barataria basin marshes, 1945-1980: Environmental Management, v. 10, no. 5, p. 671-680.

Sasser, C.E., Swenson, E.M., Evers, D.E., Visser, J.M., Holm, G.O., and Gosselink, J.G., 1994, Floating marshes in Barataria and Terrebonne basins, Louisiana: Baton Rouge, Louisiana State University, Coastal Ecology Institute, p. 186.

Sasser, C.E., Evers, D.E., Gosselink, J.G., Holm, G.O., Jr., Swenson, E.M., and Visser, J.M., 2002, Ecological evaluation of the CWPPRA central and eastern Terrebonne basin freshwater delivery project: Baton Rouge, submitted to Louisiana Department of Natural Resources, final report, $113 \mathrm{p}$.

Saucier, R.T., 1994, Geomorphology and quaternary geologic history of the Lower Mississippi Valley: Vicksburg, Miss., U.S. Army Corps of Engineers, v. 1, 364 p.

Schubauer, J.P., and Hopkinson, C.S., 1984, Above- and belowground emergent macrophyte production and turnover in a coastal marsh ecosystem, Georgia: Limnology and Oceanography, v. 29, no. 5, p. 1052-1065.

Slocum, M.G., Mendelssohn, I.A., and Kuhn, N.L., 2005, Effects of sediment slurry enrichment on salt marsh rehabilitation - plant and soil responses over seven years: Estuaries, v. 28, no. 4, p. 519-528.

Smith, C.J., DeLaune, R.D., and Patrick, W.H., Jr., 1983, Carbon dioxide emission and carbon accumulation in coastal wetlands: Estuarine, Coastal and Shelf Science, v. 17 , p. 21-29.

Spalding, E.A., and Hester, M.W., 2007, Interactive effects of hydrology and salinity on oligohaline plant species productivity-implications of relative sea-level rise: Estuaries and Coasts, v. 30, no. 2, p. 214-225.

Steyer, G.D., Raynie, R.C., Steller, D.L., Fuller, D., and Swenson, E., 1995, Quality management plan for Coastal Wetland Planning, Protection, and Restoration Act monitoring program: Louisiana Department of Natural Resources Open-File Report 95-01, 103 p.

Steyer, G.D., Sasser, C.E., Visser, J.M., Swenson, E.M., Nyman, J.A., and Raynie, R.C., 2003, A proposed Coastwide Reference Monitoring System for evaluating wetland restoration trajectories in Louisiana: Environmental Monitoring and Assessment, v. 81, p. 107-117. 
Steyer, G.D., Perez, B.C., Piazza, S., Suir, G., 2007, Potential consequences of saltwater intrusion associated with Hurricanes Katrina and Rita, in Farris, G.S., Smith, G.J., Crane, M.P., Demas, C.R., Robbins, L.L., and Lavoie, D.L., eds., Science and the storms - the USGS response to the hurricanes of 2005: U.S. Geological Survey Circular 1306, p. 137-146. (Also available at http://pubs.usgs.gov/ circ/1306.)

Steyer, G.D., 2008, Landscape analysis of vegetation change in coastal Louisiana following Hurricanes Katrina and Rita: Baton Rouge, Louisiana State University, Ph.D. dissertation, $158 \mathrm{p}$.

Steyer, G.D., Cretini, K.F., Piazza, S., Sharp, L.A., Snedden, G.A., Sapkota, S., 2010, Hurricane influence on vegetation community change in coastal Louisiana: U.S. Geological Survey Open-File Report 2010-1105, 21. p.

Stone, G.W., Grymes, J.M., Dingler, J.R., and Pepper, D.A., 1997, Overview and significance of hurricanes on the Louisiana coast, USA: Journal of Coastal Research, v. 13, no. 3, p. 656-669.

Swarzenski, C.M., Doyle, T.M., Fry, B., and Hargis, T.G., 2008, Biogeochemical response of organic-rich freshwater marshes in the Louisiana delta plain to chronic river water influx: Biogeochemistry, v. 90, p. 49-63.

Swenson, E.M., and Turner, R.E., 1994, Indicator development for evaluating estuarine emergent condition — salt marsh pilot study, v. II —appendices: Wetland Research Team, submitted to U.S. Environmental Research Laboratory, final report, $274 \mathrm{p}$.

Turner, R.E., Swenson, E.M., Rabalais, N.N., and Smith, L.E., 1998, EMAP wetlands southeastern pilot study (phase 2): Submitted to U.S. Environmental Protection Agency, Office of Research and Development, Environmental Research Laboratory, final report, $231 \mathrm{p}$.

Turner, R.E., Swenson, E.M., and Milan, C.S., 2001, Organic and inorganic contributions to vertical accretion in salt marsh sediment, in Weinstein, M., and Kreeger, K., eds., Concepts and controversies in tidal marsh ecology: Drodrecht, The Netherlands, Kluwer Academic Publishing, p. 583-595.

Turner, R.E., Swenson, E.M., Milan, C.S., Lee, J.M., and Oswald, T.A., 2004, Below-ground biomass in healthy and impaired salt marshes: Ecological Research, v. 19, p. 29-35.

Turner, R.E., Baustian, J.J., Swenson, E.M., and Spicer, J.S., 2006, Wetland sedimentation from Hurricanes Katrina and Rita: Science, v. 314, p. 449-452.
Twilley, R.R., and Nyman, J.A., 2000, The role of biogeochemical processes in marsh restorationimplications to freshwater diversions: Baton Rouge, submitted to Louisiana Department of Natural Resources, final report, $99 \mathrm{p}$.

Valentine, J.M., Jr., 1976, Plant succession after sawgrass mortality in southwestern Louisiana: Southeastern Association of Fish and Wildlife Agencies, v. 30, p. 634-640.

Visser, J.M., Evers, D.E., Holm, G.O., Jr., Peterson, G.W., and Sasser, C.E., 1996, 1995 annual report, environmental monitoring program Louisiana offshore oil port pipeline: $186 \mathrm{p}$.

Visser, J.M., Sasser, C.E., and Cade, B.S., 2006, The effect of multiple stressors on salt marsh end-of-season biomass: Estuaries and Coasts, v. 29, p. 331-342.

Visser, J.M., Steyer, G.D., Shaffer, G.P., Höppner, S.S., Hester, M.W., Reyes, E., Keddy, P., Mendelssohn, I.A., Sasser, C.E., and Swarzenski, C., 2003, Habitat switching module, chap. 9, in Twilley, R.R., ed., Coastal Louisiana Ecosystem Assessment and Restoration (CLEAR) model of Louisiana Coastal Area (LCA) Comprehensive Ecosystem Restoration Plan-v. I-tasks 1-8: Baton Rouge, Louisiana Department of Natural Resources, Coastal Restoration Division, 319 p.

Visser, J.M., Sasser, C.E., and Cade, B.S., 2006, The effect of multiple stressors on salt marsh end-of-season biomass: Estuaries and Coasts, v. 29, p. 331-342.

Vogt, K.A., Gordon, J.C., Wargo, J.P., Vogt, D.J., Asbjornsen, H., Palmiotto, P.A., Clark, H.J., O'Hara, J.L., Keeton, W.S., Patel-Weynand, T., and Witten, E., 1997, Ecosystemsbalancing science with management: New York, SpringerVerlag, $457 \mathrm{p}$.

Walker, N.D., and Hammack, A.B., 2000, Impacts of winter storms on circulation and sediment transport-AtchafalayaVermilion Bay region, Louisiana, USA: Journal of Coastal Research, v. 16, p. 996-1010.

White, D.A., Weiss, T.E., Trapani, J.M., and Thien, L.B., 1978, Productivity and decomposition of the dominant salt marsh plants in Louisiana: Ecology, v. 59, no. 4, p. 751-759.

Wiseman, W.J., Swenson, E.M., and Kelly, F.J., 1990, Control of estuarine salinities by coastal ocean salinity: Coastal and Estuarine Studies, v. 38, p. 184-193.

Wunderlin, R.P., and Hansen, B.F., 2003, Guide to the vascular plants of Florida ( $2 \mathrm{~d}$ ed.): Gainesville, University Press of Florida, $787 \mathrm{p}$. 


\section{Appendix 1. Hydrographs for study sites within the Coastwide Reference Monitoring System (CRMS)}
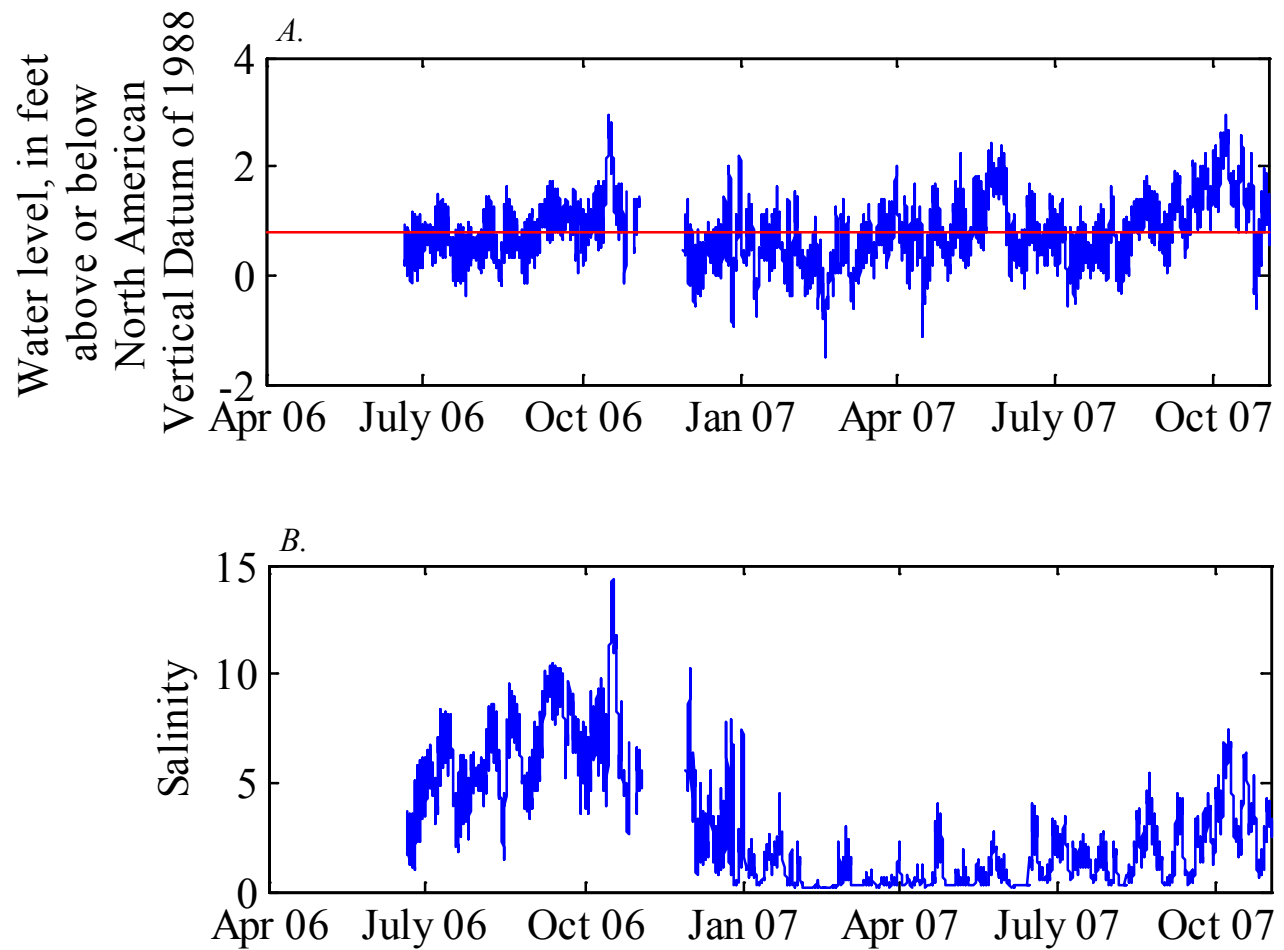

Figure 1-1. Water level, with marsh elevation (red line), and surface salinity at site 0135 of the Coastwide Reference Monitoring System (CRMS) from April 1, 2006, to November 1, 2007. A, Water level. B, Surface salinity.
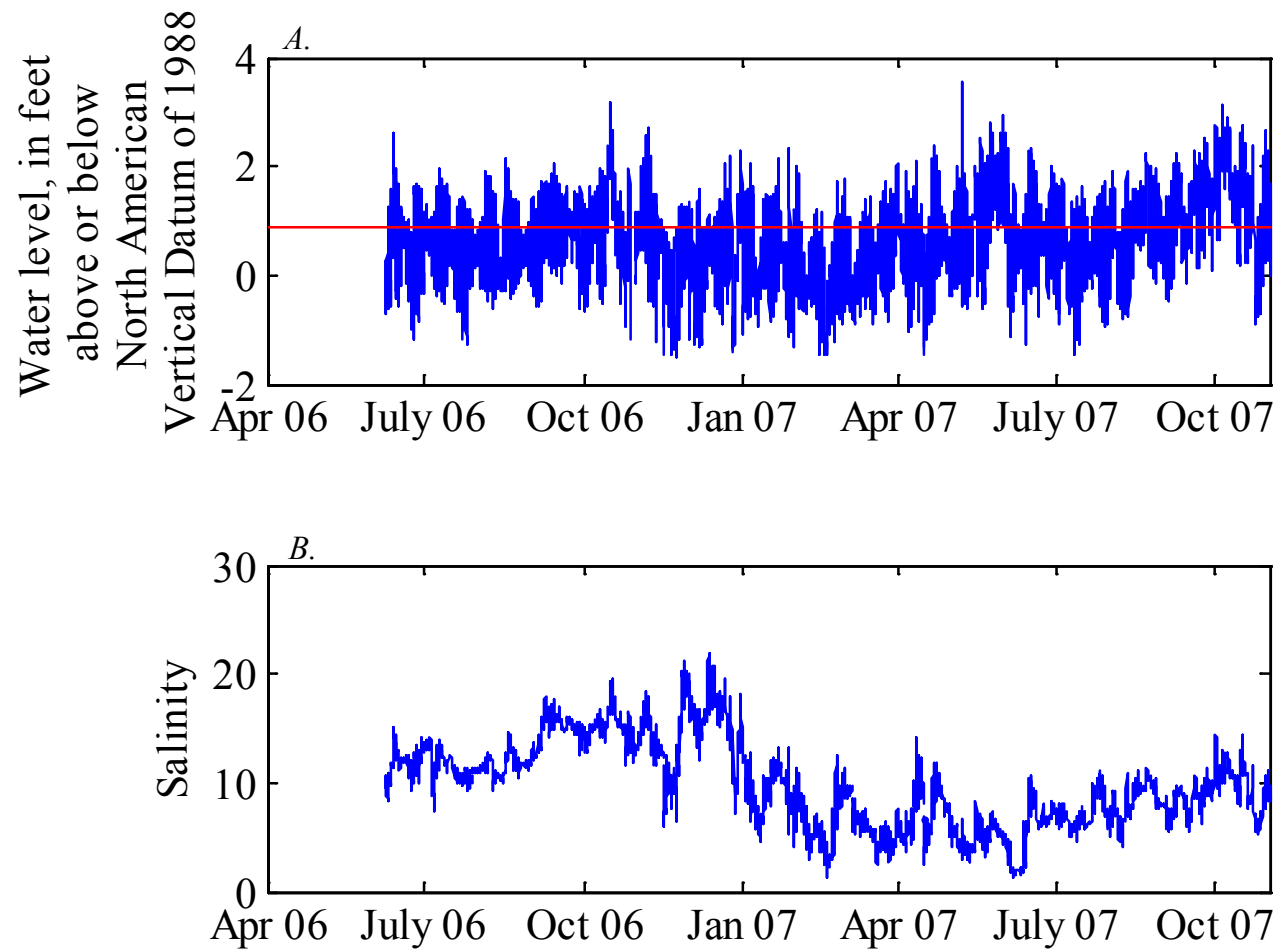

Figure 1-2. Water level, with marsh elevation (red line), and surface salinity at site 0147 of the Coastwide Reference Monitoring System (CRMS) from April 1, 2006, to November 1, 2007. A, Water level. B, Surface salinity. 

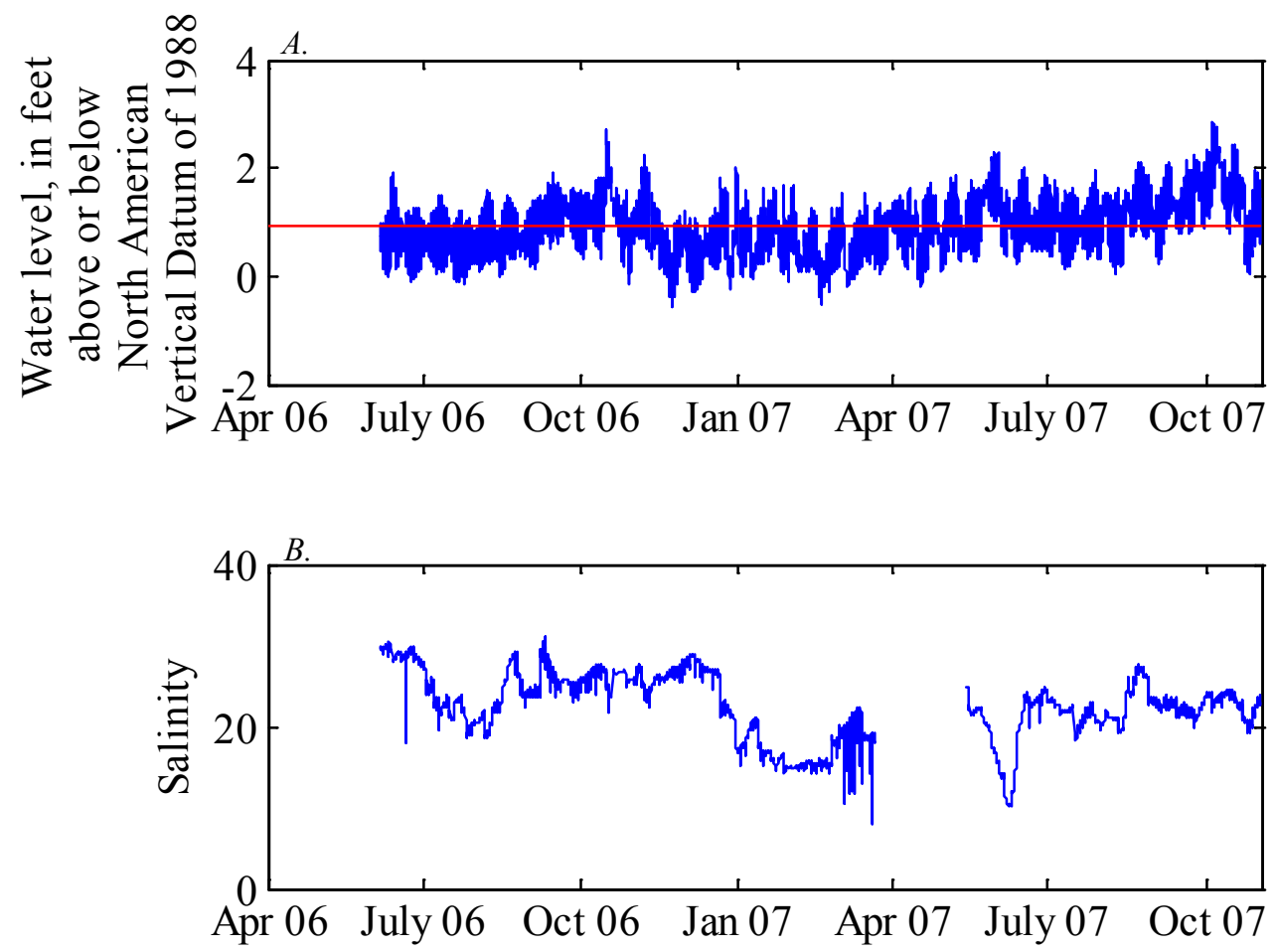

Figure 1-3. Water level, with marsh elevation (red line), and surface salinity at site 0164 of the Coastwide Reference Monitoring System (CRMS) from April 1, 2006, to November 1, 2007. A, Water level. B, Surface salinity.
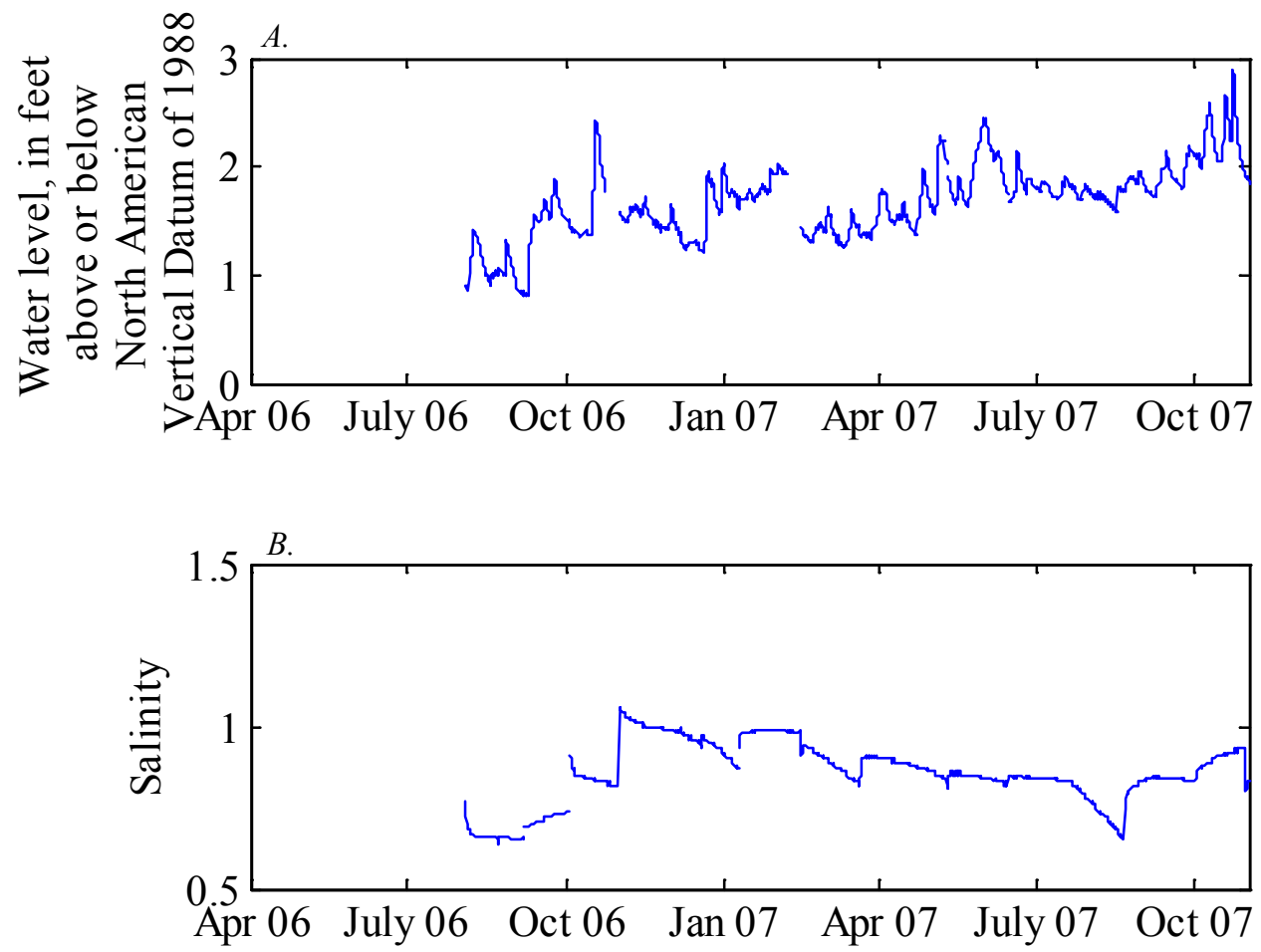

Figure 1-4. Water level, with marsh elevation (red line), and surface salinity at site 0219 of the Coastwide Reference Monitoring System (CRMS) from April 1, 2006, to November 1, 2007. A, Water level. B, Surface salinity. 

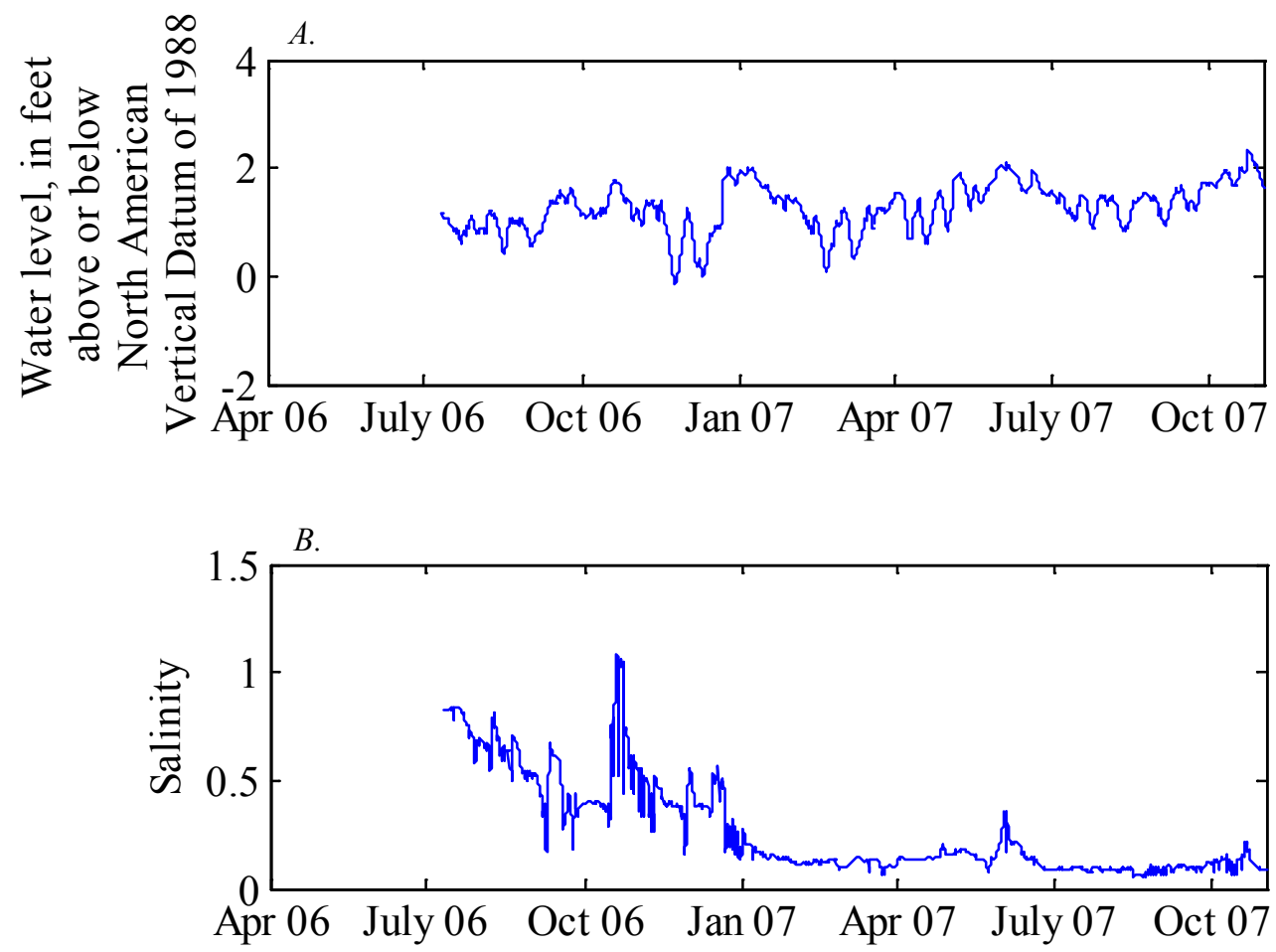

Figure 1-5. Water level, with marsh elevation (red line), and surface salinity at site 0268 of the Coastwide Reference Monitoring System (CRMS) from April 1, 2006, to November 1, 2007. A, Water level. $B$, Surface salinity.
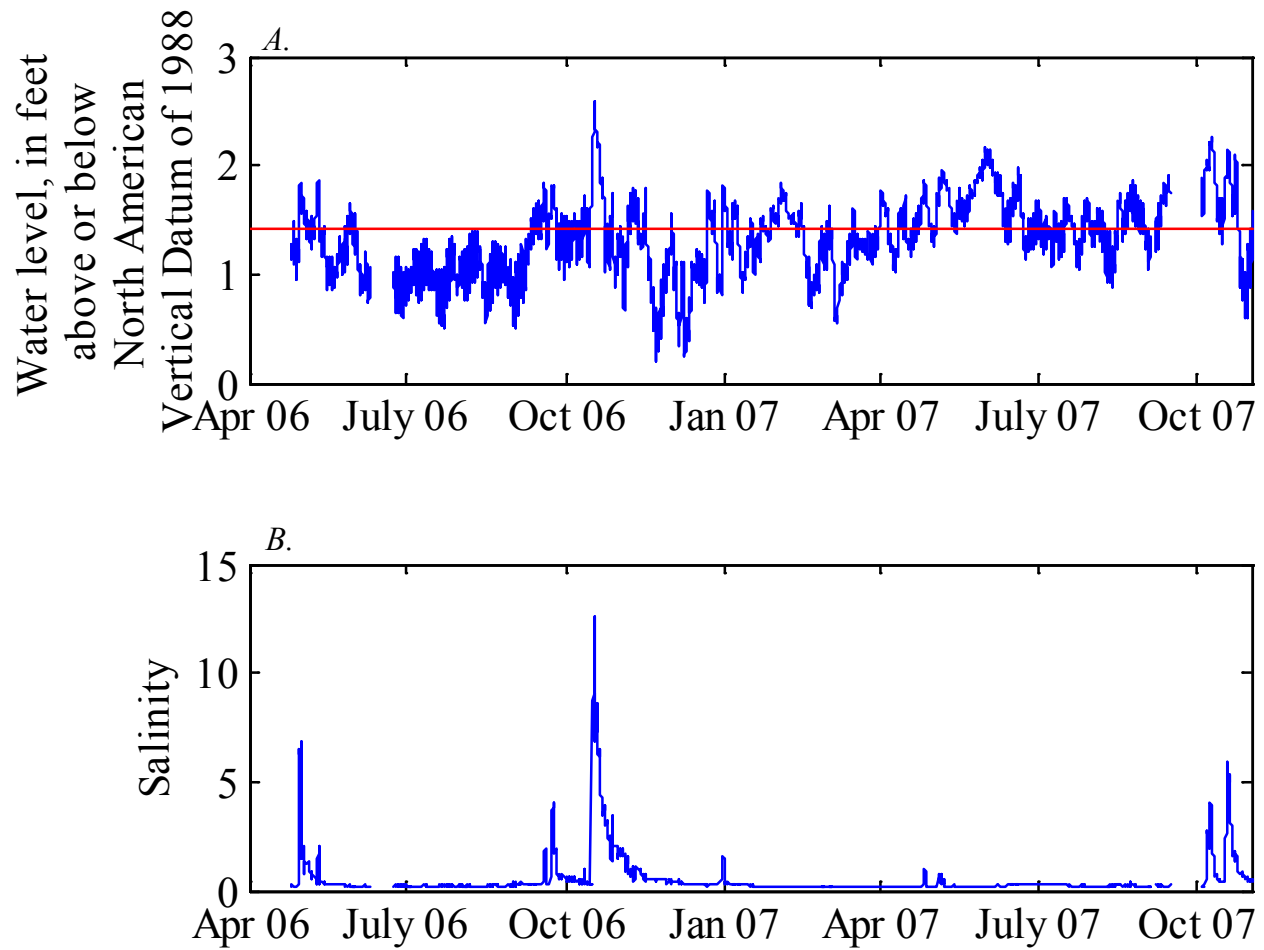

Figure 1-6. Water level, with marsh elevation (red line), and surface salinity at site 0294 of the Coastwide Reference Monitoring System (CRMS) from April 1, 2006, to November 1, 2007. A, Water level. B, Surface salinity. 

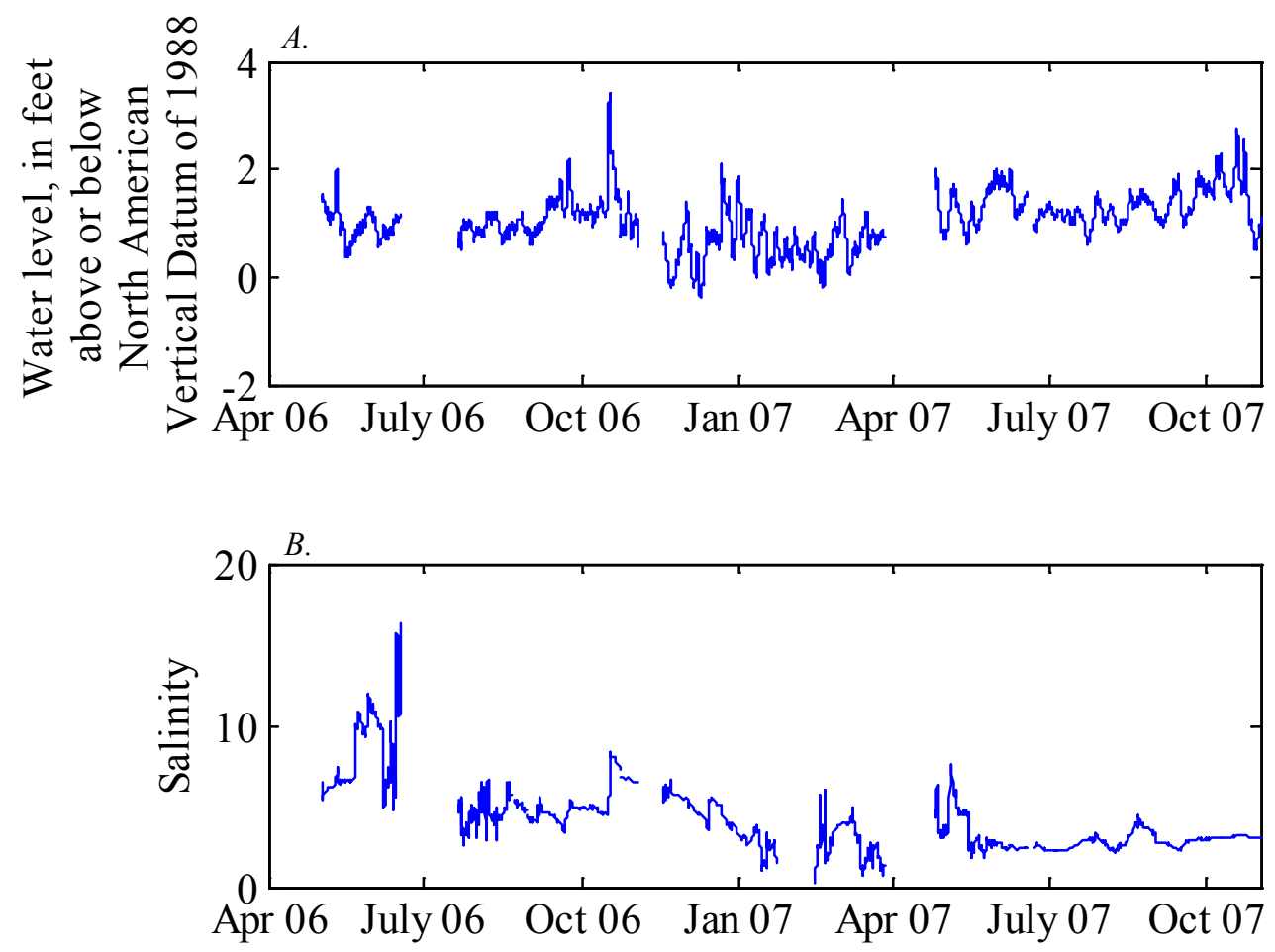

Figure 1-7. Water level, with marsh elevation (red line), and surface salinity at site 0312 of the Coastwide Reference Monitoring System (CRMS) from April 1, 2006, to November 1, 2007. A, Water level. B, Surface salinity.
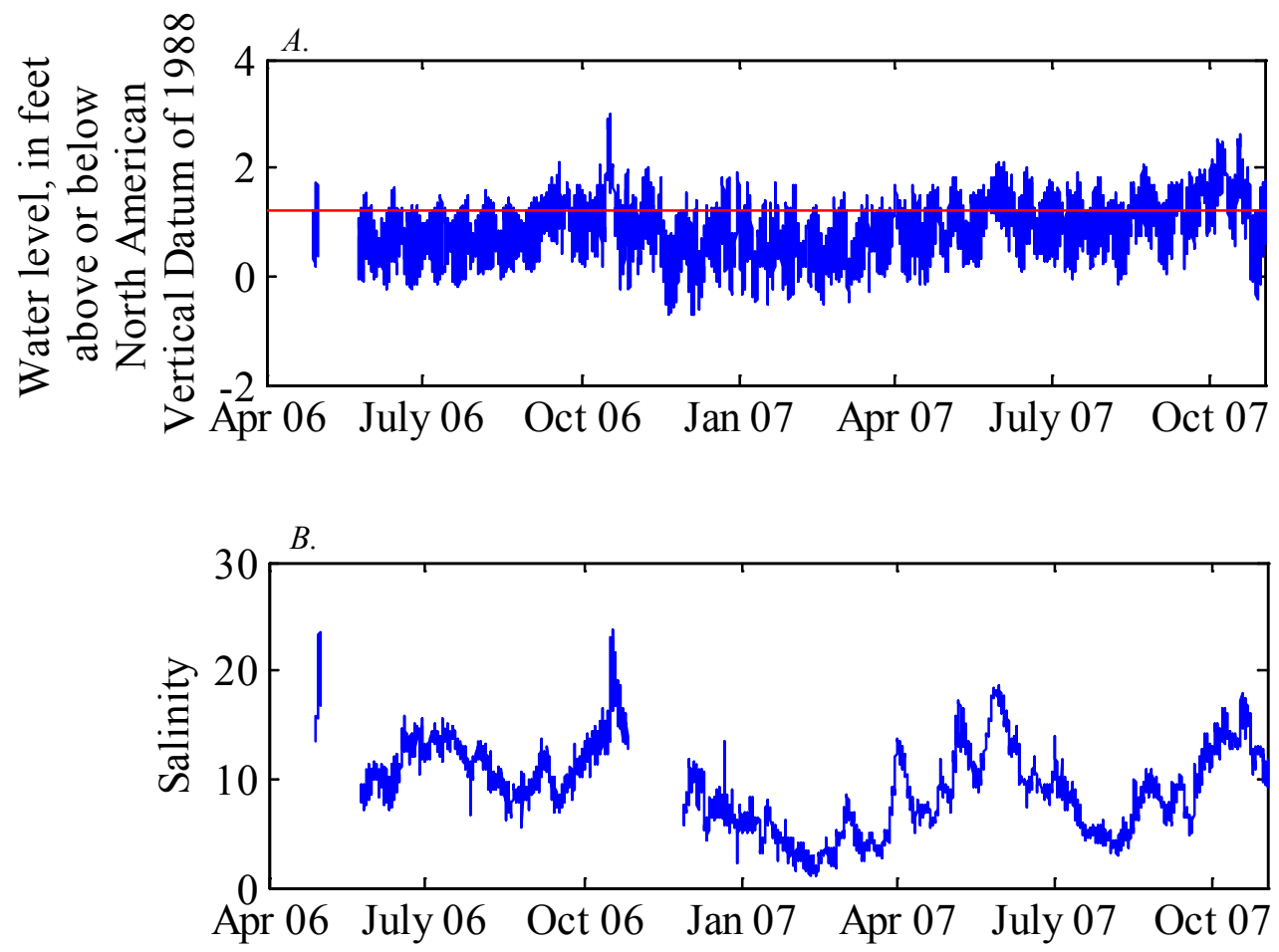

Figure 1-8. Water level, with marsh elevation (red line), and surface salinity at site 0326 of the Coastwide Reference Monitoring System (CRMS) from April 1, 2006, to November 1, 2007. A, Water level. B, Surface salinity. 

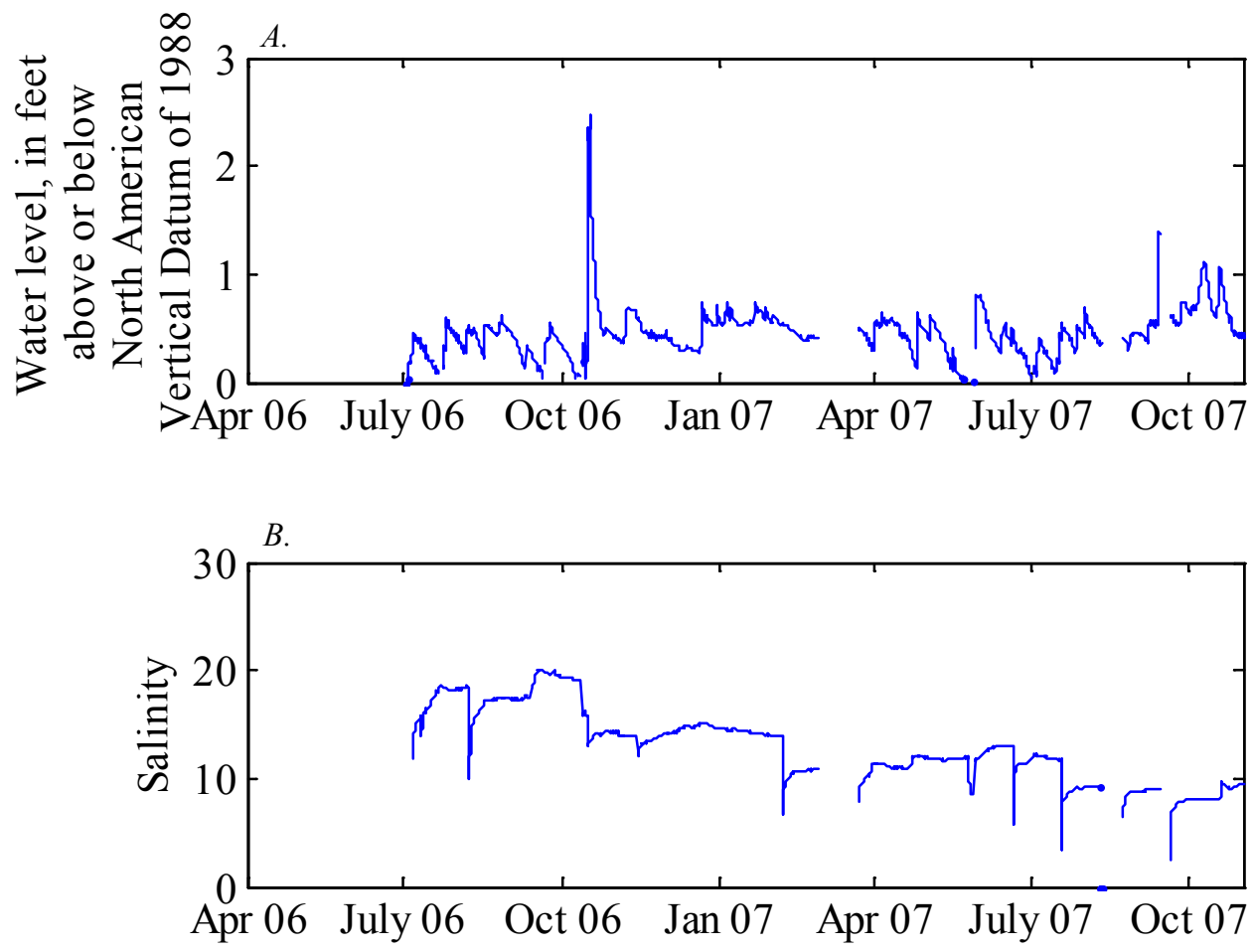

Figure 1-9. Unadjusted water level and raw surface salinity at site 0610 of the Coastwide Reference Monitoring System (CRMS) from April 1, 2006, to November 1, 2007. No adjusted water level or salinity data were available; therefore, the data presented should be used for trend purposes only, not exact water-level or salinity values. $A$, Unadjusted water level. $B$, Raw surface salinity.
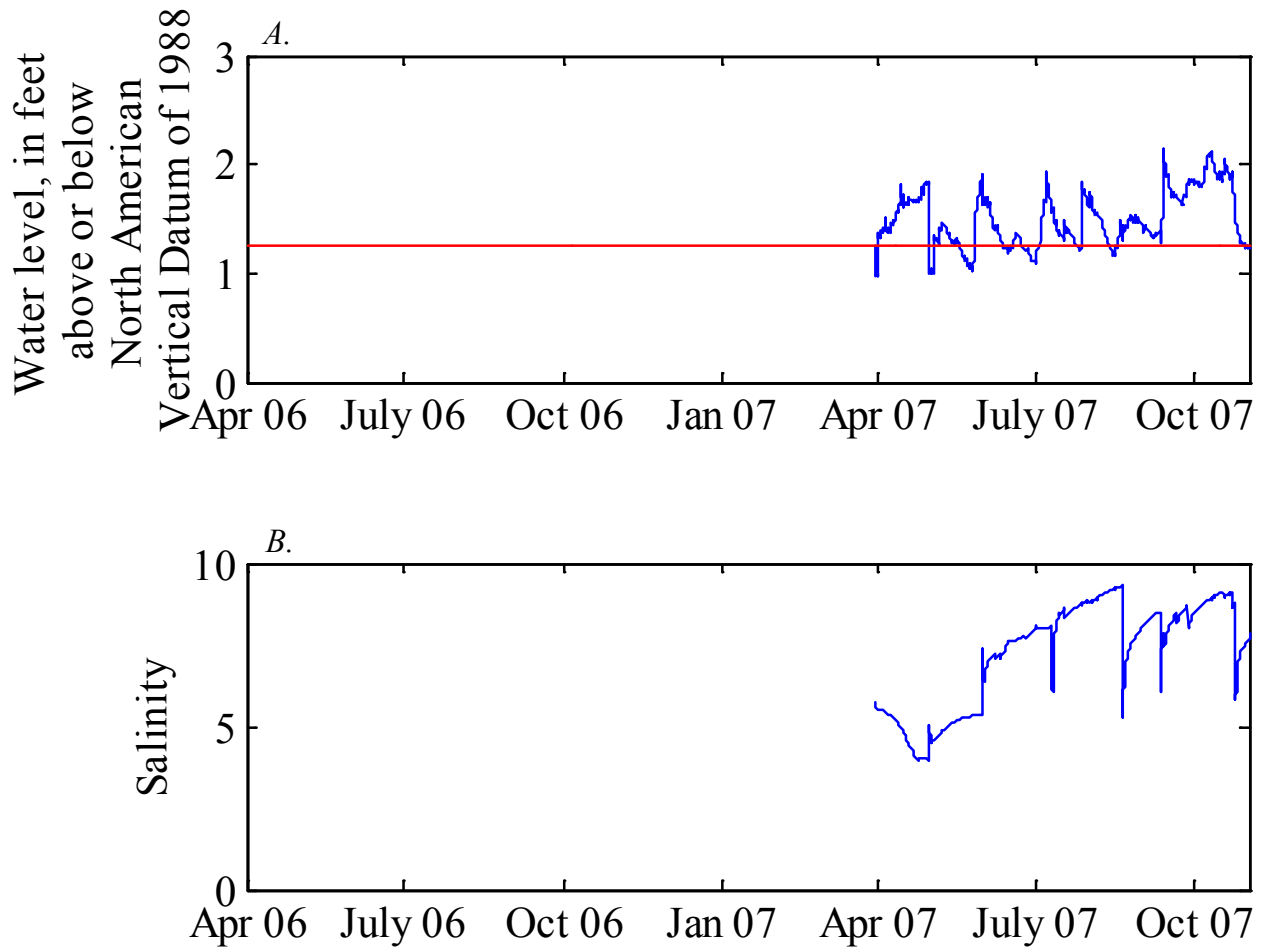

Figure 1-10. Water level, with marsh elevation (red line), and raw surface salinity at site 0651 of the Coastwide Reference Monitoring System (CRMS) from April 1, 2006, to November 1, 2007. No adjusted salinity data were available; therefore, the data presented should be used for trend purposes only, not exact salinity values. $A$, Water level. $B$, Raw surface salinity. 

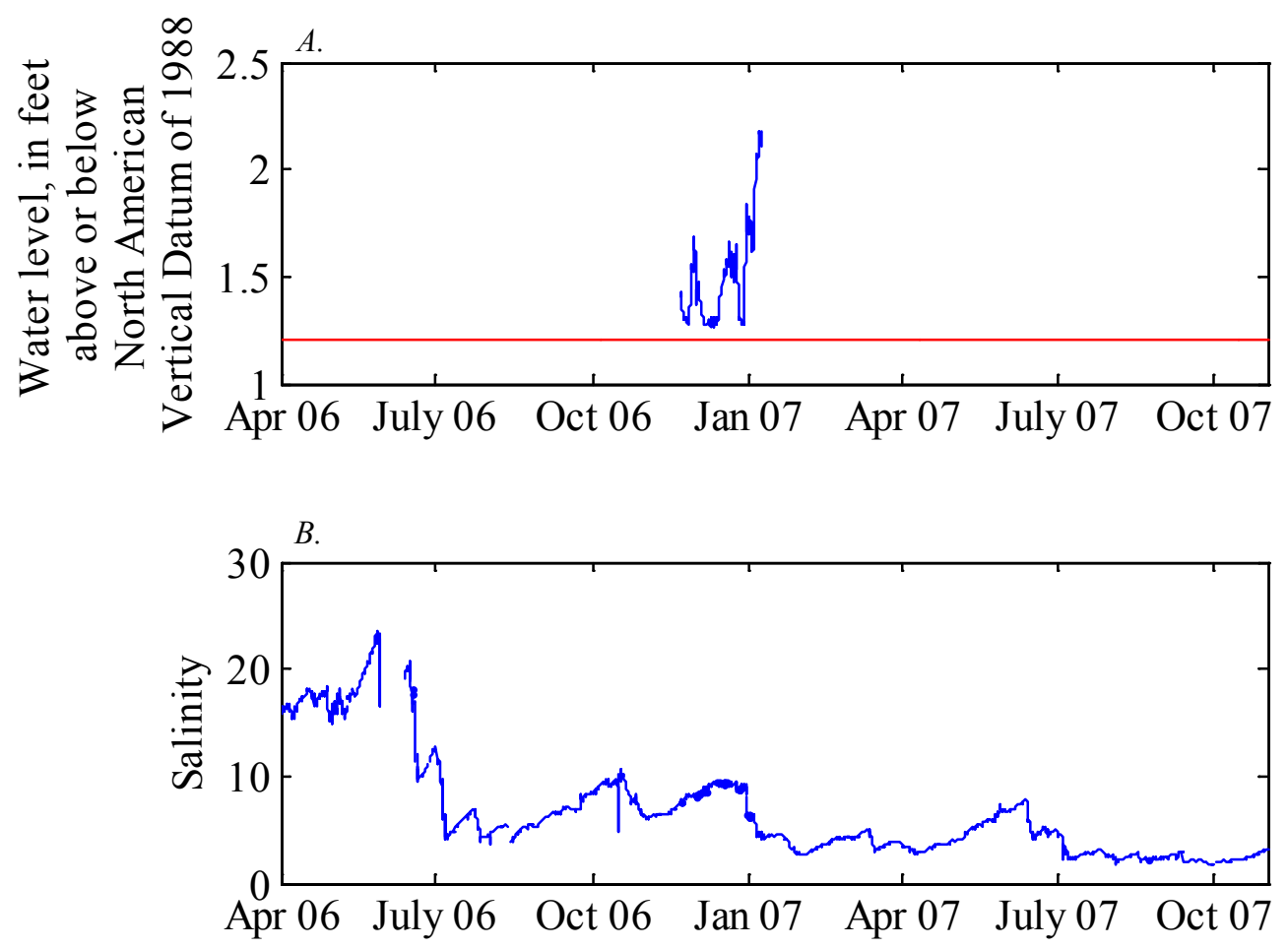

Figure 1-11. Water level, with marsh elevation (red line), and surface salinity at site 0669 of the Coastwide Reference Monitoring System (CRMS) from April 1, 2006, to November 1, 2007. A, Water level. $B$, Surface salinity.
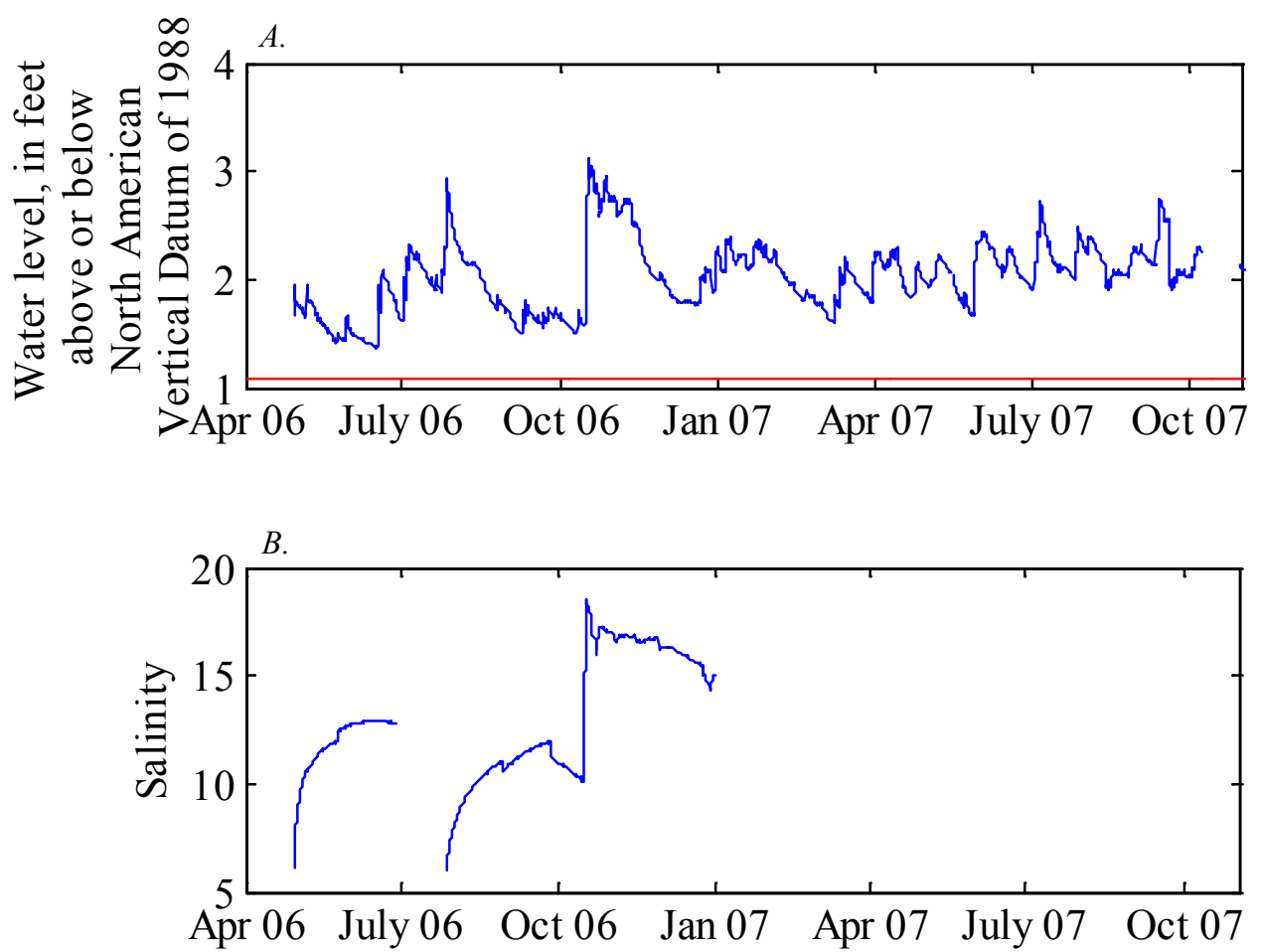

Figure 1-12. Water level, with marsh elevation (red line), and surface salinity at site 0672 of the Coastwide Reference Monitoring System (CRMS) from April 1, 2006, to November 1, 2007. A, Water level. B, Surface salinity. 

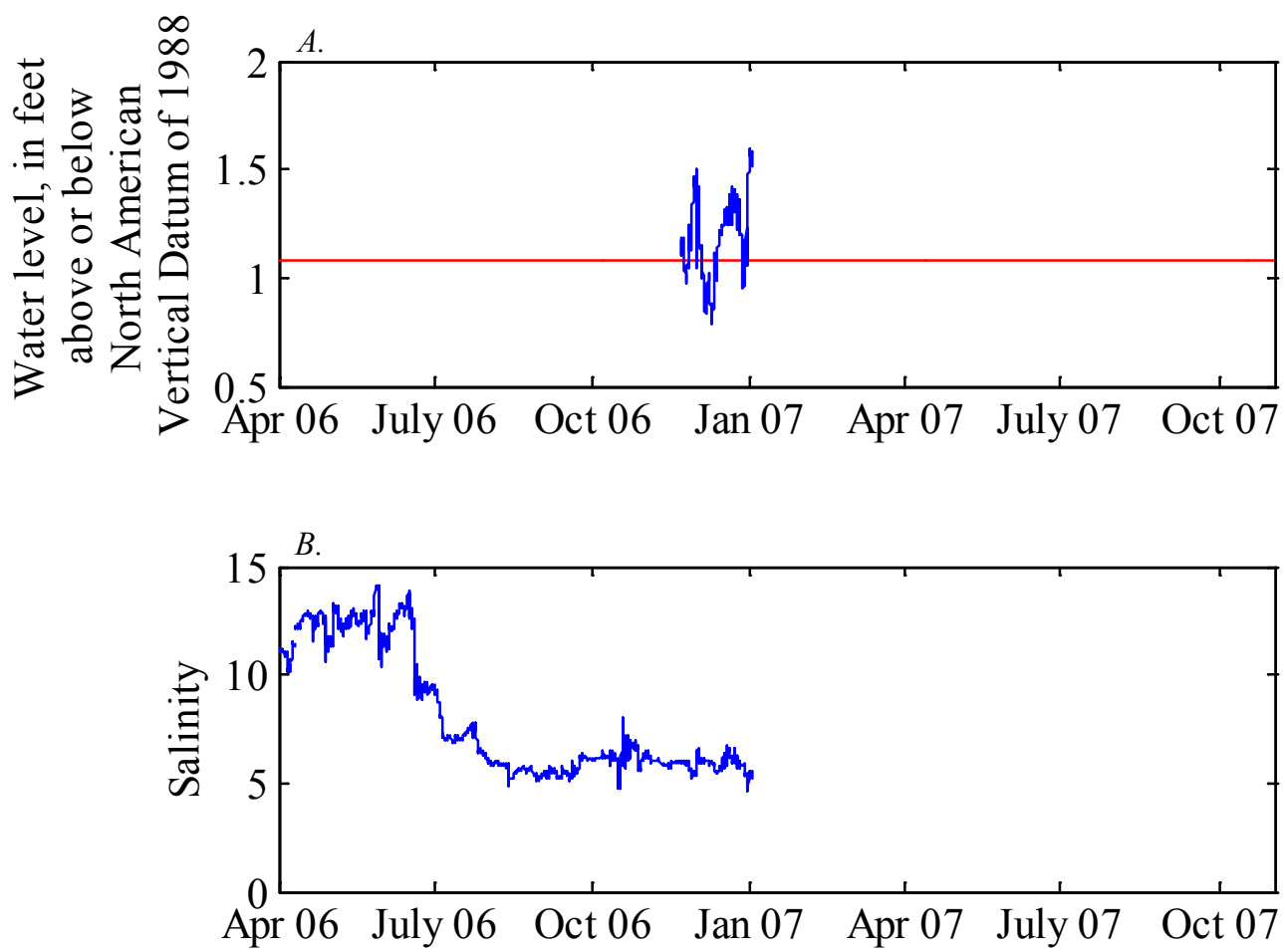

Figure 1-13. Water level, with marsh elevation (red line), and surface salinity at site 2156 of the Coastwide Reference Monitoring System (CRMS) from April 1, 2006, to November 1, 2007. A, Water level. $B$, Surface salinity. 


\section{Appendix 2. Site elevation and accretion at study sites within the Coastwide Reference Monitoring System (CRMS)}

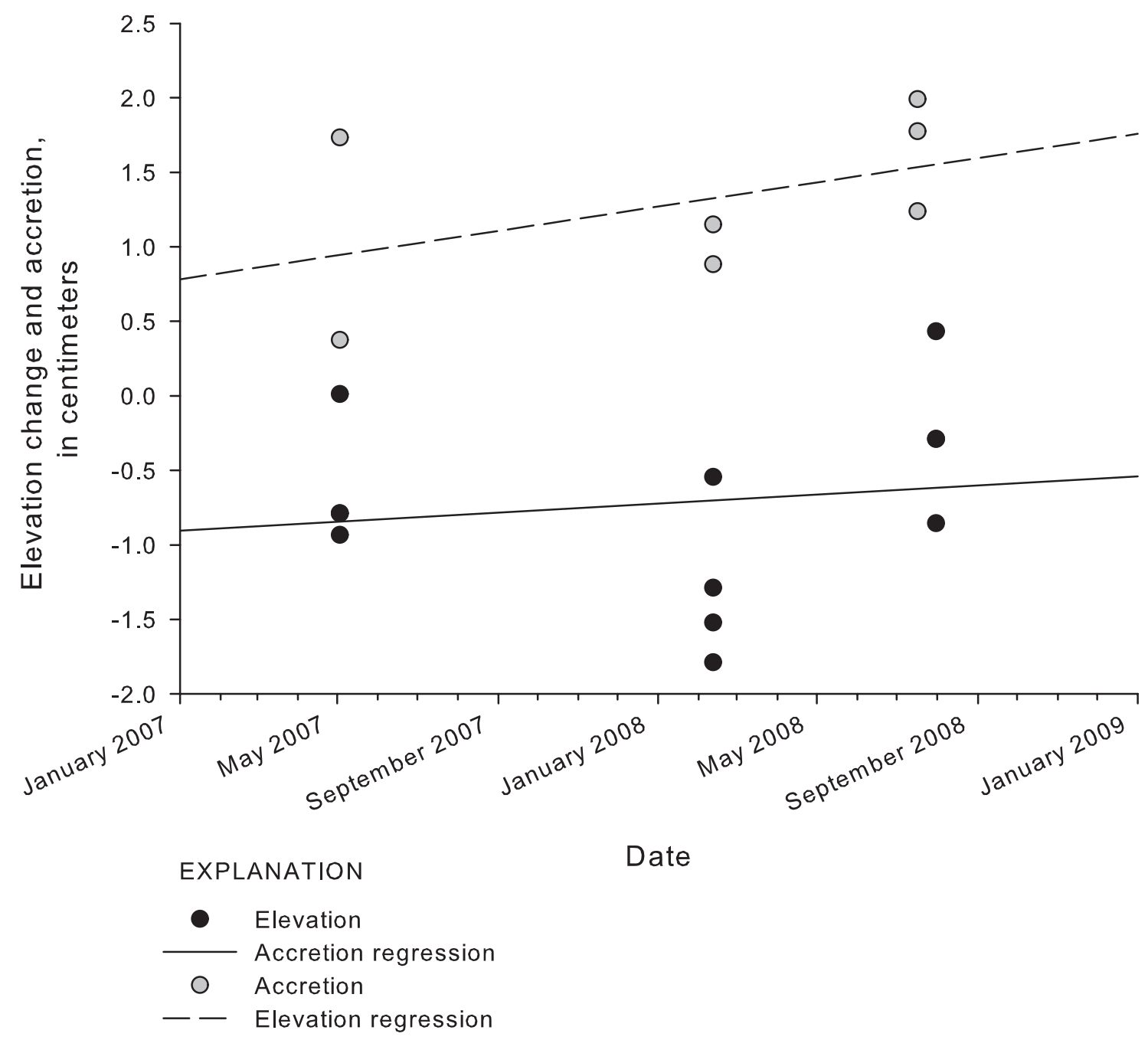

Figure 2-1. Changes in elevation and vertical accretion at Coastwide Reference Monitoring System (CRMS) site 0135 from January

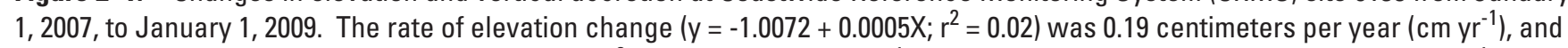
the rate of vertical accretion $\left(y=0.5679+0.0013 X ; r^{2}=0.21\right)$ was $0.49 \mathrm{~cm} \mathrm{yr}^{-1}$. The rate of shallow subsidence was $0.30 \mathrm{~cm} \mathrm{yr}^{-1}$, and the relative sea level rise (RSLR) was $0.92 \mathrm{~cm} \mathrm{yr}^{-1}$. Elevation change at CRMS0135 is projected to be $0.73 \mathrm{~cm} \mathrm{yr}^{-1}$ less than $\mathrm{RSLR}$. Trend lines represent a best-fit linear regression from data collected in three sampling periods. Shallow subsidence is calculated by subtracting the rate of vertical accretion from the rate of elevation change. 


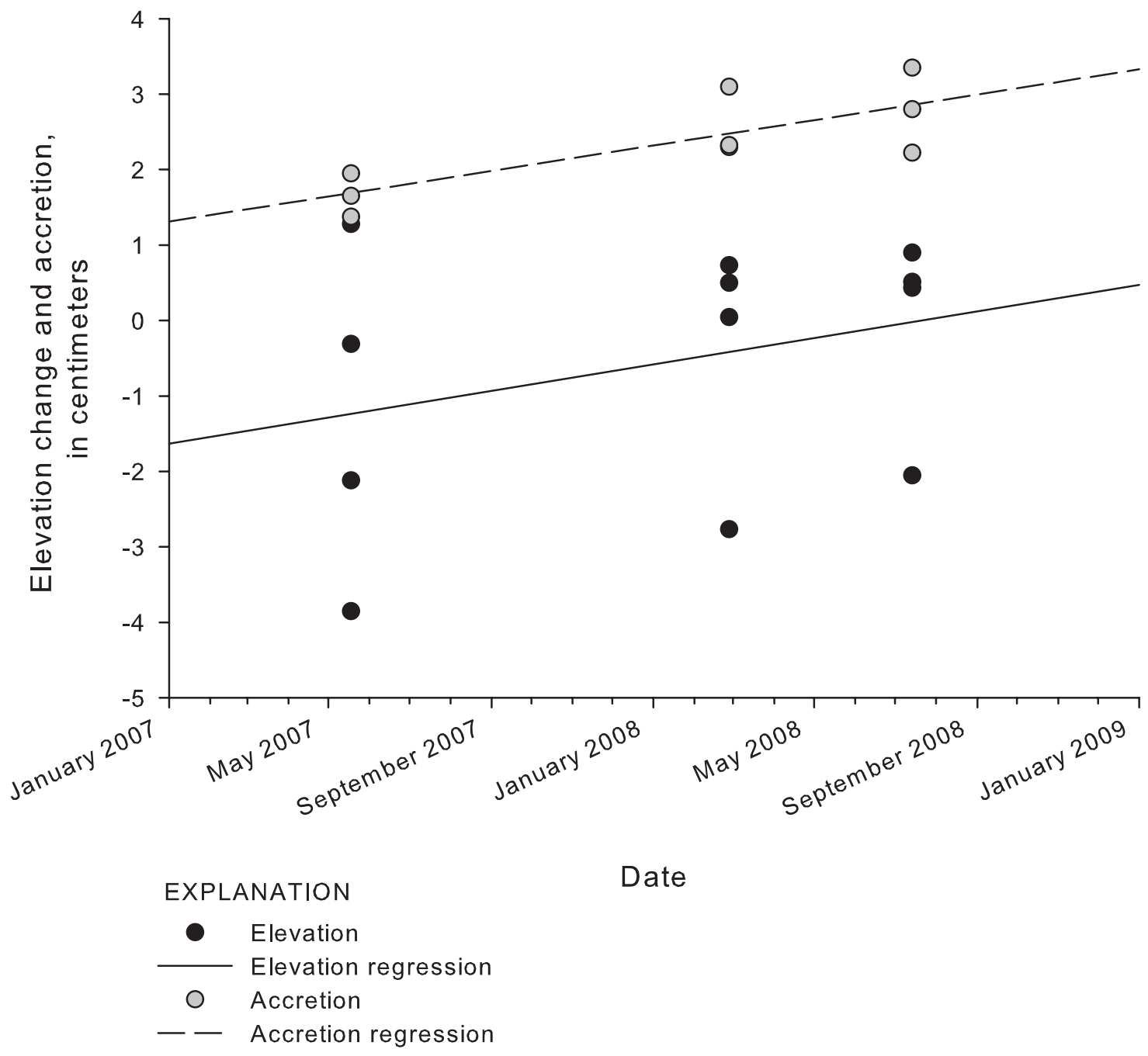

Figure 2-2. Changes in elevation and vertical accretion at Coastwide Reference Monitoring System (CRMS) site 0147 from January 1,2007 , to January 1,2009 . The rate of elevation change $\left(y=-2.2311+0.0029 X ; r^{2}=0.09\right)$ was 1.05 centimeters per year $\left(\mathrm{cm} \mathrm{yr}^{-1}\right)$, and

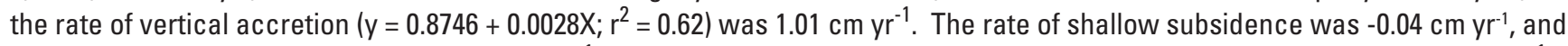
the relative sea level rise (RSLR) was $0.92 \mathrm{~cm} \mathrm{yr}^{-1}$. Elevation change at CRMS0147 is projected to exceed the RSLR by $0.13 \mathrm{~cm} \mathrm{yr}$. Trend lines represent a best-fit linear regression from data collected in three sampling periods. Shallow subsidence is calculated by subtracting the rate of vertical accretion from the rate of elevation change. 


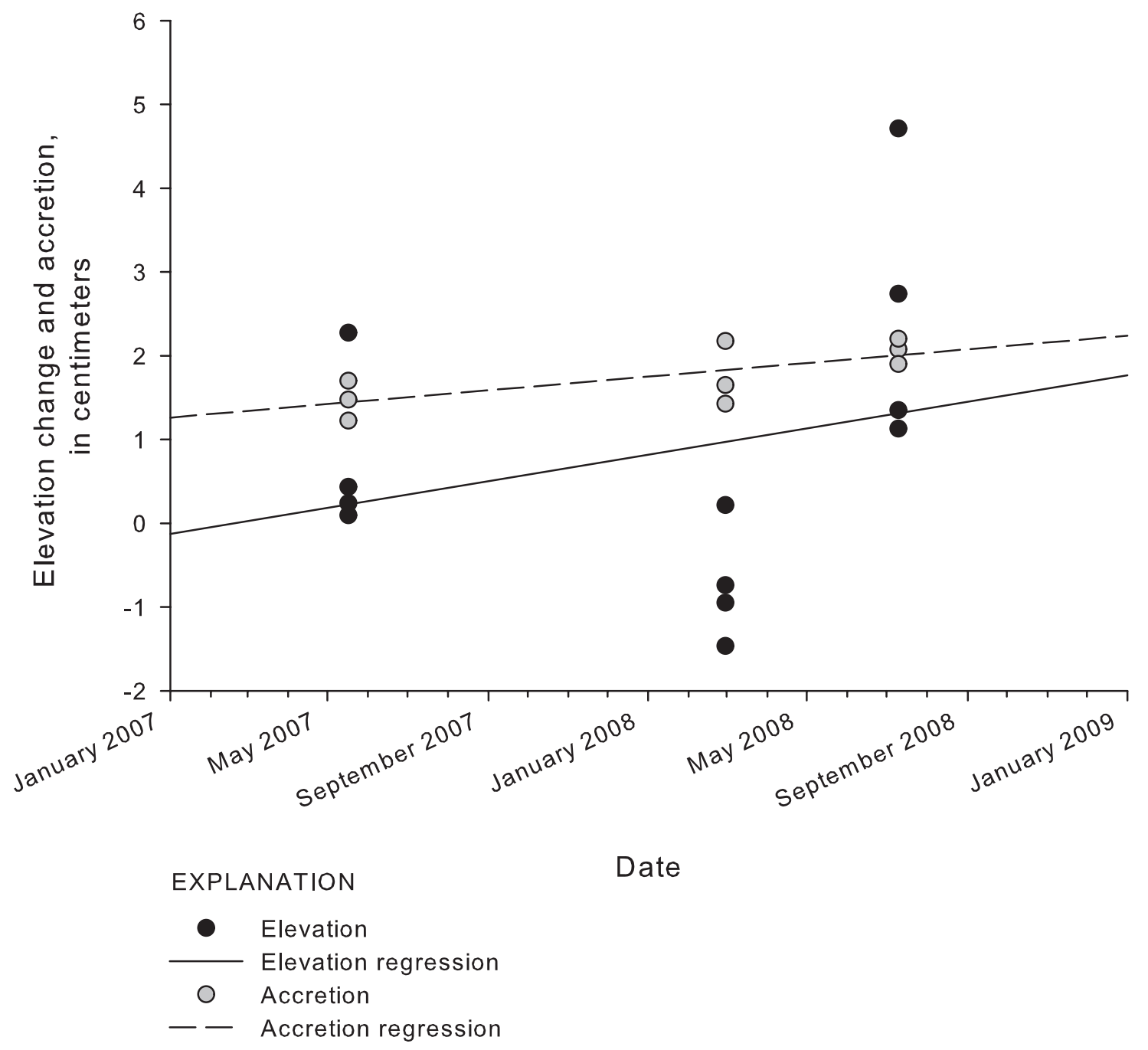

Figure 2-3. Changes in elevation and vertical accretion at Coastwide Reference Monitoring System (CRMS) site 0164 from January

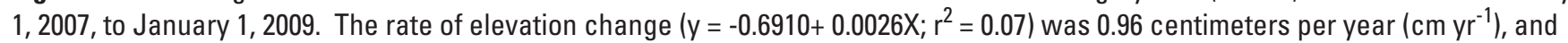
the rate of vertical accretion $\left(y=1.0274+0.0013 X ; r^{2}=0.50\right)$ was $0.49 \mathrm{~cm} \mathrm{yr}^{-1}$. The rate of shallow subsidence was $-0.47 \mathrm{~cm} \mathrm{yr}^{-1}$, and

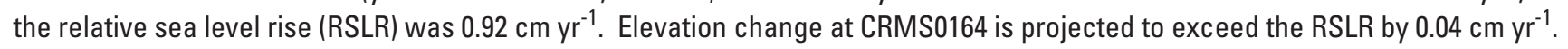
Trend lines represent a best-fit linear regression from data collected in three sampling periods. Shallow subsidence is calculated by subtracting the rate of vertical accretion from the rate of elevation change. 


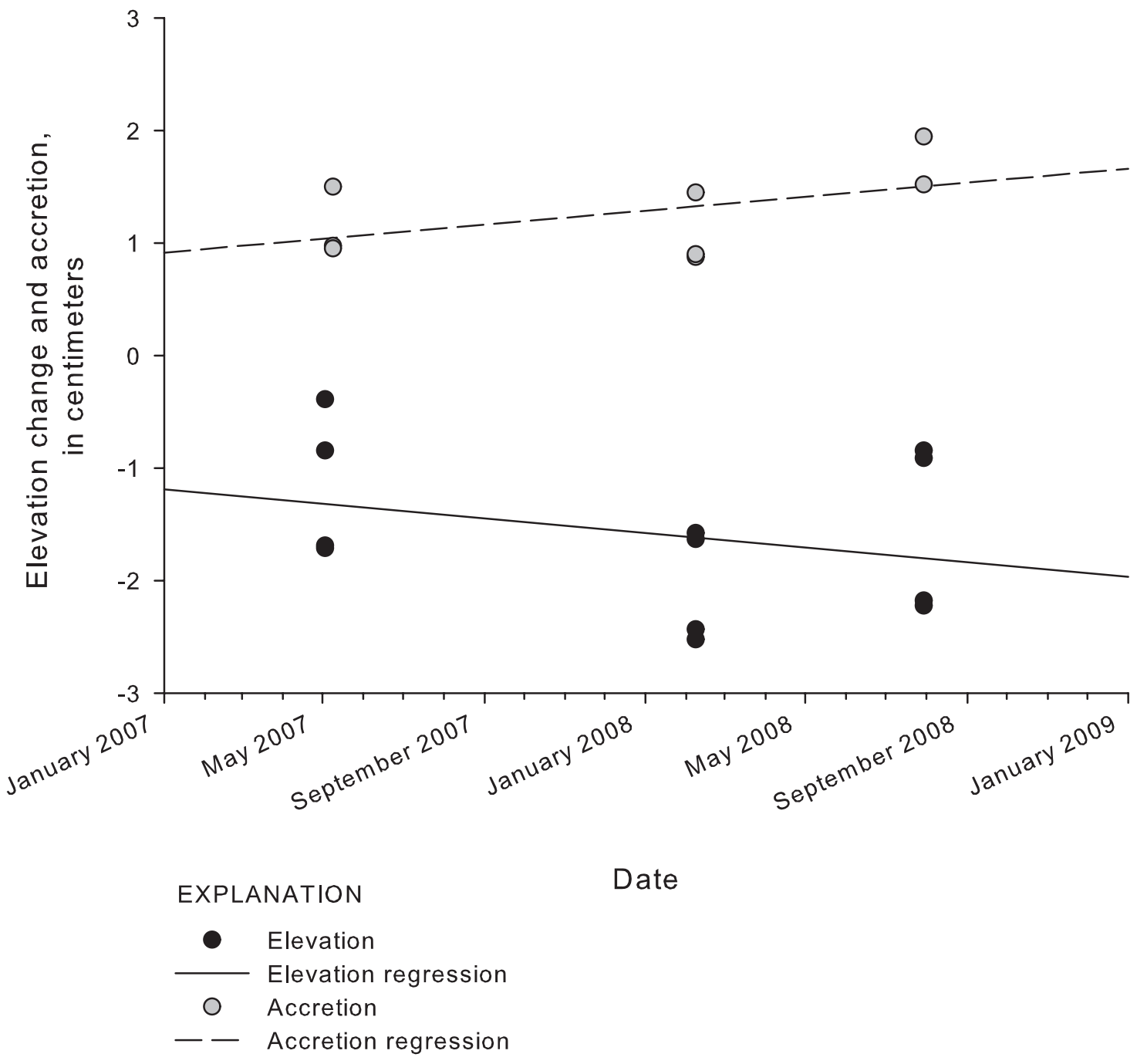

Figure 2-4. Changes in elevation and vertical accretion at Coastwide Reference Monitoring System (CRMS) site 0326 from January 1,2007 , to January 1,2009 . The rate of elevation change $\left(y=-0.9312-0.0010 X ; r^{2}=0.08\right)$ was -0.39 centimeters per year $\left(\mathrm{cm} \mathrm{yr}^{-1}\right)$, and the rate of vertical accretion $\left(y=0.7184+0.0010 X ; r^{2}=0.25\right)$ was $0.37 \mathrm{~cm} \mathrm{yr}^{-1}$. The rate of shallow subsidence was $0.76 \mathrm{~cm} \mathrm{yr}^{-1}$, and the relative sea level rise (RSLR) was $0.92 \mathrm{~cm} \mathrm{yr}^{-1}$. Elevation change at CRMSO326 is projected to be $1.31 \mathrm{~cm} \mathrm{yr}^{-1}$ less than RSLR. Trend lines represent a best-fit linear regression from data collected in three sampling periods. Shallow subsidence is calculated by subtracting the rate of vertical accretion from the rate of elevation change. 


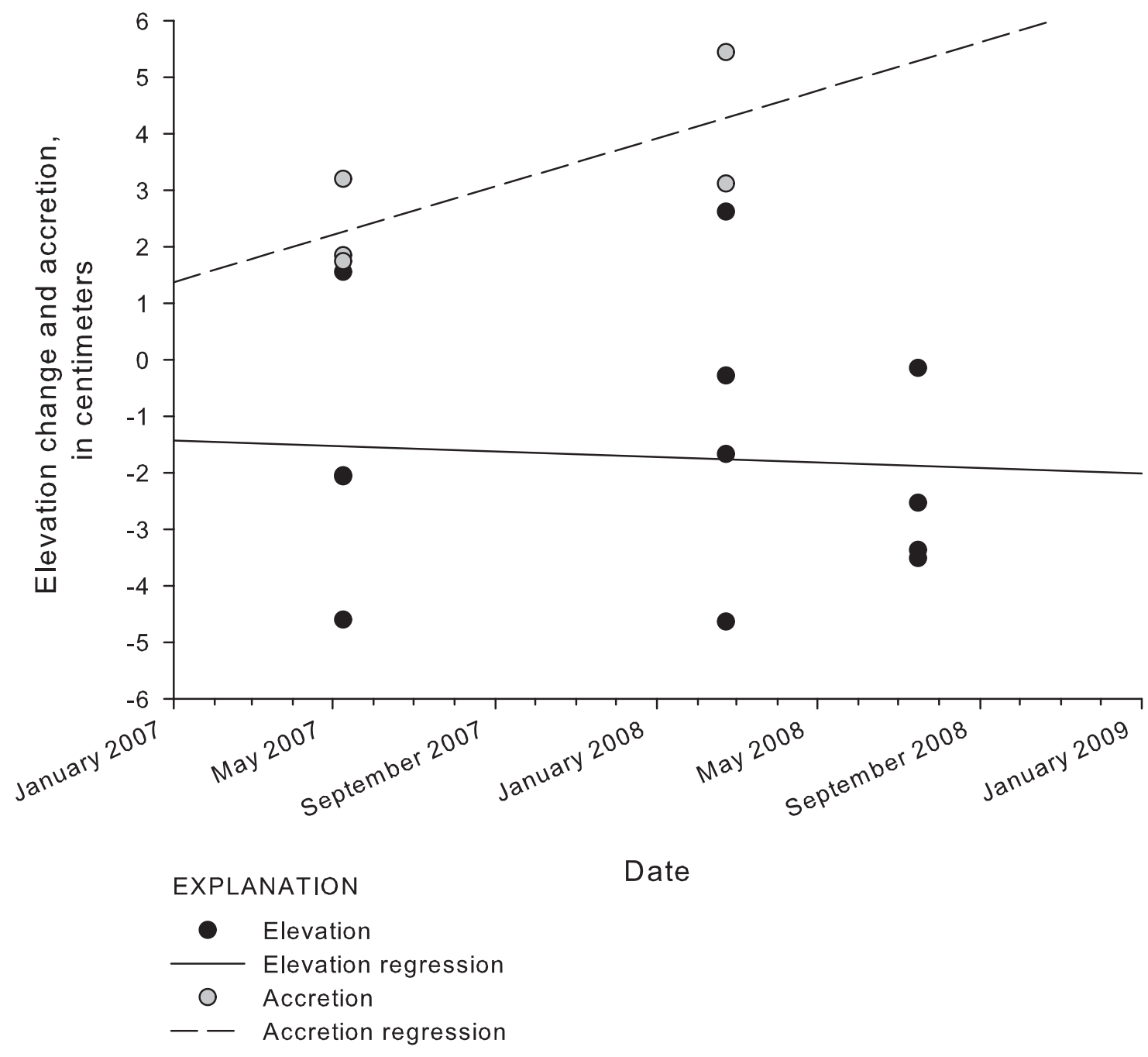

Figure 2-5. Changes in elevation and vertical accretion at Coastwide Reference Monitoring System (CRMS) site 0605 from January 1,2007 , to January 1, 2009. The rate of elevation change $\left(y=-1.1953-0.0008 X ; r^{2}=0.004\right)$ was -2.94 centimeters per year $\left(\mathrm{cm} \mathrm{r}^{-1}\right)$, and

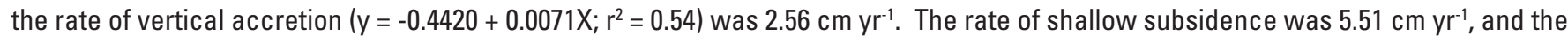
relative sea level rise (RSLR) was $0.57 \mathrm{~cm} \mathrm{yr}^{-1}$. Elevation change at CRMS0605 is projected to be $3.51 \mathrm{~cm} \mathrm{yr}^{-1}$ less than RSLR. Trend lines represent a best-fit linear regression from data collected in three sampling periods. Shallow subsidence is calculated by subtracting the rate of vertical accretion from the rate of elevation change. 


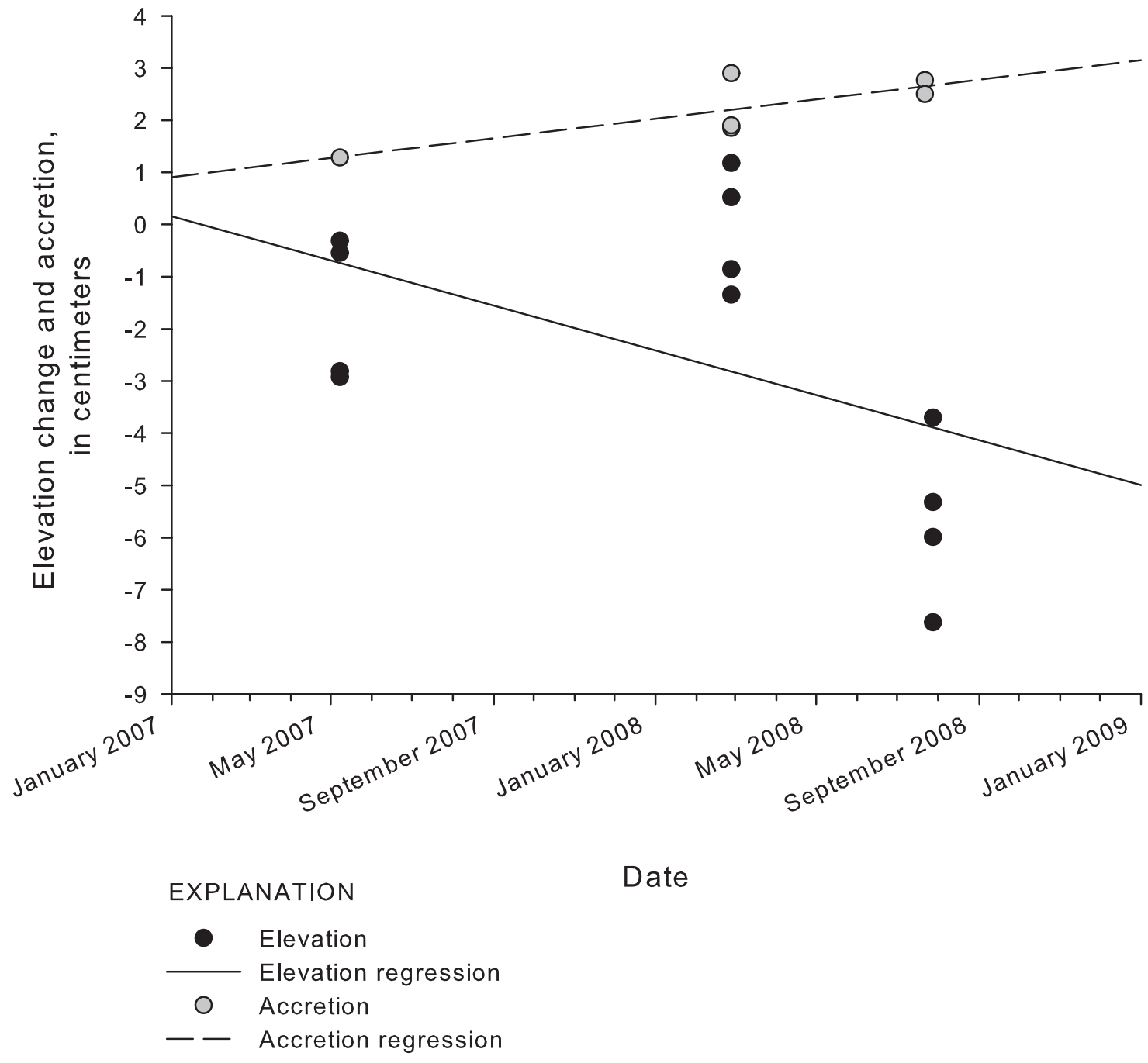

Figure 2-6. Changes in elevation and vertical accretion at Coastwide Reference Monitoring System (CRMS) site 0610 from January 1,2007 , to January 1 , 2009. The rate of elevation change $\left(y=1.6651-0.0072 X ; r^{2}=0.24\right)$ was -2.59 centimeters per year $\left(\mathrm{cm} \mathrm{yr}^{-1}\right)$, and the rate of vertical accretion $\left(y=0.1248+0.0031 X ; r^{2}=0.62\right)$ was $1.12 \mathrm{~cm} \mathrm{yr}^{-1}$. The rate of shallow subsidence was $3.71 \mathrm{~cm} \mathrm{yr}^{-1}$, and the relative sea level rise (RSLR) was $0.57 \mathrm{~cm} \mathrm{yr}^{-1}$. Elevation change at CRMS0610 is projected to be $3.16 \mathrm{~cm} \mathrm{yr}^{-1}$ less than RSLR. Trend lines represent a best-fit linear regression from data collected in three sampling periods. Shallow subsidence is calculated by subtracting the rate of vertical accretion from the rate of elevation change. 


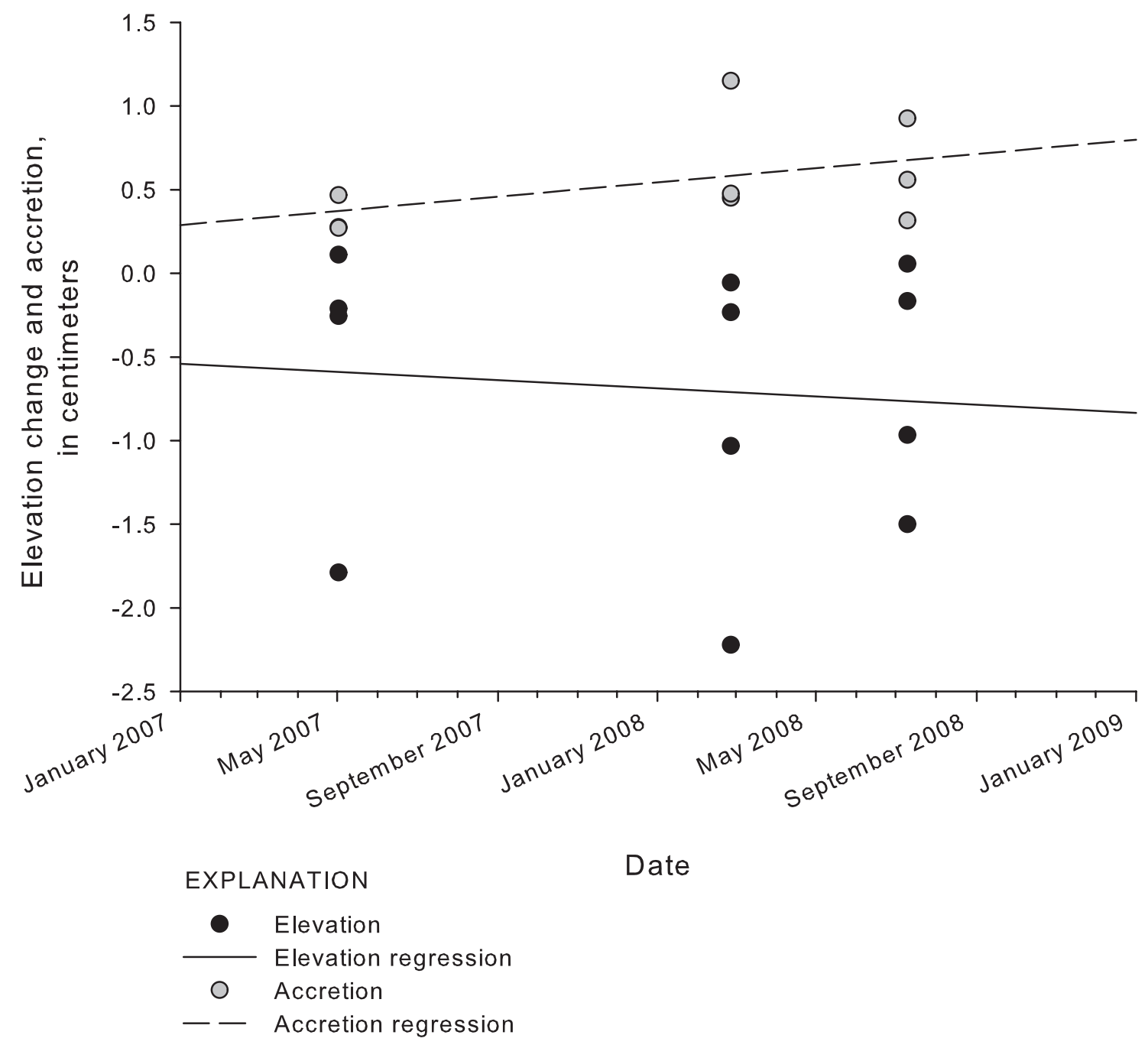

Figure 2-7. Changes in elevation and vertical accretion at Coastwide Reference Monitoring System (CRMS) site 0651 from January 1,2007 , to January 1, 2009. The rate of elevation change $\left(y=-0.5780-0.0004 X ; r^{2}=0.009\right)$ was -0.15 centimeters per year $\left(\mathrm{cm} \mathrm{r}^{-1}\right)$, and the rate of vertical accretion $\left(y=0.1077+0.0007 X ; r^{2}=0.19\right)$ was $0.25 \mathrm{~cm} \mathrm{yr}^{-1}$. The rate of shallow subsidence was $0.40 \mathrm{~cm} \mathrm{yr}^{-1}$, and the relative sea level rise (RSLR) was $0.57 \mathrm{~cm} \mathrm{yr}^{-1}$. Elevation change at CRMS0651 is projected to be $0.72 \mathrm{~cm} \mathrm{yr}^{-1}$ less than RSLR. Trend lines represent a best-fit linear regression from data collected in three sampling periods. Shallow subsidence is calculated by subtracting the rate of vertical accretion from the rate of elevation change. 

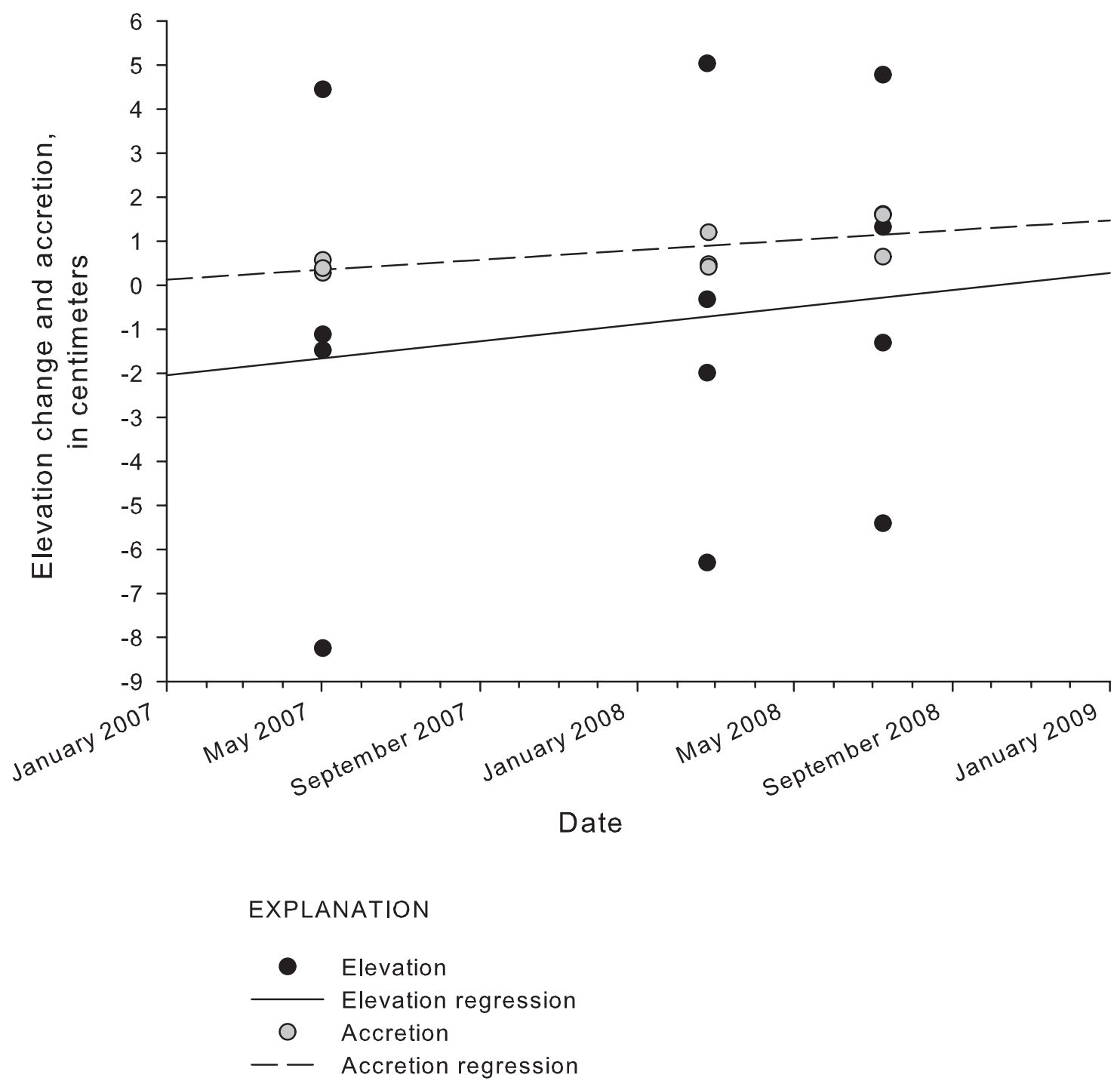

Figure 2-8. Changes in elevation and vertical accretion at Coastwide Reference Monitoring System (CRMS) site 0672 from January 1,2007 , to January 1 , 2009. The rate of elevation change $\left(y=-2.9544+0.0032 X ; r^{2}=0.01\right)$ was 1.16 centimeters per year $\left(\mathrm{cm} \mathrm{yr}^{-1}\right)$, and

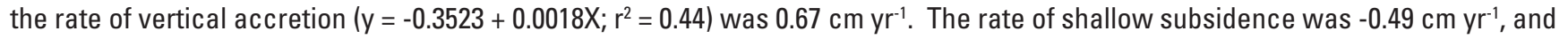
the relative sea level rise (RSLR) was $0.57 \mathrm{~cm} \mathrm{yr}^{-1}$. Elevation change at CRMS0672 is projected to exceed the RSLR by $0.59 \mathrm{~cm} \mathrm{yr}^{-1}$. Trend lines represent a best-fit linear regression from data collected in three sampling periods. Shallow subsidence is calculated by subtracting the rate of vertical accretion from the rate of elevation change. 

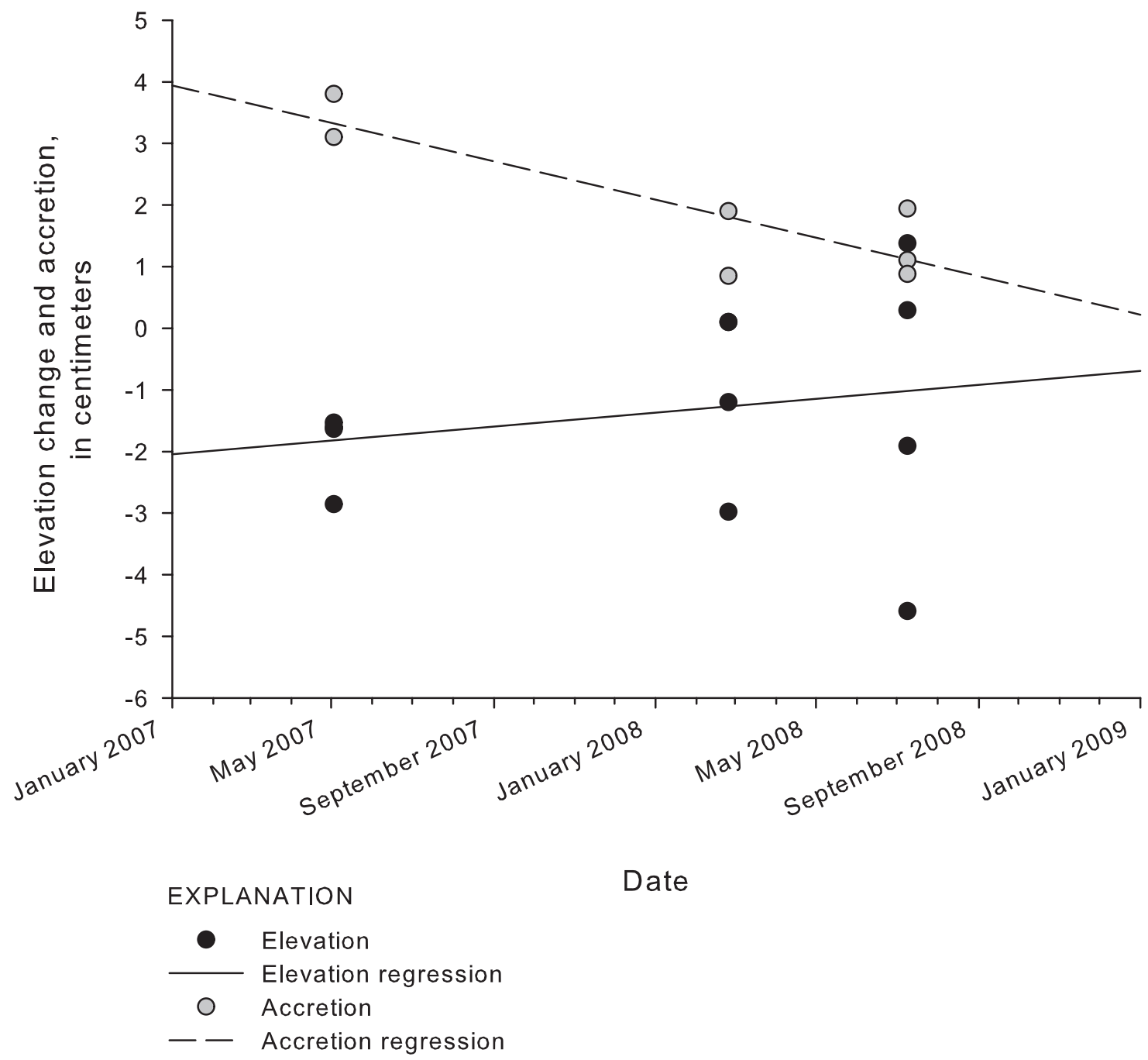

Date

Figure 2-9. Changes in elevation and vertical accretion at Coastwide Reference Monitoring System (CRMS) site 2156 from January 1 , 2007, to January 1, 2009. The rate of elevation change $\left(y=-2.6014+0.0018 X ; r^{2}=0.04\right)$ was 0.68 centimeters per year $\left(\mathrm{cm} \mathrm{rr}^{-1}\right)$, and the rate of vertical accretion ( $\left.y=4.5957-0.0044 X ; r^{2}=0.68\right)$ was $-1.59 \mathrm{~cm} \mathrm{yr}^{-1}$. The rate of shallow subsidence was $-2.27 \mathrm{~cm} \mathrm{yr}^{-1}$, and the relative sea level rise (RSLR) was $0.57 \mathrm{~cm} \mathrm{yr}^{-1}$. Elevation change at CRMS2156 is projected to exceed the RSLR by $0.11 \mathrm{~cm} \mathrm{yr}^{-1}$. Trend lines represent a best-fit linear regression from data collected in three sampling periods. Shallow subsidence is calculated by subtracting the rate of vertical accretion from the rate of elevation change. 
